\title{
Fragility Assessment of Combined Heavy Timber-Steel Bracing System Through Hybrid Simulation
}

\author{
by \\ Sean P. Miller \\ A thesis submitted to the
Faculty of Graduate and Postdoctoral Affairs
in partial fulfillment of the requirements for the degree of
}

Master of Applied Science

Ottawa-Carleton Institute for Civil and Environmental Engineering

Department of Civil and Environmental Engineering

Carleton University

Ottawa, Ontario

January, 2018

${ }^{\circ}$ Copyright

Sean P. Miller, 2018 
The undersigned hereby recommends to the

Faculty of Graduate and Postdoctoral Affairs

acceptance of the thesis

\title{
Fragility Assessment of Combined Heavy Timber-Steel Bracing System Through Hybrid Simulation
}

\author{
submitted by Sean P. Miller \\ in partial fulfillment of the requirements for the degree of \\ Master of Applied Science
}

"Name", External Examiner

Professor Jeffrey Erochko, David Lau, Thesis Supervisor

Professor "Name", Chair,

Ottawa-Carleton Institute for Civil and Environmental Engineering

Department of Civil and Environmental Engineering

Carleton University

January, 2018 


\section{Abstract}

This study performs a fragility assessment of a combined heavy timber-steel friction braced framing system through hybrid testing. Hybrid simulation is an innovative testing method that combines analytical modeling with experimental testing utilizing the unique advantages that each has to offer. In a hybrid test a large portion of the structure is modeled analytically while critical structural elements, whose behaviour is expected to be highly nonlinear and thus difficult to capture analytically, are physically tested in the laboratory. In this study, one bottom storey bay of a 7 storey prototype structure is physically tested in the laboratory while the remaining lower bays and the upper 6 storeys are modeled numerically in OpenSees. One hundred and sixty five hybrid tests are performed through incremental dynamic analysis and fragility curves are developed to estimate the probability of damage at varying seismic intensities. The prototype structure is assessed at various performance levels including design and maximum credible hazard levels. The results from the hybrid test are compared with the results from the purely analytical simulation to assess the accuracy of the current finite element modeling techniques. Results show good agreement up to 2.0 percent maximum interstorey drift. The combined heavy-timber steel seismic force resisting system containing friction braces as the primary source of lateral resistance is an effective means of reducing seismic damage to this type of structure. The modeling system exhibits predictable behaviour and experimental results indicate the model is conservative. 


\section{Acknowledgments}

The author would like to acknowledge Dr. Jeffrey Erochko and Dr. David Lau for their mentorship and assistance that made completion of this research possible. For Jeffrey's countless efforts to help secure scholarship funding that made the graduate student experience much easier. For the support of all his friends and family during this journey. The author would like to extend a special thanks to Josh Woods and Said Said for their countless hours of help in Carleton University's structures laboratory through the experimental program. 


\section{Table of Contents}

Abstract $\quad$ iii

Acknowledgments $\quad$ iv

Table of Contents $\quad$ v

List of Tables $\quad$ xi

List of Figures $\quad$ xiv

Nomenclature $\quad \mathbf{x x}$

1 Introduction 1

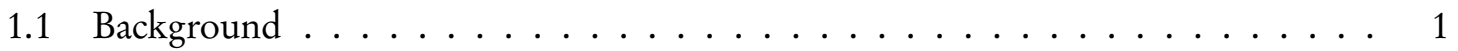

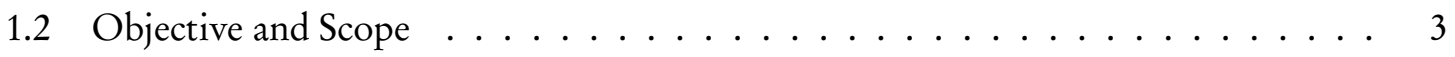

2 Literature Review $\quad 5$

2.1 Over-strength and Ductility of Seismic Force Resisting Systems (National Research Council, 2011) . . . . . . . . . . . . . . 5

2.2 Combined Timber-Steel Building System Design Methodology _ . . . . . . . 6

2.2.1 Previous Combined Timber-Steel and Timber-Concrete SFRS . . . . . . . 6

2.3 Friction Damping Devices $\ldots \ldots \ldots \ldots \ldots$

2.3.1 Friction Behavior . . . . . . . . . . . . . . 19

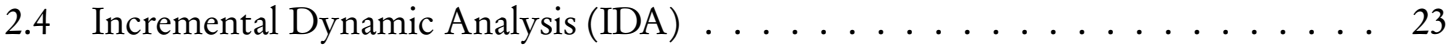

2.4.1 Steps to Perform IDA by (Vamvatsikos and Cornell, 2004) . . . . . . . . 24 
2.5 Collapse Fragility Curves . . . . . . . . . . . . . . . . . . . 30

2.5.1 Structural Performance Levels: Drift and Acceleration (ASCE, 2007) . . . 31

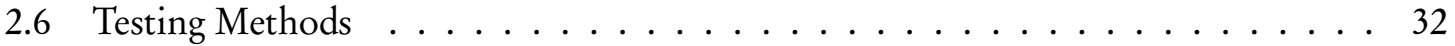

2.6.1 Quasi Static Testing Method . . . . . . . . . . . . . . . 32

2.6.2 Shake Table Testing Method . . . . . . . . . . . . . . . . 33

2.6.3 Quasi Static Pseudo-Dynamic Testing . . . . . . . . . . . . . . 33

2.6.4 Continuous Pseudo-Dynamic Testing . . . . . . . . . . . . . . 33

2.7 Hybrid Testing Method . . . . . . . . . . . . . . . . . . 34

2.7.1 Sub-Structured Pseudo-Dynamic Hybrid Test . . . . . . . . . . . . 34

2.7.2 Real Time Hybrid Test . . . . . . . . . . . . . . . . 35

2.7.3 Accuracy and Stability of Hybrid Testing Methods . . . . . . . . . . . 35

$2.7 .4 \quad$ Previous Hybrid Tests . . . . . . . . . . . . . . . . . . . . . . 37

2.8 Finite Element and Control Framework . . . . . . . . . . . . . . . . 41

2.8.1 OpenSees Framework . . . . . . . . . . . . . . . . 41

2.8 .2 OpenFresco Framework . . . . . . . . . . . . . . . . . 42

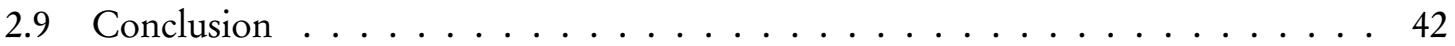

\section{Prototype Specimen and}

$\begin{array}{ll}\text { Experimental Setup } & 44\end{array}$

3.1 Prototype Structure Design . . . . . . . . . . . . . . . . . 44

3.1.1 Structural Analysis and Loads . . . . . . . . . . . . . . . . . . . 47

3.1.2 Structural Member and Connection Design . . . . . . . . . . . . . . 47

3.2 Experimental Setup . . . . . . . . . . . . . . . . . . 54

3.2 .1 Specimen Design . . . . . . . . . . . . . . . . 57

3.2.2 Laboratory Setup Upgrades . . . . . . . . . . . . . . . . . . . 61

3.2.3 Prototype Specimen Stiffness Verification . . . . . . . . . . . . . . . . 65

3.3 Control and Instrumentation $\ldots \ldots \ldots \ldots$

3.3 .1 Control .............................. 70

3.3.2 Data Acquisition and Instrumentation . . . . . . . . . . . 70 
3.3.3 Hybrid Simulation Hardware and Software Components . . . . . . . . 72

4 Numerical Model Development $\quad 74$

4.1 Introduction . . . . . . . . . . . . . . . . 74

4.2 OpenSees Model . . . . . . . . . . . . . . . . . . . 75

4.2.1 Two Bay OpenSees Model Analysis Parameters . . . . . . . . . . . . . 82

4.3 Hybrid Model in OpenSees/OpenFresco . . . . . . . . . . . . . . . . . . . 83

4.3.1 Hybrid Model Verification . . . . . . . . . . . . . . . . . . . . 89

4.4 Earthquake Record Scaling . . . . . . . . . . . . . . . . . . . . . 91

5 Numerical Modeling Results and Discussion $\quad 98$

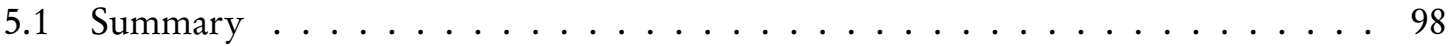

5.2 Incremental Dynamic Analysis . . . . . . . . . . . . . . . . . . 99

5.2.1 Analysis Parameters for Analytical Incremental Dynamic Analysis . . . . 99

5.2.2 Response Behaviour of Prototype Structure . . . . . . . . . . . . . . 108

5.2.3 Fragility Curves for Two Bay OpenSees Model . . . . . . . . . . . . . . 110

6 Experimental Results and

$\begin{array}{ll}\text { Discussion } & 114\end{array}$

6.1 Introduction . . . . . . . . . . . . . . . . . . 114

6.2 Experimental IDA Earthquake Record Selection ～. . . . . . . . . . . . . 114

6.2.1 Analytical Fragility Curve Comparison

Suite of 44 Records and Subset of 11 Records . . . . . . . . . . . . . . . . 119

6.3 Experimental Hybrid Test Analysis Parameters . . . . . . . . . . . . . . . . 124

6.4 Prototype Specimen Brace Slip Force Calibration . . . . . . . . . . . . . . . . 127

6.4.1 Gravity Load Application in Numerical Substructure . . . . . . . . . . 127

6.5 Experimental Hybrid Test Termination Parameters . . . . . . . . . . . . . . . . 127

6.6 Experimental Hybrid Test Temperature Monitoring . . . . . . . . . . . . . . . 127

6.7 Experimental Hybrid Test and Analytical Response Comparison . . . . . . . . 128

6.8 Experimental Incremental Dynamic Analysis Results . . . . . . . . . . . . . 133 
6.8.1 Maximum Interstorey Drift Results . . . . . . . . . . . . . . . . . 141

6.8.2 Maximum Interstorey Residual Drift Results . . . . . . . . . . . . . 143

6.8.3 Comparison of Maximum Interstorey Drift and Maximum Interstorey Residual Drift Results . . . . . . . . . . . . . . . . . . . . 144

6.8.4 Sources of Error Between Analytical and Experimental Results . . . . . 145

6.9 Prototype Specimen Post Test Condition . . . . . . . . . . . . . . . 146

6.10 Experimental and Analytical Fragility Curves . . . . . . . . . . . . . . 152

6.11 Results Summary . . . . . . . . . . . . . . . . . . . . 156

7 Concluding Remarks 159

7.1 Summary of Findings . . . . . . . . . . . . . . . . . . 160

7.2 Key Conclusions . . . . . . . . . . . . . . . . . . . . 162

7.3 Future Research . . . . . . . . . . . . . . . . . . . . . . 162

$\begin{array}{ll}\text { List of References } & 164\end{array}$

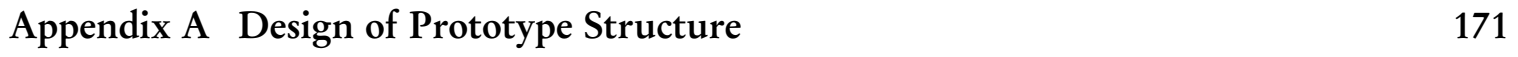

A.0.1 Loads on the Structure . . . . . . . . . . . . . . . . . 171

A.0.2 Dead Loads . . . . . . . . . . . . . . . . . . . . . 172

A.1 Snow Loads . . . . . . . . . . . . . . . . . . . . . . . . 173

A.1.1 Wind Loads . . . . . . . . . . . . . . . . . . . . . . 174

A.1.2 Seismic Design . . . . . . . . . . . . . . . . . . . . 175

A.2 Final Member Sizing . . . . . . . . . . . . . . 183

A.2.1 Capacities of Glulam Beam and Column Elements . . . . . . . . . 185

A.2.2 Beam Deflection . . . . . . . . . . . . . . . . . . . . . . 194

A.3 CLT Floor Design . . . . . . . . . . . . . . . . . . . 195

A.3.1 CLT Floor Design Moment Resistance . . . . . . . . . . . . . . . 197

A.3.2 CLT Floor Design Shear Resistance . . . . . . . . . . . . . . . 198

A.3.3 CLT Floor Design Deflection Check . . . . . . . . . . . . . . . 198

A.3.4 CLT Floor Design Vibration . . . . . . . . . . . . . . . . 199 
A.4 Friction Brace Design . . . . . . . . . . . . . . . . . . 200

A.5 Glued-in Rod Design . . . . . . . . . . . . . . . . . . . . . . 201

A.6 Full and Half Scale Specimen Forces . . . . . . . . . . . . . . . . 205

A.6.1 Friction Slip Force . . . . . . . . . . . . . . . . . . . 205

A.6.2 Gusset Plate . . . . . . . . . . . . . . . . . . . . . 205

A.6.3 Hybrid Connection . . . . . . . . . . . . . . . 205

A.6.4 Beam Connection . . . . . . . . . . . . . . . . 205

A.6.5 Beam Fasteners . . . . . . . . . . . . . . . . . . . . . 206

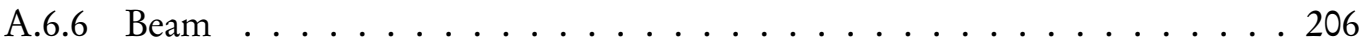

A.6.7 Timber Fasteners . . . . . . . . . . . . . . . . 206

A.6.8 Timber Columns . . . . . . . . . . . . . . . . 206

$\begin{array}{lll}\text { Appendix B Design of OpenSees and Hybrid Models } & 207\end{array}$

B.1 OpenSees and Hybrid Models Mass and Stiffness Properties . . . . . . . . . . 207

\section{Appendix C Prototype Specimen Design}

(Gilbert, 2016) 212

C.1 Physical Specimen Design by $($ Gilbert, 2016) . . . . . . . . . . . . . . . . . 212

C.1.1 Friction Device Component Design . . . . . . . . . . . . . . . . . . 214

C.1.2 Gusset Plate Design (Gilbert, 2016) . . . . . . . . . . . . . . . . . . . 218

C.1.3 Glued-in Rod Design (Gilbert, 2016) . . . . . . . . . . . . . . . . . . 218

C.1.4 Intermediate Steel Connection Component (Gilbert, 2016) . . . . . . . 220

C.1.5 Timber Member Design (Gilbert, 2016) . . . . . . . . . . . . . . . 220

$\begin{array}{ll}\text { Appendix D Capacity of Physical Specimen } & 221\end{array}$

D.0.1 Timber Elements in Tension . . . . . . . . . . . . . . . . . 221

D.0.2 Timber Elements in Compression . . . . . . . . . . . . . . . . 222

D.0.3 Group Tear out Steel Connections . . . . . . . . . . . . . . . 222

D.0.4 Bolts in Bearing . . . . . . . . . . . . . . . . . 223

D.0.5 Bolts in Shear . . . . . . . . . . . . . . . . . . 223 
D.0.6 Axial Tension . . . . . . . . . . . . . . . . . . . . 224

D.0.7 Glued-in Rods Tensile Resistance . . . . . . . . . . . . . . . . . . 224

D.0.8 Glued-in Rod Capacity Summary . . . . . . . . . . . . . . . . . . . 229

Appendix E Fabrication Drawings (Gilbert, 2016) 231

E.1 Prototype Specimen Shop Drawings (Gilbert, 2016) … . . . . . . . . 231 


\section{List of Tables}

3.1 Member Sizes . . . . . . . . . . . . . . . . . . 45

3.2 Summary of Gravity Loads . . . . . . . . . . . . . . . . . . . . 48

3.3 Building Weight and Periods of Vibration . . . . . . . . . . . . . . 49

3.4 Member Sizes . . . . . . . . . . . . . . . . . 53

3.5 Adhesive Properties (Gilbert, 2016) . . . . . . . . . . . . . 53

3.6 B7 Threaded Steel Rod Properties (Gilbert, 2016) . . . . . . . . . . . . . . . 53

3.7 Nordic Glulam Material Properties (Gilbert, 2016) . . . . . . . . . . . . . . . . 54

3.8 Scaling Factors for the Experimental Specimen (Gilbert, 2016) . . . . . . . . . 60

3.9 Full-Scale Design Forces . . . . . . . . . . . . . . . . . 61

3.10 Half-Scale Design Forces . . . . . . . . . . . . . . . . . . 61

3.11 Prototype Beam Stiffness . . . . . . . . . . . . . . . . 66

3.12 Prototype Brace Stiffness . . . . . . . . . . . . . . . . 66

3.13 Prototype Column Stiffness . . . . . . . . . . . . . . . . . . 67

4.1 ATC Far Field Ground Motions (Applied Technology Council, 2009) . . . . 93

5.1 ATC A Far Field Ground Motions Termination Response . . . . . . . . . . 106

5.2 ATC B Far Field Ground Motions Termination Response . . . . . . . . . . . 107

6.1 ATC Far Field Ground Motions Used in Experimental IDA (Applied Technology Council, 2009) . . . . . . . . . . . . . . . . . . 117

6.2 Incremental Dynamic Analysis Scale Factors and Records for Quasi Static Continuous Hybrid Tests . . . . . . . . . . . . . . . . . . . 120

A.1 Storey and Roof Pressures . . . . . . . . . . . . . . . . . . 172

A.2 Storey - Roof - Wall loads . . . . . . . . . . . . . . . . . . . . 173 
A.3 Snow Load Variables . . . . . . . . . . . . . . . . . . . . 174

A.4 Wind Load Variables . . . . . . . . . . . . . . . . . . . 175

A.5 Wind Load Calculation . . . . . . . . . . . . . . . . . . . 175

A.6 Design Spectrum For Victoria British Columbia Canada . . . . . . . . . . 176

A.7 Seismic Design Forces _ . . . . . . . . . . . . . . . . . . . . . 179

A.8 Modal Mass Participation Ratio of Structure . . . . . . . . . . . . . . 182

A.9 Force in Friction Braces From Response Spectrum Analysis . . . . . . . . . . . 183

A.10 Storey Drift Response . . . . . . . . . . . . . . . . . . . 183

A.11 Member Sizes . . . . . . . . . . . . . . . . . . . . . . 184

A.12 Variables and Descriptions for Timber Design Equations A.16 to A.23 . . . . 186

A.13 Tension Capacity of Beam and Column Elements . . . . . . . . . . . . . 188

A.14 Compressive Capacity of Beam and Column Elements . . . . . . . . . . . 190

A.15 Shear Capacity of Beam and Column Elements . . . . . . . . . . . . . 191

A.16 Moment Capacity of Beam and Column Elements . . . . . . . . . . . . . 193

A.17 Combined Axial Tension / Axial Compression and Bending Resistance of Beam

Elements . . . . . . . . . . . . . . . . . . . 194

A.18 Static Beam Deflections . . . . . . . . . . . . . . . . . . . . 195

A.19 CLT Floor Variables . . . . . . . . . . . . . . . . . . . 196

A.20 CLT Floor Loads and Capacity Summary . . . . . . . . . . . . . . . . 199

A.21 Activation Force in Friction Braces . . . . . . . . . . . . . . . . 201

A.22 Glued-in Rods Tensile Capacity DIN 1052 Method Beam and Column . . . . . . 202

A.23 Variables Used in Glued-in Rod Shear Calculation . . . . . . . . . . . . . . 204

A.24 Shear Capacity of Glued-in Rod Beam Connection . . . . . . . . . . . . . . 204

B.1 Nodal Mass Break Down in Four Bay OpenSees Model Lateral Direction . . . . . 208

B.2 Nodal Mass Break Down in Two Bay OpenSees Model Lateral Direction . . . . . 208

B.3 Nodal Mass Break Down in Four Bay OpenSees Model Vertical Direction . . . 209

B.4 Nodal Mass Break Down in Two Bay OpenSees Model Vertical Direction . . . . . 210

B.5 Properties of Lean Column in Four Bay OpenSees Model . . . . . . . . . . . 211

B.6 Properties of Lean Column in Two Bay OpenSees Model . . . . . . . . . . 211 
C.1 Adhesive Properties (Gilbert, 2016) ․ . . . . . . . . . . . . . . . . . 213

C.2 B7 Threaded Steel Rod Properties (Gilbert, 2016) . . . . . . . . . . . . . . . 213

C.3 Nordic Glulam Material Properties (Gilbert, 2016) ․ . . . . . . . . . . . . 213

C.4 Torque Requirements (Erick et al., 2008) . . . . . . . . . . . . . . . . 216

C.5 Elongation Requirements (Erick et al., 2008) _ . . . . . . . . . . . . . 217

D.1 Timber Tension Capacity Forces Beam and Column . . . . . . . . . . . 221

D.2 Timber Compressive Capacity Forces Beam and Column . . . . . . . . . 222

D.3 Gusset Plate Capacity . . . . . . . . . . . . . . . . . . . 223

D.4 Gusset Plate Capacity Bolt Bearing . . . . . . . . . . . . . . . 223

D.5 Gusset Plate Capacity Bolt Shear . . . . . . . . . . . . . . . . . . . 224

D.6 Gusset Plate Capacity Axial Tension . . . . . . . . . . . . . . . . . . 224

D.7 Glued-in Rods Tensile Capacity Beam and Column . . . . . . . . . . . . . 225

D.8 Glued-in Rods Tensile Capacity GIRod Report 2002 . . . . . . . . . . . . . . . 226

D.9 Glued-in Rods Tensile Capacity GIRod Report 2002 Method Beam and Column . 226

D.10 Glued-in Rods Tensile Capacity EUROCODE 5 . . . . . . . . . . . . . . 227

D.11 Glued-in Rods Tensile Capacity EUROCODE 5 Method Beam and Column . . . 227

D.12 Glued-in Rods Tensile Capacity DIN 1052 Method Beam and Column . . . . . 228

D.13 Glued-in Rods Shear Capacity GIROD (2002) Method Beam and Column . . . . 229

D.14 Glued-in Rods Connection Summary Snug Tight and Pretensioned . . . . . . . 230 


\section{List of Figures}

2.1 Friction Device Developed by Tjahyadi (2002) $\ldots \ldots \ldots \ldots$

2.2 Reinforcement Scheme For Reinforced Concrete Joint (Negrao et al., 2016) . . 9

2.3 Friction Device Developed by Duff $(1999) \ldots \ldots \ldots$

2.4 Hysteretic Response of Friction Device Developed by Duff (1999) . . . . . . . . . 11

2.5 Friction Device Developed by Tjahyadi (2002) . . . . . . . . . . . . . . . . 12

2.6 Hysteretic Response of Friction Device Developed by Tjahyadi (2002) _ . . . . 13

2.7 Prototype Specimen Left, Prototype SFRS Right (Gilbert, 2016) . . . . . . . . . 15

2.8 Prototype Specimen Response at Increasing Cycle Amplitudes (Gilbert, 2016) . 16

2.9 Prototype Specimen Velocity Dependant Hysteretic Response (Gilbert, 2016) . 17

2.10 Prototype Specimen Hysteretic Response to Seismic Loading (Gilbert, 2016) . . 18

2.11 Relation Between Sliding Velocity, Coefficient of Friction and Pressure (Left) Relation Between Temperature, Coefficient of Friction and Sliding Velocity (Right) (Christopoulos and Filiatrault, 2006) f . . . . . . . . . . 20

2.12 Before Applied Normal Pressure (Christopoulos and Filiatrault, 2006) . . . . . 21

2.13 After Applied Normal Pressure (Christopoulos and Filiatrault, 2006) . . . . . . 21

2.14 Hysteretic Behaviour of Friction Surface (Kim et al., 2004) . . . . . . . . . . . . 22

2.15 Incremental Dynamic Analysis 20\% Tangent Slope Exceedance Collapse (Vamvatsikos and Cornell, 2002) . . . . . . . . . . . . . . . . 26

2.16 Incremental Dynamic Analysis Intermediate Collapse (Vamvatsikos and Cornell,

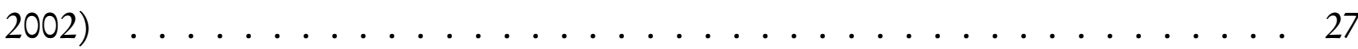

2.17 Incremental Dynamic Analysis Response Curves Damage Measure Rule (Vamvatsikos and Cornell, 2002) . . . . . . . . . . . . . . . . . 28 
2.18 Incremental Dynamic Analysis Response Curves Intensity Measure Rule (Vamvatsikos and Cornell, 2002) . . . . . . . . . . . . . . . . . . . . 29

2.19 Incremental Dynamic Analysis Response Curves (Top Left) Softening Case, (Top Right) Minor Hardening Case, (Bottom Left) Severe Hardening Case, (Bottom Right) Weaving Case (Vamvatsikos and Cornell, 2002) . . . . . . . . . . . . 30

2.20 Real Time Hybrid Test of Architecture (Zargar and Medina, 2014) . . . . . . . 39

2.21 Psuedo-Dynamic Test of Light Frame Wood Structure (Jennings et al., 2013) . . . 41

2.22 OpenSees - OpenFresco Coordinate System a) Global Coordinates b) Local Element Coordinates . . . . . . . . . . . . . . . . . . . 42

3.1 Structural Plan and Elevation $\ldots \ldots \ldots \ldots \ldots$

3.2 Combined Heavy Timber-Steel Braced Frame Detail . . . . . . . . . . . . . 51

3.3 Glued-in Rod Detail for Each Frame Element . . . . . . . . . . . . . . . . . . 52

3.4 Experimental Test Setup for Heavy Timber-Steel Friction Braced Frame $\quad \ldots \ldots$

3.5 Labratory Setup Plan Elevation E-W and N-S . . . . . . . . . . . . . . 56

3.6 Geometry of specimen $($ Gilbert, 2016$) \ldots \ldots \ldots \ldots$

3.7 Experimental Hybrid Braced Frame Components (Gilbert, 2016) a) Intermediate Brace Connection b) Beam Shear Connection c) Friction Damping Device d) Timber Beam with Glued-in Rod Connections e) Timber Column with Glued-in Rod Connections . . . . . . . . . . . . . . . . . . . . . 59

3.8 Experimental Setup Gilbert to This Research a) Gilbert Experimental Setup (Gilbert, 2016) b) Current Experimental Setup . . . . . . . . . . . . . . . 62

3.9 Instrumentation on Friction Brace Support Column . . . . . . . . . . . . . 64

3.10 Stiffening of Friction Brace Support Column $\ldots \ldots$. . . . . . . . . 65

3.11 Prototype Specimen Individual Component Stiffness Labels . . . . . . . . . . 68

3.12 Prototype Specimen Stiffness Model . . . . . . . . . . . . . . . . . . . . . . 69

3.13 Strain Gauge Instrumentation $\ldots \ldots \ldots$. . . . . . . . . . 71

3.14 String Pot and LVDT Instrumentation . . . . . . . . . . . . . . 72

3.15 Hybrid Test Communication Network . . . . . . . . . . . . . . . 73

4.1 Experimental Substructure Green and Numerical Substructure Black . . . . . . 75 
4.2 Four Bay OpenSees Model . . . . . . . . . . . . . . . . . . 78

4.3 Two Bay OpenSees Model . . . . . . . . . . . . . . . 78

4.4 Four Bay OpenSees Model . . . . . . . . . . . . . . . . . . . . . . . 79

4.5 Two Bay OpenSees Model . . . . . . . . . . . . . . . . . . 80

4.6 Four Bay OpenSees Model and Two Bay OpenSees Model Roof Displacement History Comparison . . . . . . . . . . . . . . . . 81

4.7 Sensitivity Analysis Time Step Substructured Model 2 Subjected to 1994 Northridge Earthquake Record Scale by $1.18 \ldots \ldots$. . . . . . . . . . . 83

4.8 Experimental Substructure Green and Numerical Substructure Black . . . . . . 85

4.9 Substructured Equal Degrees of Freedom (EDOF) Between Numerical and Phys-

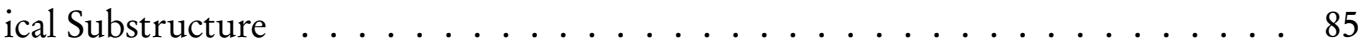

4.10 Hybrid Model of Two Bay OpenSees Model _ . . . . . . . . . . . . 86

4.11 Communication Link between OpenSees, OpenFresco and Data and Control in Laboratory for Local Hybrid Test (Woods, 2016) . . . . . . . . . . . . . . . 87

4.12 Degrees of Freedoms in Standard 2D Beam Column Element $\ldots \ldots \ldots$. . . . 88

4.13 Experimental Degrees of Freedom Beam Column Element . . . . . . . . . . . . 89

4.14 Response of Hybrid Model and OpenSees Model . . . . . . . . . . . . . . 90

4.15 Individual and Median Response Spectra of Normalized Far Field Record Set (Applied Technology Council, 2009) . . . . . . . . . . . . . . . . 94

4.16 Response Spectra of Normalized Far Field Record Set (Applied Technology Council, 2009) . . . . . . . . . . . . . . . . . . 94

4.17 Suite of 44 Records Scaled to MCE Hazard Level . . . . . . . . . . . . . . . . 95

4.18 Suite of 44 Records Scaled to DBE Hazard Level . . . . . . . . . . . . . . . . 96

5.1 Incremental Dynamic Analysis Response Limits Case 1 . . . . . . . . . . . 101

5.2 Incremental Dynamic Analysis Response Limits Case 2 . . . . . . . . . . . 102

5.3 Incremental Dynamic Analysis Response Limits Case 3 . . . . . . . . . . . 103

5.4 Incremental Dynamic Analysis of Two Bay OpenSees Model . . . . . . . . . 104

5.5 Incremental Dynamic Analysis of Two Bay OpenSees Model for Residual Drifts . 105 
5.6 Incremental Dynamic Analysis Response Curves: Weaving, A Bit of Hardening, Severe Hardening (Vamvatsikos and Cornell, 2002) . . . . . . . . . . . . . 109

5.7 ATC-F11A and ATC-F05B IDA Response Two Bay OpenSees Model . . . . . . 110

5.8 Fragility Curve of Two Bay OpenSees Model For Maximum Interstorey Drift . 111

5.9 Fragility Curve of Two Bay OpenSees Model For Maximum Interstorey Residual

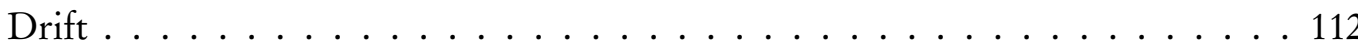

6.1 Response Spectra of Records used in Hybrid Tests ～. . . . . . . . . . . . . . 116

6.2 Analytical Maximum Interstorey Drift IDA Curves of 11 Selected Records . . . . 118

6.3 Analytical Maximum Interstorey Residual Drift IDA Curves of 11 Selected Records 119

6.4 Fragility Curve Comparison Between Suite of 11 Records Selected for Experimental Testing and Entire Suite of 44 Records for Maximum Interstorey Drift . . 122

6.5 Fragility Curve Comparison Between Suite of 11 Records Selected for Experimental Testing and Entire Suite of 44 Records for Residual Interstorey Drift . . . 123

6.6 Suite of 44 Records Scaled to MCE Hazard Level . . . . . . . . . . . . . . . . . 124

6.7 Hybrid Test Time Step Sensitivity Analysis . . . . . . . . . . . . . . . . . 125

6.8 Hybrid Test Maximum Number of Iterations Sensitivity Analysis . . . . . . . . 126

6.9 Displacement Time History of ATC-F11A Record at Scale Factor 1.375 . . . . . 129

6.10 Brace Hysteresis ATC-F11A at Scale Factor 1.375 . . . . . . . . . . . . . . . 130

6.11 Displacement History of Record ATC-F12A at a Scale Factor of 5 . . . . . . . 131

6.12 Displacement History of Record ATC-F12A at a Scale Factor of 1.025 . . . . . . 132

6.13 IDA Maximum Interstorey Drift Response of ATC-F02A, ATC-F05A and ATCF07A Records Analytical and Experimental . . . . . . . . . . . . . . . . 134

6.14 IDA Maximum Interstorey Drift Response of ATC-F09A, ATC-F11A and ATCF12A Records Analytical and Experimental . . . . . . . . . . . . . . 135

6.15 IDA Maximum Interstorey Drift Response of ATC-F17A, ATC-F19A and ATCF05B Records Analytical and Experimental . . . . . . . . . . . . . . . 136

6.16 IDA Maximum Interstorey Drift Response of ATC-F08B and ATC-F22B Records Analytical and Experimental . . . . . . . . . . . . . . . . . 137 
6.17 IDA Maximum Residual Interstorey Drift Response of ATC-F02A, ATC-F05A and ATC-F07A Records Analytical and Experimental _ . . . . . . . . 138

6.18 IDA Maximum Residual Interstorey Drift Response of ATC-F09A, ATC-F11A and ATC-F12A Records Analytical and Experimental . . . . . . . . . . 139

6.19 IDA Maximum Residual Interstorey Drift Response of ATC-F17A, ATC-F19A and ATC-F05B Records Analytical and Experimental . . . . . . . . . . . . 140

6.20 IDA Maximum Residual Interstorey Drift Response of ATC-F08B and ATC-F22B Records Analytical and Experimental . . . . . . . . . . . . . . . . 141

6.21 Hysteretic Response of Prototype Specimen at Actuator Interface and at Friction Brace Slip Location . . . . . . . . . . . . . . . . . . . . 146

6.22 Overhead View of Prototype Specimen in Laboratory . . . . . . . . . . . . 147

6.23 Gusset Condition Post Testing . . . . . . . . . . . . . . . . . . . 148

6.24 Beam Joint Condition Post Testing … . . . . . . . . . . . . . . . 149

6.25 Brass Friction Plates Condition Post Testing . . . . . . . . . . . . . . . 150

6.26 Bottom Stainless Steel Friction Plate Condition Post Testing . . . . . . . . . . . 151

6.27 Top Stainless Steel Friction Plate Condition Post Testing . . . . . . . . . . . . . 152

6.28 Fragility Plot of 11 Analytical and Experimental Record Responses at Maximum Interstorey Drifts . . . . . . . . . . . . . . . . . . . 154

6.29 Fragility Plot of 11 Analytical and Experimental Record Responses at Maximum Residual Interstorey Drifts . . . . . . . . . . . . . . . . 155

6.30 Maximum Interstorey Drift Convergence with Maximum Interstorey Residual

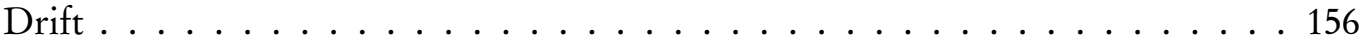

A.1 Structures First 6 Mode Shapes and Associated Periods . . . . . . . . . . . 181

A.2 Cross Laminated Timber Cross Section . . . . . . . . . . . . . . . . . . 195

A.3 Typical Brace Stiffness and Length Properties . . . . . . . . . . . . . . 200

C.1 Friction Brace Assembly (Gilbert, 2016) . . . . . . . . . . . . . . . . . . 214

C.2 Glued-in rod Detail for Each Frame Element . . . . . . . . . . . . . . . 217

C.3 Gusset Plate (Gilbert, 2016) _ . . . . . . . . . . . . . . . . . . 218

C.4 Glued-in Rod Connection Beam Plan View (Gilbert, 2016) . . . . . . . . . . . 219 
C.5 Glued-in Rod Connection Column Plan View (Gilbert, 2016) . . . . . . . . . . 220 


\title{
Nomenclature
}

\author{
a - unloaded edge distance \\ A - element area \\ $A_{b} \quad$ - cross-sectional area of bolt \\ $A_{g} \quad$ - gross cross-sectional area \\ $A_{\text {gv }} \quad$ - gross area in shear for block failure \\ $A_{n} \quad$ - tensile area of the steel rod; net cross-sectional area \\ $A_{n e} \quad$ - effective net area reduced for shear lag \\ $A_{r} \quad$ - cross-sectional area of a rod \\ $A_{r} \quad$ - distance between the plastic hinge in rod and end grain \\ $A_{w} \quad$ - cross-sectional area of wood \\ b - lamination width \\ $B \quad$ - beam width \\ $B_{r} \quad$ - factored bearing resistance \\ $B_{x} \quad$ - lateral sensitivity factor \\ $B_{y} \quad$ - CLT slab design width for analysis \\ $C_{a} \quad$ - shape factor \\ $C_{b} \quad$ - basic roof snow load factor \\ $C_{c} \quad$ - slenderness ratio \\ $C_{e} \quad$ - exposure factor for open terrain \\ $C_{g} \quad$ - gust effect factor \\ $C_{p} \quad$ - external pressure coefficient
}




$$
\begin{array}{ll}
C_{s} & \text { - roof slope factor } \\
C_{v} & \text { - shear load coefficient } \\
C_{w} & \text { - wind exposure factor } \\
d & \text { - element depth } \\
d & \text { - nominal rod diameter } \\
d_{b} & \text { - diameter of bolt } \\
d_{h} & \text { - embedment hole diameter } \\
D_{i} & \text { - inside diameter of the bearing surface contact area of the nut } \\
D_{o} & \text { - outside diameter of the bearing surface contact area of the nut } \\
d_{r} & \text { - nominal rod diameter } \\
d_{t s} & \text { - minimum thread diameter } \\
D_{w} & \text { - equivalent diameter of friction torque bearing surface } \\
d_{2} & \text { - pitch diameter of the tread } \\
E_{b} & \text { - characteristic elastic modulus } \\
F_{b} & \text { - normal force in bolt } \\
f_{b} & \text { - effective bending stiffness } \\
e_{m i n} & \text { - minimum edge distance } \\
E_{r} & \text { - elastic modulus of threaded steel rod } \\
E_{s} & \text { - modulus of elasticity for stiffness calculation } \\
E_{w} & \text { - elastic modulus of wood } \\
E_{a} & \text { - modulus of elasticity longitudinal } \\
E_{05} & \text { - modulus of elasticity } 5 \text { percent } \\
E_{90} & \text { - modulus of elasticity perpendicular } E_{90} / 30 \\
F_{a} & \text { - glued-in rod shear strength characteristic } \\
f_{a} &
\end{array}
$$


$f_{b n} \quad$ - negative bending strength

$f_{b p} \quad$ - positive bending strength

$f_{b 0} \quad$ - bending strength longitudinal

$f_{b 90} \quad$ - bending strength perpendicular

$f_{c} \quad$ - compression parallel to grain strength

$f_{c p} \quad$ - compression perpendicular to grain strength

$F_{f, d y n} \quad$ - dynamic friction resistance

$f_{f a t, d} \quad$ - glued-in rod fatigue resistance

$F_{\text {Frame }}$ - frame friction contribution

$F_{f, \text { static }}$ - static friction resistance

$f_{h, 1} \quad$ - embedment strength of the timber determined from DIN 1052

$f_{k 1, d} \quad$ - glued-in rod pull out resistance

$F_{N b} \quad$ - normal pre-tensioned bolt force

$f_{s} \quad$ - specified strength in rolling shear

$f_{t} \quad$ - tension parallel to grain strength

$f_{t} \quad$ - Higher mode effect force (whipping force)

$f_{\text {tg }} \quad$ - tension strength parallel to grain gross

$f_{t 0} \quad$ - tension parallel to grain strength longitudinal

$f_{u} \quad$ - ultimate strength

$f u_{\text {rod }}$ - ultimate strength

$f_{v} \quad$ - longitudinal shear strength

$F_{v} \quad$ - velocity based ground motion amplification factor

$f_{v r o} \quad$ - shear strength longitudinal

$f_{v 90} \quad$ - shear yield strength perpendicular

$F_{x} \quad-$ seismic force contribution at storey $x$

$f_{y} \quad$ - characteristic yield strength of steel

$f_{y, k} \quad$ - characteristic yield strength of steel glued-in rod fastener

$f_{1} \quad$ - local element axial force node i 


$$
\begin{aligned}
& f_{2} \quad \text { - local element axial force node } \mathrm{j} \\
& 9 \text { - force of gravity } \\
& G A_{e f f} \text { - effective in plane shear rigidity } \\
& \text { Go - shear modulus longitudinal } E_{0} / 16 \\
& G_{90} \quad \text { - shear modulus perpendicular } E_{90} / 160 \\
& \text { h - CLT floor thickness } \\
& \text { h - floor height } \\
& \text { H - beam depth } \\
& H_{B} \quad \text { - bolt head thickness } \\
& h_{i} \quad \text { - distance from the lower edge to } i^{\text {th }} \mathrm{rod} \\
& h_{n} \quad \text { - building height } \\
& H_{N} \quad \text { - nut thickness } \\
& h_{s} \quad \text { - storey height } \\
& h_{s x} \quad \text { - storey height } \\
& \text { I - element moment of inertia } \\
& I_{E} \quad \text { - building importance factor } \\
& I_{s} \quad \text { - importance factor for snow loading } \\
& I_{w} \quad \text { - importance factor for wind loading } \\
& K \quad \text { - torque coefficient } \\
& K_{c} \quad \text { - slenderness factor } \\
& K_{\text {creep }} \quad \text { - creep coefficient } \\
& K_{D} \quad \text { - duration factor } \\
& K_{H} \quad \text { - system factor } \\
& k_{\text {initial }} \text { - initial stiffness matrix } \\
& K_{L} \quad \text { - lateral stability factor } \\
& k_{r} \quad \text { - geometric lateral resistance parameters } \\
& K_{\text {rby }} \quad \text { - adjustment factor bending } \\
& k_{s} \quad \text { - geometric lateral resistance parameters }
\end{aligned}
$$




$$
\begin{aligned}
& K_{S b} \quad \text { - service condition factor for bending } \\
& K_{S c} \quad \text { - service condition factor compression parallel to grain } \\
& K_{S E} \quad \text { - service condition factor for modulus of elasticity } \\
& K_{S t} \quad \text { - service condition factor tension parallel to grain } \\
& K_{S v} \quad \text { - service condition factor for shear } \\
& K_{T} \quad \text { - treatment factor } \\
& K_{X} \quad \text { - curvature factor } \\
& K_{Z c g} \quad \text { - member size factor } \\
& l \quad \text { - larger plan dimension } \\
& \text { l - thread angle } \\
& \text { L } \quad \text { - length of segment } \\
& l_{a} \quad \text { - embedment (or anchorage) length } \\
& l_{a d} \quad \text { - embedment (or anchorage) length } \\
& L_{b} \quad \text { - beam length } \\
& l_{c} \quad \text { - characteristic length of roof } \\
& L_{e} \quad \text { - elastic braced length } \\
& l_{\text {geo }} \quad \text { - geometric characteristic parameter } \\
& L_{J} \quad \text { - total joint or grip length } \\
& l_{m} \quad \text { - material length parameter } \\
& L_{s} \quad \text { - un-threaded bolt shank length } \\
& l_{v} \quad \text { - vibration controlled span limit } \\
& m \quad \text { - number of shear planes } \\
& \text { m - mass per unit length } \\
& M_{r} \quad \text { - factored bending moment } \\
& M_{r 1} \quad \text { - factored moment resistance } \\
& M_{r 2} \quad \text { - factored moment resistance } \\
& M_{y} \quad \text { - yield moment resistance of the rod } \\
& M_{v} \quad \text { - higher mode factor }
\end{aligned}
$$




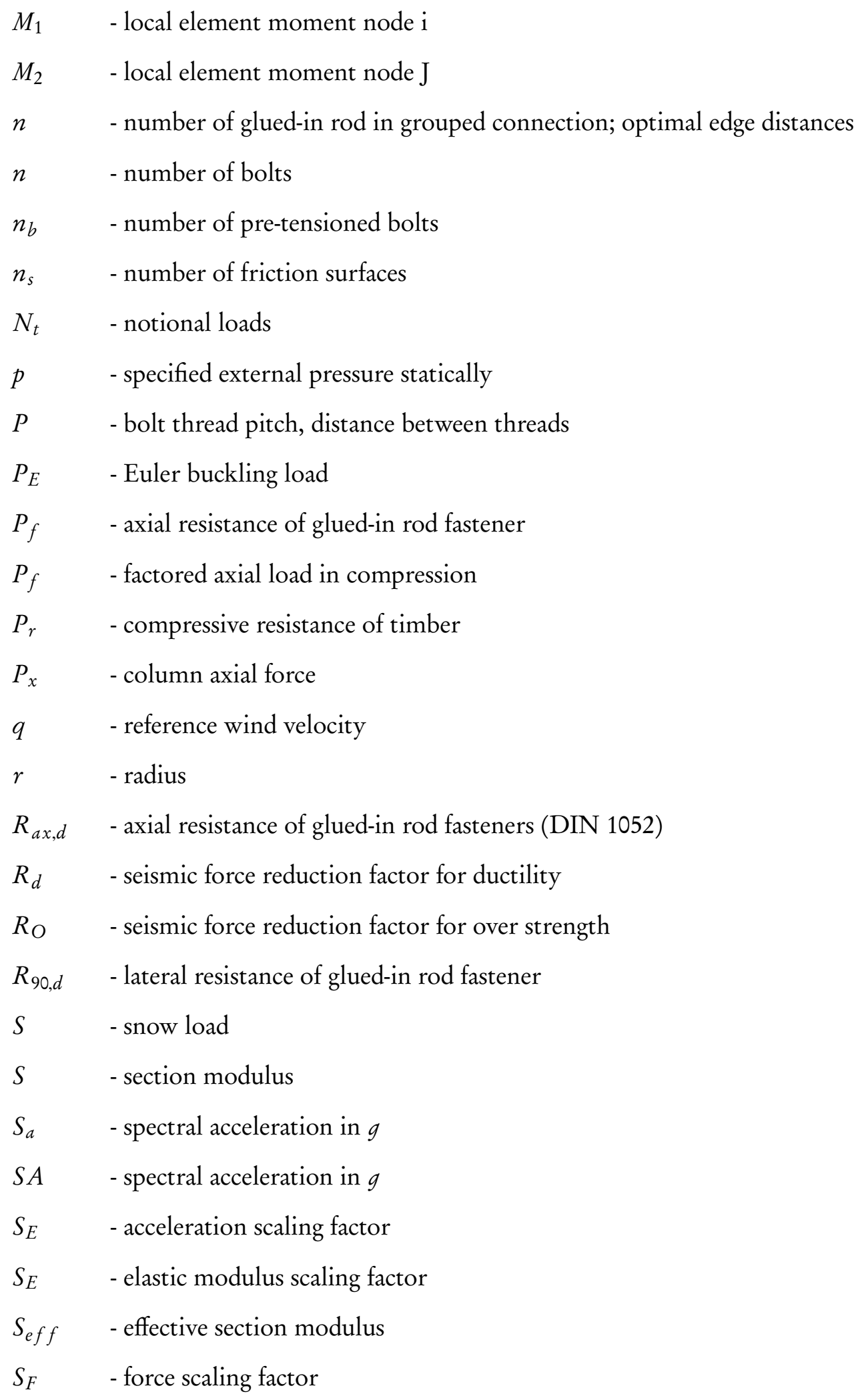




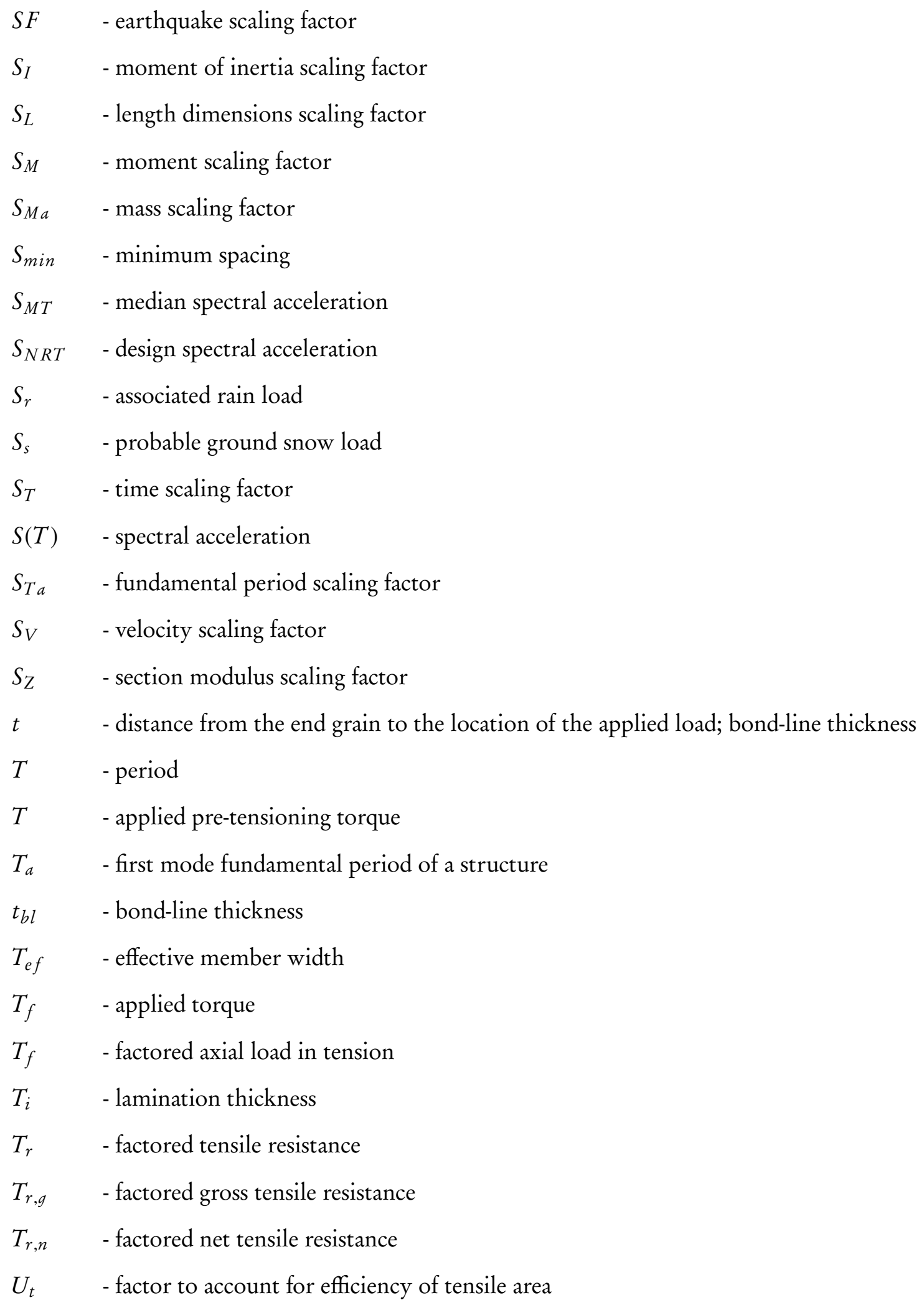




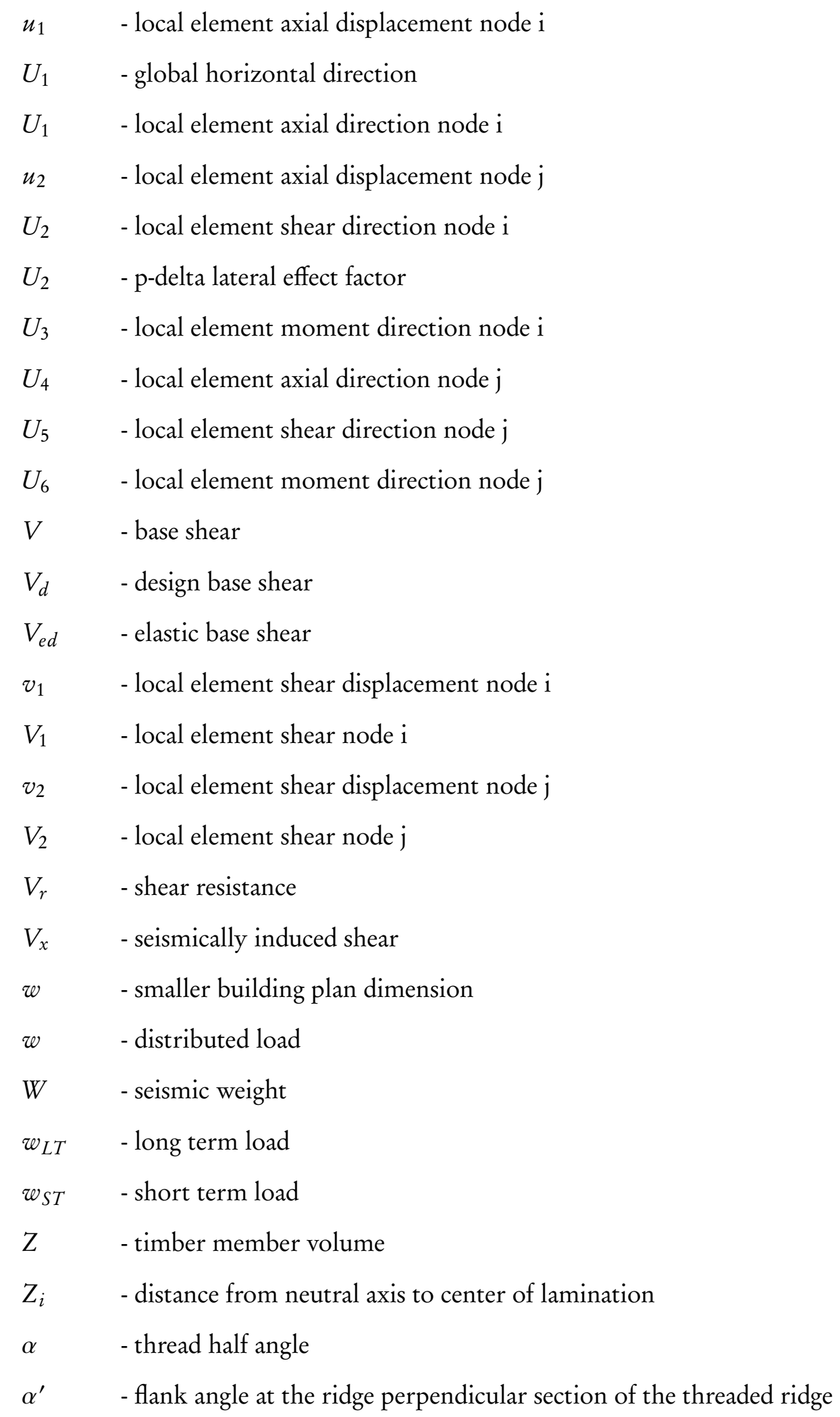




$$
\begin{array}{ll}
\beta & \text { - thread helix, or lead angle } \\
\Delta & \text { - deflection } \\
\delta_{b} & \text { - bolt elongation } \\
\delta_{m a x} & \text { - maximum anticipated deflection } \\
\delta_{U D L, S T} & \text { - short term deflection of uniform load } \\
\delta_{U D L, L T} & \text { - long term deflection of uniform load } \\
\Delta_{x} & \text { - anticipated storey drift } \\
\theta_{x} & \text { - stability coefficient } \\
\theta_{1} & \text { - local element rotational displacement node i } \\
\theta_{2} & \text { - local element rotational displacement node j } \\
\mu_{d} & \text { - dynamic friction coefficient } \\
\mu_{s} & \text { - static friction coefficient } \\
\mu_{s} & \text { - static friction coefficient, thread surface friction coefficient } \\
\mu_{w} & \text { - bearing surface friction coefficient } \\
\phi & \text { - resistance modification factor of steel } \\
\phi_{f} & \text { - resistance modification factor of wood } \\
\phi_{A r} & \text { - anchor rod resistance factor } \\
\phi_{b} & \text { - structural bolt resistance factor } \\
\phi_{b r} & \text { - bearing resistance modification factor } \\
\phi_{u} & \text { - resistance modification factor of steel } \\
\rho & \text { - timber density } \\
\rho_{k} & \text { - timber density } \\
\sigma_{f} & \text { - bond-line shear strength } \\
\hline &
\end{array}
$$




\section{Chapter 1: Introduction}

\subsection{Background}

The use of heavy timber in high rise construction has steadily increased as governments and building owners strive to reduce their structure's environmental footprint. Consequently, this has driven innovation and resulted in many unique structural designs that incorporate heavy timber as an integral component of a building's structural system. Despite this, many of these innovative structures still only incorporate heavy timber in the gravity resisting system, while more conventional concrete shear wall Seismic Force Resisting Systems (SFRS) remain to resist seismic loads. This is partly due to modern heavy timber connections poor seismic performance coupled with the systems relatively limited past proven use in high rise structure's SFRSs. This poor performance can be linked to brittle failure mechanisms often exhibited by modern heavy timber connections that transfer frame element forces from one member to another through connections that load members in their weak perpendicular-to-grain orientation. This loading results in splitting failure mechanisms that are brittle and undesirable especially under seismic loading.

In Canada, heavy timber SFRSs are assigned low force reduction factors and are thus less desirable compared to concrete or wood shear wall systems. Consequently, some research in heavy timber SFRSs is focused on increasing the ductility of heavy timber connections. Similarly, emphasis can be made to further increase reliability by coupling heavy timber SFRSs with systems that reduce seismic loads. This has been achieved by several researchers who combined heavy timber and ductile steel systems to improve the performance of these types of SFRSs. Implementing systems used in advanced steel structures into heavy timber structures, as well as, 
proper capacity design detailing allows designers to use higher force reduction factors thus reducing seismic design forces. Many past researchers have focused on improving the performance of heavy timber SFRS; two recent examples of this innovative technique have been developed and tested under cyclic loading by Gilbert (2016) and Gohlich (2015). These systems utilized steel connections at the heavy timber column and beam connection locations to transfer forces into the strong parallel-to-grain direction. The systems used seismic bracing or yielding elements to dissipate energy. The focus of the past research was verification of connection performance. The global performance of the entire SFRS at varying seismic intensities is not well-understood due to limited testing. Similarly, the accuracy of the current modeling techniques for these types of systems has not been verified. Verification of current modeling techniques can be done using hybrid testing.

The use of hybrid testing provides a cost-effective and accurate method to capture the overall behaviour of full-scale structures under seismic loading. In a hybrid test, a critical portion of a structure that is expected to experience significant nonlinear behaviour is tested in the lab while the rest of the structure is modeled numerically in a finite element program (McCrum and Williams, 2016). The process of splitting the structure into experimental and numerical components is referred to as substructuring (McCrum and Williams, 2016). The portion of the structure that is tested in the lab is referred to as the experimental or physical substructure, while the remaining portion of the building that is modeled in a finite element software is referred to as the numerical or analytical substructure. The benefits of performing hybrid tests are the ability to accurately incorporate the nonlinear behaviour of structural elements that are difficult to model analytically by experimentally testing only those elements in the laboratory, reducing the need for expensive full-scale tests (McCrum and Williams, 2016). By comparing fully numerical structural response behaviour with response behaviour obtained through experimental hybrid testing, the accuracy of current modeling techniques can be verified. In addition, observing how structural response behaviour trends compare experimentally to numerical predictions over a wide range of seismic intensities can verify the the accuracy limits of current modeling techniques. Incremental Dynamic Analysis (IDA) is an effective means of presenting a structure's response over a wide range of seismic intensities and is an effective means of comparing numerical predictions 
to experimental results to verify model accuracy and it's limits.

Incremental dynamic analysis involves performing multiple nonlinear dynamic analyses on a structure to understand it's seismic behaviour throughout it's full range of dynamic responses under a suite of ground motions (Vamvatsikos and Cornell, 2004). This is accomplished by applying a suite of ground motion records at increasing levels of intensity that will cause the structure to experience an elastic response all the way to final global dynamic instability (Vamvatsikos and Cornell, 2004). By performing an IDA through hybrid testing, realistic behaviour of an experimental specimen, as well as, the global response of the system can be captured. This is unique since IDAs are generally performed only numerically.

Performing an IDA on this type of system numerically and through hybrid testing and comparing structural response behaviour can be an effective means of validating current modeling techniques. In addition, the use of an IDA is an effective means of visualizing overall response behaviour of this type of system over a wide range of seismic intensities.

\subsection{Objective and Scope}

This research investigates the global response behaviour of a combined heavy timber-steel friction braced framing system using the same combined heavy timber-steel connections developed by Gilbert (2016). The system combines traditional glue-laminated heavy timber elements with selective amounts of steel at critical beam-column connections. Glulam and steel components are fastened together using glued-in steel rod connections. These connections are designed to transfer the forces to the timber elements in the strong parallel-to-grain direction. The combined timber-steel connection design forms a stronger connection and allows the beam-column connections to transfer higher forces into specially designed elements that dissipate seismic energy. In this study friction braces are used to dissipate seismic energy and reduce load on the SFRS.

This research employs hybrid testing methodology to perform an experimental incremental dynamic analysis on the newly developed system. The experimental IDA is compared with an analytical IDA to assess accuracy of the finite element model. Hybrid-testing methodology is

Sean Miller, Department of Civil and Environmental Engineering, Carleton University 
used to perform the IDA. In this study, the term experimental IDA is an IDA developed from hybrid test results. The physical specimen developed by Gilbert (2016) is physically tested in the laboratory while the remainder of a newly developed prototype structure is analytically modeled. The IDA of the structure involved performing 165 hybrid tests of the structural model under a suite of 11 ground motion records. Each ground motion record was scaled to several levels of seismic intensity forcing the structure through a wide range of behaviour from elastic to inelastic and finally to global dynamic instability. In these tests, all records are run to their full length plus additional time for free vibration. IDA curves are developed for maximum interstorey and maximum interstorey residual drift of the structure. These tests are compared against purely numerical analysis results to assess the viability of the finite element model and overall performance of the structure at various seismic intensities. Using the IDA results, fragility curves are generated to estimate the probabilistic seismic response at varying intensity measurements and to assess the agreement between analytical and experimental results. In addition, convergence of maximum interstorey drift and maximum interstorey residual drifts is quantified for this type of structure.

The following key objectives are highlighted:

- Investigate the feasibility of using combined heavy timber-steel friction braced SFRS in mid rise structures located in earthquake prone regions

- Validate the current analytical finite element modeling technique for this type of system by comparing the analytical incremental dynamic analysis structure response prediction with the experimental incremental dynamic analysis results developed from hybrid testing 


\section{Chapter 2: Literature Review}

This chapter provides a brief background on past and present combined timber-steel framing systems, structural testing methods, friction braced systems, incremental dynamic analysis and other topics related to this research. Within each section, results and conclusions from past research is presented and summarized.

\subsection{Over-strength and Ductility of Seismic Force Resisting Systems (National Research Council, 2011)}

The National Building Code of Canada (National Research Council, 2011) permits engineers to reduce seismic loads for elastic design of Seismic Force Resisting Systems (SFRS), by dividing the design base shear by the product of a ductility and over-strength factor Rd and Ro, respectively. The National Building Code ductility factor ranges between 1.0 to 5.0 and overstrength factor ranges between 1.0 to 1.7 (National Research Council, 2011). Heavy timber systems contain low force reduction factors making them less economical in comparison to systems that are assigned higher reduction factors. Systems with high reduction factors include ductile wood shear walls, concrete shear walls and Buckling Restraining Bracing (BRB) systems. Improving the ductility of heavy timber braced systems up to a similar level to that of BRBs would dramatically improve the economic viability of this type of system. The National Building Code ductility and over-strength factors for BRBs range between 2.0 to 4.0 and 1.2 to 1.5 , respectively. This is significantly greater than any braced heavy timber SFRS with ductility factors ranging between 1.0 to 2.0 and over-strength factors ranging between 1.0 to 1.5 (National Research Council, 2011). 


\subsection{Combined Timber-Steel Building System Design Methodology}

Combined timber-steel buildings utilize the inherent benefits of both materials to improve building performance. Combining these materials allows designers to take advantage of the high strength-to-weight ratio of wood and the ductility of steel. Reductions in overall building weight, as well as, application of higher ductility and over-strength ratios in advanced timber-steel structures could make mid-rise combined timber-steel structures as economical as current ductile shear wall systems or BRB systems.

\subsubsection{Previous Combined Timber-Steel and Timber-Concrete SFRS}

Research over the past decade has been put into developing better performing heavy timber SFRSs. All of these systems attempt to improve the brittle frame element end connections for either heavy timber beams, braces, columns and or all of the above. These systems are mainly intended for moment and braced frame systems. Presented below are some recent examples of past research into combined heavy timber-steel and combined heavy timber-concrete systems.

Tjahyadi (2002) developed a brass friction device for use in heavy timber bracing systems. The system consisted of a steel on brass interface clamped together with structural bolts. Timber elements were fastened to the friction device with bolts. The system was proven to provide stable and reliable energy dissipation under cyclic loading. The set-up is presented in Figure 2.1.

Sean Miller, Department of Civil and Environmental Engineering, Carleton University 


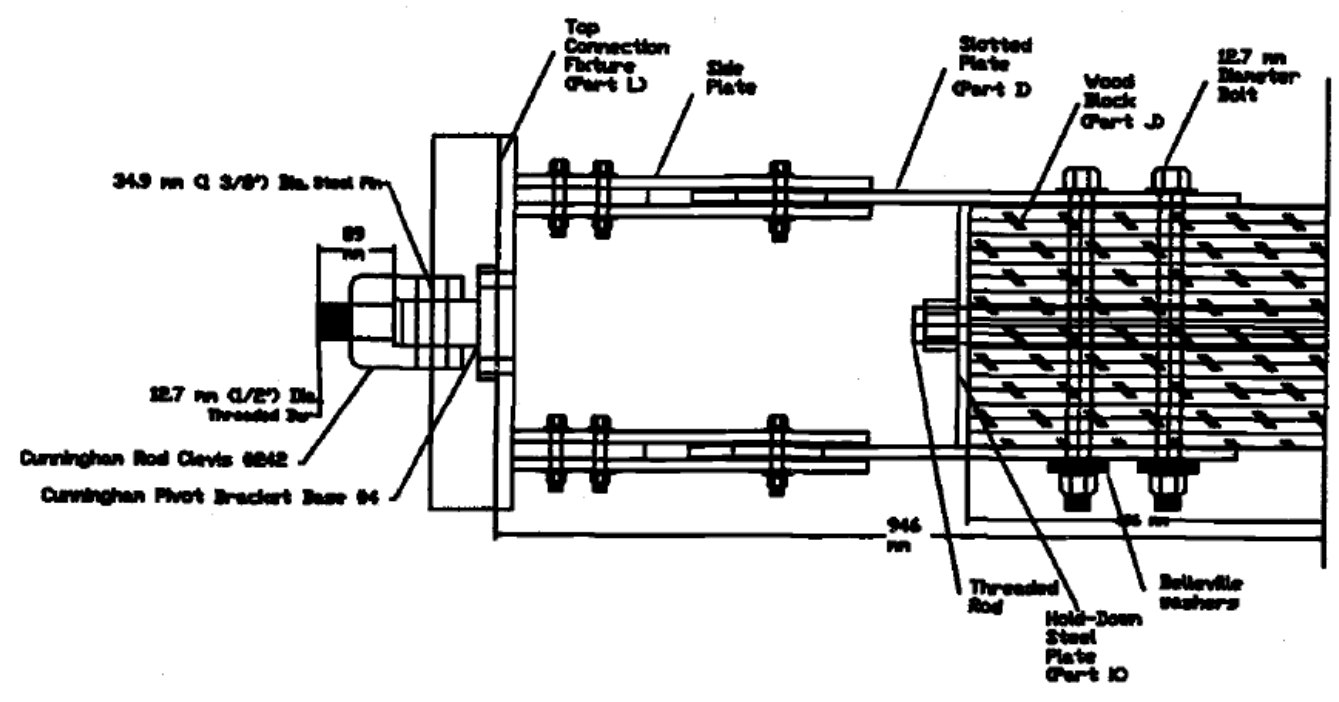

Figure 2.1: Friction Device Developed by Tjahyadi (2002)

Andreolli et al. (2011) developed a combined heavy timber-steel connection system that utilized a steel W-section with welded-on end plates to replace brittle frame element end connections. The steel sections were connected to timber frame elements with glued-in rod connections. Ductility in these connections was achieved through yielding of the steel end-plate, glued-in rod connections or a combination of both. Cyclic tests showed high rotation capacity with moderate pinching behaviour.

Closen (2012) developed a moment connection that fastened a steel collar to a wood beam and column using STS and ZD-plates and structural self-tapping screws. The seismic performance of multiple specimens was evaluated using reverse cyclic loading tests. The results showed that structural self-tapping wood screws were effective under reverse cyclic loading conditions.

Humbert et al. (2014) developed an embedded steel knife plate connection for heavy timber column foundation connections. The connection was shown to have low ductility and energy dissipation due to over-sized gaps in the connection. Experimental tests were conducted under monotonic and reversed cyclic loading. The author concluded that optimization in the design could improve the moment resistance of the joint and prevent brittle wood fracture.

Komatsu et al. (2014) developed a combined heavy timber-steel moment connection that utilized U-shaped brackets at the brittle beam to column interface. These brackets were then 
bolted together using slotted steel plates. The brackets were attached to the timber elements using lagscrewbolts to transfer moment and shear forces. Shaking table testing showed appreciable ductility and energy dissipation. It should be noted that energy dissipation was reliant on friction developed in the slotted bolt holes. The author concluded that extended cyclic loading may reduce energy dissipation. It should also be noted that longitudinal shear failure occurred during testing.

Gohlich (2015) developed a combined heavy timber-steel moment frame that utilized a steel yielding link at the beam-column joint. This system vastly improved the performance of the typical brittle wood connections with ductile steel elements. The system utilized self-tapping screws to transfer high bending moments from steel components into heavy timber frame elements. The seismic performance of the system was determined to be similar to that of a steel only moment frame through experimental testing and nonlinear dynamic modeling.

Gilbert (2016) developed a combined heavy timber-steel buckling restraining braced frame that utilized glued-in rod connections between steel connection components and timber frame elements. The system was capacity designed to maintain linear behaviour in timber frame elements. All nonlinear behaviour in the system was in the buckling restraining braced frame braces. The system proved reliable through dynamic testing and it's performance was similar to that of a steel structure outfitted with buckling restraining braces. Additional details on this system are provided in Chapter 3.

Negrao et al. (2016) developed and tested a reinforced concrete corner connection for heavy timber frame elements. The connections consisted of reinforcing bars, commonly found in reinforced concrete construction, glued-in with epoxy resin into the end grain of the timber elements. Figure 2.2 illustrates a detail of the connection. The specimens were tested in pure bending and by directly loading on the beam with an actuator. It was found that the joint behaviour was similar to that of two heavy timber elements cross connected with bolts. 


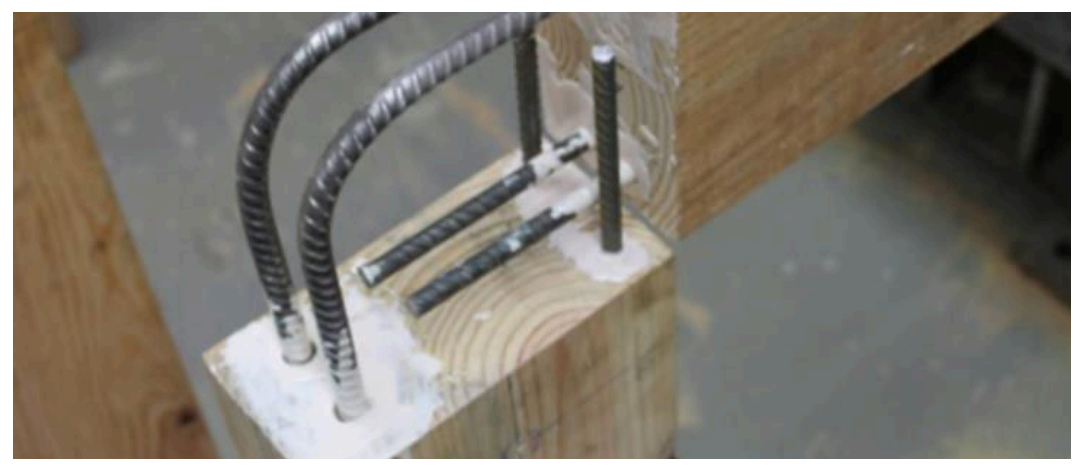

Figure 2.2: Reinforcement Scheme For Reinforced Concrete Joint (Negrao et al., 2016)

These previous studies can be broken down into two categories; improvement of heavy timber moment resisting framed structures, and improvement of braced framed heavy timber structures. In both categories, refinement and improvements from study to study are evident. Grouped into the category of improvement of moment resisting framed structures are works by: Andreolli et al. (2011), Closen (2012), Humbert et al. (2014), Komatsu et al. (2014), Gohlich (2015) and Negrao et al. (2016). Grouped into the category of improvement of braced framed structures are works by: Tjahyadi (2002), Andreolli et al. (2011), and Gilbert (2016). In both moment and braced framed systems, initial development was focused on either reducing seismic load on the SFRS or improving the brittle connections of heavy timber elements. Following these developments, the focus of research was a combination of both objectives, improving heavy timber connection performances, as well as, incorporation of systems that effectively reduced load on the SFRS. In all cases, however. the focus of the research remained verification of connection performance using these specified methods. The global response of these structures over a wide range of seismic intensities is still not widely understood.

\subsection{Friction Damping Devices}

Friction devices rely on surface friction between two or more friction interface elements to dissipate seismic energy through sliding action. The surface friction is calibrated by adjusting the normal force being applied between the friction interfaces. In most systems, this is done by adjusting the pretension force on bolts that clamp the friction elements together. A major 
advantage to friction damping is that these devices do not yield and will perform well if subjected to multiple seismic events (Christopoulos and Filiatrault, 2006).

The hysteretic response of friction damping devices is directly linked to the static and dynamic friction forces exhibited at every stage of a cyclic movement while stationary and while in motion. The response is slightly higher at the activation point which is when the device slips. This is because the system must overcome static friction, this phenomena is present every time the device stops (Christopoulos and Filiatrault, 2006). Surface contact area, material defects, surface ploughing effects, rolling friction, and sliding velocity all affect the hysteretic performance (Christopoulos and Filiatrault, 2006).

Friction devices in structural systems have been developed and improved over many decades. Initial development and testing of friction devices for use in steel braced structures were carried out by Pall and Marsh (1982) and later by Filiatrault (1988), Tremblay (1993) and Grigorian (1994). Since then, friction based systems have been further developed and implemented into modern heavy timber structures, as well as, more resilient steel braced and moment frames. Presented below is a list of recent developments in friction research.

Pall and Marsh (1982) demonstrated the seismic response of friction devices outfitted in braced frames. The author's concluded that the addition of friction dampers to a braced frame dramatically improved its performance under seismic loading. The members in the system remained in the elastic range with the exception of the friction devices. Following an earthquake, if the structure is out of alignment, the friction device can be loosened, the structure straightened and the friction devices re-torqued. Inelastic time-history dynamic analysis was carried out using the computer program Drain-2D.

Duff (1999) developed slotted bolt connection friction dampers for use in heavy timber bracing systems. The system contained two outer plates that sandwiched an inner plate, see Figure 2.3. The plates were pretensioned together using structural bolts that passed through slotted holes in the inner plate. The friction surface was brass or bronze on steel. This system was shown to have stable hysteretic behaviour with minimal pitching as gaps in the system closed. The hysteretic response of the system is illustrated in Figure 2.4. The author estimated 85\% of seismic input energy was dissipated through the use of this system. In this study, a timber 
column, a timber beam and a timber brace were connected together using steel plates and bolt connections. The friction device was connected to the timber brace with bolts and to the column beam joint with bolts.

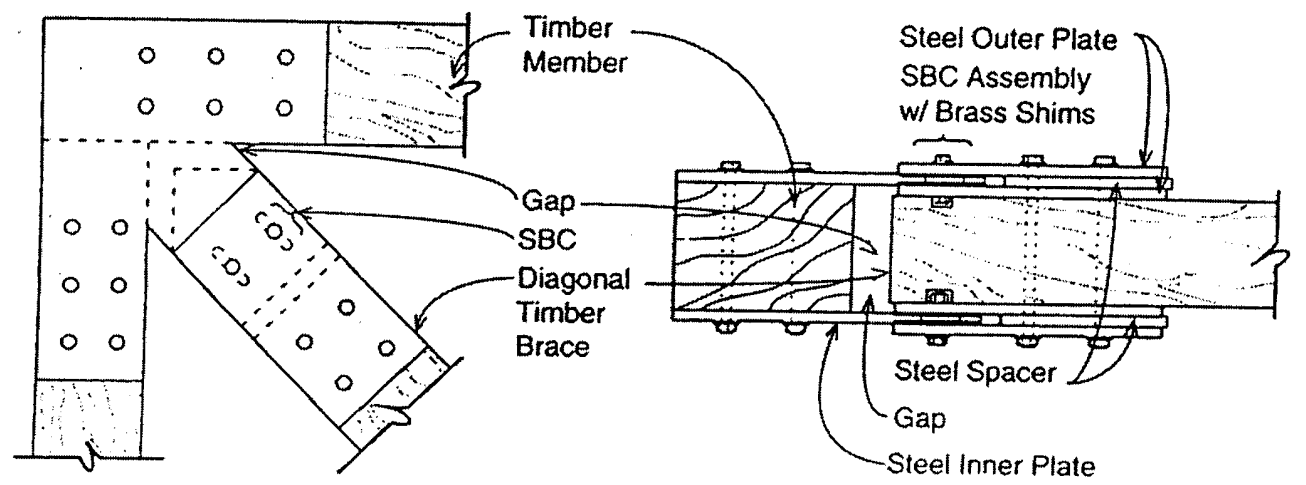

Figure 2.3: Friction Device Developed by Duff (1999)

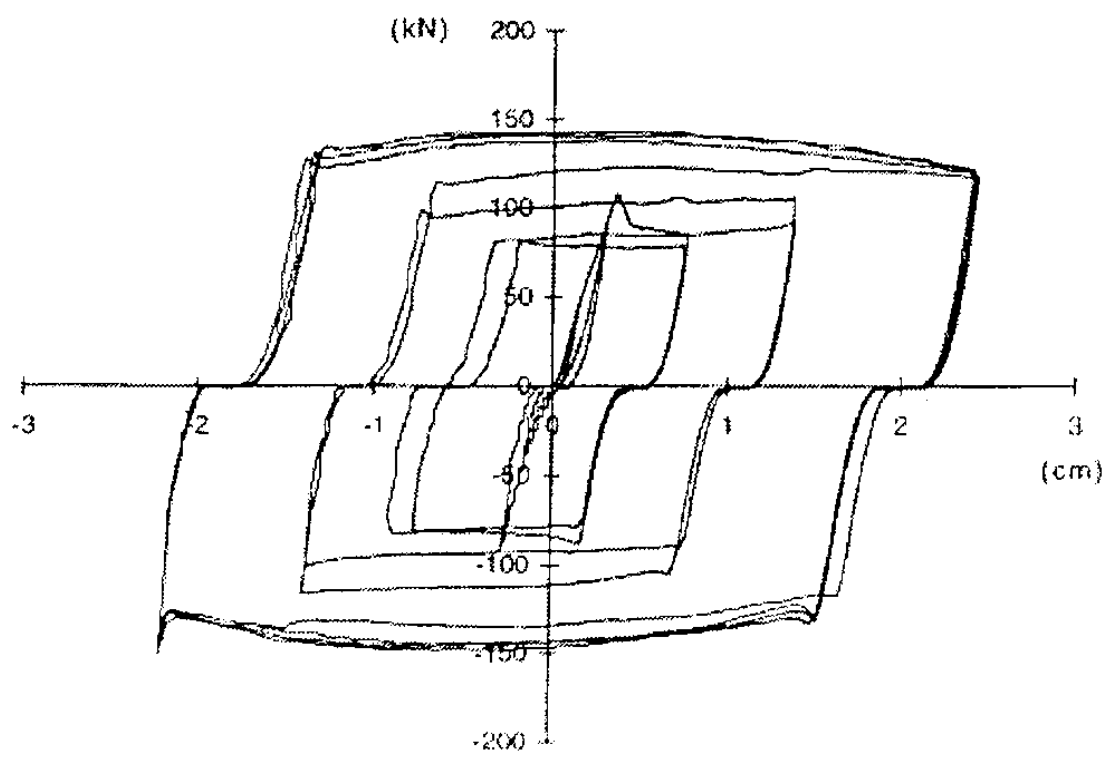

Figure 2.4: Hysteretic Response of Friction Device Developed by Duff (1999)

Butterworth (2000) investigated sliding bolt joints for use in concentrically braced frames. The system contained 3 steel plates clamped together with the inner steel plate having slotted holes. Brass shim plates were added to the system to make the friction interface brass on steel. Sample joints were found to have ductility ranging from 6.7 to 18.6 at maximum drift limits. The experiments were carried out with a 6 storey prototype structure subjected to a time history 
analysis. The author investigated the uses of a steel on steel friction interface prior to the final brass on steel interface selected. The system was modified as the steel on steel proved unreliable.

Tjahyadi (2002) developed a brass friction device for use in heavy timber bracing systems. The system consisted of a steel on brass interface clamped together with structural bolts, see Figure 2.5. Timber elements were fastened to the friction device with bolts. The system was proven to provide stable and reliable energy dissipation under cyclic loading. The hysteretic behaviour of the friction brace is illustrated in Figure 2.6.

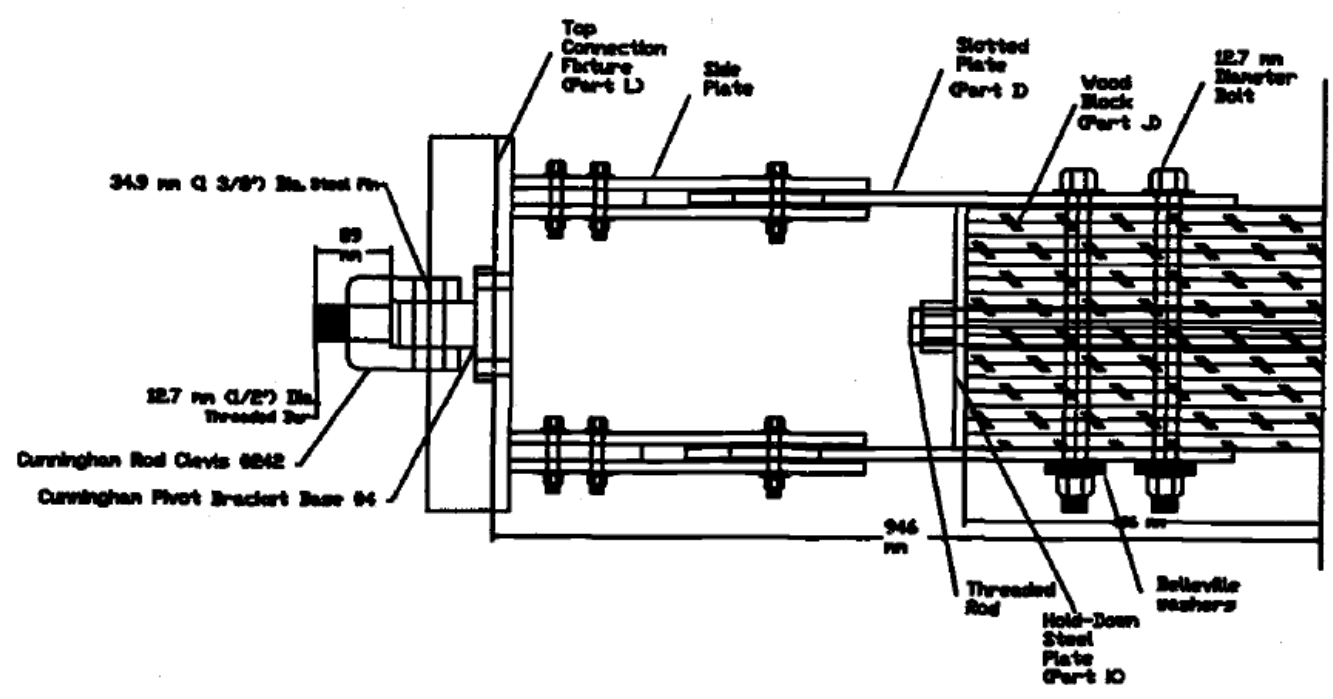

Figure 2.5: Friction Device Developed by Tjahyadi (2002) 

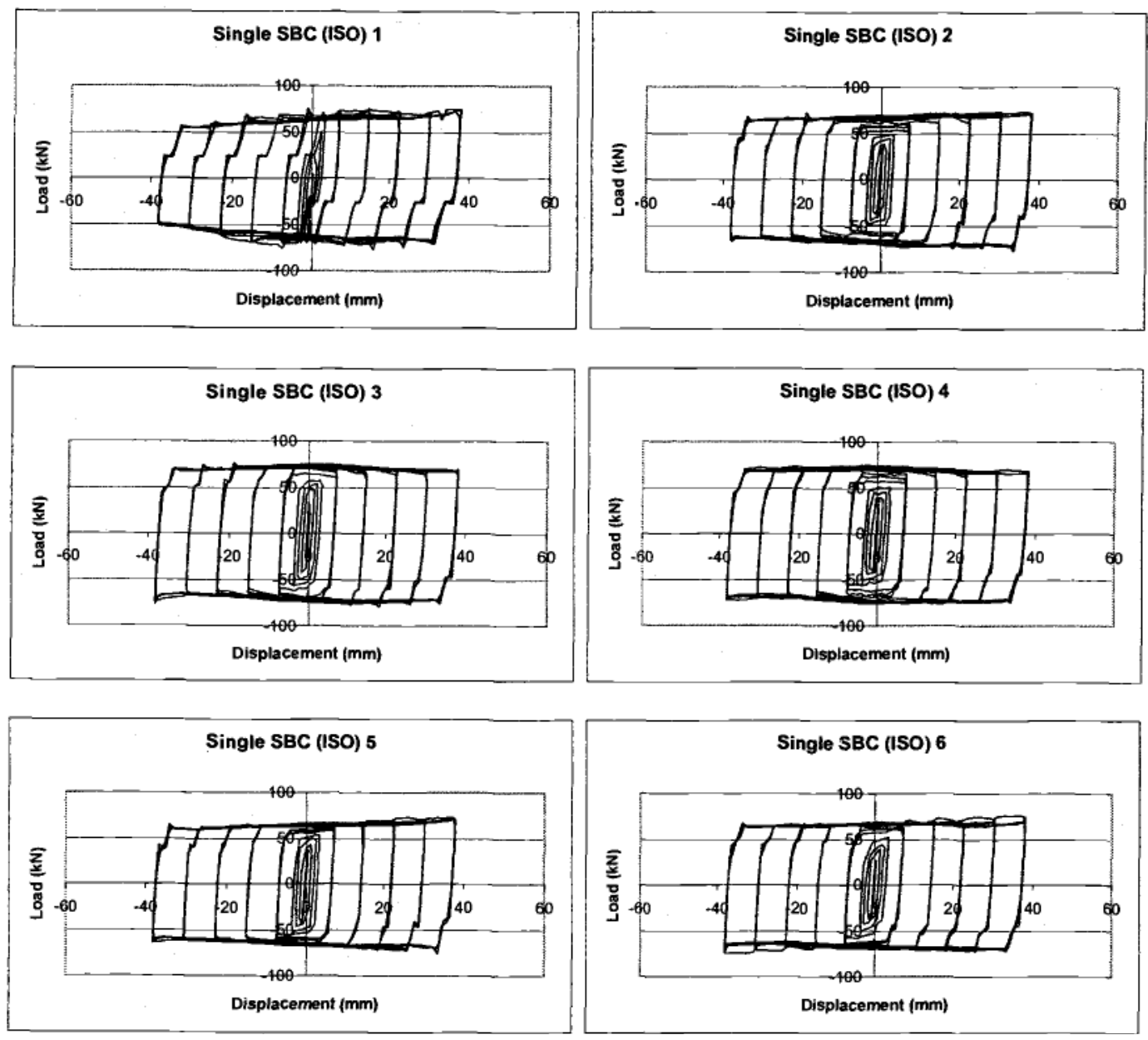

Figure 2.6: Hysteretic Response of Friction Device Developed by Tjahyadi (2002)

Christopoulos et al. (2008) later improved by Erochko (2013) developed a self centering energy dissipative bracing system. The system contained a restoring mechanism of high strength tendons to limit residual drifts. Energy dissipation was provided through a non-asbestos organic pad on stainless steel friction interface.

Latour et al. (2013) performed cyclic tests on different friction surface materials to evaluate friction coefficients and damping characteristics. It was determined that steel on brass friction surface behaviour was more stable and repeatable than steel on steel surfaces.

Borzouie et al. (2015) tested column base plates outfitted with sliding hinge joints. The system was comprised of a series of steel plates pretensioned together that connected a column to it's base plate. The plates were connected with structural bolts through round holes. The round 
holes allowed rotation of the column base relative to the base plate during strong axis bending. Shims were placed on all sliding surfaces to ensure stable hysteretic behaviour. Friction plates were clamped with high strength bolts. The system was tested under cyclic displacement loading without axial load. The system showed potential as low damage was experienced at large drifts.

Gilbert (2016) developed a combined heavy timber steel buckling restraining braced SFRS and a half-scale prototype specimen representing the analytical model's first storey corner bay. Figure 2.7 depicts the prototype SFRS and prototype specimen. The frame utilized glued-in rod connections between steel and timber elements. An experimental study was performed on the prototype specimen under cyclic, monotonic and time history loading to evaluate it's performance. Quasi-static cyclic loading tests were compliant with AISC 341-05(2005) and ASCE705(2005). Dynamic earthquake time history loading of the prototype specimen was determined from the analytical model's first storey displacement history response when the prototype structure was subjected to three DBE and MCE hazard level earthquake records. The study results validated the design of the glued-in rod connections and the prototype specimen's resilience to realistic loading of a BRB braced frame. The prototype specimen was detailed with a friction brace to facilitate multiple tests. Based on Gilbert (2016) results presented in Figures 2.8 to 2.10, the friction brace behaviour at velocities varying between $10 \mathrm{~mm} / \mathrm{sec}$ and $60 \mathrm{~mm} / \mathrm{sec}$ did not affect hysteretic response. Similarly, increasing cycle amplitudes and time history results illustrated stable reliable behaviour. The study did not evaluate the proposed framing system at varying seismic intensities or the response of the prototype specimen to loading from a friction braced structure.

Sean Miller, Department of Civil and Environmental Engineering, Carleton University 


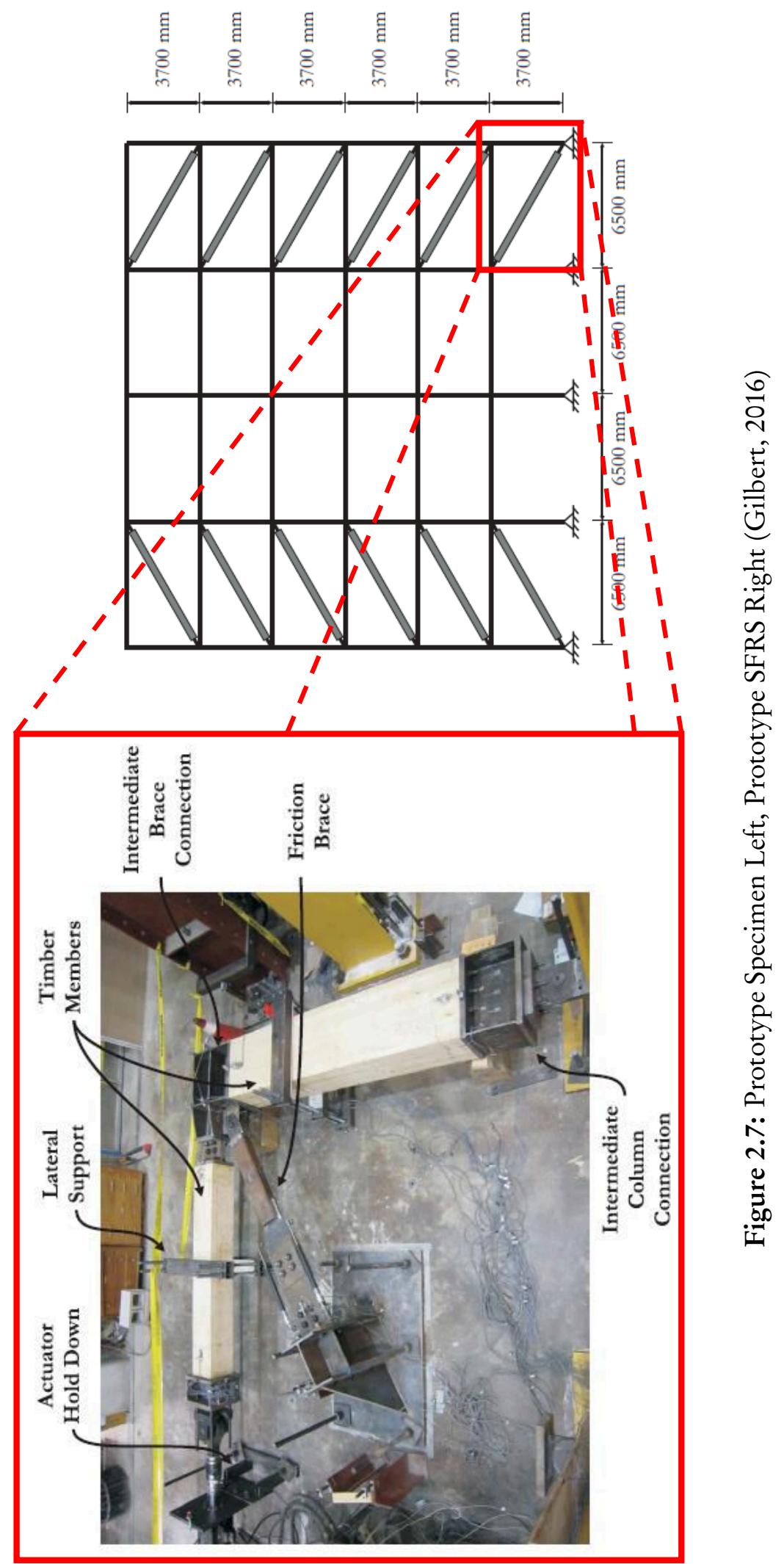



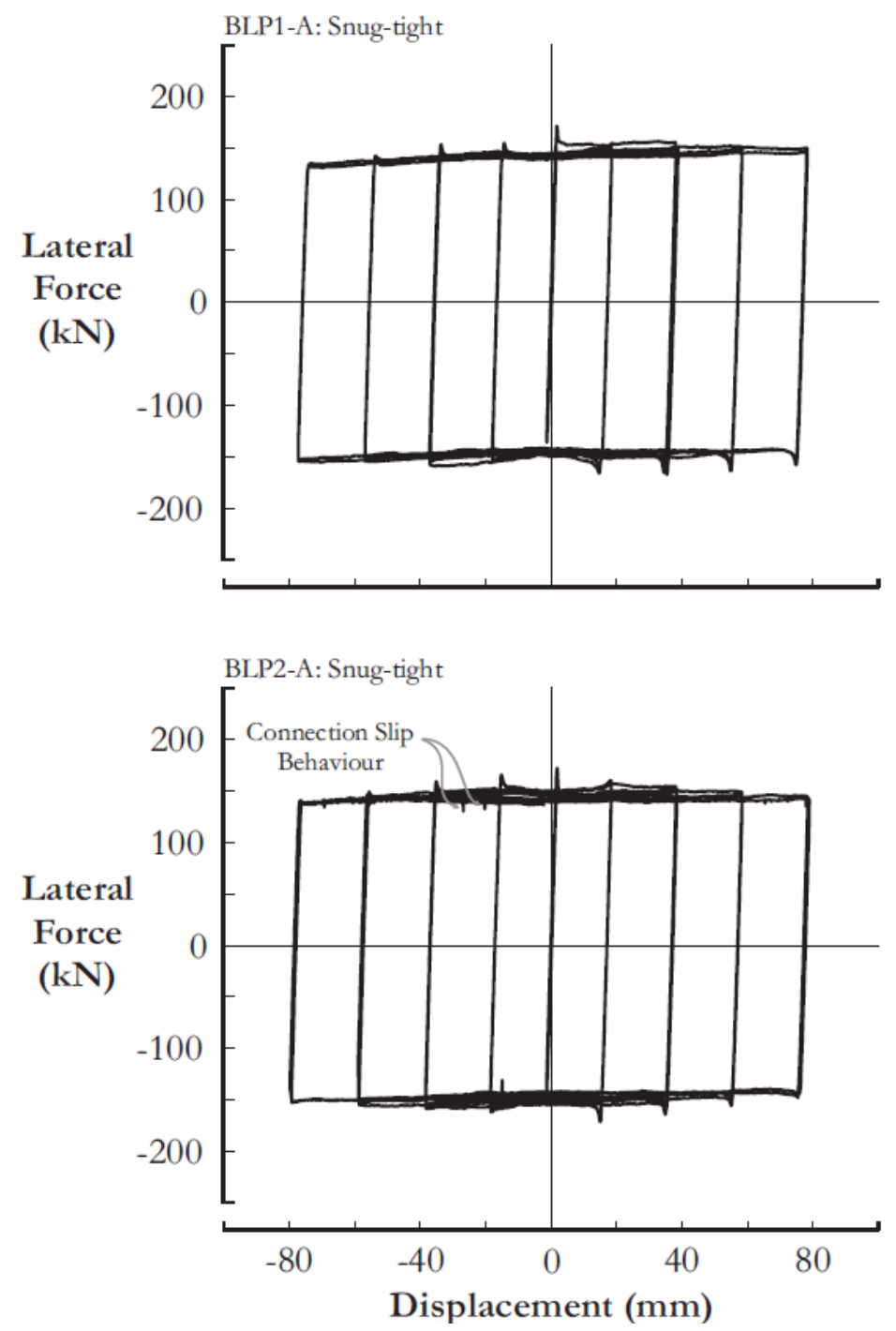

Figure 2.8: Prototype Specimen Response at Increasing Cycle Amplitudes (Gilbert, 2016) 

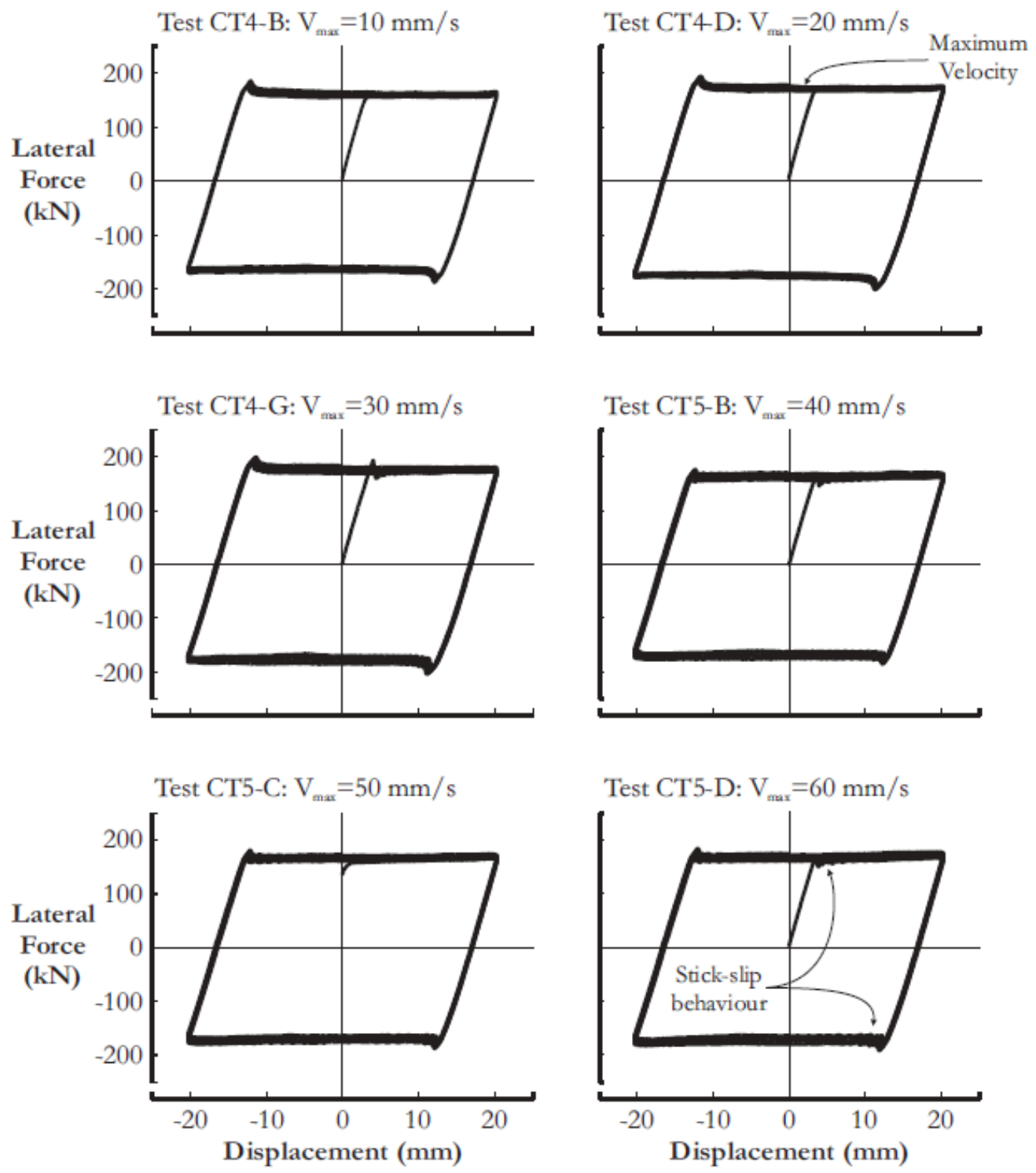

Figure 2.9: Prototype Specimen Velocity Dependant Hysteretic Response (Gilbert, 2016) 

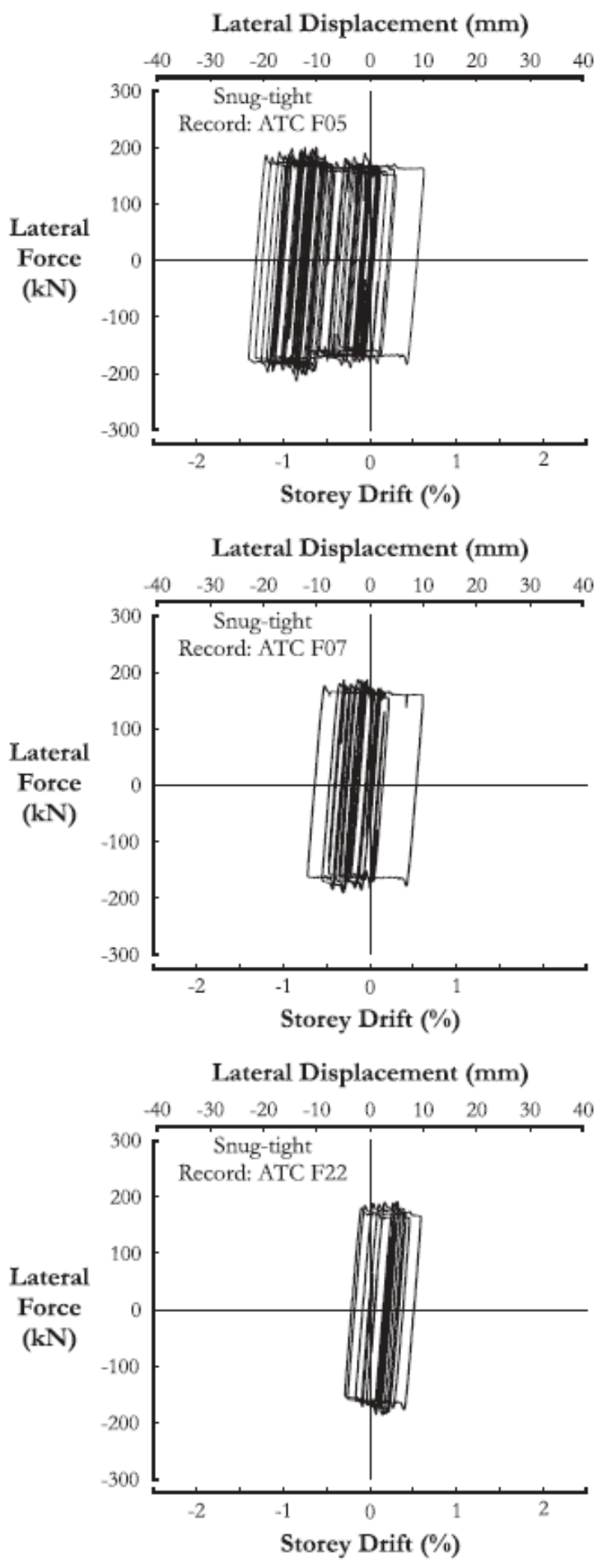

Lateral Displacement (mm)

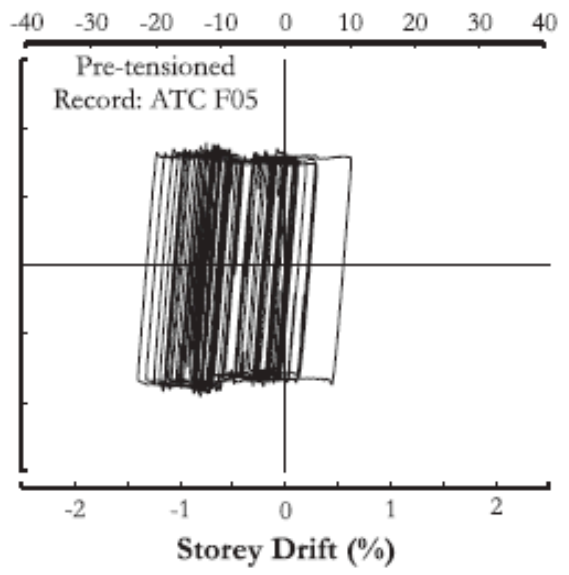

Lateral Displacement (mm)

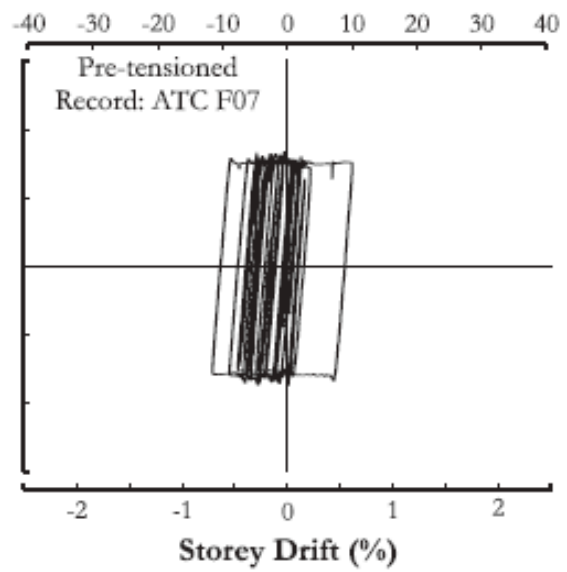

Lateral Displacement (mm)

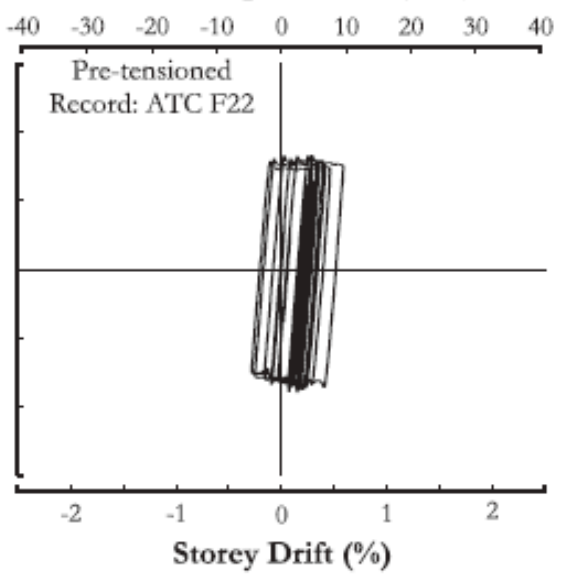

Figure 2.10: Prototype Specimen Hysteretic Response to Seismic Loading (Gilbert, 2016) 
The concept and use of friction braces has remained virtually unchanged since their development in the early 1980s. Most studies concluded that dissimilar materials provide reliable and predictable behaviour. Brass on stainless steel is an example of this and it's behaviour was reliable in studies performed by Gilbert (2016) and Tjahyadi (2002). Similarly, Duff (1999), Tjahyadi (2002) and Gilbert (2016) implemented brass on stainless steel friction braces in heavy timber structures. In Duff (1999) and Tjahyadi (2002), bolt connections were used to connect the friction device to heavy timber elements. In Gilbert (2016) study, friction assemblies were connected to steel braces. These braces then framed into heavy timber beam and column elements which utilized glued-in rod connections to eliminate brittle failure mechanisms. These studies did not address or investigate the response behaviour of these types of systems implemented into mid-rise structures and their change in behaviour over a wide range of seismic intensities.

\subsubsection{Friction Behavior}

Many factors affect friction behaviour and the coefficient of friction. These factors include sliding velocity, temperature, applied normal force, friction materials, length of sliding surface and contamination of friction interface; changes to the friction interface due to wear, debris accumulation and temperature all affect the coefficient of friction (Christopoulos and Filiatrault, 2006). The coefficient of friction can change during every cycle depending on conditions (Christopoulos and Filiatrault, 2006). Sliding velocity also affects the coefficient of friction(Constantinou et al., 1999). The following text will highlight factors that may affect friction behaviour and their implications for a brass on stainless steel interface.

Figure 2.11 illustrates the relation between sliding velocity, apparent pressure and coefficient of friction, as well as, the relation between temperature, sliding velocity and coefficient of friction. It can be seen that initially when sliding begins at low sliding velocities, the coefficient of friction is much lower than when static. This is due to a thin film formed by a chemical reaction between the materials and oxygen (Christopoulos and Filiatrault, 2006). As a result, the film formed by both friction materials is sheared at the interface which is easier to shear than the friction material itself (Christopoulos and Filiatrault, 2006). As sliding velocity increases, the softer friction interface begins to deposit debris onto the harder surface leading to an increased 
friction force (Constantinou et al., 1999). As the sliding velocity increases further, the softer material begins to melt locally reducing its shear capacity and thus decreasing the friction force (Constantinou et al., 1999). Both Christopoulos and Filiatrault (2006) and Constantinou et al. (1999) concluded that the combination of soft and hard materials leads to stable and predictable behaviour.
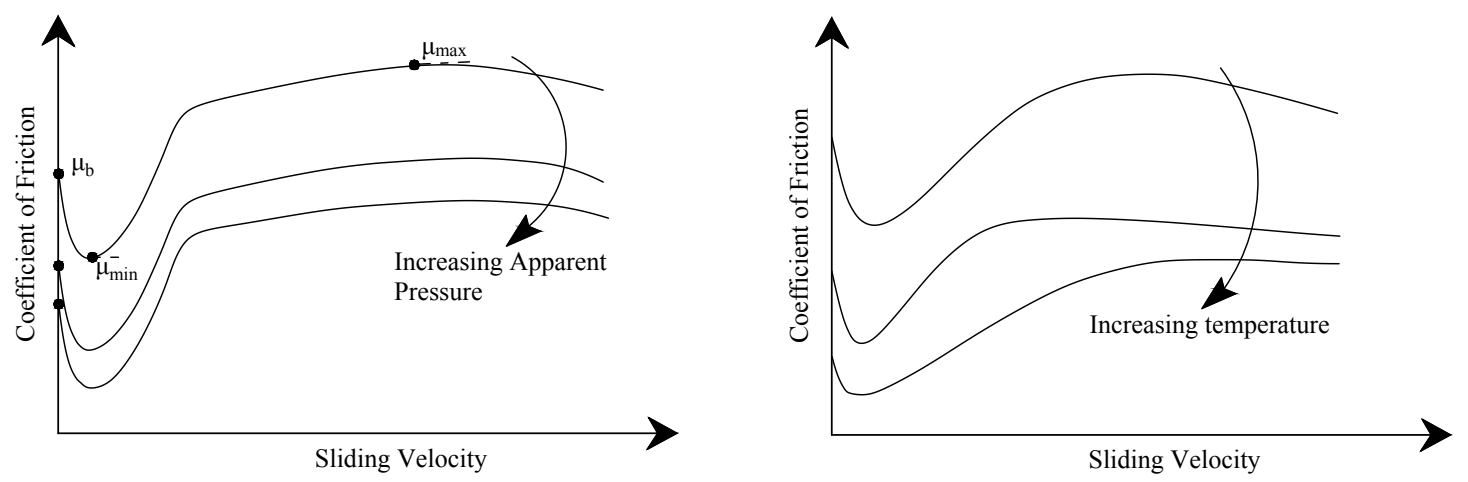

Figure 2.11: Relation Between Sliding Velocity, Coefficient of Friction and Pressure (Left) Relation Between Temperature, Coefficient of Friction and Sliding Velocity (Right) (Christopoulos and Filiatrault, 2006)

The adhesion component of a friction interface is directly linked to the static and dynamic friction forces of the sliding surfaces (Bowden and Tabor, 1973). As normal pressure is applied between the friction surfaces, asperities on both faying surfaces begin to deform plastically increasing the true contact area between the two bodies at the junction (Christopoulos and Filiatrault, 2006). This phenomena is illustrated in Figures 2.12 and 2.13. As the true contact area increases, so does the shear strength at the junction; likewise when the faying surfaces begin to slide, the shear strength is lost and thus reduces the frictional force between the bodies (Christopoulos and Filiatrault, 2006). The larger the shear strength of the bodies, the larger the magnitude difference between the static and dynamic friction coefficients (Rabinowicz, 1966). Since the shear strength of brass is relatively low in comparison to stainless steel, similar coefficients of static and dynamic friction should exist. 


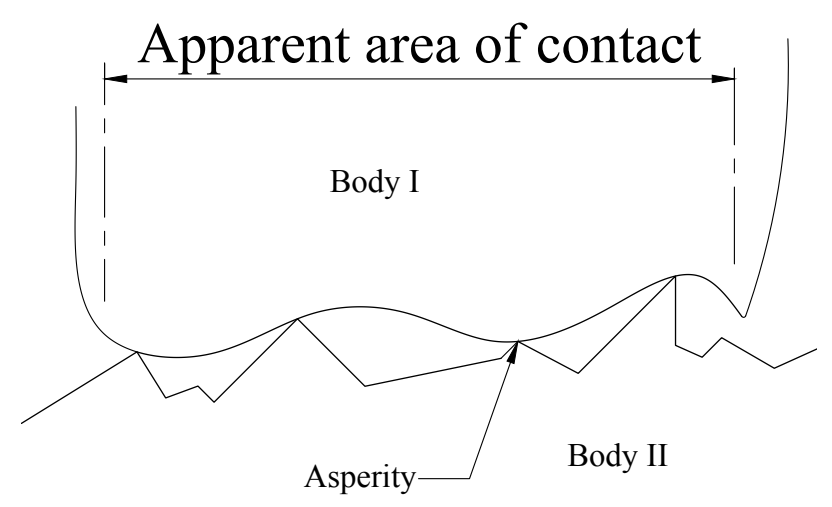

Figure 2.12: Before Applied Normal Pressure (Christopoulos and Filiatrault, 2006)

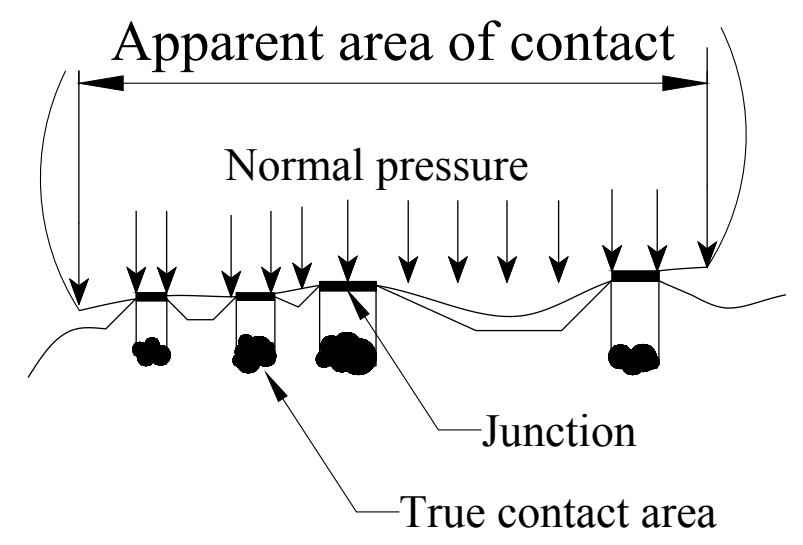

Figure 2.13: After Applied Normal Pressure (Christopoulos and Filiatrault, 2006)

Ploughing is a phenomena that occurs between two bodies when asperities from a harder frictional material dig into the sliding surface of a softer body at their junction (Rabinowicz, 1966). This causes debris to form and accumulate at the edge of the ploughing surface often times slightly changing the static and dynamic friction properties of the assembly. The degree of change is directly tied to the shape of the debris, the amount of debris, and the bodies that are in contact (Rabinowicz, 1966). In the case of round debris forming, the static friction force may actually decrease since the surfaces roll across the debris instead of shearing at the junction of asperities (Christopoulos and Filiatrault, 2006). In the case of sharp edged debris forming, the static friction force may increase since the debris can remain between asperities increasing the true contact area of the bodies and the overall shear required to begin sliding (Christopoulos 
and Filiatrault, 2006). Thus, it is difficult to estimate how the effects of ploughing will affect the overall performance of the system. Since brass is much softer than stainless steel, it is expected that the brass friction surface will wear as opposed to the stainless steel friction surface.

Stick slip motion occurs when loading direction on the friction interface is reversed and there is a temporary stop in movement of the faying surfaces (Christopoulos and Filiatrault, 2006). This is most noticeable when there is a significant difference between the coefficient of static and dynamic friction (Christopoulos and Filiatrault, 2006). Figure 2.14 illustrates this behaviour. This should not be very dramatic in a stainless steel on brass interface.

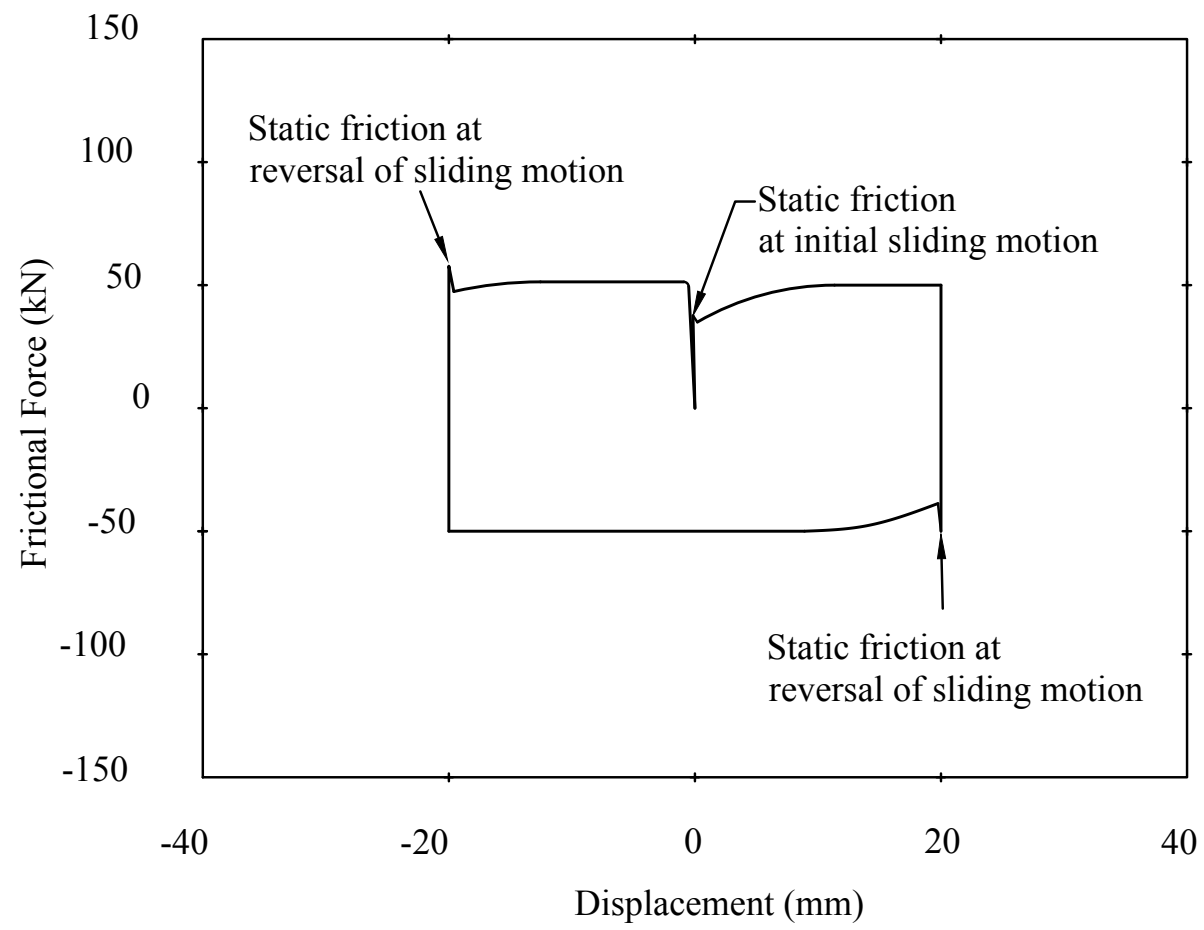

Figure 2.14: Hysteretic Behaviour of Friction Surface (Kim et al., 2004)

Bolt preload is important in sliding surfaces due to the fact that fluctuation in preload can cause unpredictable energy dissipation and hysteretic behaviour (Christopoulos and Filiatrault, 2006). Bolt preload is usually achieved through torquing of a nut, turn of the nut, or elongation of the bolt methods (Kulak et al., 2001). Independent of which method of preloading is chosen, it is important to consider the length of the threaded portion below the nut since 
most of the elongation occurs in this portion of the bolt (Kulak et al., 2001). This is important since torque estimation greatly depends on the length of the threaded portion of the bolt in tension (Christopoulos and Filiatrault, 2006). Consideration must also be given to long term effects of relaxation in the bolt preload (Christopoulos and Filiatrault, 2006). Factors that may affect this behaviour include bolt grip, thread length, and the number of surfaces being clamped (Christopoulos and Filiatrault, 2006). A 1\% drop in preload can be expected immediately after torquing and an additional percent on average after 21 days (Kulak et al., 2001). Regardless of what friction interface is chosen, the issues surrounding bolt preload will exist.

Changes to the sliding surface such as wear, temperature rise, and debris accumulation all affect the elongation of the bolt and the preload. As wear occurs, the sliding surface material is removed and the preload decreases. The opposite is true for temperature rise which causes the materials to expand and increases bolt preload. In the case of debris accumulation from wearing, the bolt preload also increases as the bolt is forced to elongate to accommodate the debris between the plates. This phenomena could present a problem as brass is much softer than stainless steel and debris will likely accumulate during testing.

\subsection{Incremental Dynamic Analysis (IDA)}

Incremental dynamic analysis of structural systems provides seismic demand and capacity prediction capabilities. The analysis consists of a series of nonlinear dynamic analyses scaled over a suite of ground motion records (Vamvatsikos and Cornell, 2004). The suite of records are scaled to several intensity levels designed to force the structure from the elastic range to final global dynamic instability (Vamvatsikos and Cornell, 2002). The term global dynamic instability means that the model failed to meet the equilibrium requirements; meaning the structure has collapsed.

The concept of incremental dynamic analysis has been around since the late 1970's beginning with Bertero (1977). Since then, many people have explored and improved the concept of IDA, including; Nassar and Krawinkler (1991), Bazzurro and Cornell (1994a), Bazzurro and Cornell (1994b), Luco and Cornell (1988), Luco and Cornell (2000), Mehanny and Deierlein (2000), 
Dubina et al. (2000), Matteis et al. (2000), Psycharis et al. (2000), and Yun (2002). More recently, the method has been adopted by the United States Federal Management Agency (Applied Technology Council, 2009) and has become more widely used to evaluate a structure's performance.

\subsubsection{Steps to Perform IDA by (Vamvatsikos and Cornell, 2004)}

There are several general steps to consider as part of an IDA. These include development of a nonlinear structural model, selection and scaling of ground motion records, interpolation of missing data points, defining limit states and finally data interpretation. Each step is presented below:

\subsubsection{Step 1: Develop Nonlinear Structural Model}

Finite element models that accurately predict structural behaviour are ideal for this type of analysis. Open System for Earthquake Engineering Simulation (OpenSees) models, for example, allow designers to assign nonlinear material properties to model elements, as well as, perform nonlinear time history analysis. Models should include P Delta effects. In this study, current finite element modeling techniques are used to develop a fully analytical model of the structure and results are compared with the results from hybrid tests. The accuracy of the analytical model is assessed by comparing an analytical IDA response with an experimental IDA response through hybrid testing. If the analytical model accurately predicts structural behaviour, the experimental and analytical IDA results will match well.

OpenSees is an open source, object oriented software framework application using finite element methods developed by the Pacific Earthquake Research Center (McKenna et al., 2000). The software uses $\mathrm{Tcl}$ script language implemented in $\mathrm{C}++$ (McKenna et al., 2000). OpenSees commands are broken down into 5 main command groups: modeling, analysis, output, misc, and database commands.

\subsubsection{Step 2: Select Suite of Ground Motion Records}

The suite of ground motions should be representative of the regional tectonic regime, the magnitudes and distances that control the seismic hazard and the local geotechnical conditions 
at the site of the prototype structure (National Research Council, 2015). Studies by Shome and Cornell (2004) indicated that for mid-rise structures, 10 to 20 records are usually enough to provide sufficient accuracy in the estimation of seismic demands.

\subsubsection{Step 3: Scale Suite of Records}

It is important to scale the suite of records over a wide range to capture the entire structural response. There are a few options to determine appropriate scaling of ground motions: the first is a brute force approach where a small increment scale factor is selected and each record is subjected to the structure until collapse. The second utilizes algorithms that increase the scaling factor until collapse and fills in the necessary gaps afterwards. It is generally recommended to begin analysis with ground motion spectral acceleration of 0.05 gravity (Vamvatsikos and Cornell, 2002). The hunt and fill algorithm is a proven approach (Vamvatsikos and Cornell, 2002).

\subsubsection{Step 4: Interpolation of Missing Points}

Interpolation of missing points can either be estimated by linear interpolation, spline or piecewise linear approximation (Vamvatsikos and Cornell, 2002). It should be noted that accuracy of each method varies greatly on data point density. If data points are close together, linear interpolation is considered accurate enough (Vamvatsikos and Cornell, 2002).

\subsubsection{Step 5: Define Limit States on Curve}

In order to determine failure of the structure, drift limits or tangent slope limits are set. Drift limits are set at a predetermined maximum interstorey drift value. When the structure exceeds the set point, it is assumed the structure will no longer be stable. Drift limits are structure type specific. Tangent slope limits are usually set at $20 \%$ of the elastic initial slope at a spectral acceleration of 0.05 gravity. It is generally assumed that the accuracy of the model is limited once the tangent slope exceeds $20 \%$. At this point, the structure has lost most of its stiffness and collapse is assumed. Figure 2.15 illustrates a typical IDA curve for a single record. Twenty percent tangent slope exceedance is illustrated; collapse of the structure is depicted by the red line.

Sean Miller, Department of Civil and Environmental Engineering, Carleton University 


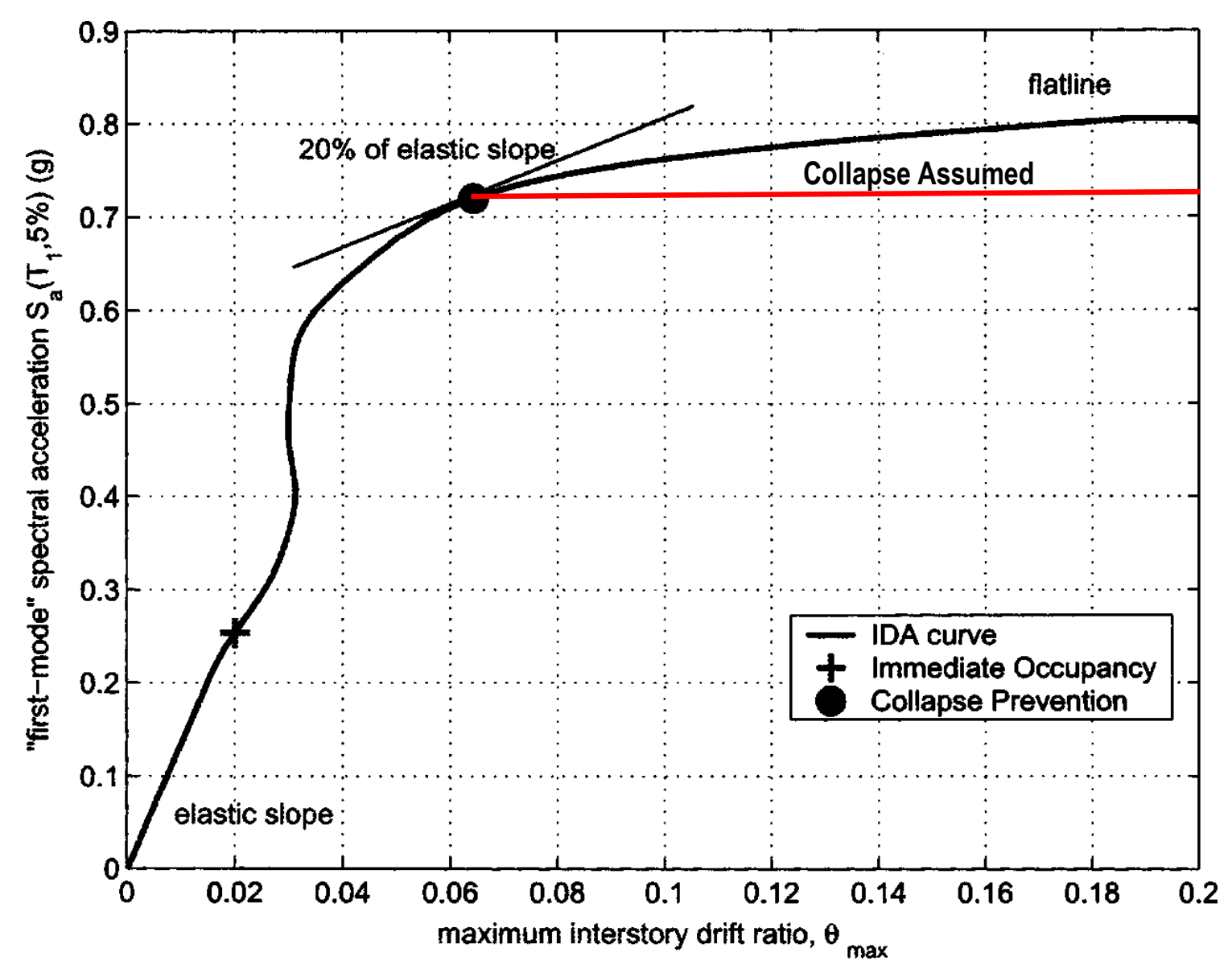

Figure 2.15: Incremental Dynamic Analysis 20\% Tangent Slope Exceedance Collapse (Vamvatsikos and Cornell, 2002)

In some cases, the response curve for an individual record may indicate collapse over a specific range of spectral acceleration and then return to safe levels. Figure 2.16 presents such a case. If this occurs, it is conservative to assume failure will occur at the lowest collapse level, indicated in red (Vamvatsikos and Cornell, 2002). 


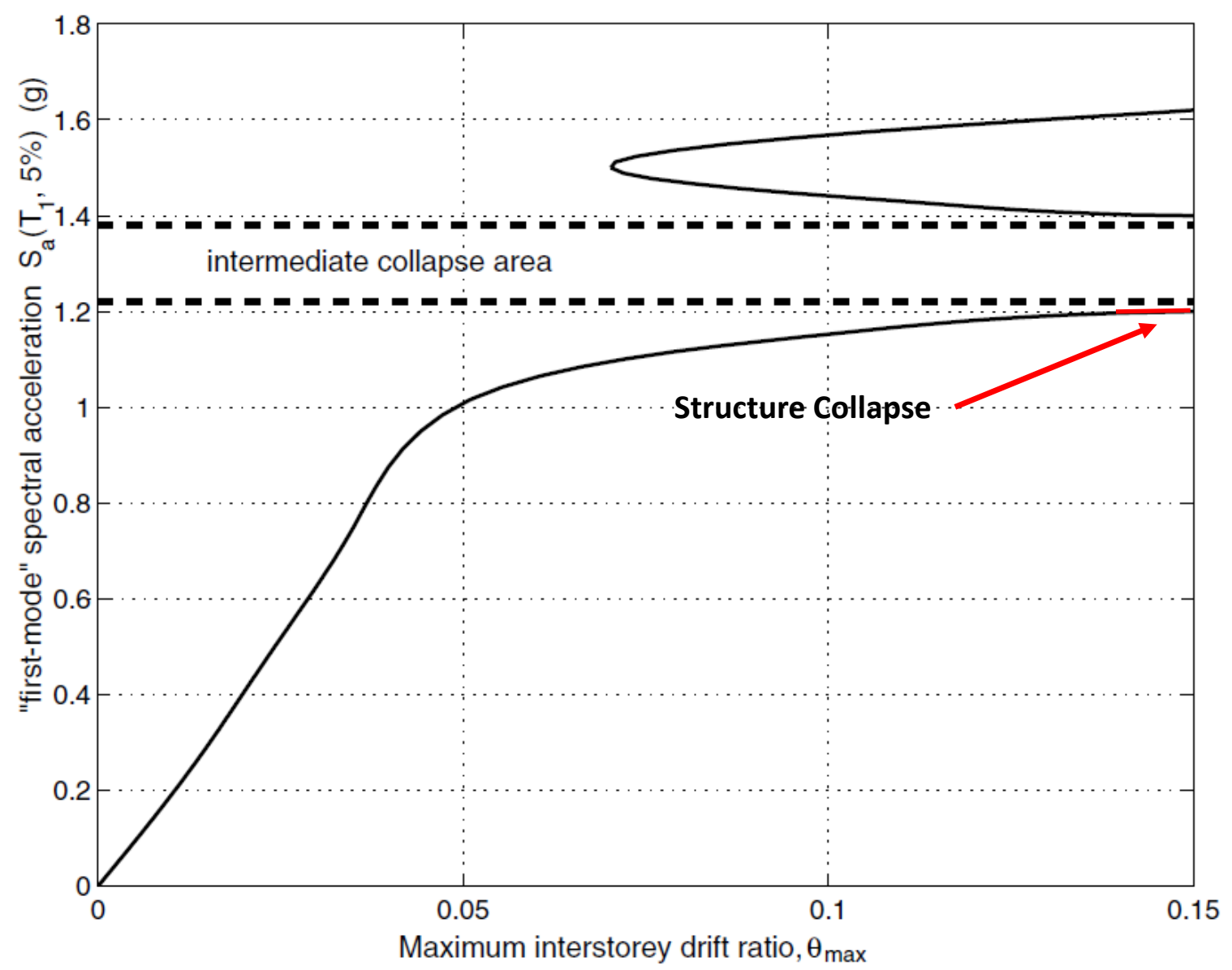

Figure 2.16: Incremental Dynamic Analysis Intermediate Collapse (Vamvatsikos and Cornell, 2002)

In some instances, the response of an individual record can reach a limit state over several points. Figure 2.17 presents one such instance where the recorded tangent slope is less than $20 \%$ over multiple points. The dashed black vertical line indicates a limit state exceedance of $20 \%$ over three points of increasing record intensity. In such cases, it is conservative to assume failure of the structure at the lowest point as indicated by the red line as any slight increase in drift could cause failure of the structure (Vamvatsikos and Cornell, 2002). The green line depicts the initial tangent slope. 


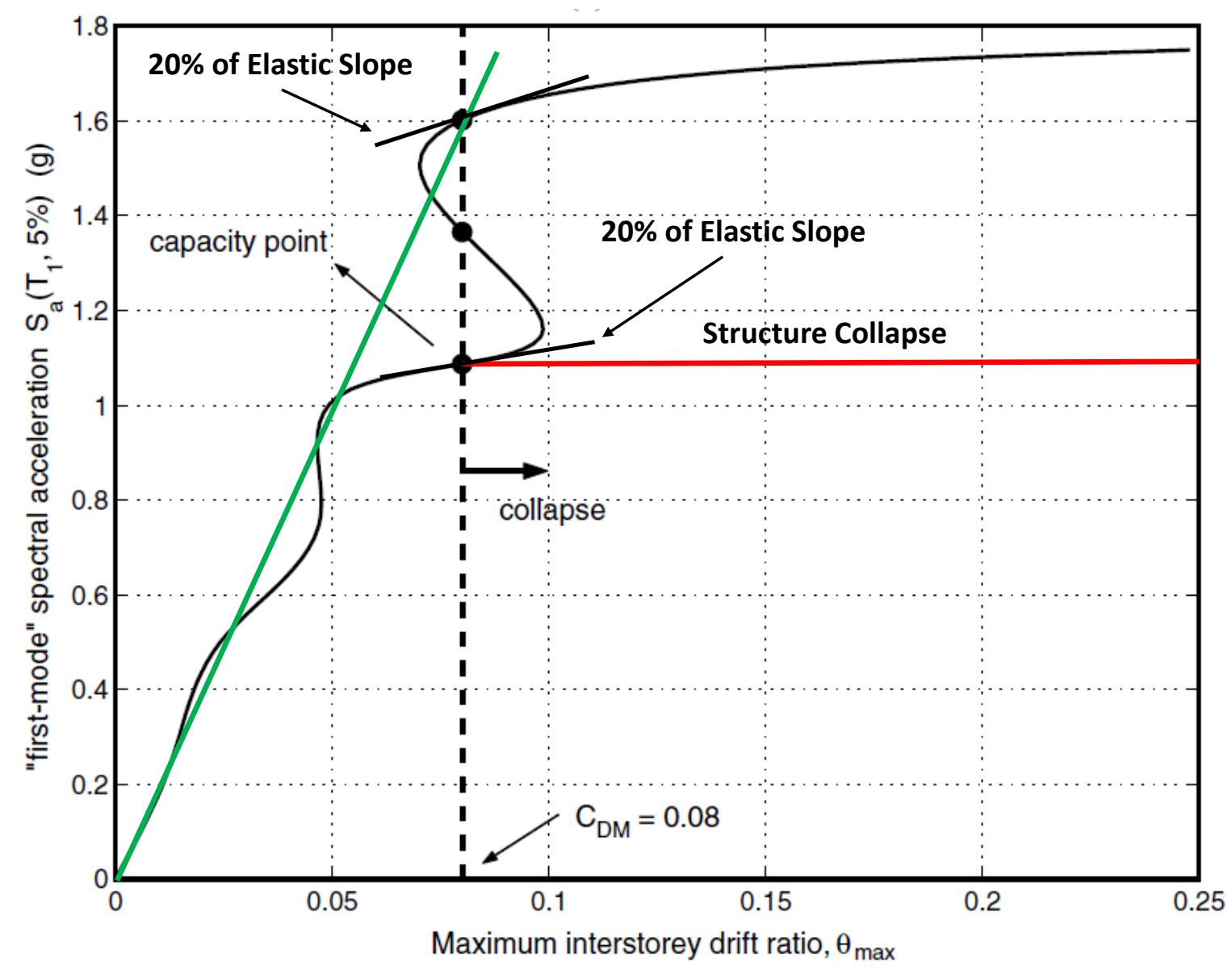

Figure 2.17: Incremental Dynamic Analysis Response Curves Damage Measure Rule (Vamvatsikos and Cornell, 2002)

In the case that response points do not lie in a vertical or nearly vertical line, determining failure of the structure can be more difficult especially if weaving patterns are present in the response. When weaving patterns are present, the $20 \%$ tangent stiffness rule may not be valid for all weaving response locations if a general direction through the weave is followed (Vamvatsikos and Cornell, 2002). Figure 2.18 presents one such case. The rejection point indicated on the plot exceeds the $20 \%$ tangent stiffness rule, but the response is weaving. There is also a separation horizontally between the two points indicated with a black dashed line. In this case, the failure of the structure should be farther up the curve as indicated by the capacity point and red line where the response clearly lays off and exceeds the 20\% threshold (Vamvatsikos and Cornell, 2002). These cases have to be reviewed individually on a case by case basis as response patterns 
are often very random.

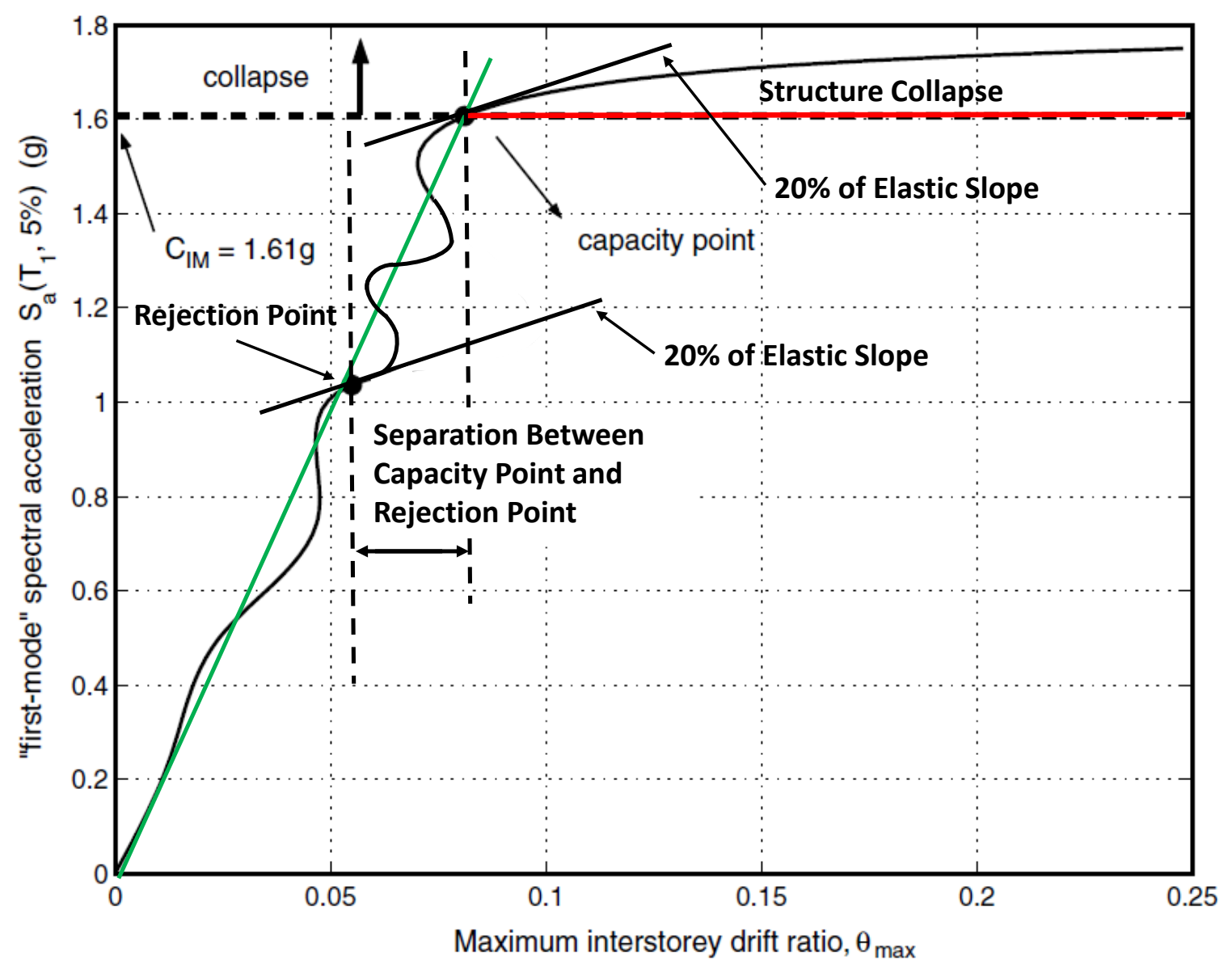

Figure 2.18: Incremental Dynamic Analysis Response Curves Intensity Measure Rule (Vamvatsikos and Cornell, 2002)

\subsubsection{Step 6: Summarize the Data}

From the IDA curves, limit state capacities can be summarized; for example immediate occupancy and collapse prevention limits. Similarly, the behaviour of each individual record over a variety of spectral accelerations when plotted against maximum interstorey drift can provide useful information on structural response. Figure 2.19 shows the response of a five storey braced frame subjected to 4 different records at gradually increasing levels of record intensity. It can be seen that the response from each record has a unique affect on the structure. In general, the response will behave similarly to one of four cases: the structure will soften, harden a slight 
amount, harden a severe amount or weave with increasing spectral acceleration (Vamvatsikos and Cornell, 2002). It can be seen in all four cases that under initial elastic range, all responses are the same (Vamvatsikos and Cornell, 2002).

(a) A softening case

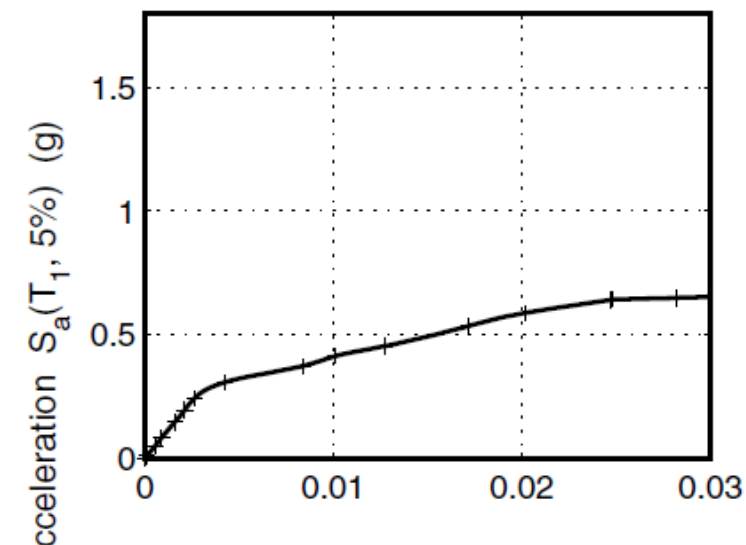

(c) Severe hardening

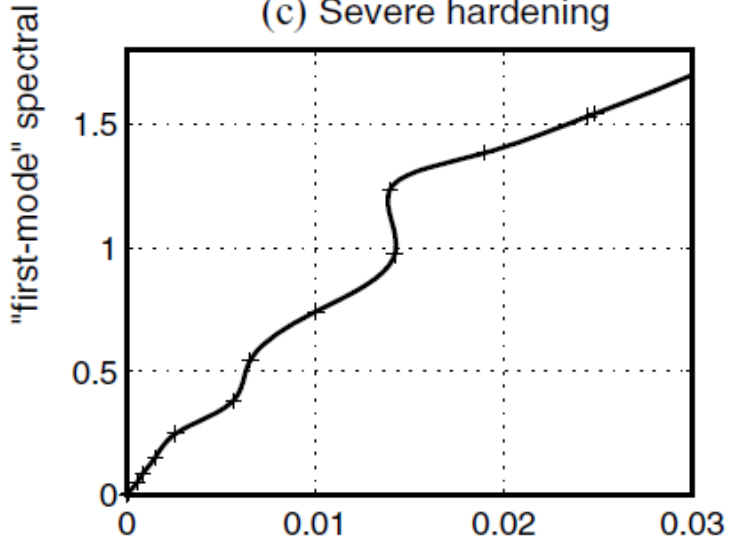

(b) A bit of hardening

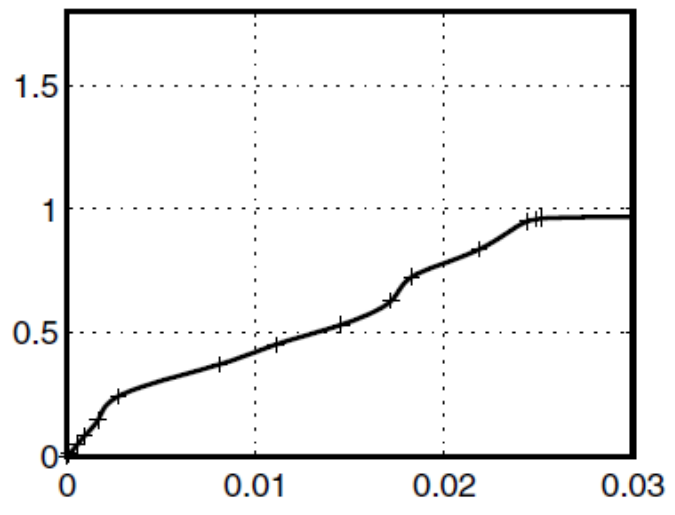

(d) Weaving behavior

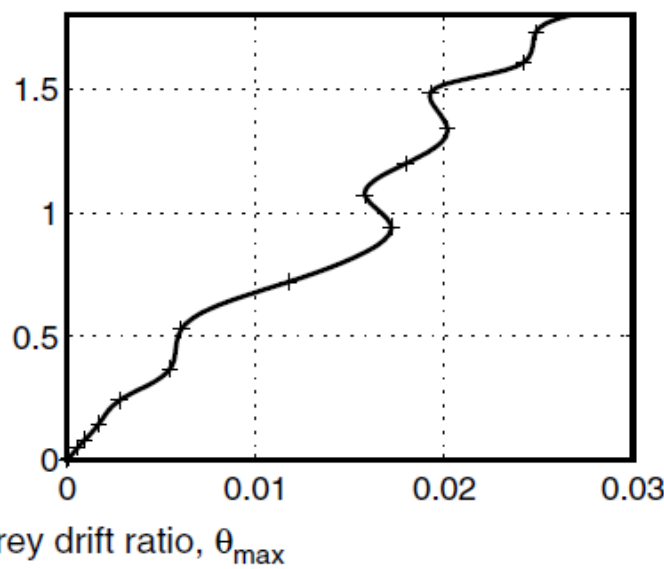

Figure 2.19: Incremental Dynamic Analysis Response Curves (Top Left) Softening Case, (Top Right) Minor Hardening Case, (Bottom Left) Severe Hardening Case, (Bottom Right) Weaving Case (Vamvatsikos and Cornell, 2002)

\subsection{Collapse Fragility Curves}

Collapse fragility curves estimate the probability of collapse of a suite of ground motions over a range of intensities. The process estimates the collapse fragility using scaled ground motion intensities (Zareian and Krawinkler, 2007). Two sample fragility analysis studies are presented 
below.

Tirca et al. (2013) performed a purely numerical incremental dynamic analysis to assess the seismic performance of 3 and 6 storey concentrically braced framed buildings located in Quebec. These structures were designed based on the 1980 Canadian code provisions. Fragility curves were created to assess the probability of failure of selected structures.

Kammula et al. (2013) performed an IDA through hybrid testing to assess the fragility of telescoping self-centering bracing systems. The tests consisted of 2 substructures: a physical substructure containing a self-centering brace and a numerical substructure consisting of the remainder of their 6 storey prototype structure. Thirty earthquake records were selected and scaled to cover a range of spectral acceleration values from 0.1 to 2.5 gravity. These records were then used to create fragility curves at varying maximum drift levels. The current study is similar to this research and illustrates the power of hybrid testing as a tool in an IDA. The author illustrates the effects of an experimental specimen on global response over a range of seismic intensities.

\subsubsection{Structural Performance Levels: Drift and Acceleration (ASCE, 2007)}

Structural performance levels are valuable tools for result interpretation and can be used following an IDA and or fragility analysis. ASCE (2007) developed structural performance levels to gauge post earthquake building conditions. These fall into three categories: collapse prevention, life safety and immediate occupancy. Structural performance is based on drifts and accelerations which are used to estimate damage. A brief description of each structural performance level, as well as, structure condition is presented below for conventional braced frames.

\subsubsection{Collapse Prevention}

Maximum interstorey drifts for collapse prevention are $2 \%$ and above, transient and or permanent. In a conventional braced frame, extensive yielding and buckling of braces is expected. In addition, many connections are also expected to fail. Accelerations are expected to be in excess of $1.0 \mathrm{~g}$ resulting in interior spaces completely in shambles, with severe damage to sensitive equipment.

Sean Miller, Department of Civil and Environmental Engineering, Carleton University 


\subsubsection{Life Safety}

Drifts for life safety performance level are expected to be $1.5 \%$ transient and $0.5 \%$ permanent. Conventional braced frames under these conditions are expected to have many braces yielded or buckled. In addition, many connections may also fail. Accelerations are expected to be between $0.5 \mathrm{~g}$ and $1.0 \mathrm{~g}$. Under these conditions, furniture will be toppled over and some damage is expected to sensitive equipment.

\subsubsection{Immediate Occupancy}

Drifts for immediate occupancy performance level are expected to be $0.5 \%$ transient and negligible permanent. Conventional braced frames are expected to experience minor yielding and buckling of braces. Accelerations are expected to be between $0.0 \mathrm{~g}$ and $0.5 \mathrm{~g}$ leaving some furniture tipping.

\subsection{Testing Methods}

There are many testing methods that can be employed to study the response of structures subjected to seismic loading. These include quasi static, shake table and most recently pseudodynamic / hybrid testing methods. Quasi static and shake table testing methods are conventional methods which apply predetermined loading histories to the test specimen and are open loop. These testing methods can be performed in real time or in a quasi static format (Shao and Griffith, 2013). Hybrid and pseudo-dynamic testing methods are closed loop; feedback from the test specimen is required to determine displacement loading for the next time step (Shao and Griffith, 2013). Each of these types of testing methods are discussed in more detail in the following subsections.

\subsubsection{Quasi Static Testing Method}

This type of testing method is used to determine nonlinearity of elements and or structural systems subjected to predefined displacement or force history using hydraulic actuators 
(McCrum and Williams, 2016). The method is economical and is often used to determine the hysteretic behaviour and capacity of components and or systems under cyclic loading (Javad, 2013). One major drawback to this method is that during seismic events the load distribution changes continuously, thus a predetermined loading protocol cannot accurately resemble actual structural behaviour (Javad, 2013).

\subsubsection{Shake Table Testing Method}

This type of testing method applies predetermined ground motions in an open loop to a shaking table on which the specimen / structure is situated (Aktan, 1986). This type of testing method often requires the entire structure to be physically built on the shaking table making it extremely expensive. Often the only way to test large structures is to scale them down which reduces the effectiveness of the test.

\subsubsection{Quasi Static Pseudo-Dynamic Testing}

This type of testing method analyzes the response of a structure by applying dynamic loading in the form of target displacements on lumped masses to determine the stiffness nonlinearity of the physical test specimen. Damping and inertial forces are numerically modeled. It is important to note that the testing is performed at slow loading rates; damping and inertial responses are accounted for numerically (McCrum and Williams, 2016). The procedure calculates the dynamic displacements based on active control theory utilizing the inertia and damping properties from the model and stiffness properties under the hypothetical seismic motion (Aktan, 1986). The resulting displacements simulate the response of the structure under seismic motion in a quasi static form (Aktan, 1986).

\subsubsection{Continuous Pseudo-Dynamic Testing}

This type of testing is similar to quasi static pseudo-dynamic testing except there is no pause in loading rates. Often, the time scale is expanded to allow time for numerical integration of the equation of motion and the implementation of the resulting command displacement by the actuator (McCrum and Williams, 2016).

Sean Miller, Department of Civil and Environmental Engineering, Carleton University 


\subsection{Hybrid Testing Method}

Hybrid testing methods fulfill the desire to understand the behaviour of complex structures comprised of many elements where the exact sequence of nonlinear behaviour affects the overall behaviour of the structure (McCrum and Williams, 2016). This is particularly important for performance-based seismic design (Delgado, 2014). The prediction of structural response to satisfy design criteria such as life safety and collapse prevention of structures requires reliable modeling of highly nonlinear behaviour that can be developed and improved through the combination of analytical and experimental research (Delgado, 2014). This methodology is a key aspect to the efficiency of hybrid testing since the method is based on substructuring. Critical structural assemblies are physically tested while the remainder of the structure is numerically modeled (McCrum and Williams, 2016). The part of the structure that is numerically simulated is called the numerical substructure and the portion that is physically tested is referred to as the experimental substructure. The combination of these substructures forms a hybrid model of the entire structure. Loading on the experimental substructure is determined as the simulation progresses for structures subjected to ground motions. The equation of motion is solved numerically using time step integration and the displacement demands are physically applied using hydraulic actuators to the experimental substructure (Javad, 2013). The resisting forces are then measured and fed back to the solver to calculate the displacement of the next time step (Javad, 2013). Hybrid tests are generally defined as either a Pseudo-Dynamic Test (PsD) or as a Real Time Hybrid Test (RTHT).

\subsubsection{Sub-Structured Pseudo-Dynamic Hybrid Test}

This testing method separates and physically tests a critical part of the structure, usually with a highly nonlinear response, while the rest of the structure is simulated numerically. This process feeds back the force and displacement from the actuator/actuators to the numerical model, where they are used to solve the next time step command (McCrum and Williams, 2016). It is important to note that the testing is performed at slow loading rates and as a result damping and inertial response of the experimental substructure are accounted for numerically (McCrum 
and Williams, 2016). The only difference between a substructured pseudo-dynamic hybrid test and a conventional pseudo-dynamic test is that there is substructuring employed. A conventional pseudo-dynamic test is not substructured. Something that should be considered during this type of test is that the structure's mass needs to be represented as a small number of lumped nodal masses where the inertial forces are replicated by a few actuators (McCrum and Williams, 2016). This induces errors because real structures are continuous systems.

\subsubsection{Real Time Hybrid Test}

This testing method is essentially a real time continuous substructured pseudo-dynamic test. In a real time hybrid test, the numerical substructure accounts for only the mass, damping and stiffness of the numerically modeled part; the damping, inertia and stiffness responses of the physical substructure are measured during the physical test (McCrum and Williams, 2016). For substructures with velocity dependent characteristics, real time hybrid testing is especially useful. One major challenge during a real time hybrid test is that the numerical model needs to be computed very quickly making computer processing speed critical.

\subsubsection{Accuracy and Stability of Hybrid Testing Methods}

There are many sources of error that can contaminate the results of a hybrid test. These errors can be separated into three distinct types: structural idealization errors, numerical integration scheme errors and experimental errors in hardware (McCrum and Williams, 2016). All these forms of errors have a significant impact on the accuracy of tests and the accuracy of the results. Structural idealization errors generally develop as a result of modeling errors and or errors generated from analysis assumptions that are not accurate (McCrum and Williams, 2016). Numerical integration scheme errors are associated with the equilibrium solution algorithm, convergence of a solution, and the integration scheme chosen (McCrum and Williams, 2016). The use of non-iterative / explicit integration schemes can help to reduce errors associated with varying time steps. It should be noted that as models / simulations become more complex, it is more efficient to use iterative integration methods to determine a solution, despite the possibility of convergence issues (Javad, 2013). Another problem associated with implicit algorithms is that the 
tangent stiffness of the structure is required but cannot be practically measured. As a result, the initial stiffness is used; such simplifications can induce numerical errors (Javad, 2013). Decisions made in this stage of an analysis greatly affect the results of the entire simulation. Experimental errors in the hardware are generated by noise in the instrumentation devices, data acquisition systems and errors generated by the control and transfer systems (Javad, 2013). Both pseudodynamic and real time hybrid tests are sensitive to actuator control errors which can result in failure of the testing procedure (McCrum and Williams, 2016). These errors can be systematic or random. Random errors are usually associated with noise in the measurement system or round off errors associated with alternating / direct current conversion of the signal (McCrum and Williams, 2016). These random errors have been shown to be irregular in nature and produce negligible effects (McCrum and Williams, 2016). Systematic errors introduced by the actuators produce undesirable energy effects on the dynamic response of the system (McCrum and Williams, 2016). These errors result in resonance like effects in error growth, as numerical integration is cumulative in nature (McCrum and Williams, 2016). It is important to note that this resonance like error growth occurs faster in higher modes (McCrum and Williams, 2016). In pseudo-dynamic multi degree of freedom tests, systematic errors can cause a sudden higher mode response due to the relatively small convergence error. In real time hybrid tests, a time lag is present between sending a command to an actuator and the actuator achieving the command displacement. This time delay is typically in the range of 5 to 10 milliseconds resulting in error (McCrum and Williams, 2016). The major problem with this delay is that the algorithm solving the time integration assumes both the target displacement and the measured force correspond to each other (McCrum and Williams, 2016). In a real time hybrid test, there are three main approaches to account for the delay / lag time: forward prediction, performance evaluation and model based filtering (McCrum and Williams, 2016). Forward prediction, commonly referred to as constant delay compensation, is not well suited to nonlinear hybrid tests. Performance evaluation, often referred to as adaptive delay compensation, recognizes that actuator delay is not constant (McCrum and Williams, 2016). This type of delay compensation is important in real time hybrid tests to maintain stability (McCrum and Williams, 2016). Model based filtering is used when the structure being tested is very stiff. All these forms of error can introduce energy 
into the simulation and cause instabilities if not minimized.

The interface between the numerical and experimental substructures is important to model accurately as well. The location of the interface and its properties needs to be realistic while still realistically achievable in the laboratory. Laboratory constraints and size dictate the complexity of structures that can be tested and must be considered during the selection of boundary conditions.

\subsubsection{Previous Hybrid Tests}

There has been a significant amount of hybrid testing research on moment resisting framed structures, braced framed structures and SFRSs equipped with advanced energy dissipative elements in steel structures over the last few decades. Initially, the majority of hybrid simulation research focused on the development of the hybrid testing techniques related to error compensation, delay, substructuring, integration schemes, error and other related elements that affect hybrid tests (McCrum and Williams, 2016). While many improvements have been made to hybrid testing techniques, limited testing has been performed on structures comprised of materials other than steel, especially timber structures. Hybrid tests have been performed on light timber structures analyzing shear wall behaviour and retrofit of light framed structures Griffith et al. (2013), Shao et al. (2016), Shao et al. (2014) and Jennings et al. (2013). To the author's knowledge, no hybrid testing has been performed on heavy timber structures or timber elements with glued-in rod connections.

The following paragraphs breakdown previous related hybrid tests based on the objective of the tests: understanding of seismic performance, system level and overall performance of structures containing special energy dissipative elements and hybrid tests on wood framed structures.

Initially, many hybrid tests focused on gaining a better understanding of the seismic performance of a structure's SFRS. Due to the reliable nonlinear behaviour of steel structures, many of the early hybrid tests were performed on steel SFRSs. Listed below are a variety of hybrid tests in chronological order from the infancy of hybrid testing to real time current day hybrid testing. One of the first uses of hybrid testing was by Balendra et al. (1987), who investigated the performance of eccentrically braced frames through hybrid testing to verify braced frames 
designed to yield in shear. At this time, all hybrid tests were relatively small since computational time was large. As years passed, more complex tests became possible and substructuring of tests became feasible. Shing et al. (1994) examined the performance of concentrically braced frames using substructuring by physically testing the first storey of their prototype structure and numerically simulating the remaining two storeys. Following this, more complex multi-directional tests became more feasible, Molina et al. (1999) investigated the performance of a three storey composite steel structure under a bi-directional hybrid test. More recently, advanced systems employed in SFRSs have been the focus of hybrid tests since these components of the system experience highly nonlinear behaviour and can be difficult to model. They are physically tested while the remainder of the structure is analytically simulated. Eatherton and Hajjar (2014) investigated the performance of a self-centering rocking steel frame through hybrid simulation. Karavasillis et al. (2011) performed real time hybrid tests on a two storey steel moment resisting frame with compressed elastomer dampers. Lee et al. (2007) performed real time substructured hybrid tests on a liquid damper in a three storey prototype structure. Kammula et al. (2013) investigated the system level performance of a six storey prototype structure with telescoping self-centering energy dissipative bracing though hybrid simulations. Tsai et al. (2008) and Tsai and Hsiao (2008) investigated the performance of a three storey prototype structure outfitted with buckling restraining braces using hybrid testing. Lin et al. (2011) performed a series of hybrid tests on a full scale three storey prototype structure outfitted with buckling restraining braces.

Zargar and Medina (2014) performed a real time hybrid simulation through collapse of an exterior steel column in a 20 storey moment resisting frame at the NEES Buffalo facility. The 20 storey prototype structure used in this test contained an exterior moment frame around the perimeter of the building with gravity columns in the center of the building. The prototype structure was simplified into a 2 dimensional model containing half of the building's tributary mass. This configuration was utilized in the hybrid simulation. The model contained one side of the building's exterior moment resisting frame and employed a lean column to carry the building's gravity mass within the tributary area that was not directly loading onto the moment resisting frame's columns. This system of simplifying the structural model is very popular and works well in real time hybrid tests. The physical substructure in this test was a single bottom 
storey corner column. This column was one eighth scale of the full scale column in the prototype structure. The numerical substructure was the remainder of the prototype structure. The physical specimen was tested using a three actuator setup, containing an axial, lateral and rotational degree of freedom at the top of the column specimen. The numerical substructure was modeled in OpenSees (McKenna et al., 2000) and OpenFresco (Schellenberg et al., 2009) was utilized as the middleware connecting the numerical model to the control and data acquisition systems in the laboratory. The communication link between the numerical substructure and the physical substructure is illustrated in Figure 2.20. The hybrid tests were performed at real time. These tests employed a predictor corrector loop to help determine the displacement of the next time step before it happened in real time.

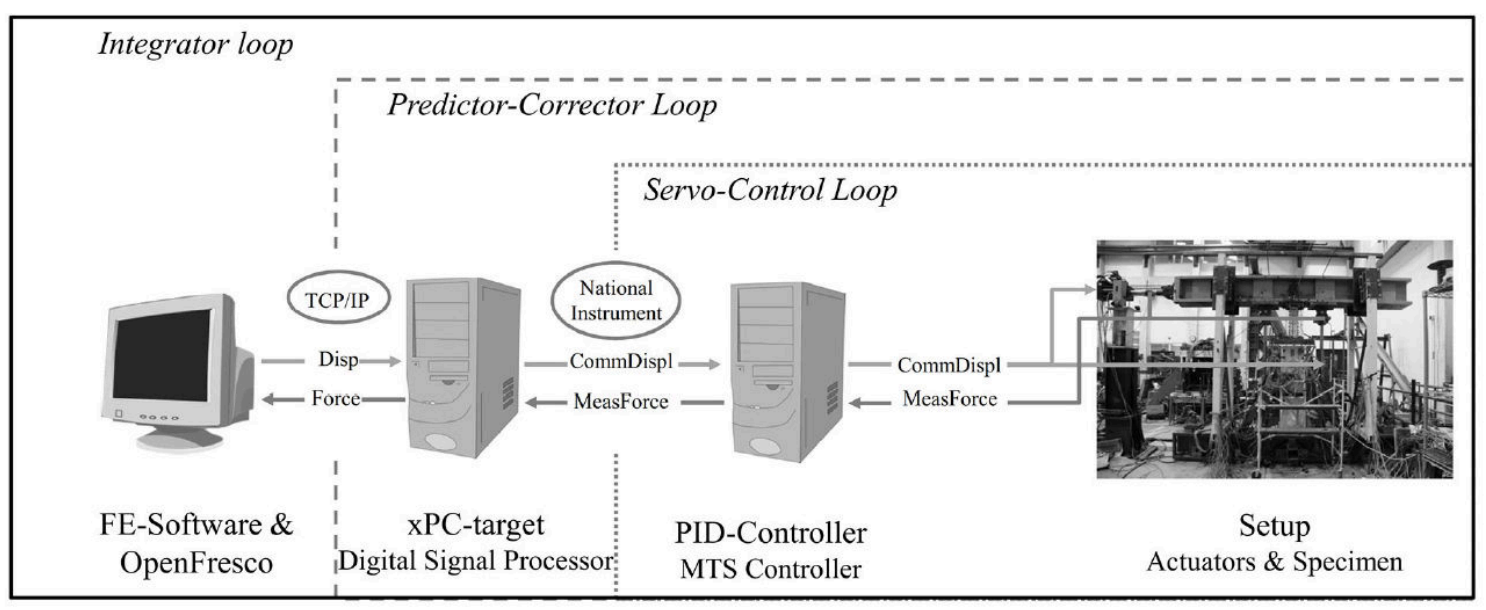

Figure 2.20: Real Time Hybrid Test of Architecture (Zargar and Medina, 2014)

Hybrid tests on timber based structures have not been performed as often as tests on steel based structures. Griffith et al. (2013) performed a substructured hybrid test on a two storey prototype light framed wood structure. In these tests, the SFRS was simplified into a first and second storey shear wall system. The physical substructure consisted of a first storey wood shear wall while the analytical portion was the second storey shear wall. This was a single degree of freedom test. Shao et al. (2016) performed hybrid testing on a three storey light framed wood prototype structure. The first two storeys of the structure were physically tested and the third storey was numerically simulated. Shao et al. (2014) also performed real time hybrid tests on 
a stacked wood shear wall frame retrofitted with viscous dampers. The three storey prototype structure was divided into a physical substructure consisting of the first storey outfitted with dampers while the upper two storeys were numerically simulated. Similarly, Jennings et al. (2013) performed pseudo-dynamic hybrid testing on a full scale light framed wood building containing a soft storey which was seismically retrofitted using shape memory alloy devices in scissor jack braces. The tests were carried out in the NEES Buffalo facility under slow loading rates. The prototype structure was 3 storeys and was retrofitted with scissor jack braces between the ground floor and the second storey of the structure. The structure was substructured into two parts, a physical substructure consisting of the top 2 storeys and a numerical substructure consisting of the first storey retrofitted with scissor jacks. The numerical model contained the mass and damping of the entire 3 storey structure. Figure 2.21 presents a break down of the hybrid test. The test contained 2 actuators per floor applying displacements on a rigid diaphragm within each floor. During each time step, the displacement response of the four actuators was applied to the corresponding floor diaphragm in the physical specimen. From this, the restoring forces were measured at the actuator's degrees of freedoms and sent back to the numerical model for the next integration time step. It should be noted that the initial stiffness of the physical specimen is provided for the first step.

Sean Miller, Department of Civil and Environmental Engineering, Carleton University 


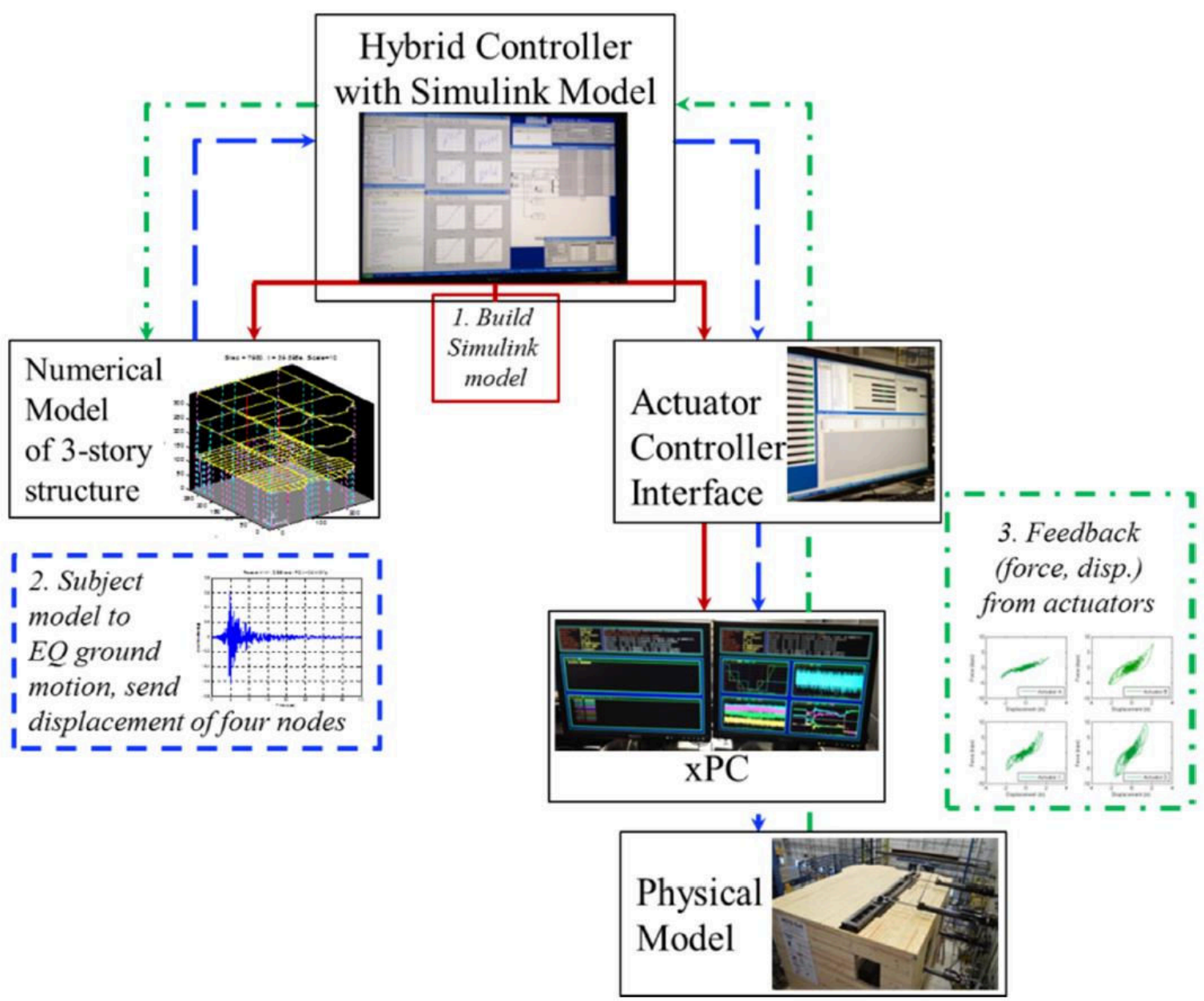

Figure 2.21: Psuedo-Dynamic Test of Light Frame Wood Structure (Jennings et al., 2013)

\subsection{Finite Element and Control Framework}

\subsubsection{OpenSees Framework}

Open System for Earthquake Engineering Simulation (OpenSees) is an open source, object oriented software framework application using finite element methods developed by the Pacific Earthquake Research Center (McKenna et al., 2000). The software uses Tcl script language implemented in $\mathrm{C}++($ McKenna et al., 2000). OpenSees is often used in collaboration with the software framework OpenFresco when performing hybrid simulation. 


\subsubsection{OpenFresco Framework}

Open source Framework for Experimental Setup and Control (OpenFresco) is a software framework that connects control and data acquisition systems in laboratories with finite element models such as OpenSees, to facilitate hybrid tests (Schellenberg et al., 2009). When used in collaboration with OpenSees, classes defined in OpenSees are used as the numerical substructure, since OpenFresco utilizes the object oriented structure of OpenSees (McCrum and Williams, 2016). Figure 2.22 illustrates the global and local coordinate systems for OpenSees and OpenFresco. Degrees of freedom are labeled as follows in global coordinates; 1-lateral, 2-vertical, and 3-rotational. Local element coordinates begin with element node i, degrees of freedoms 1-lateral, 2-vertical, and 3-rotational to node j, degrees of freedoms 4-lateral, 5-vertical, and 6-rotational.

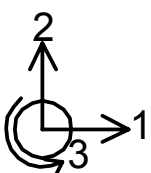

(a)

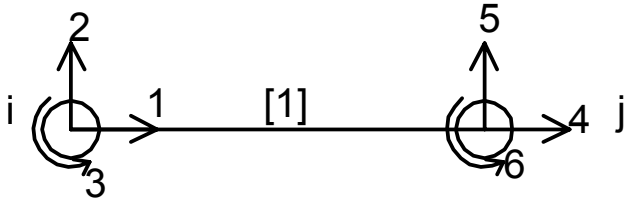

(b)

Figure 2.22: OpenSees - OpenFresco Coordinate System

a) Global Coordinates b) Local Element Coordinates

\subsection{Conclusion}

In the current study, the work conducted by past researchers furthering the development of friction braces in heavy timber SFRS and the implication of more ductile heavy timber connections is extended and applied to taller multi-storey structures. The system level performance of the friction brace and the heavy timber connection has been investigated and verified but the overall response of mid-rise structures containing these systems is not widely understood and has not been quantified over a wide range of seismic intensities. Similarly the accuracy of the current modeling technique for a combined heavy timber-steel system has not been verified to accurately predict structural response. 
This research employs hybrid testing methodology to perform an experimental IDA on the newly developed system to validate the accuracy of the current modeling technique. Previous studies that used incremental dynamic analysis concluded that it is an effective means of capturing a structure's response over a wide range of seismic intensities. Similarly, previous studies concluded that hybrid testing is an effective means of capturing the effects of a prototype specimen on the global response of a structure. Thus comparing analytical model predictions with experimental hybrid test results through IDA is an effective means to validate if the analytical model accurately captures the behaviour of a physical specimen. In addition, an IDA presents the structures response over a wide range of seismic intensities.

In this study, a 7 storey combined heavy timber-steel friction braced prototype structure was developed and utilized in combination with the prototype specimen developed by Gilbert (2016) in these hybrid tests. The hybrid tests were substructured into a numerical substructure consisting of the prototype structure's SFRS modeled in OpenSees and a physical substructure consisting of the prototype specimen developed by Gilbert (2016). The 7 storey prototype structure utilized glued-in rod connections between steel and timber elements, similar to Gilbert (2016) prototype model. Glued-in rod connections were utilized for two reasons: first for consistency since the prototype specimen contains glued-in rod connections and secondly since they transfer loads into the strong parallel-to-grain direction of heavy timber frame elements well. These tests evaluated the performance of the newly developed friction braced framed combined heavy timber-steel SFRS at various performance levels through experimental IDA. The hybrid tests were performed at slow loading rates in a continuous quasi-static format, since Gilbert (2016) results indicate the friction brace's response was not affected greatly by velocity. The IDA of the structure involved performing 165 hybrid tests of the structural model under a suite of 11 ground motion records. Each ground motion record was scaled to several levels of seismic intensity forcing the structure through a wide range of behaviour from elastic to inelastic and finally to global dynamic instability. These tests are compared against purely numerical analysis results to assess the viability of the finite element model and overall performance of the structure at various seismic intensities. Using the IDA results, fragility curves were generated to estimate the probabilistic seismic response at varying intensity measurements. 


\section{Chapter 3: Prototype Specimen and Experimental Setup}

This chapter summarizes the prototype structure, prototype specimen and laboratory setup used for hybrid tests. Design assumptions, material properties and member sizes are presented. The prototype specimen was previously designed and constructed by Gilbert (2016) as part of his Masters of Applied Science thesis project and has been adapted for used in this study. The prototype specimen was used as the physical substructure in these hybrid tests. Design assumptions, member sizes and capacities of each component of the prototype specimen and prototype structure are presented. Appendix A illustrates tables, figures and a detailed discussion of the design of the prototype structure.

\subsection{Prototype Structure Design}

This section presents the final design of a combined heavy timber-steel prototype structure located in western Canada. A plan and elevation view of the prototype structure is illustrated in Figure 3.1. The structure is 7 storeys tall and $4 \times 4$ bays in plan. It is designed to be located in Victoria, British Columbia, Canada and is assumed to be on site class C soil. Each storey is $3.7 \mathrm{~m}$ tall and bays are $6.5 \mathrm{~m}$ in length. All corner exterior bays are braced with friction braces. Glued-in rod connections connect glulam beam and column frame elements to steel joint panel zones. Steel joint panel zones transfer loads between glued-in rod connections. They are located at the intersection of beam and column elements. Glued-in rod connections were utilized for two reasons: first for consistency since the prototype specimen contains glued-in rod connections and 
secondly since they transfer loads into the strong parallel-to-grain direction of heavy timber frame elements well. All floor and roof diaphragms are comprised of a one-way cross laminated slab system as illustrated in Figure 3.1. The roof also contains a $0.5 \mathrm{~m}$ parapet. All column to beam and panel zone to friction brace connections are pinned and all column to column connections are moment connected. The structure's columns are pin connected to it's foundation. The following subsections illustrate loads on the structure, member sizes and their properties. Table 3.1 presents the final member sizes, as well as, the friction brace's slip forces.

Table 3.1: Member Sizes

\begin{tabular}{|c|c|c|c|c|c|}
\hline location & $\begin{array}{l}\text { Column } \\
\text { D.Fir-L } \\
\text { 16c-E } \\
(\mathrm{mm})\end{array}$ & $\begin{array}{c}\text { Beam } \\
\text { D.Fir-L } \\
24 \mathrm{f}-\mathrm{E} \\
(\mathrm{mm})\end{array}$ & $\begin{array}{c}\text { CLT Floor } \\
\text { Stress Grade } \\
\text { V2 } \\
\text { (\# 35mm plys) }\end{array}$ & $\begin{array}{c}\text { Friction Brace } \\
\qquad \begin{array}{c}\text { Steel } \\
350 \mathrm{~W} \\
(\mathrm{~mm})\end{array}\end{array}$ & $\begin{array}{c}\text { Friction Brace } \\
\text { Activation } \\
\text { Force } \\
(\mathrm{kN})\end{array}$ \\
\hline Roof & & $265 \times 494$ & 7 & & \\
\hline Storey 7 - R & $265 \times 265$ & & & HSS152x203x13 & 220 \\
\hline Floor 7 & & $265 \times 494$ & 7 & & \\
\hline Storey 6 - 7 & $265 \times 265$ & & & HSS152x $203 \times 13$ & 380 \\
\hline Floor 6 & & $265 \times 494$ & 7 & & \\
\hline Storey 5 - 6 & $265 \times 265$ & & & HSS152x203x13 & 480 \\
\hline Floor 5 & & $265 \times 494$ & 7 & & \\
\hline Storey 4 - 5 & $342 \times 342$ & & & HSS152x $203 \times 13$ & 505 \\
\hline Floor 4 & & $265 \times 494$ & 7 & & \\
\hline Storey 3 - 4 & $342 \times 342$ & & & HSS152x203x13 & 640 \\
\hline Floor 3 & & $265 \times 494$ & 7 & & \\
\hline Storey 2 - 3 & $465 \times 465$ & & & HSS152x203x13 & 680 \\
\hline Floor 2 & & $265 \times 494$ & 7 & & \\
\hline Ground - 2 & $465 \times 465$ & & & HSS152x203x13 & 825 \\
\hline
\end{tabular}




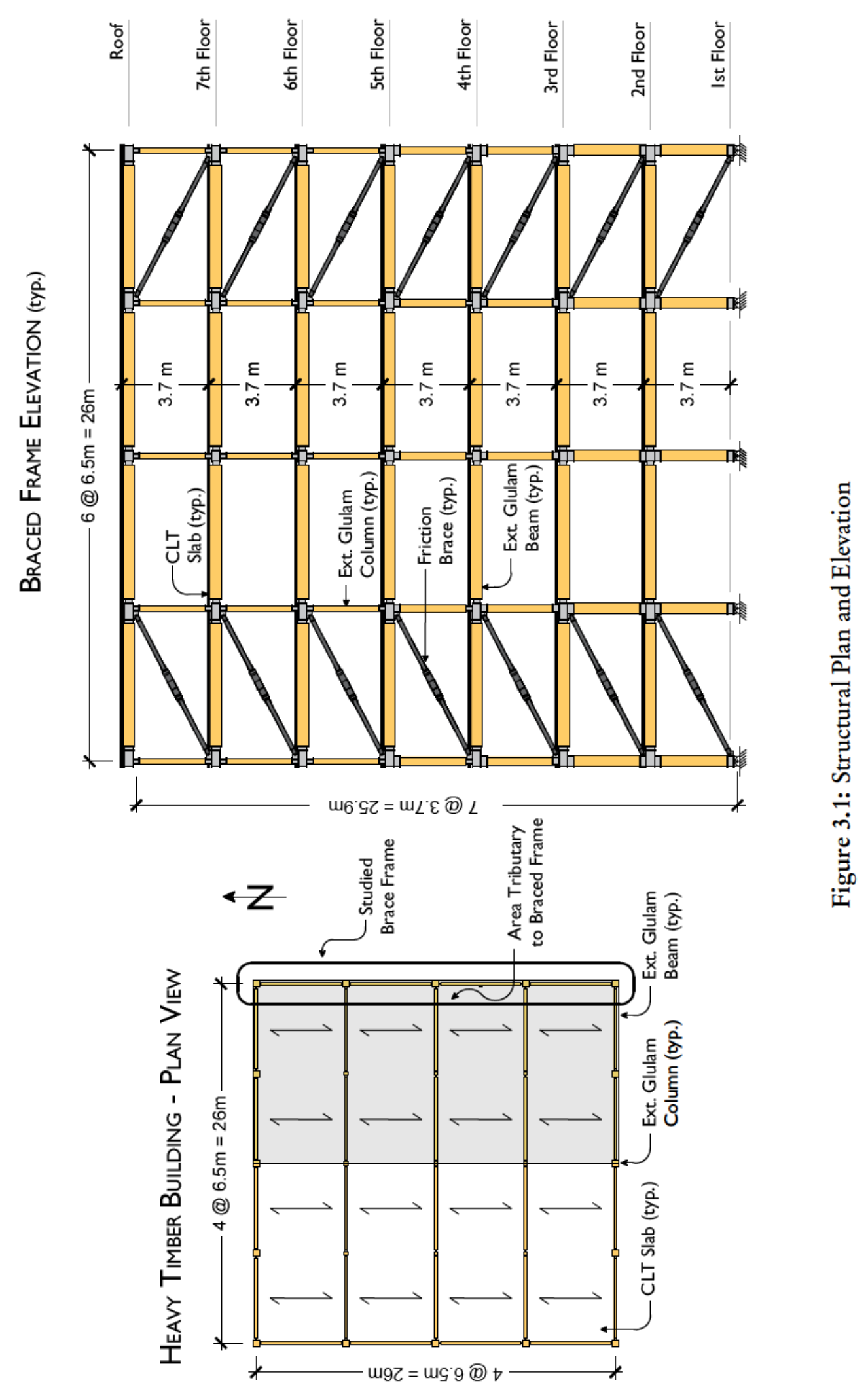




\subsubsection{Structural Analysis and Loads}

The loads on the structure are based on the National Building code requirements (National Research Council, 2011). The wind, snow, dead, live and earthquake loading are discussed below.

Live load requirements are based on the National Building code for office space resulting in a distributed live load of $2.4 \mathrm{kpa}$ for all floor areas and $1.0 \mathrm{kpa}$ for the roof (National Research Council, 2011). Dead and wind loads on each floor are illustrated in Table 3.2. A detailed summary of dead loads is discussed in Appendix A.0.2 on page 172.

The snow load on the structure's roof is $1.08 \mathrm{kpa}$ uniformly distributed across the entire surface. A detailed summary of snow loads is discussed in Appendix A.1 on page 173.

Wind loads on the structure did not govern the design. A detailed summary of wind loads is discussed in Appendix A.1.1 on page 174.

The structure's preliminary design for seismic loads was completed using the equivalent static design method; it was then refined using the iterative response spectrum analysis outlined in the National Building code (National Research Council, 2011). A ductility factor of 4.0 and an over strength factor of 1.2 were assumed. This assumption was based on the ductility and over strength factors of buckling restraining braces (CSA S16, 2010). A detailed discussion of the earthquake analysis procedure is in Appendix A.1.2 beginning on page 175. Table 3.3 illustrates a summary of the structure's first 6 periods of vibration.

\subsubsection{Structural Member and Connection Design}

The design of structural elements contained in the prototype structure are illustrated in the following subsections. All members within the SFRS were capacity designed so that the friction braces acted as the primary structural fuses in the building. The gusset plates connecting the friction braces to the column beam joints were the secondary fuses in the SFRS. All gusset plates were capacity designed by 1.1 over the friction braces. Column elements were further capacity designed by a factor of 1.1 over the gusset plates. The second capacity design factor was considered for the case if the friction braces were bearing on the ends of their slotted holes. At this point all 


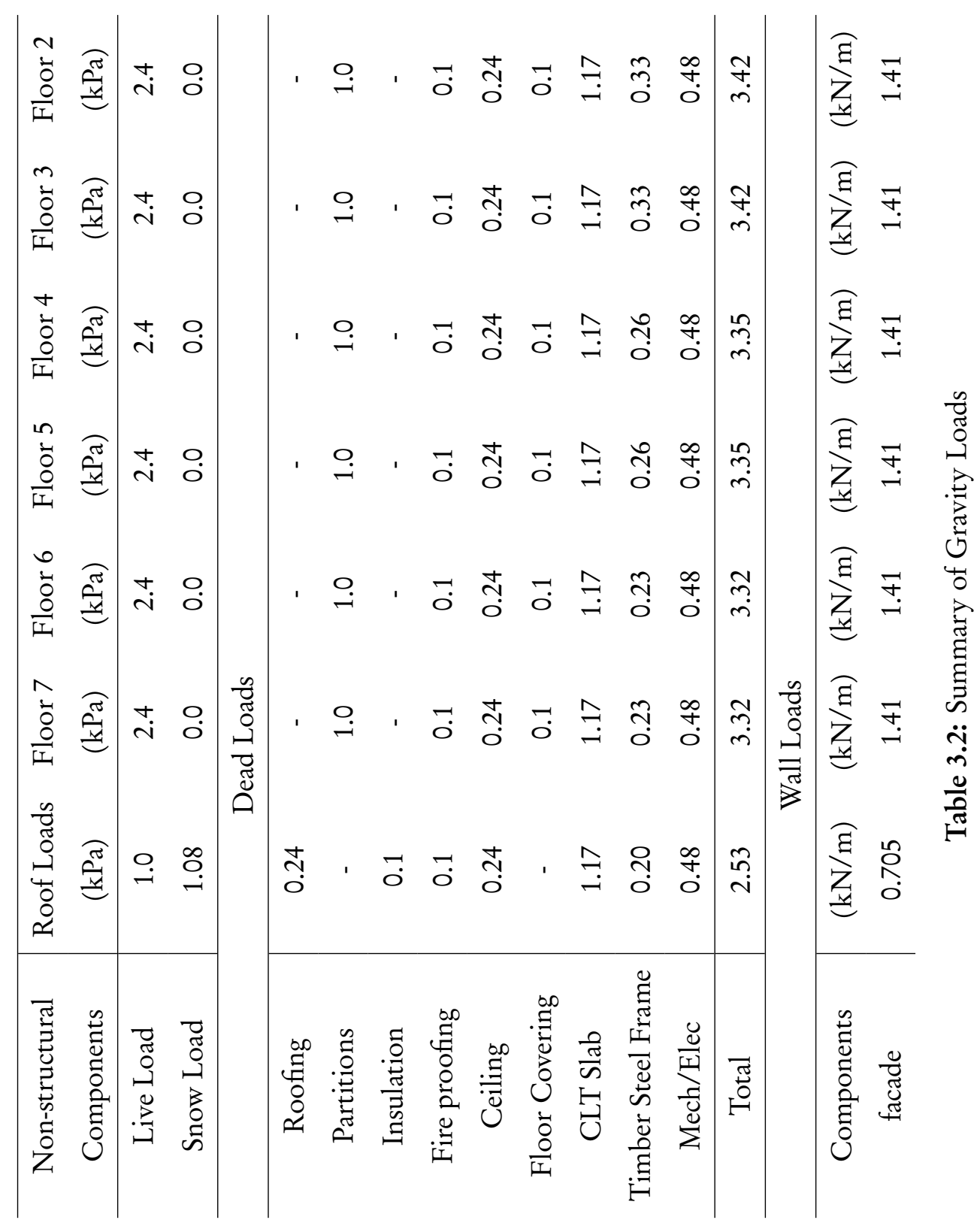


Table 3.3: Building Weight and Periods of Vibration

\begin{tabular}{c|c}
\hline Total Seismic Weight & $16500 \mathrm{kN}$ \\
\hline Mode & Period Seconds \\
\hline 1 & 0.91 \\
2 & 0.91 \\
3 & 0.52 \\
4 & 0.27 \\
5 & 0.27 \\
6 & 0.16 \\
\hline
\end{tabular}

further energy dissipation would be provided through yielding of the gusset plates which could increase load on the SFRS. Providing additional capacity in the column is warranted to avoid premature failure. All elements were then designed to the 5th percentile using the appropriate design code: CSA 086-09 Wood Design Manual (CSA 086-14, 2014), CSA S16-09 Handbook of Steel Construction (CSA S16, 2010), German Design Code DIN 1052 (Bauwesen, 2004).

\subsubsection{Glulam Frame Elements}

The design of glulam beam and column elements is illustrated in Table 3.1. All beams in the structure are the same size. Three column sizes are used. Appendix A.2 beginning on page 183 discusses the procedure used to determine member capacities.

\subsubsection{Cross Laminated Timber (CLT) Floor and Roof Slabs}

The CLT floor slab was designed as a one-way slab in the direction shown in Figure 3.1 and is 7 plys of stress grade V2 lumber $35 \mathrm{~mm}$ thick. The design procedure for the CLT slabs is discussed in Appendix A.3 beginning on page 195. As a result of the large clear spans, vibration governed the design.

\subsubsection{Friction Braces}

The friction braces utilized in this structure consist of a stainless steel on brass friction interface pretensioned together to achieve a dynamic slip force as defined in Table 3.1. The 
coefficient of static and dynamic friction for the brass on stainless steel friction interface was determined by Gilbert (2016) to be 0.45 . Two HSS152x203x13 tube sections connected to either end of the friction assembly combined to make the complete friction brace. The stiffness of each friction brace was $248.5 \mathrm{kN} / \mathrm{m}$. The design procedure for the friction braces is located in Appendix A.4 beginning on page 200. The slip load referred to as activation force of each friction brace is defined in Table 3.1. The activation force of all braces within a storey are the same. Activation forces were assigned based on the maximum loads in brace elements during the response spectrum analysis. Activation forces were not factored up to account for variability in slip forces.

\subsubsection{Glued-in Rod Connections}

Glued-in rod connections are used to connect glulam frame elements to steel panel zone joints; an illustration of a typical glued-in rod connection is shown in Figure 3.2. The number of glued-in rods per connection in the structure are illustrated in Table 3.4. Typical beam and column glued in rod details are illustrated in Figure 3.3. The embedment depth of all glued-in rod connections is $600 \mathrm{~mm}$. The adhesive chosen to anchor the glued-in rods was Sika AnchorFix300, a two component epoxy resin characterized as a high strength and low volatile organic compound, as shown in Table 3.5. The timber products and threaded rod specifications are illustrated in Tables 3.6 and 3.7. The adhesive, threaded rod and threaded rod embedment lengths used in the prototype structure design are the same as those used in the physical specimen. The German Design Code DIN 1052 (Bauwesen, 2004) was used to calculate all glued-in rod connection capacities. The design procedure for the glued-in rods is located in Appendix A.5 beginning on page 201.

Sean Miller, Department of Civil and Environmental Engineering, Carleton University 


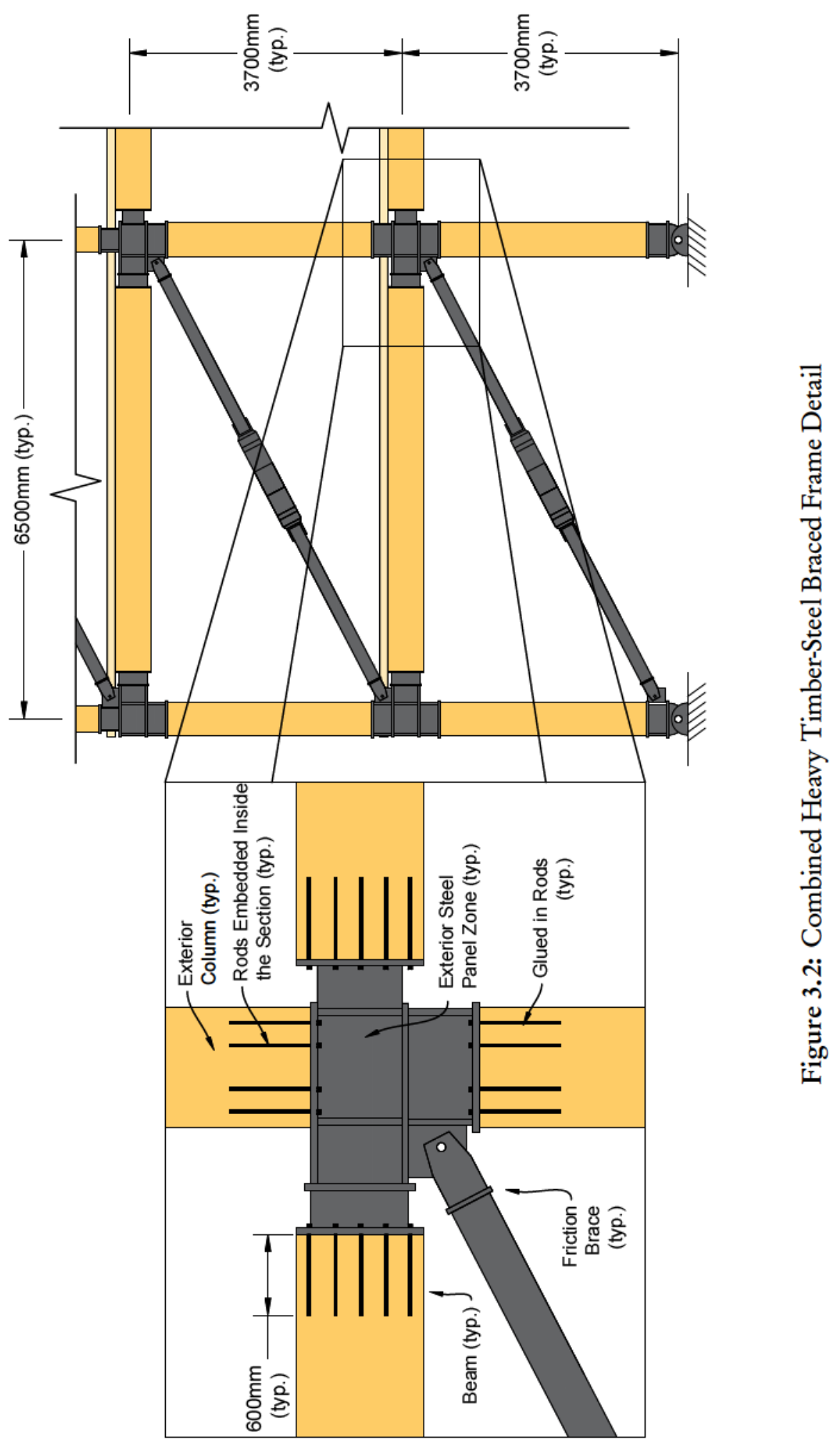


Beam Element D.Fir-L 24f-E 265x494, All Beams
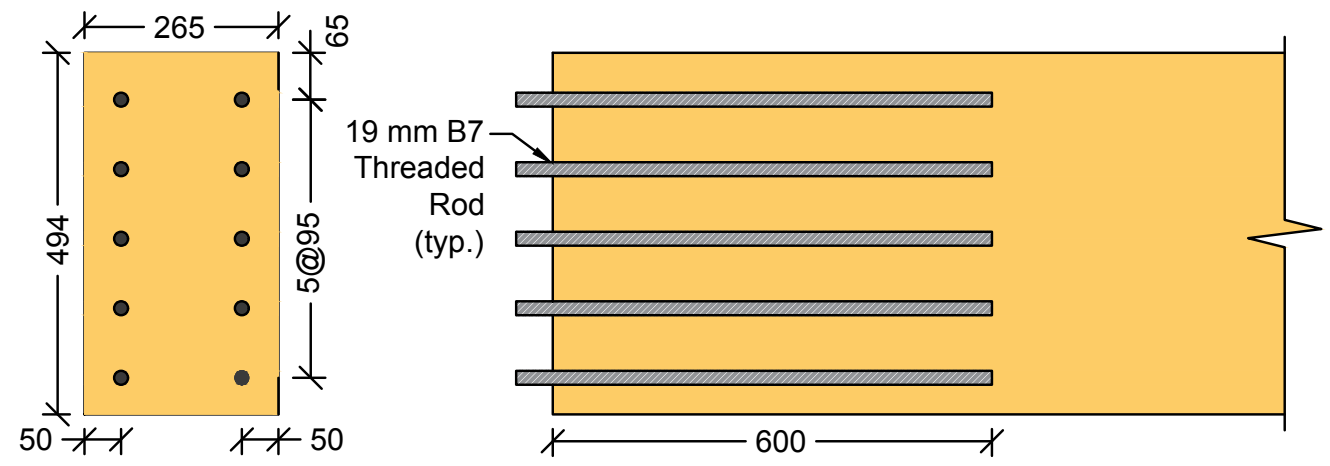

Column Element D.Fir-L 16c-E 465x465, Ground to Floor 3
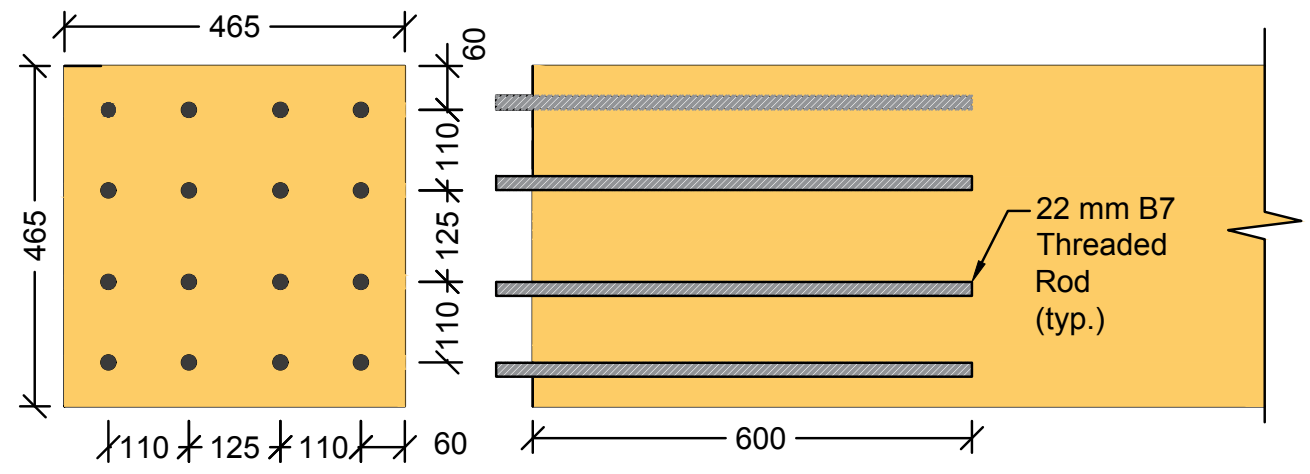

Column Element D.Fir-L 16c-E 342×342, Floor 3 to Floor 5
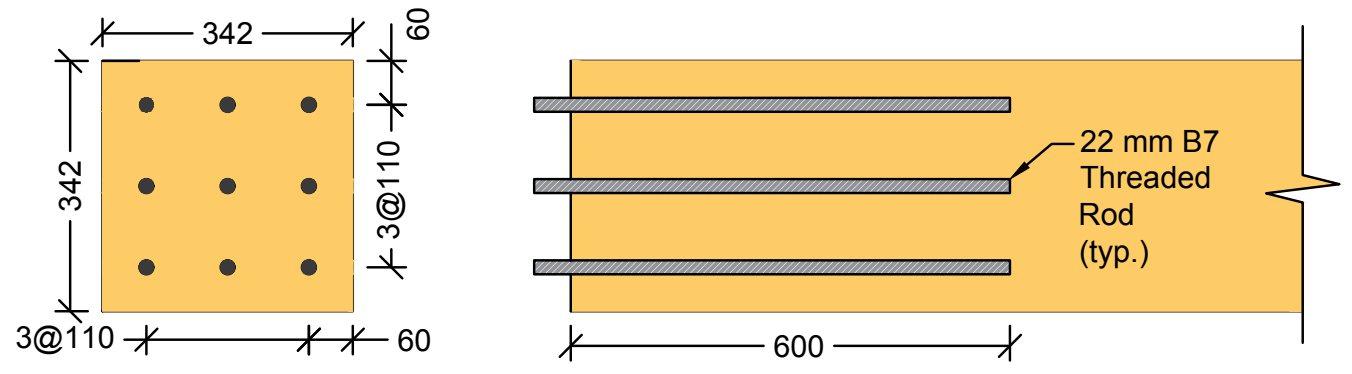

Column Element D.Fir-L 16c-E 265x265, Floor 5 to Roof
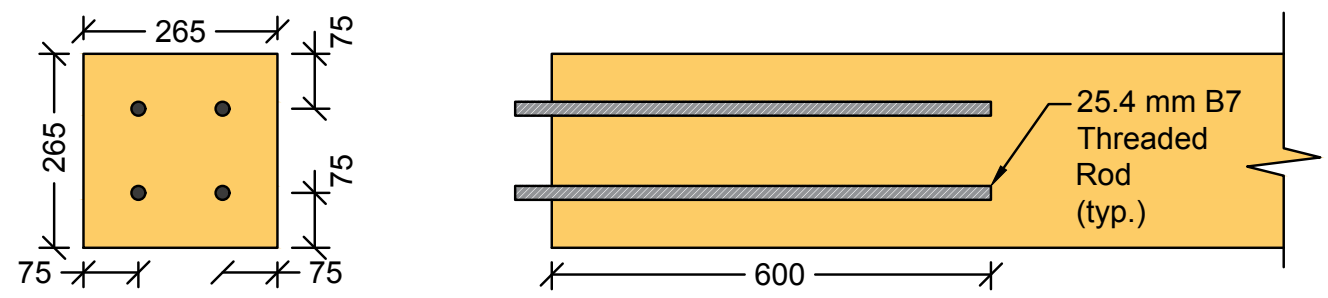

Figure 3.3: Glued-in Rod Detail for Each Frame Element 
Table 3.4: Member Sizes

\begin{tabular}{c|c}
\hline Member & \# Rods \\
\hline Column G-2,2-3 & 16 \\
Column 3-4,4-5 & 9 \\
Column 5-6,6-7,7-R & 4 \\
Beams & 10 \\
\hline
\end{tabular}

Table 3.5: Adhesive Properties (Gilbert, 2016)

\begin{tabular}{c|cc}
\hline Property & Strength $(\mathrm{MPa})$ & Modulus $(\mathrm{GPa})$ \\
\hline \multicolumn{3}{c}{ Compression } \\
\hline 1 Day & 59 & - \\
7 Days & 85 & 5 \\
\hline \multicolumn{3}{c}{ Tension } \\
\hline 1 Day & 18 & 5.7 \\
7 Days & 23.5 & 5.5 \\
\hline \multicolumn{3}{c}{ Flexure } \\
\hline 1 Day & 45 & - \\
\hline
\end{tabular}

Table 3.6: B7 Threaded Steel Rod Properties (Gilbert, 2016)

\begin{tabular}{c|cc}
\hline Property & Specified Value & Unit of Measure \\
\hline Tension Strength, $f_{u}$ & 860 & $\mathrm{MPa}$ \\
Yield Strength, $f_{y}$ & 725 & $\mathrm{MPa}$ \\
Elastic Modulus & 200000 & $\mathrm{MPa}$ \\
Thread Pitch & 10 & $\mathrm{~mm}$ \\
\hline
\end{tabular}


Table 3.7: Nordic Glulam Material Properties (Gilbert, 2016)

\begin{tabular}{c|cc}
\hline Property & Specified Value & Unit of Measure \\
\hline Compression Parallel to Grain, $f_{c}$ & 33.0 & $\mathrm{MPa}$ \\
Compression Perpendicular to Grain, $f_{c p}$ & 7.5 & $\mathrm{MPa}$ \\
Tension Parallel to Grain, $f_{t}$ & 20.4 & $\mathrm{MPa}$ \\
Positive Bending, $f_{b p}$ & 30.7 & $\mathrm{MPa}$ \\
Negative Bending, $f_{b n}$ & 30.7 & $\mathrm{MPa}$ \\
Shear, $f_{v}$ & 2.2 & $\mathrm{MPa}$ \\
Elastic Modulus, $E$ & 13100 & $\mathrm{GPa}$ \\
Density, $\rho$ & 560 & $\frac{\mathrm{kg}}{\mathrm{m}^{3}}$ \\
\hline
\end{tabular}

\subsection{Experimental Setup}

The experimental setup, referred to as an experimental substructure in hybrid tests, is illustrated in Figures 3.4 and 3.5. The setup consists of: a half scale physical specimen, an actuator to apply displacements and forces, a series of rigid supports and a series of lateral supports to facilitate the testing of the specimen. The physical specimen is a half scale representation of a lower bay beam, column, brace and panel zone of the prototype building. Appendix $\mathrm{C}$ provides details on the physical specimen designed by Gilbert (2016). Improvements made in the laboratory setup from Gilbert (2016) tests, the equipment and the instrumentation are discussed below. Within this section, reasons for improving the laboratory setup are discussed. The shop drawings for the prototype specimen are illustrated in Appendix E. 


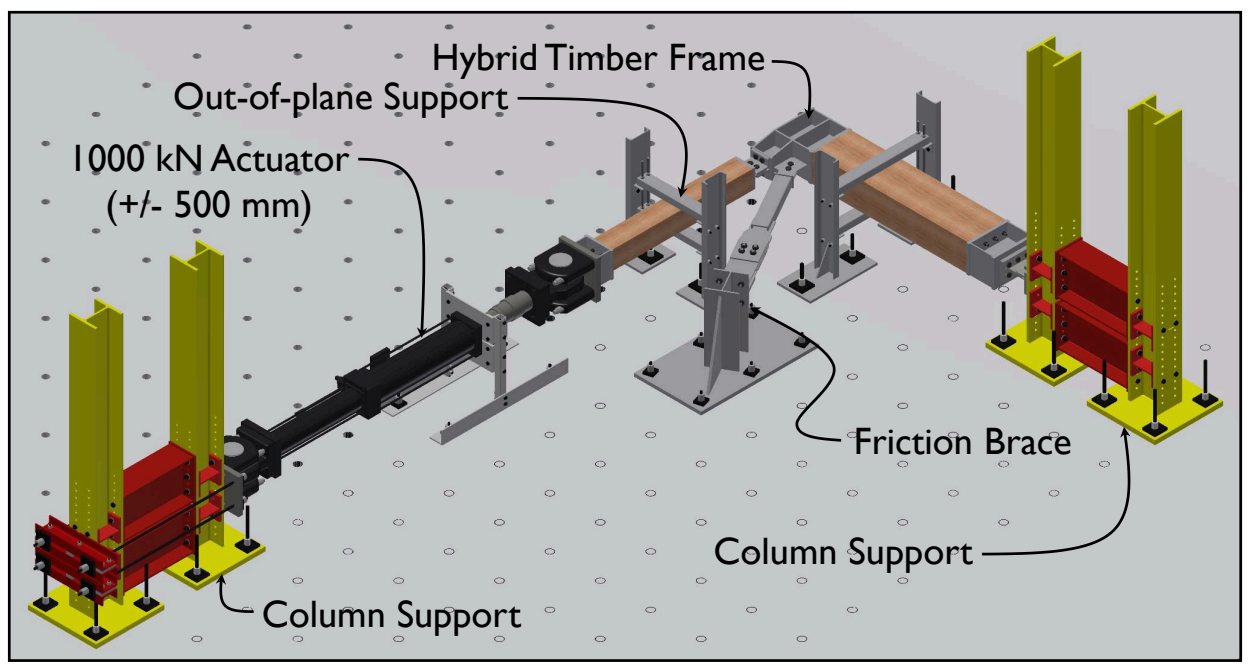

Figure 3.4: Experimental Test Setup for Heavy Timber-Steel Friction Braced Frame 


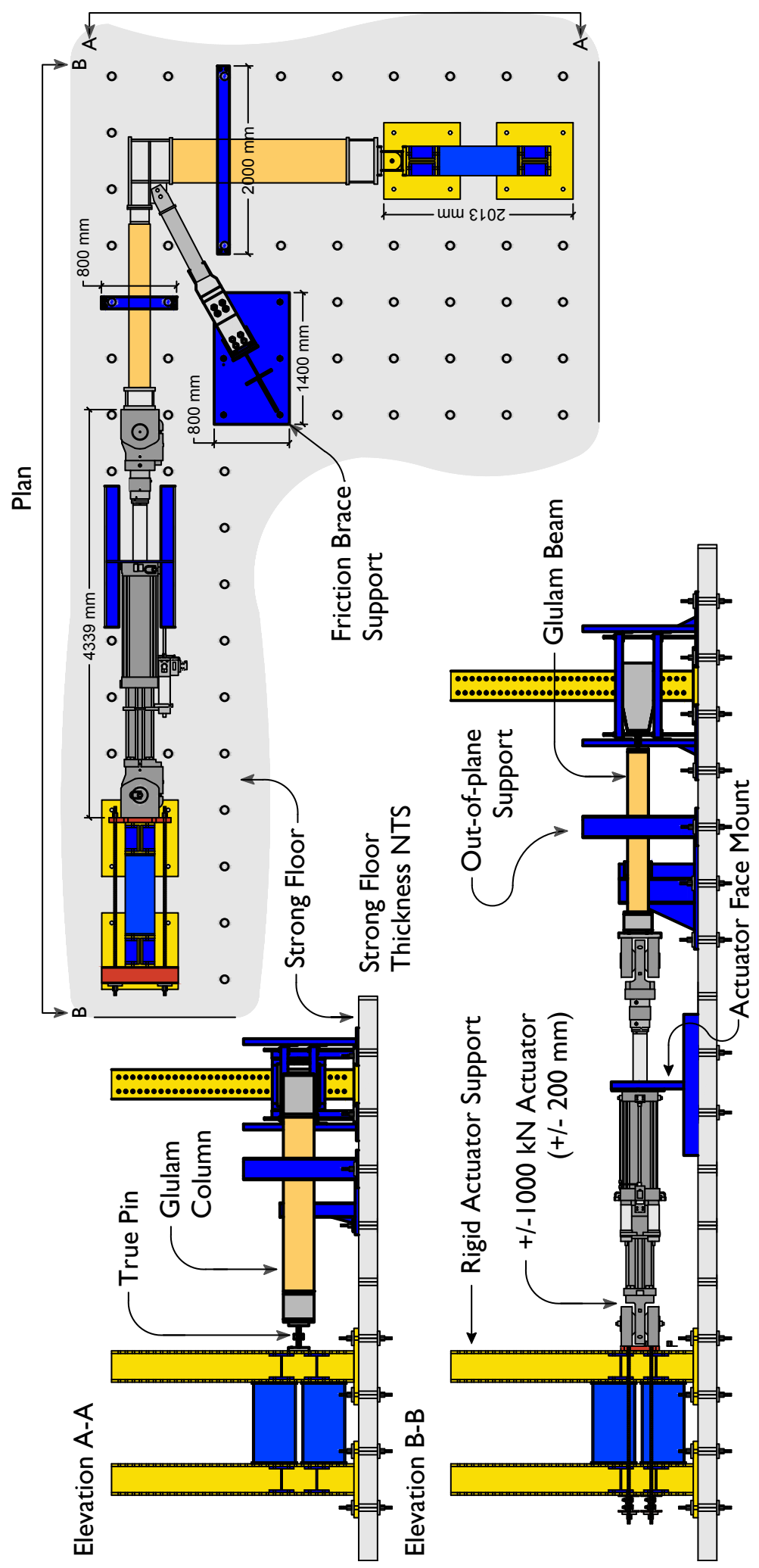

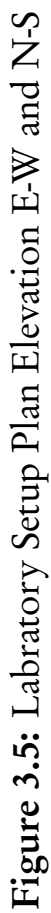




\subsubsection{Specimen Design}

The prototype structure discussed above was intentionally designed to contain the same bay widths and storey heights as Gilbert (2016) prototype structure. This allowed for the use of his prototype specimen in these hybrid simulations. The prototype specimen contained the same types of connections, glulam frame members and steel panel zones as the prototype structure.

The geometry of the prototype specimen was half scale to the prototype structure and is illustrated in Figure 3.6. The scaling factors are illustrated in Table 3.8. The experimental specimen consisted of a friction brace element, intermediate brace connection, gusset plate, beam shear connection and glulam beam and column members. Figure 3.7 illustrates the experimental specimen components. 


\section{CHAPTER 3. PROTOTYPE SPECIMEN AND}
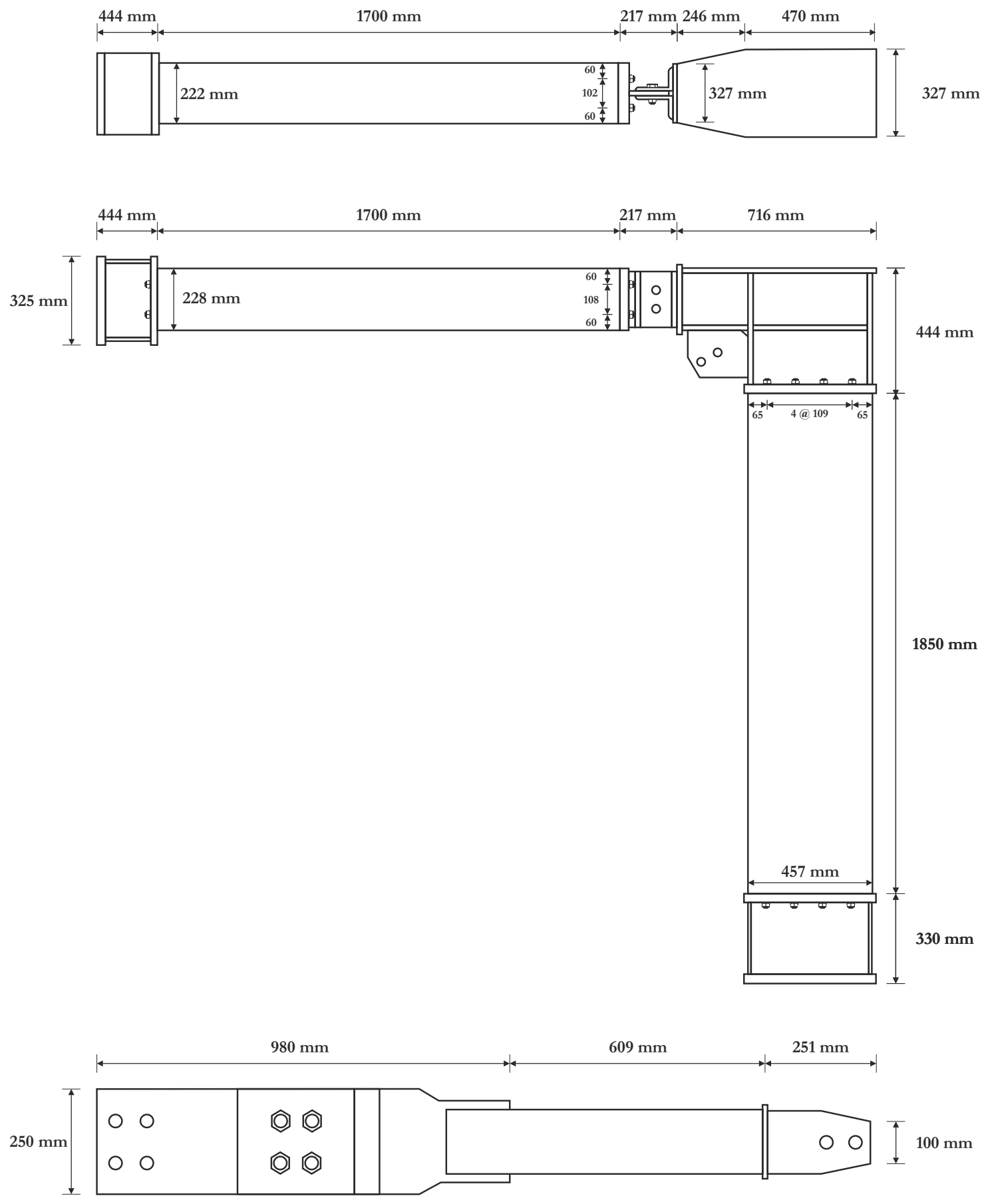

Figure 3.6: Geometry of specimen (Gilbert, 2016) 


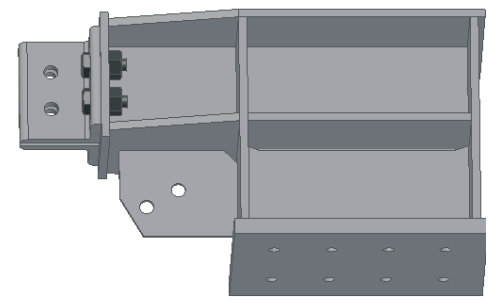

a)

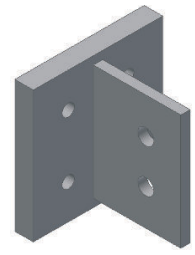

b)

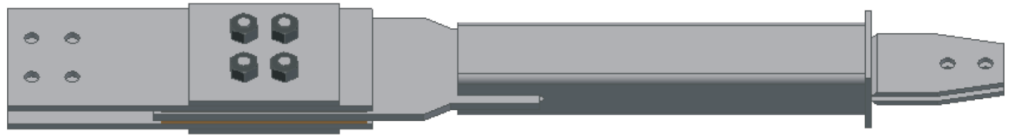

c)

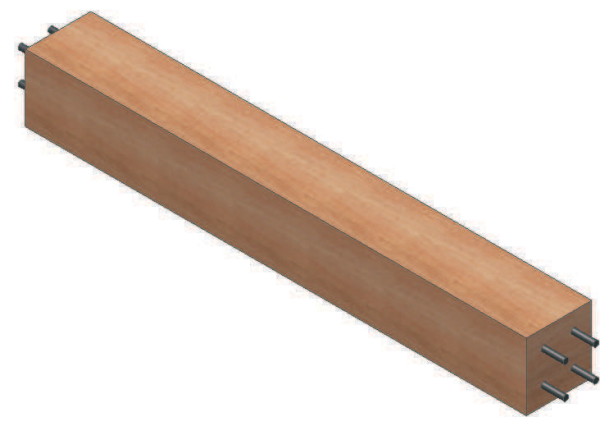

d)

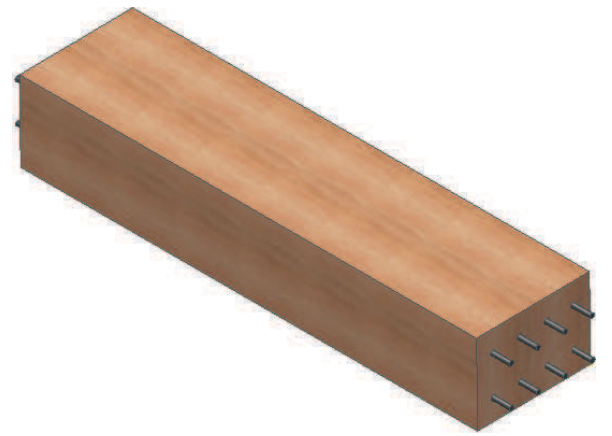

e)

Figure 3.7: Experimental Hybrid Braced Frame Components (Gilbert, 2016) a) Intermediate Brace Connection b) Beam Shear Connection c) Friction Damping Device d) Timber Beam with Glued-in Rod Connections e) Timber Column with Glued-in Rod Connections

The physical specimen was designed based on its friction brace's scaled slip force of $205 \mathrm{kN}$ (Gilbert, 2016). The friction brace was the primary fuse in the system. The secondary fuse was the corner connection gusset plate, it's probable yield force was $225 \mathrm{kN}$ Gilbert (2016). The gusset was designed with a force multiplication factor of 1.1 as per CSA S16 (2009) as part of the capacity design procedure. The brace and beam connection and the timber fasteners were designed with an additional force multiplication factor of 1.1. Gilbert (2016) included this extra force multiplication factor since he intended on testing the secondary fuse in the system and did not want the connections to behave inelastically. The secondary fuse was not tested in either Gilbert (2016) tests or during this study. The anticipated full and half scale design forces from 
this study are illustrated in Tables 3.9 and 3.10; these include the appropriate force multiplication factors. The design procedure used to determine each value illustrated in Tables 3.9 and 3.10 is illustrated in Appendix A.6 beginning on page 205.

Table 3.8: Scaling Factors for the Experimental Specimen (Gilbert, 2016)

\begin{tabular}{c|cc}
\hline Quantity & Description & Scaling Factor \\
\hline \multicolumn{3}{c}{ Geometric Properties } \\
Length & $S_{L}$ & 0.500 \\
Elastic Modulus & $S_{E}$ & 1.000 \\
Force & $S_{F}=S_{E} S_{L}^{2}$ & 0.250 \\
Moment & $S_{M}=S_{F} S_{L}$ & 0.125 \\
Area & $S_{A}=S_{L}^{2}$ & 0.250 \\
Section Modulus & $S_{Z}=S_{L}^{3}$ & 0.125 \\
Moment of Inertia & $S_{I}=S_{L}^{4}$ & 0.063 \\
\hline \multicolumn{2}{c}{ Dynamic Properties } \\
\hline Acceleration & $S_{A}$ & 1.000 \\
Mass & $S_{M a}=S_{F} / S_{A}$ & 0.250 \\
Time & $S_{T}=\sqrt{\left(S_{M} S_{L}\right) / S_{F}}$ & 0.250 \\
Fundamental Period & $S_{T a}=\sqrt{S_{M} /\left(S_{F} / S_{D}\right)}$ & 0.250 \\
Velocity & $S_{V}=S_{L} / S_{T}$ & 0.500
\end{tabular}


Table 3.9: Full-Scale Design Forces

\begin{tabular}{c|cccc}
\hline $\begin{array}{c}\text { Frame } \\
\text { Component }\end{array}$ & $\begin{array}{c}\text { Tension } \\
(\mathrm{kN})\end{array}$ & Compression & $\begin{array}{c}\text { Shear } \\
(\mathrm{kN})\end{array}$ & $\begin{array}{c}\text { Moment } \\
(\mathrm{kN} \cdot \mathrm{m})\end{array}$ \\
\hline Friction Slip Force & 825 & 825 & 0 & 0 \\
Gusset Plate & 909 & 909 & 0 & 0 \\
Hybrid Connection & 1525 & 2039 & 547 & 0 \\
Beam Connection & 868 & 868 & 89 & 0 \\
Beam Fasteners & 955 & 955 & 89 & 0 \\
Column Fasteners & 1668 & 2242 & 0 & 0 \\
Timber Beam & 1051 & 1051 & 89 & 145 \\
Timber Columns & 1835 & 2467 & 0 & 0 \\
\hline
\end{tabular}

Table 3.10: Half-Scale Design Forces

\begin{tabular}{c|cccc}
\hline $\begin{array}{c}\text { Frame } \\
\text { Component }\end{array}$ & $\begin{array}{c}\text { Tension } \\
(\mathrm{kN})\end{array}$ & $\begin{array}{c}\text { Compression } \\
(\mathrm{kN})\end{array}$ & $\begin{array}{c}\text { Shear } \\
(\mathrm{kN})\end{array}$ & $\begin{array}{c}\text { Moment } \\
(\mathrm{kN} \cdot \mathrm{m})\end{array}$ \\
\hline Friction Slip Force & 206 & 206 & 0 & 0 \\
Gusset Plate & 227 & 227 & 0 & 0 \\
Hybrid Connection & 381 & 735 & 136 & 0 \\
Beam Connection & 217 & 217 & 22 & 0 \\
Beam Fasteners & 239 & 239 & 22 & 0 \\
Column Fasteners & 419 & 809 & 0 & 0 \\
Timber Beam & 263 & 263 & 22 & 18 \\
Timber Columns & 461 & 889 & 0 & 0 \\
\hline
\end{tabular}

\subsubsection{Laboratory Setup Upgrades}

Gilbert observed flexibility during his tests in the reaction columns and in the out of plane supports (Gilbert, 2016). In addition, the column out of plane support did not provide enough clearance for the column element to rotate up to the designed 5\% drift. Figure 3.8a illustrates Gilbert (2016) experimental setup. Figure 3.8b illustrates the experimental setup for the current study. The lateral supports, actuator face mount, rigid column support for the brace and the rigid 
column supports were all replaced and or modified from Gilbert's test with stiffer assemblies. The actuator was also replaced to increase the actuator capacity and stroke.

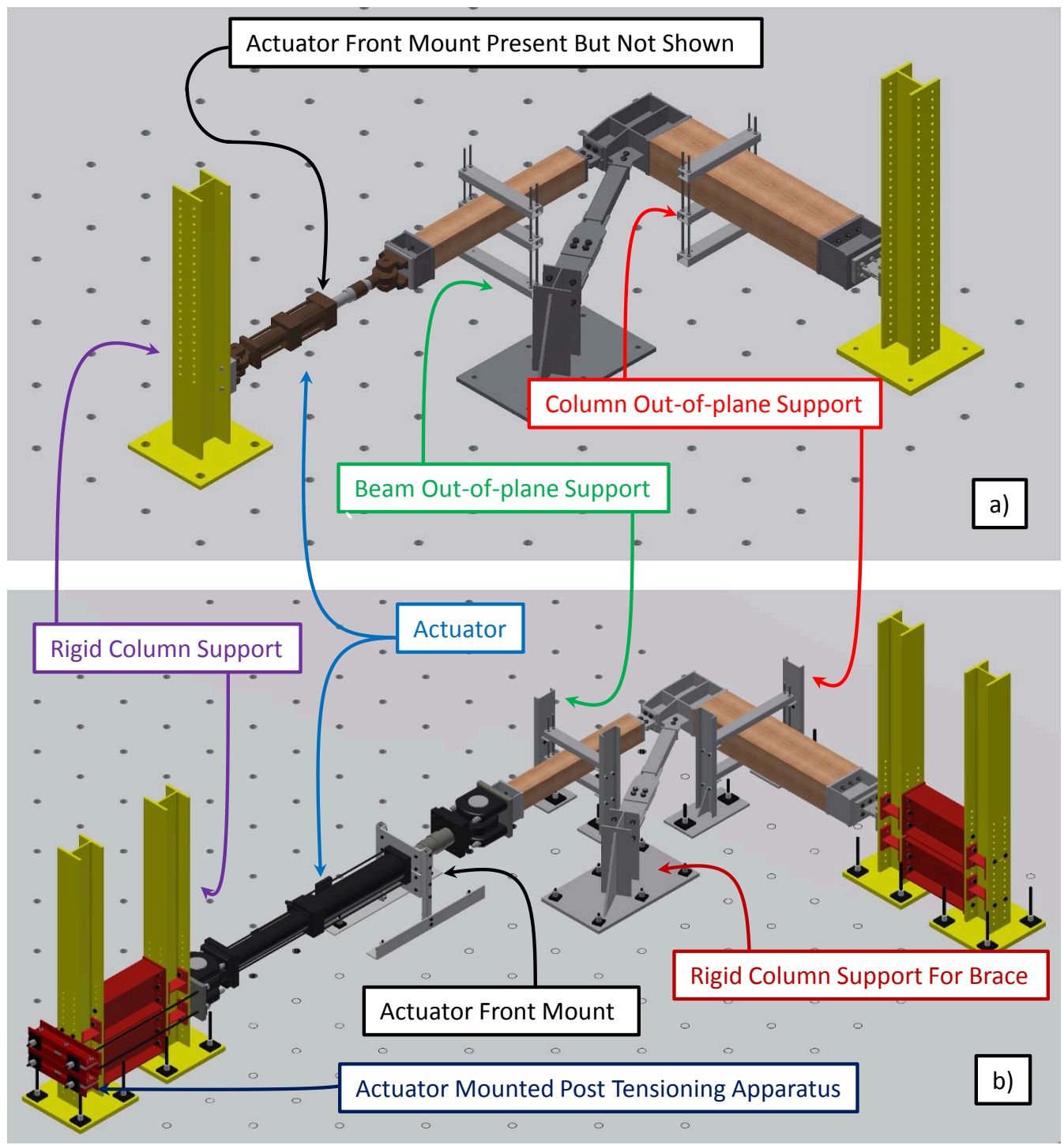

Figure 3.8: Experimental Setup Gilbert to This Research a) Gilbert Experimental Setup (Gilbert, 2016) b) Current Experimental Setup

The column supports illustrated in Figure 3.8 were completely replaced with much stiffer assemblies. The post tensioning apparatus, where the actuator was mounted to the reaction columns, further increased the stiffness of the assembly. The stiffness of the assemblies during Gilbert (2016) test was measured to be approximately $1250 \mathrm{kN} / \mathrm{mm}$. The modified assembly 
stiffness was measured in this study to be approximately $4500 \mathrm{kN} / \mathrm{mm}$.

The out of plane support for the beam and column specimens indicated with green and red labels in Figure 3.8 were also completely replaced. The old assemblies did not have adequate lateral resistance; they bent when the specimen slid across them. This caused the specimen to dip towards the ground during testing resulting in a misalignment between the specimen and the actuator. The column out of plane support also did not provide enough room for the column specimen to slide during testing. This problem was eliminated by increasing the length of the assembly by $600 \mathrm{~mm}$ which provided adequate room for the specimen at 2 times MCE level drifts.

The actuator, actuator front mount and actuator rear mount to the reaction column assembly were also all new to this test. The new dynamic actuator capacity is $1000 \mathrm{kN}$ with a stroke of $1200 \mathrm{~mm}$ which was significantly greater than the expected resistance of the prototype specimen.

The rigid column support for the brace was also stiffened. The stiffened assembly is illustrated in Figures 3.9 and 3.10. The stiffness of the assemblies during Gilbert (2016) test was measured to be approximately $380 \mathrm{kN} / \mathrm{mm}$. The modified assembly stiffness was measured in this study to be approximately $580 \mathrm{kN} / \mathrm{mm}$. 
CHAPTER 3. PROTOTYPE SPECIMEN AND

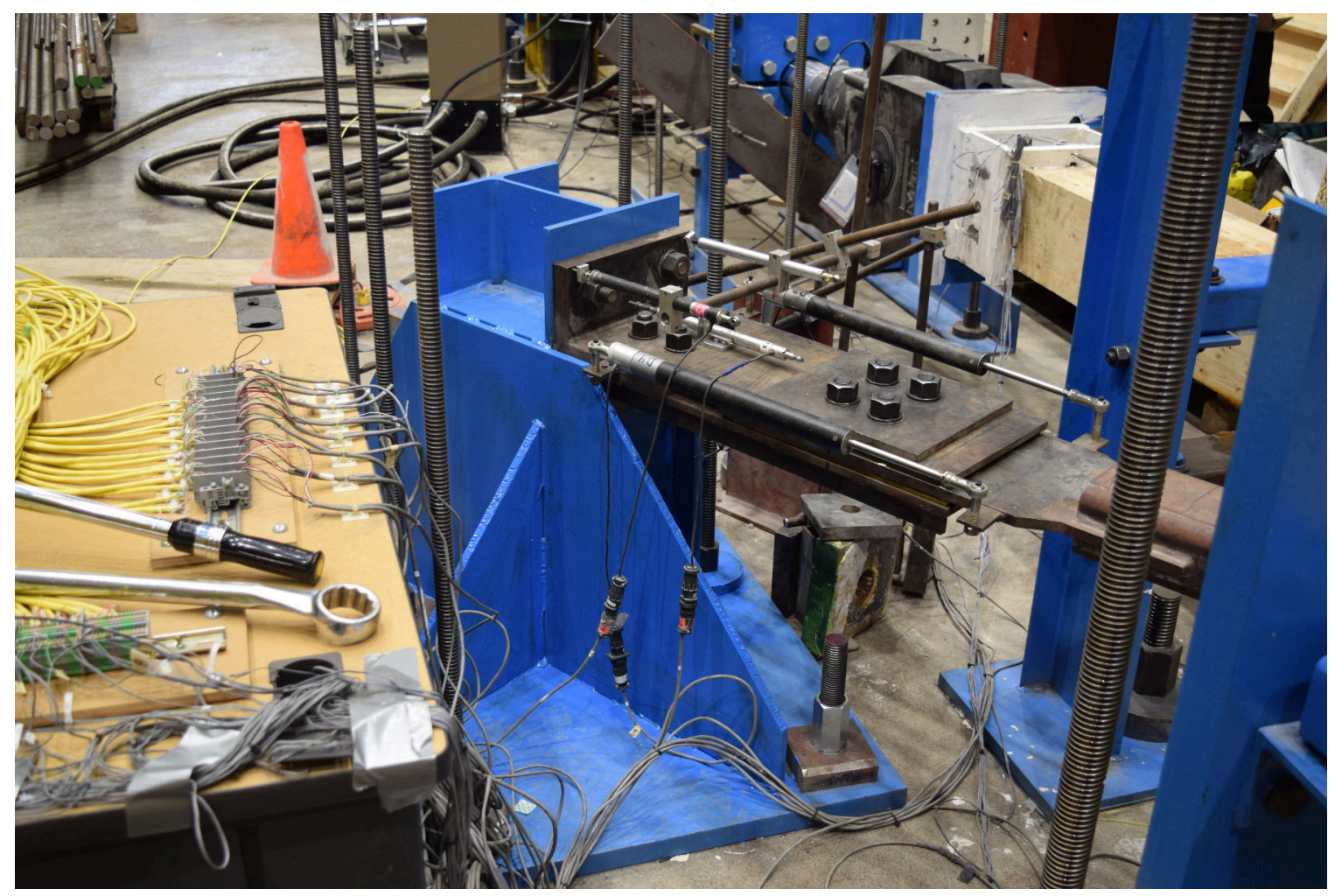

Figure 3.9: Instrumentation on Friction Brace Support Column 


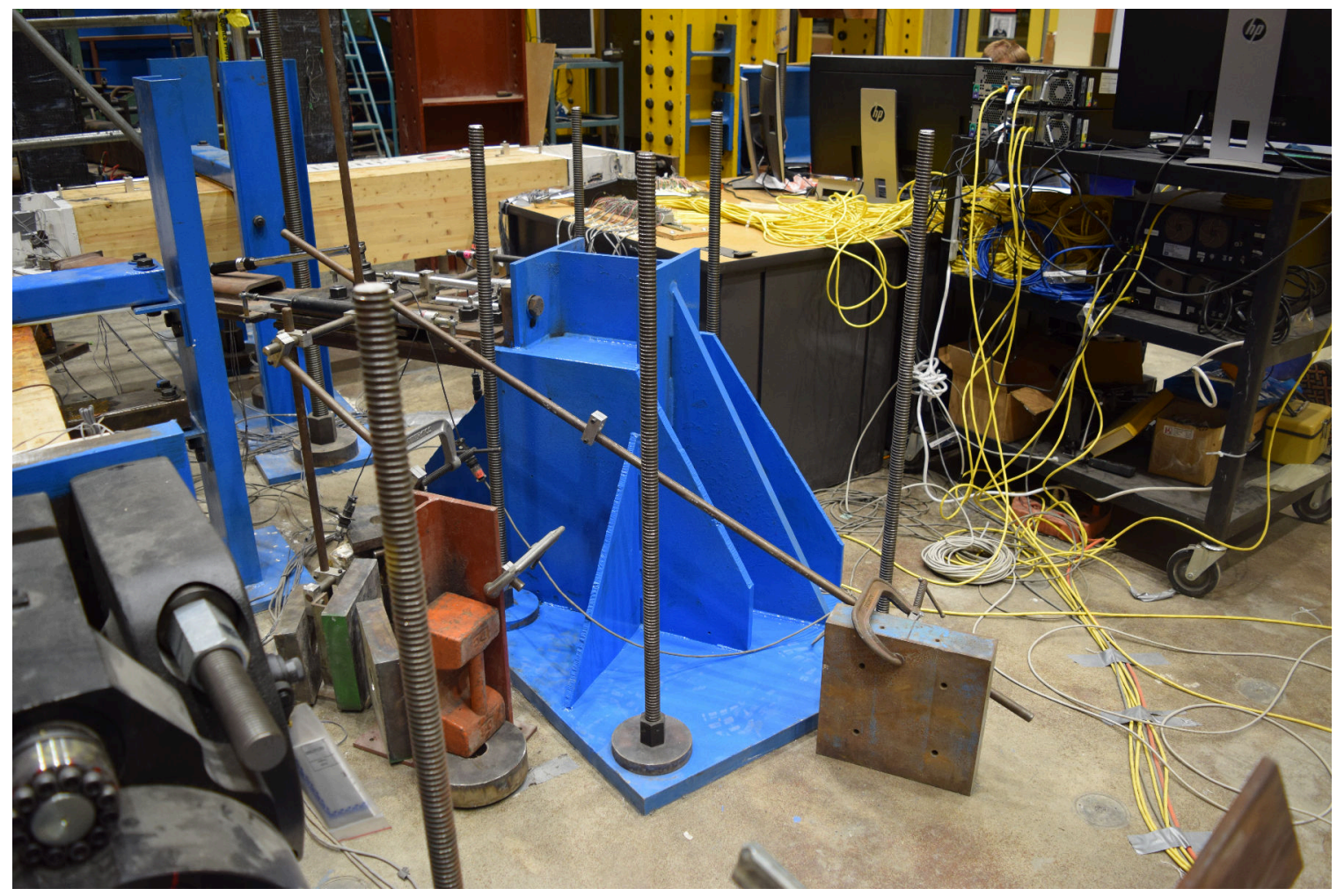

Figure 3.10: Stiffening of Friction Brace Support Column

\subsubsection{Prototype Specimen Stiffness Verification}

The stiffness of the prototype specimen was measured in the laboratory to be $73 \mathrm{kN} / \mathrm{mm}$ at the actuator interface. Since the initial stiffness was expected to be slightly higher, approximately $105 \mathrm{kN} / \mathrm{mm}$ over the entire assembly, a study was performed to investigate possible sources of stiffness loss. It was determined that the rigid column brace support stiffness was the major source of stiffness reduction in the system. The rigid column brace support stiffness was less than originally anticipated. This directly led to a reduced stiffness of the assembly measured at the actuator interface. Tables 3.11 to 3.13 display the stiffness of each component in the system. Figure 3.11 illustrates the location of each stiffness component for the beam, brace and column assemblies. Using the stiffness measured and stiffness estimated from each component, a simple model of the prototype specimen containing each member's length and stiffness properties was developed to verify the overall measured stiffness of the prototype specimen at the actuator interface. Figure 3.12 depicts this model. It can be seen that the stiffness of this model matches the 
measured stiffness of the prototype specimen. The measured laboratory stiffness was $73 \mathrm{kN} / \mathrm{mm}$ and the model estimated the stiffness at $72 \mathrm{kN} / \mathrm{mm}$. It should be noted that if the rigid column brace support was as rigid as the other boundary conditions at $4500 \mathrm{kN} / \mathrm{mm}$ as illustrated in Tables 3.11 and 3.13 the stiffness of the brace assembly including the support apparatus would be approximately $338 \mathrm{kN} / \mathrm{mm}$, resulting in an overall prototype specimen stiffness at the actuator interface of approximately $110 \mathrm{kN} / \mathrm{mm}$.

Table 3.11: Prototype Beam Stiffness

\begin{tabular}{c|cccc}
\hline $\begin{array}{c}\text { Location } \\
\text { Units }\end{array}$ & $\begin{array}{c}\text { Area } \\
(\mathrm{mm})\end{array}$ & $\begin{array}{r}\text { Modulus of Elasticity } \\
(\mathrm{MPa})\end{array}$ & $\begin{array}{c}\text { Length } \\
(\mathrm{mm})\end{array}$ & $\begin{array}{c}\text { Stiffness } \\
(\mathrm{kN} / \mathrm{mm})\end{array}$ \\
\hline B1: Support Column & \multicolumn{2}{|c}{ Stiffness Measured In Laboratory } & 4500 \\
B2: Steel Assembly & 11099 & 200000 & 167 & 13300 \\
B3: Steel Connection & 3160 & 200000 & 150 & 4213 \\
B4: Glued-in Rods & Stiffness Measured In Laboratory & 782 \\
B5: Glulam Beam & 50600 & 13100 & 1700 & 390 \\
B6: Steel Joint & 9530 & 200000 & 116 & 16400 \\
\hline Series Stiffness & \multicolumn{4}{|}{}
\end{tabular}

Table 3.12: Prototype Brace Stiffness

\begin{tabular}{c|cccc}
$\begin{array}{c}\text { Location } \\
\text { Units }\end{array}$ & $\begin{array}{c}\text { Area } \\
(\mathrm{mm})\end{array}$ & $\begin{array}{c}\text { Modulus of Elasticity } \\
(\mathrm{MPa})\end{array}$ & $\begin{array}{c}\text { Length } \\
(\mathrm{mm})\end{array}$ & $\begin{array}{c}\text { Stiffness } \\
(\mathrm{kN} / \mathrm{mm})\end{array}$ \\
\hline BR1: Support Column & \multicolumn{2}{|c}{ Stiffness Measured In Laboratory } & 572 \\
BR2: Friction Assembly & 3968 & 200000 & 870 & 912 \\
BR4: Steel Plate Section & 1900 & 200000 & 100 & 3800 \\
BR4: HSS Section & 5390 & 200000 & 609 & 1770 \\
BR5: Brace Gusset Connection & 2850 & 200000 & 120 & 4750 \\
BR6: Gusset Plate & 640 & 200000 & 110 & 1160 \\
\hline Series Stiffness & & & & 304
\end{tabular}


Table 3.13: Prototype Column Stiffness

\begin{tabular}{|c|c|c|c|c|}
\hline $\begin{array}{l}\text { Location } \\
\text { Units }\end{array}$ & $\begin{array}{l}\text { Area } \\
(\mathrm{mm})\end{array}$ & $\begin{array}{l}\text { Modulus of Elasticity } \\
\qquad(\mathrm{MPa})\end{array}$ & $\begin{array}{l}\text { Length } \\
(\mathrm{mm})\end{array}$ & $\begin{array}{l}\text { Stiffness } \\
(\mathrm{kN} / \mathrm{mm})\end{array}$ \\
\hline C1: Support Column & \multicolumn{3}{|c|}{ Stiffness Measured In Laboratory } & 4500 \\
\hline C2: True Pin & 3700 & 200000 & 275 & 2690 \\
\hline C3: Steel Connection & 13800 & 200000 & 266 & 10400 \\
\hline C4: Glued-in Rods & \multicolumn{3}{|c|}{ Stiffness Measured In Laboratory } & 633 \\
\hline C5: Glulam Column & 149000 & 13100 & 1850 & 1060 \\
\hline C6: Steel Joint & 13700 & 200000 & 200 & 13700 \\
\hline Series Stiffness & & & & 223 \\
\hline
\end{tabular}




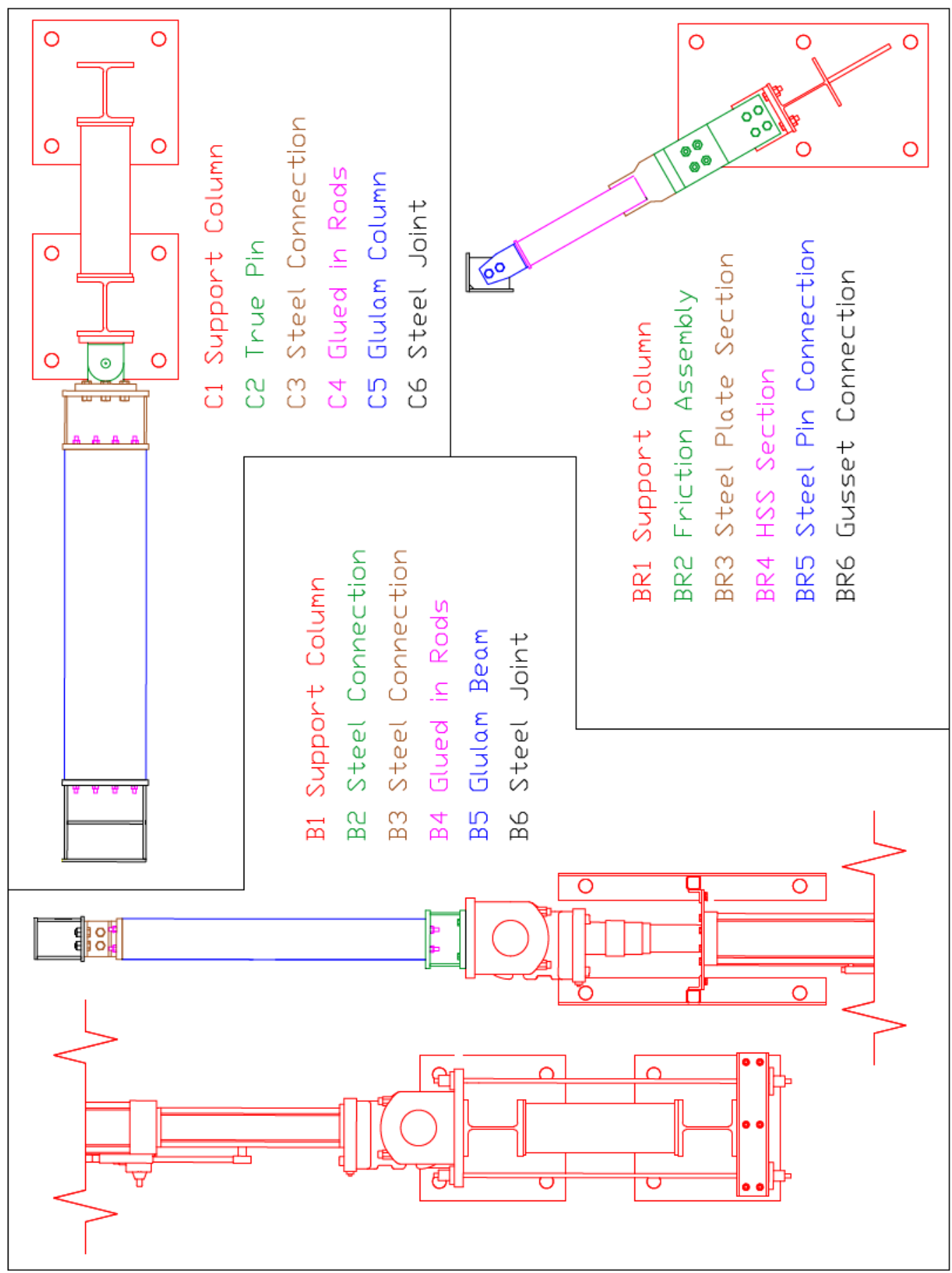

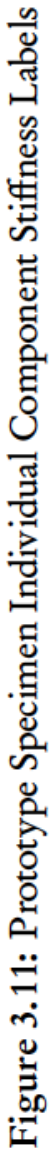




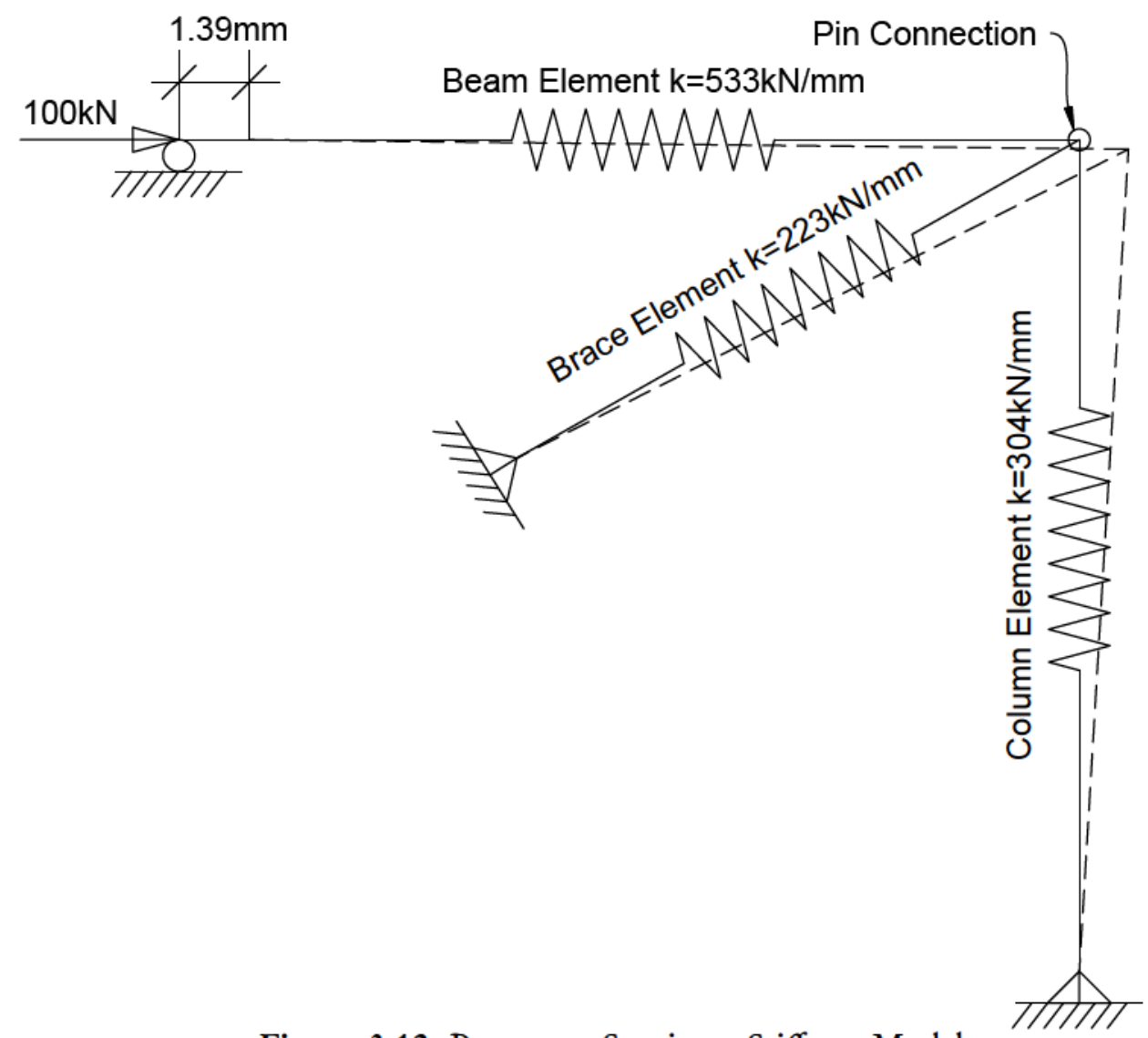

Figure 3.12: Prototype Specimen Stiffness Model

\subsection{Control and Instrumentation}

The experimental setup of the hybrid test is illustrated in Figure 3.8b. The setup contains 2 support column assemblies, a friction brace support assembly, as well as, 2 out of plane supports and a $1000 \mathrm{kN}$ capacity $(+/-500 \mathrm{~mm})$ stroke dynamic actuator. The rigid support columns, brace and out of plane assemblies are all secured to the laboratory's strong floor. The dynamic actuator is a MTS series 244.51 hydraulic actuator which is used to apply displacements to the beam specimen. The out of plane supports prevent the specimen from shifting out of plane during testing. These supports contain teflon sliding sheets and are greased to reduce sliding friction when contact is made between the glulam specimens and the supports. 


\subsubsection{Control}

The hybrid test setup contains a host computer, predictor corrector host computer, controller, data acquisition system, dynamic actuator and prototype specimen. The controller and data acquisition system are used to communicate between the numerical substructure on the host computer and the experimental substructure in the laboratory at each time-step in the analysis. The actuator applies target command displacements and reads back force which is sent back into the solver to calculate the next target displacement. This process is repeated until the test is complete.

\subsubsection{Data Acquisition and Instrumentation}

The instrumentation used in the experiment is illustrated in Figures 3.13 and 3.14. Linear Variable Differential Transformers (LVDTs) and String Potentiometers (SP) were used to monitor horizontal and vertical movement of the physical specimen and support apparatus. Electrical strain gauges monitored any areas where yielding may have occurred; these included the friction brace HSS section and beam and column element steel sections. The HSS section contained a strain gauge on each side. Gauges on the steel sections were lined up with the glued-in rods. LVDTs are located on the support columns, steel joint panel zone and glulam members to monitored for unanticipated movement. LVDTs on the friction brace monitored the friction interface movement and any rotations that occurred. LVDTs 17 and 19 monitor movement in the friction brace support.

Sean Miller, Department of Civil and Environmental Engineering, Carleton University 


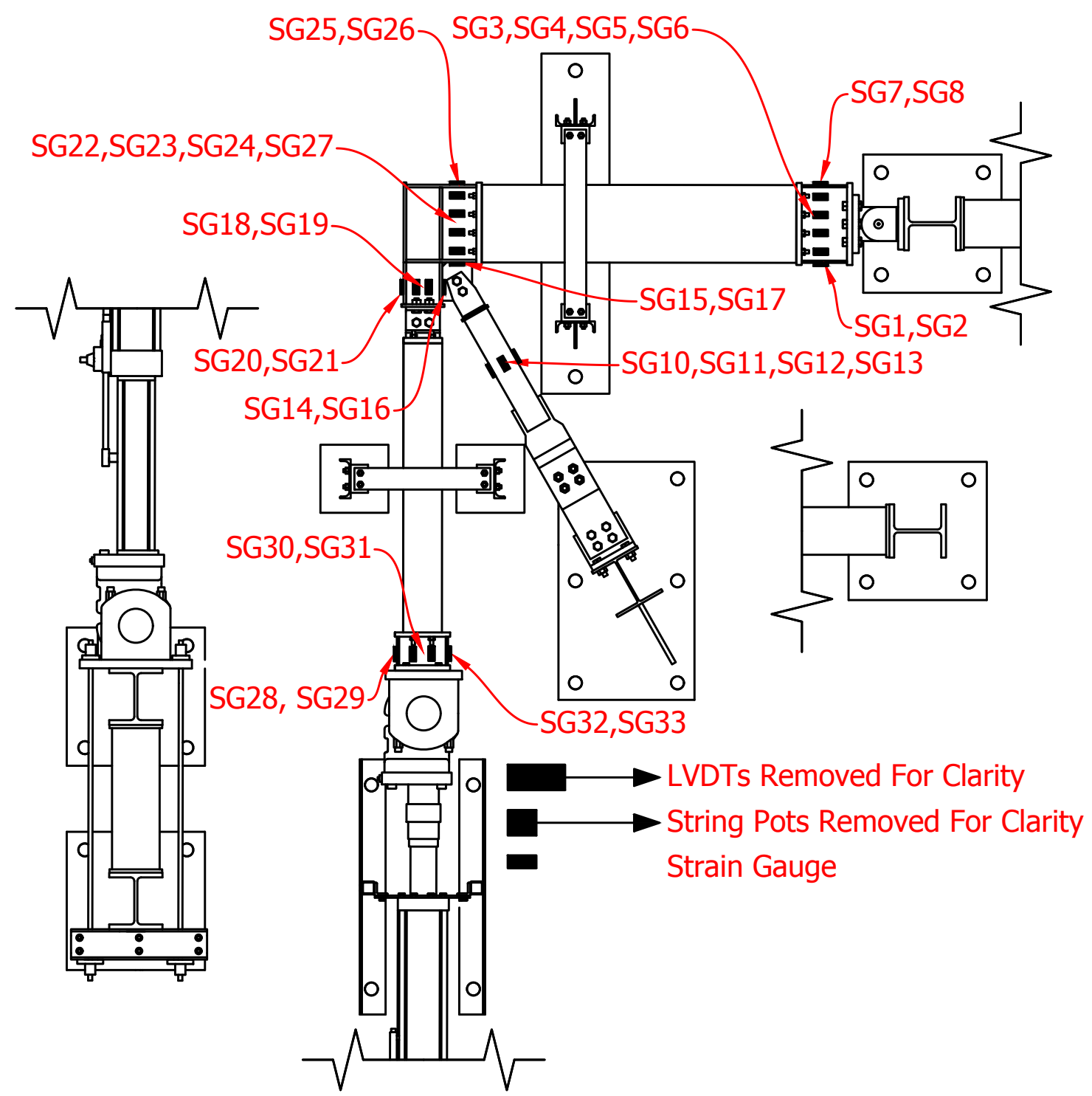

Figure 3.13: Strain Gauge Instrumentation 


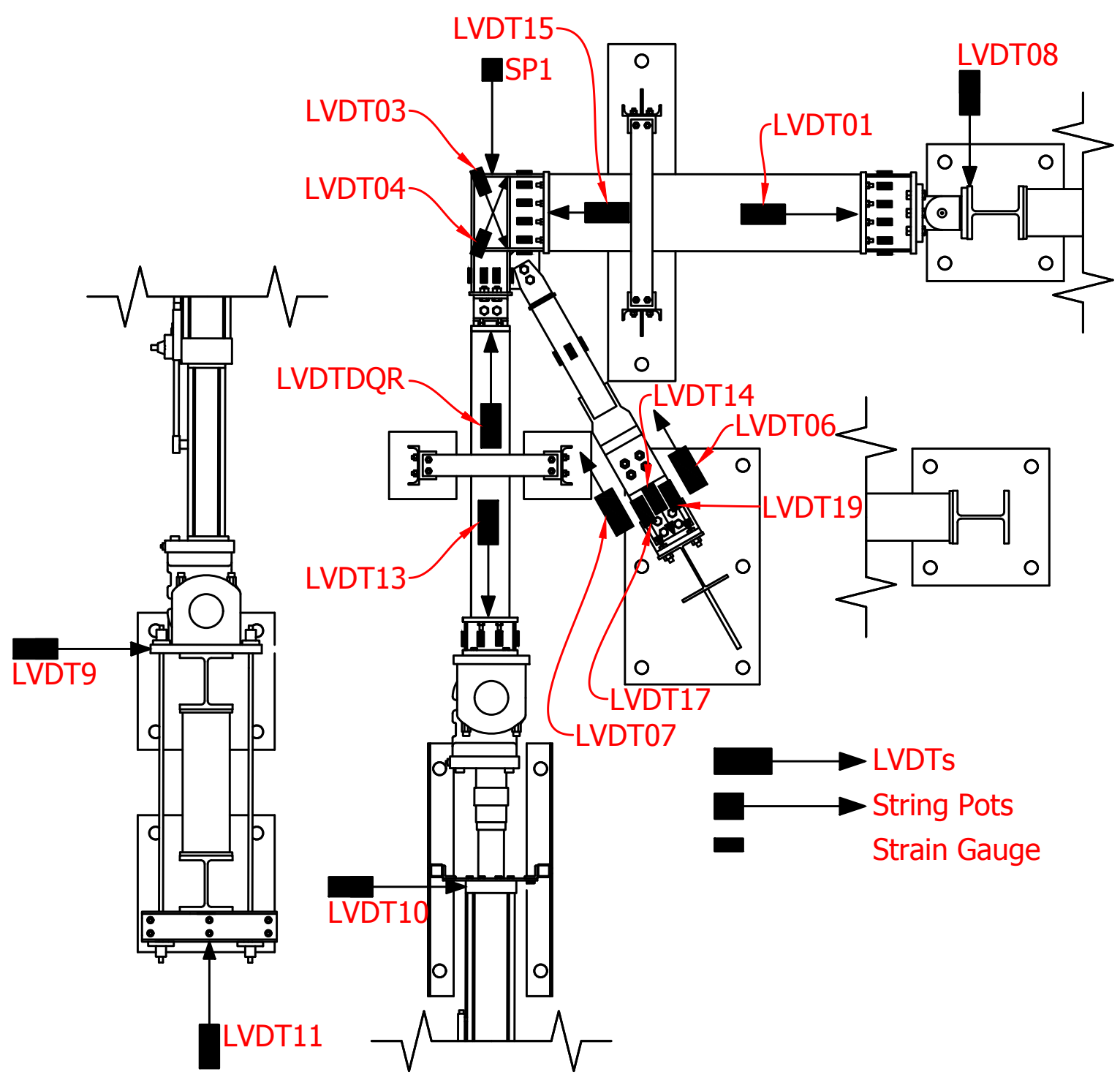

Figure 3.14: String Pot and LVDT Instrumentation

\subsubsection{Hybrid Simulation Hardware and Software Components}

The hardware and software applications used during this experiment are illustrated in Figure 3.15. The hardware configuration was setup to ensure high speed communication between the servo-controller and the computer solving the equation of motion. The main hardware components consisted of the controller, $\mathrm{xPC}-$ Target digital signal processor, $\mathrm{xPC}$ host computer containing Matlab, OpenSees and OpenFresco and the Data Acquisition System. The controller linked between the laboratory substructure and the xPC-Target digital signal processor. The 
xPC-Target digital signal processor linked with the controller, the data acquisition system and the $\mathrm{xPC}$ host computer. The $\mathrm{xPC}$ host computer linked with the $\mathrm{xPC}-$ Target digital signal processor and the data acquisition system. The data acquisition system communicated with the experimental substructure and the $\mathrm{xPC}$-Target digital signal processor. Matlab was used to scale forces and displacements between the numerical substructure and the physical substructure.

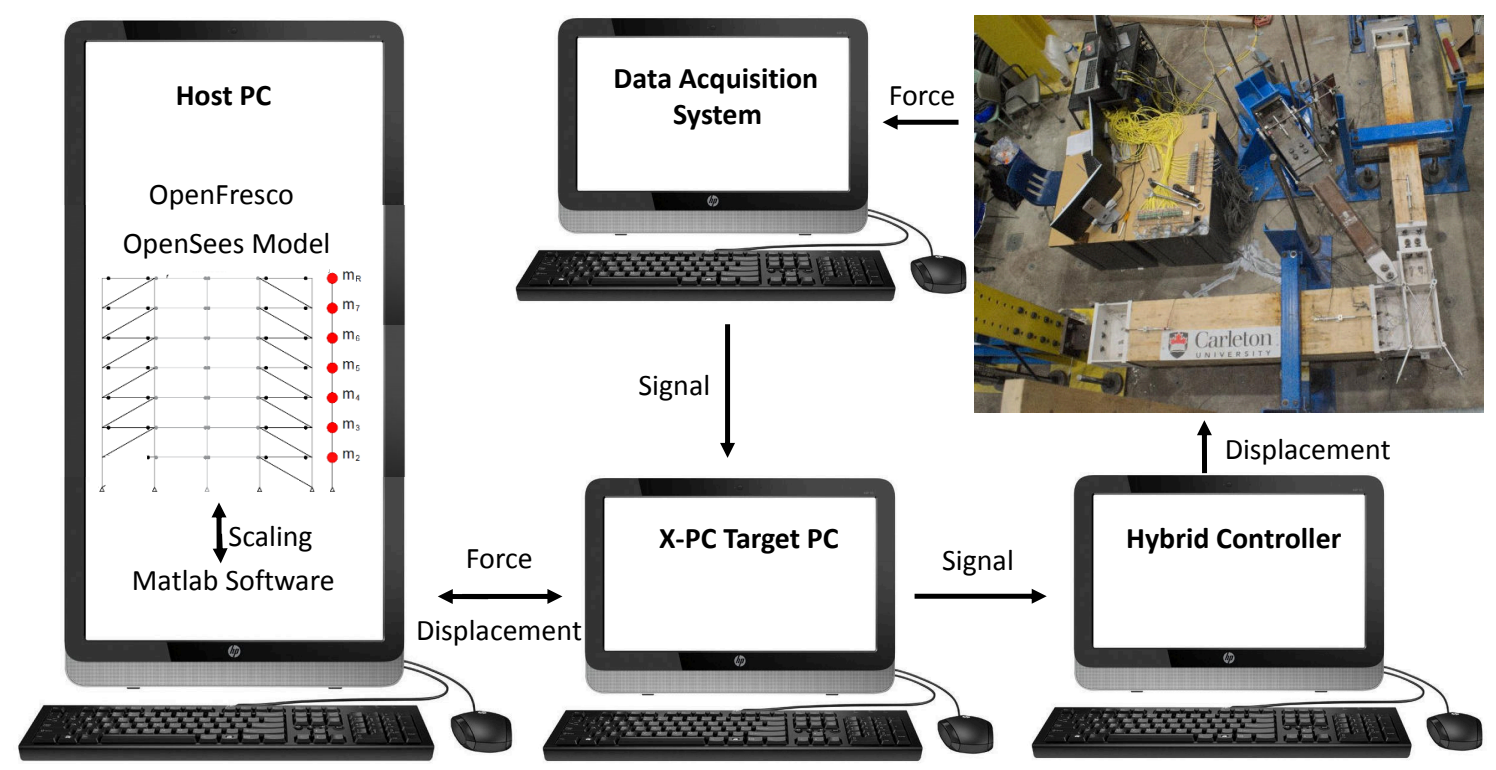

Figure 3.15: Hybrid Test Communication Network 


\section{Chapter 4: Numerical Model Development}

\subsection{Introduction}

This chapter summarizes 2 finite element models developed to analyze the prototype structure prior to performing hybrid tests. The first model was developed using OpenSees, while the second model was developed using OpenSees and OpenFresco.

The first model was a 2 dimensional OpenSees model of the 3 dimensional prototype structure's SFRS. This model was developed for 3 main reasons. Firstly, a large portion of the OpenSees model was required in the numerical substructure for the hybrid tests. Secondly, purely analytical IDA results were generated from the model and compared with experimental results of the hybrid tests. Finally, the model provided a check to ensure the model was behaving as expected prior to developing the Hybrid Model.

The second model developed was a 2 dimensional substructured Hybrid Model of the SFRS modeled in OpenSees and OpenFresco. This model was purely numerical; it analytically modeled the numerical and experimental substructures of the hybrid test. This model was developed to verify boundary conditions for the hybrid test and to verify the model was behaving as expected prior to performing the experimental hybrid tests in the laboratory. The substructured components of the purely analytical Hybrid Model are illustrated in Figure 4.1. The experimental substructure is illustrated in green while the analytical substructure is illustrated in black. The boundary conditions between the two substructures are discussed in this chapter.

Scaling and selection of ground motion records used in the analytical IDA are illustrated in this Chapter, as well as, analysis parameters as defined in the OpenSees model. The scaling factors used to analyze the structure's performance at Design Basis Earthquake (DBE) and Maximum 
Considered Earthquake (MCE) hazard levels are discussed within this chapter. Experimental IDA earthquake record selection and scaling is discussed in Chapter 6.

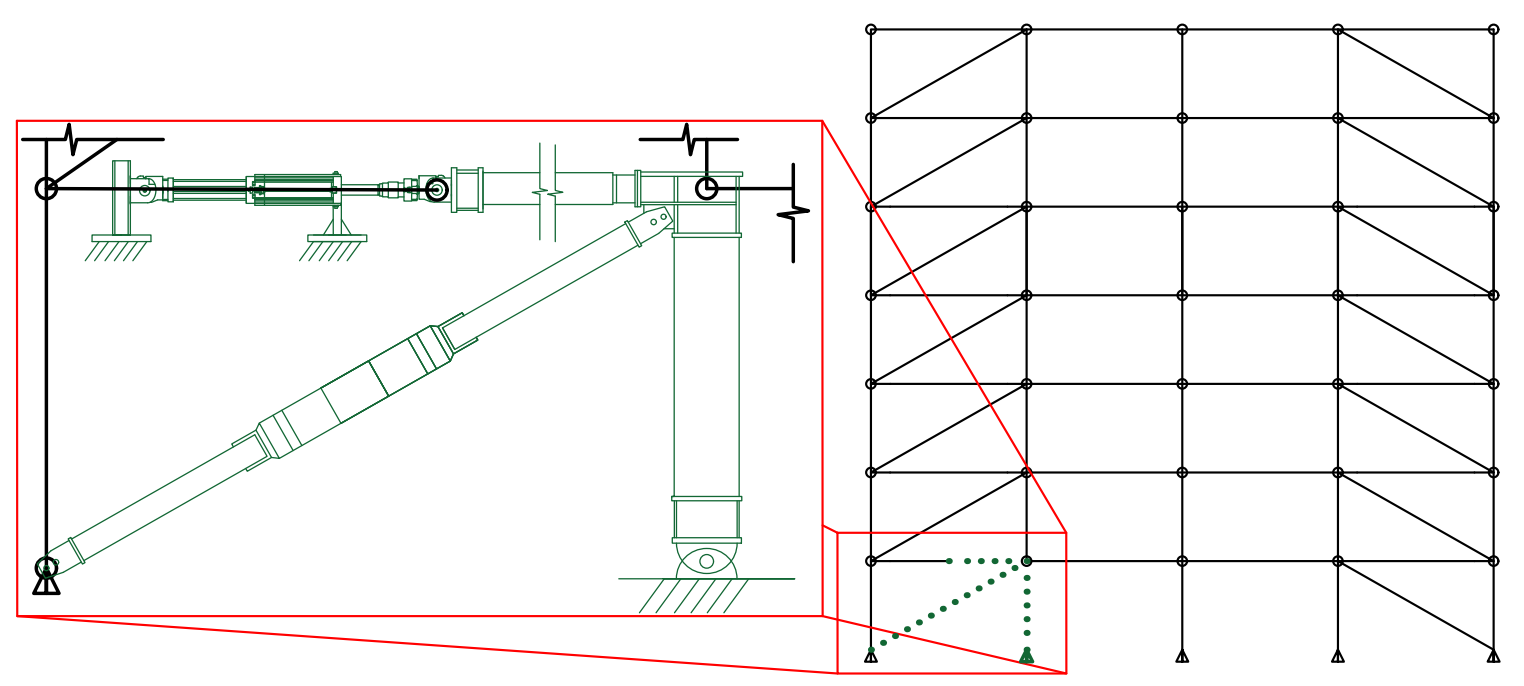

Figure 4.1: Experimental Substructure Green and Numerical Substructure Black

\subsection{OpenSees Model}

An OpenSees model of the prototype structure's SFRS was developed for 3 main reasons. Firstly, a large portion of the OpenSees model was required in the numerical substructure of the hybrid tests. Secondly, purely analytical IDA results were generated from the model and compared with experimental hybrid test results. Finally, the model provided a check to ensure the model was behaving as expected prior to developing the Hybrid Model.

A 2 dimensional model of the 3 dimensional prototype structure's SFRS is illustrated in Figure 4.4. Each of the 4 exterior walls contained 1 line of braced SFRS. The 3 dimensional prototype structure was symmetric in both of it's orthogonal axes. Figure 4.4 illustrates one of the 3 dimensional prototype structures 4 independent lines of braced SFRS, as well as, it's tributary area. When the prototype structure is seismically analyzed in only one of it's two orthogonal directions, only 2 lines of braced SFRS will be actively resisting lateral loads. Both lines of braced SFRS will behave the same thus only one line of braced SFRS is required to 
accurately capture the behaviour of the entire structure under seismic loading. The consequence of this is that an offset to account for a separation of the structure's center of mass and center of rigidity can not be applied. This assumption dramatically reduced the complexity of the OpenSees model required to perform the IDA. This simplification facilitated modeling of the SFRS in OpenSees.

Two OpenSees models were developed as part of this study. The first OpenSees model contained all elements in the SFRS line and is referred to as the Four Bay OpenSees Model. The second OpenSees model only contained elements that resisted lateral loading within the SFRS line and is referred to as the Two Bay OpenSees Model. Figures 4.2 and 4.4 illustrate the Four Bay OpenSees Model. Figures 4.3 and 4.5 illustrate the Two Bay OpenSees Model. The two models were developed to verify that the response of the simplified Two Bay OpenSees Model produced the same results as the more complex Four Bay OpenSees Model. Reducing model complexity was essential as it reduced the computational time required to perform the analytical IDA. The results of this analysis are discussed following an explanation of the OpenSees models. Both OpenSees models contained glulam beam and column elements, friction braces, rigid stub elements and a rigid CLT slab from the prototype structure. The CLT slab was not directly modeled in OpenSees but was assumed to be rigid in comparison to the flexible column and brace elements. The CLT slab diaphragm was modeled in OpenSees through an equal degrees of freedom command. The Equal Degrees Of Freedoms (EDOF) on each floor are illustrated in Figure 4.4 for the Four Bay OpenSees Model and in Figure 4.5 for the Two Bay OpenSees Model. The glulam beam and column elements were modeled as elastic beam column elements. Their cross sectional area, moment of inertia and modulus of elasticity were provided. Table 3.1 illustrates the beam and column element's sizes and material properties. All beam elements were pin to pin connected to rigid stub elements. All column to column connections were moment connections. Rigid stub elements were used to offset the connection of beam elements from the center of the column elements. Rigid stub elements were moment connected to column elements and pin connected to beam elements. They were modeled as elastic beam column elements and provided elastic properties of steel and a large cross sectional area and moment of inertia making them quite rigid. The friction braces were modeled as two node link elements with a biaxial 
nonlinear material type. Each brace was provided an axial stiffness of $310 \mathrm{kN} / \mathrm{mm}$ and a slip force as illustrated in Table 3.1. The post slip stiffness was $0 \mathrm{kN} / \mathrm{mm}$. All braces were pin to pin connected. The base of the structure was pin connected. A leaning column was utilized in both models to account for mass and gravity loads within the tributary area of the SFRS that were not directly assigned to nodes within the SFRS nodes. The lean column elements were modeled as beam column elements and were assigned area and moment of inertia based on the summation of these properties of columns within the SFRS not already modeled. The leaning column elements were assigned the same modulus of elasticity as the beam and column elements. The geometric and stiffness properties of the lean column are illustrated in Appendix B.1 beginning on page 207.

The mass of the structure that was directly on the SFRS was assigned to nodes within the SFRS. All other masses within the tributary area of the SFRS were assigned to the leaning column in the model. The tributary area of the SFRS is the same for both the Four Bay OpenSees Model and the Two Bay OpenSees Model. Mass was assigned in both the vertical and horizontal axes of the models. The mass distribution on each node in the model is illustrated in Appendix B.1 beginning on page 207. The mass in the model is used by the program to calculate inertial forces. The weights assigned to the model nodes are completely separate.

All weights consisting of dead loads and a portion of snow loads are applied to the SFRS and leaning column's nodes. The portion of weight that is transferring down the SFRS to the ground is assigned to nodes within the SFRS; all other weights are assigned to the leaning column nodes.

The Two Bay OpenSees Model illustrated in Figure 4.5 does not contain the elements highlighted in gray. These elements are all pin connected elements and do not provide any lateral resistance to the system. Removal of these elements yielded the same results as maintaining them in the model. Figure 4.6 illustrates the roof displacement history of the Two Bay OpenSees Model and the Four Bay OpenSees Model. Earthquake record ATC-18A, Cape Mendocino 1992 scaled by a factor of 1.18 was used in the analysis. Both analyses were performed with the same time step of 0.005 seconds and with the same analysis parameters. In both models, $3 \%$ initial stiffness Rayleigh damping is assumed in modes 1 and 6, as a conservative assumption for a wood structure (Welch et al., 2014). It can be seen that the response is nearly identical. The Two Bay OpenSees 
Model is used to perform the analytical IDA and is used as part of the experimental hybrid tests.

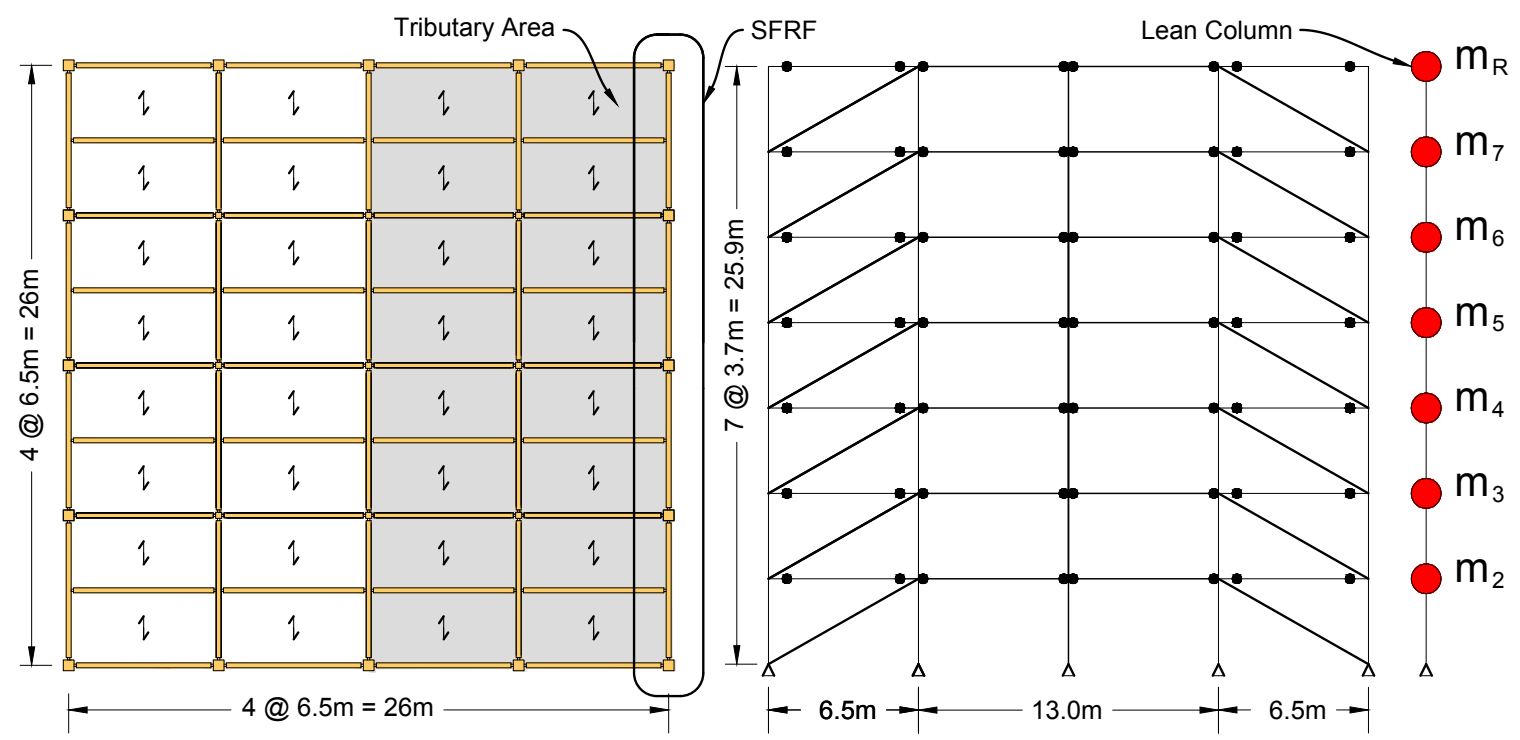

Figure 4.2: Four Bay OpenSees Model

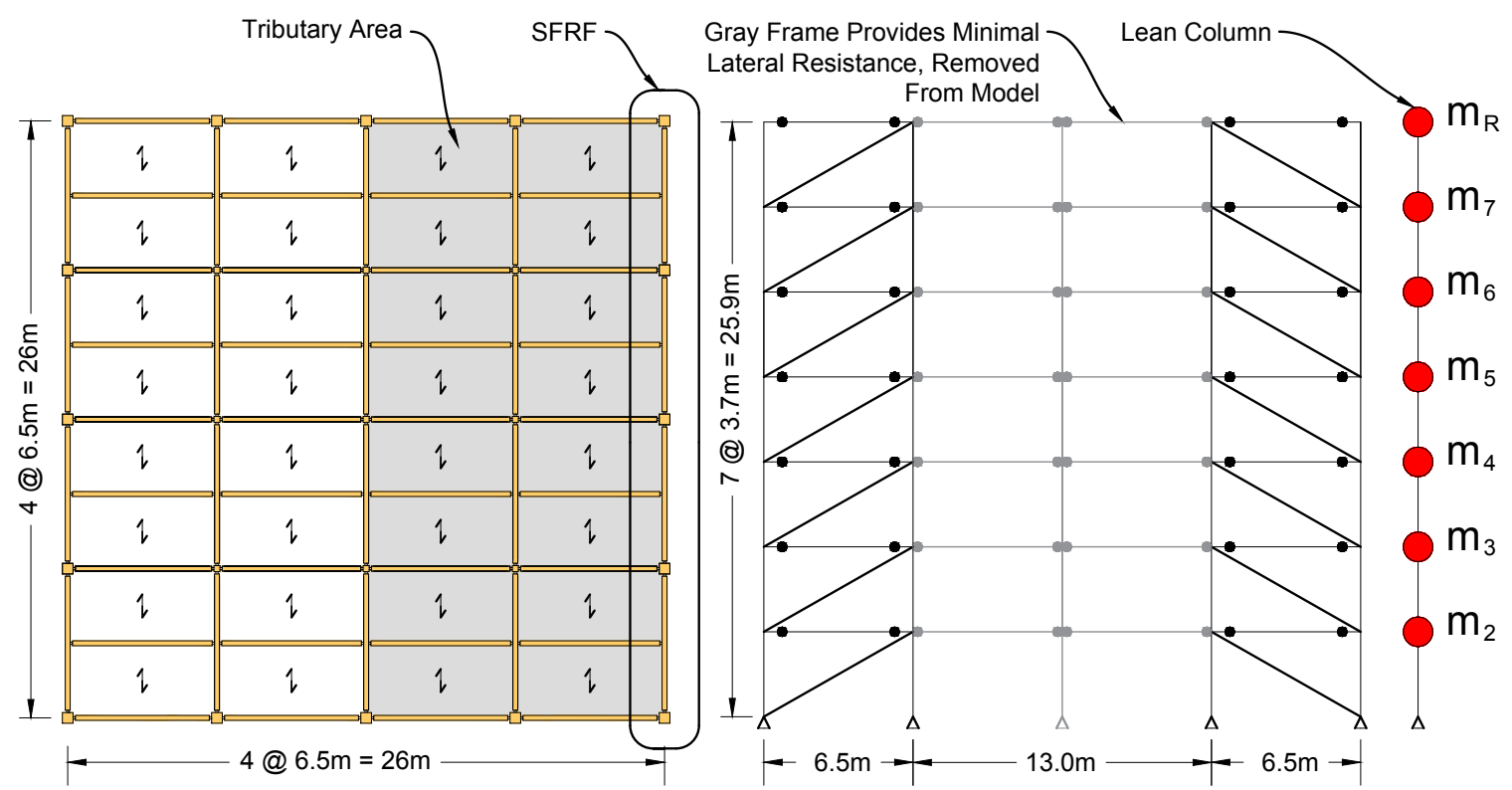

Figure 4.3: Two Bay OpenSees Model 


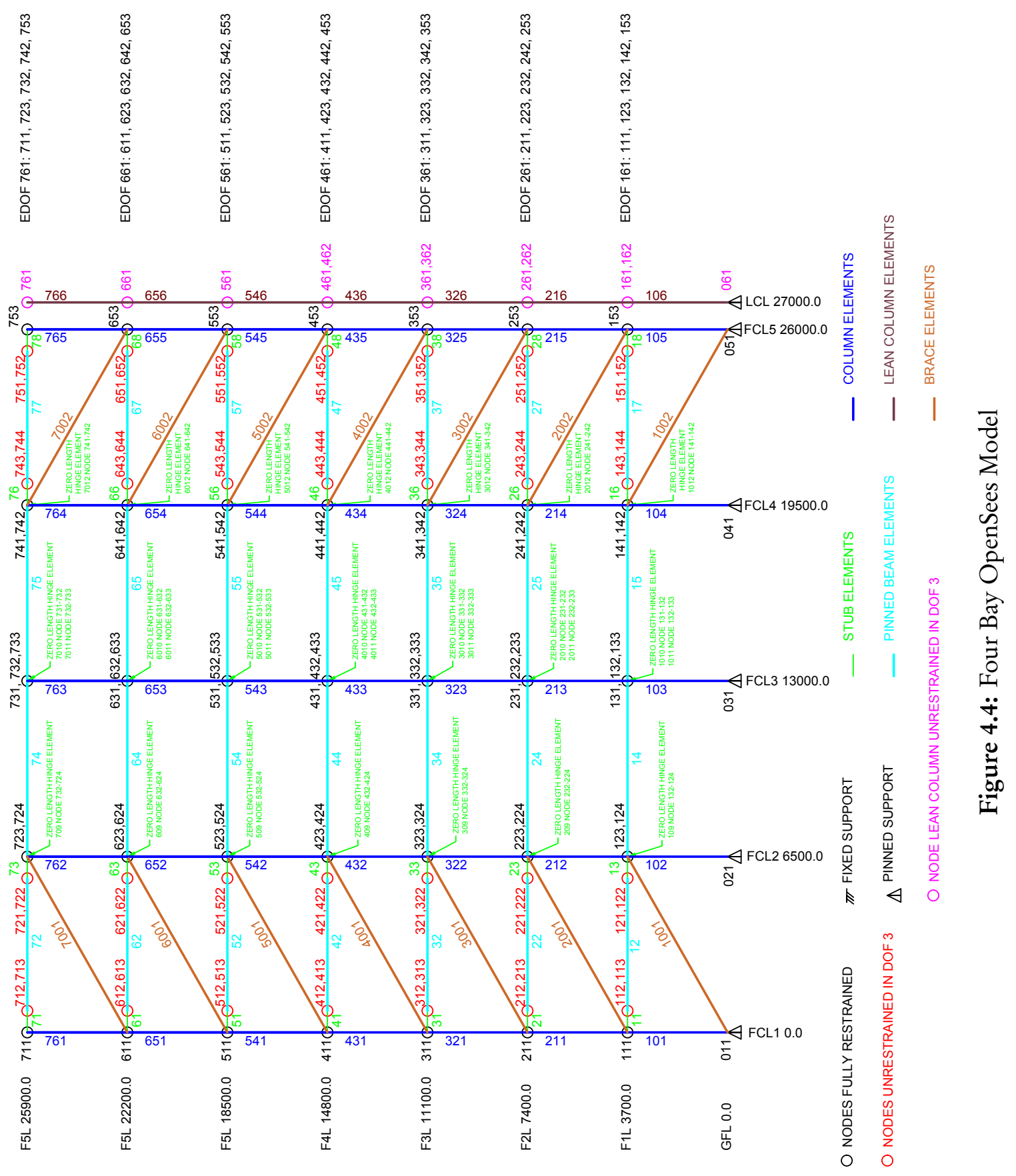




\begin{tabular}{|c|c|c|c|c|c|}
\hline 品 & ஜ: & 怘 & 艿 & 䩆 & 怘 \\
\hline 疋 & ปี & 胥 & $\mathscr{f}$ & f్f & ป̃ \\
\hline న్ల & జ్ & 尺్̃ & 设 & 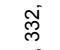 & N్ల్ \\
\hline$\underset{N}{\text { N }}$ & ్ָర & ్ָర్లే & ๙ુ๊ & ల్లో & స్ల \\
\hline & 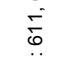 & 它 & 字 & हं & $\stackrel{i}{i}$ \\
\hline & $\ddot{\bar{ष}}$ & $\ddot{\overline{0}}$ & $\ddot{\bar{g}}$ & $\ddot{\ddot{0}}$ & $\ddot{\ddot{\circ}}$ \\
\hline оे & 㫕 & 㟧 & 范 & 蒿 & 蒿 \\
\hline
\end{tabular}
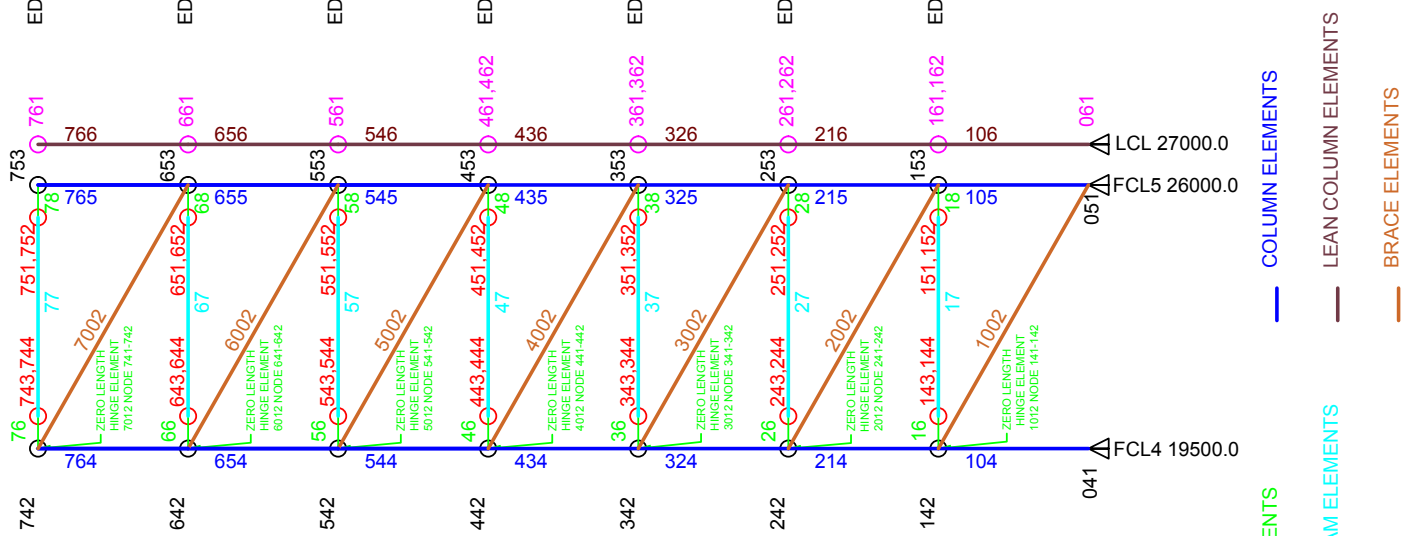

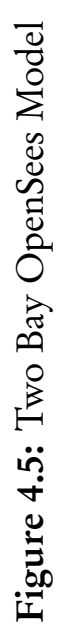
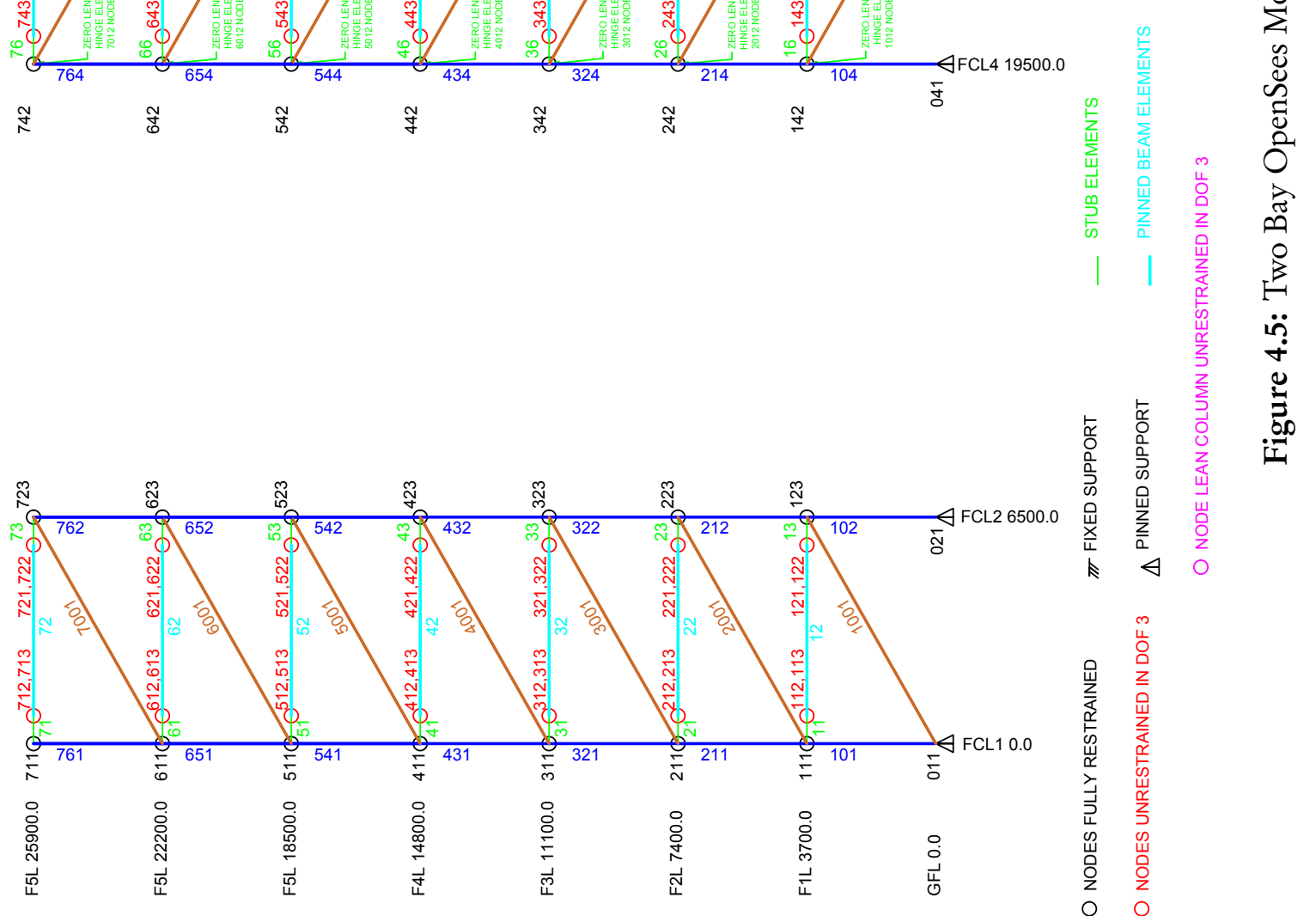


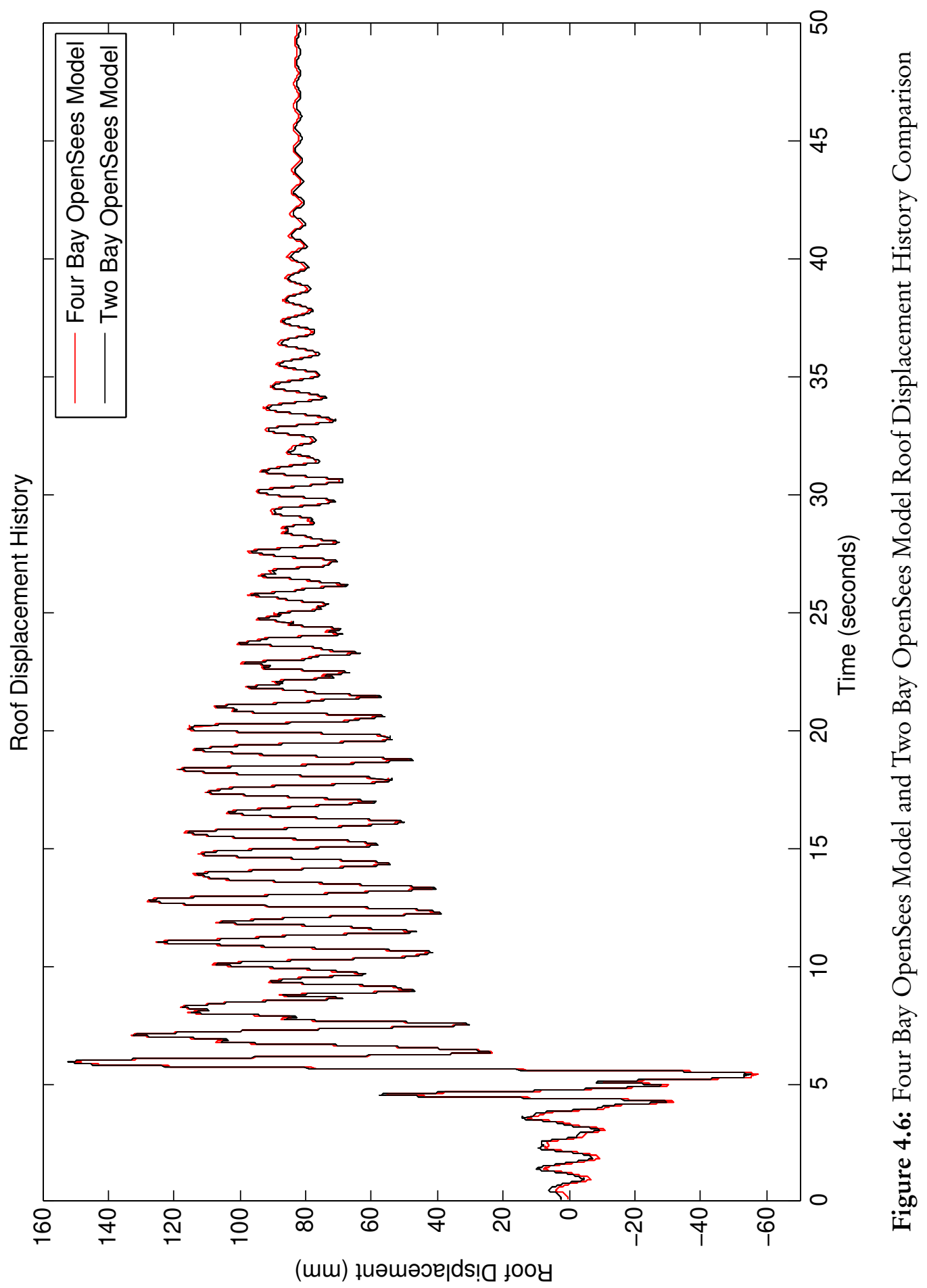




\subsubsection{Two Bay OpenSees Model Analysis Parameters}

The analytical IDA performed using the Two Bay OpenSees Model utilized Newmark integration with the two parameter time stepping method developed by Newmark with NewmarkGamma and NewmarkBeta equal to 0.5 and 0.25 , respectively. The time used was 0.005 seconds. A time step sensitivity analysis was performed to determine the largest time step that maintained accurate results. The timestep sensitivity analysis was performed using the 1994 Northridge earthquake record, scaled by 1.18. The results indicated that a time step equal to or smaller than 0.005 seconds generated very similar results. As the time step increased past 0.005 seconds, the response began to vary from the tight grouping, as illustrated Figure 4.7. The optimum time step of 0.005 seconds is presented in red. 

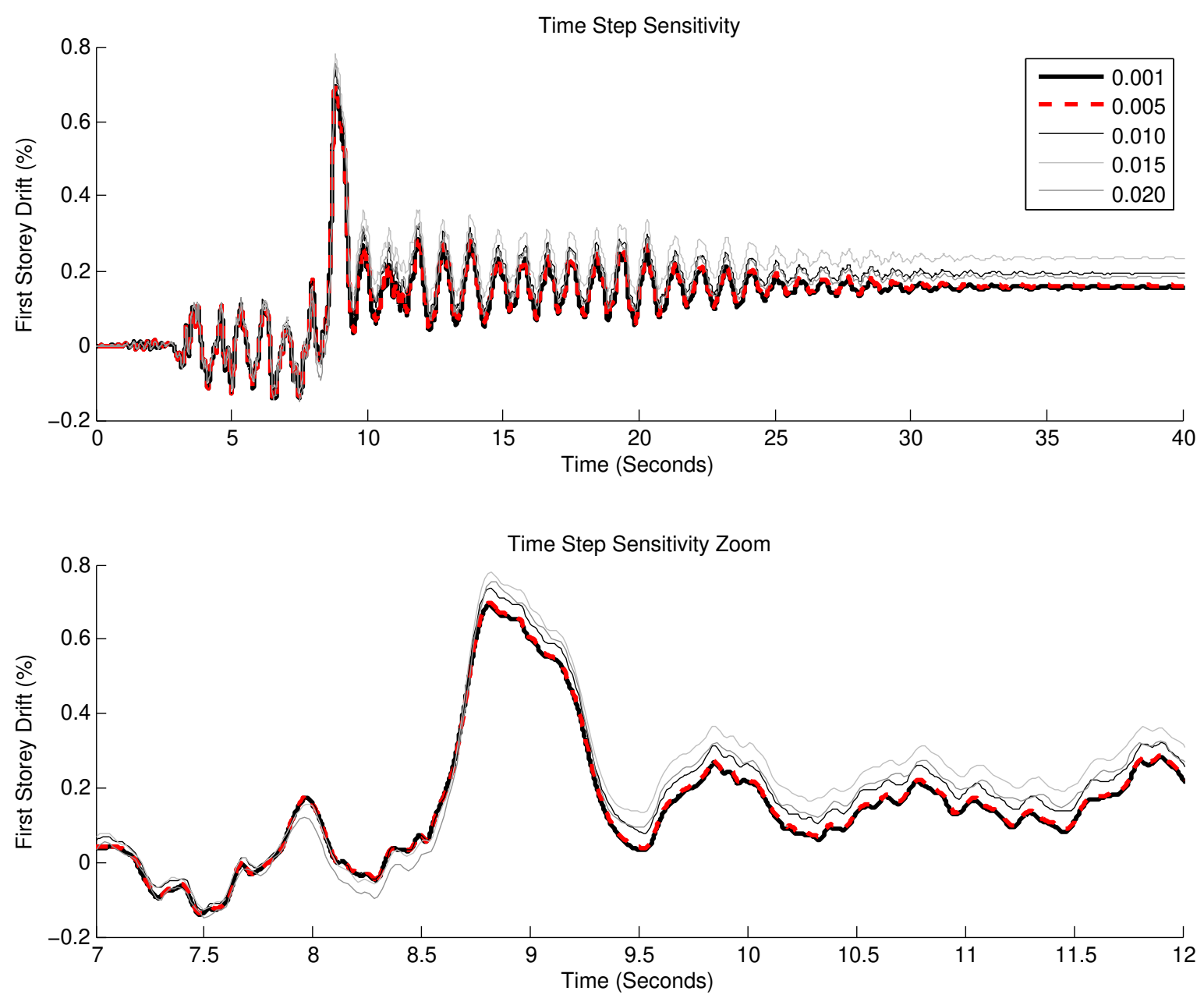

Figure 4.7: Sensitivity Analysis Time Step Substructured Model 2 Subjected to 1994

Northridge Earthquake Record Scale by 1.18

\subsection{Hybrid Model in OpenSees/OpenFresco}

A fully analytical Hybrid Model was developed based on the Two Bay OpenSees Model discussed above. This model was purely analytical; it analytically modeled the numerical and experimental substructures of the hybrid test. This model was developed to verify boundary conditions for the hybrid test and to verify that the model was behaving as expected prior to performing the experimental hybrid tests in the laboratory. The substructured components of the purely analytical Hybrid Model are illustrated in Figure 4.8. The experimental substructure 
is illustrated in green while the analytical substructure is illustrated in black. The experimental substructure in green was modeled at half scale in the model. This was done to ensure that proper scaling between the numerical and experimental substructures was performed prior to performing the experimental hybrid tests. The analytical Hybrid Model's experimental substructure defined in green consisted of a glulam beam, glulam column, friction brace and rigid stub element. The numerical substructure is the remainder of the frame illustrated in black.

The geometry of the Hybrid Model was the same as the Two Bay OpenSees Model discussed above except the brace, right half of the second storey beam, left column and rigid stub were separated from the structure and were analytically modeled as the experimental substructure. The boundary conditions linking the numerical and analytically modeled experimental substructures are illustrated in Figure 4.9. The analytically modeled experimental substructure was linked to the numerical substructure through a lateral degree of freedom. The lateral degree of freedom links the end of the beam element in the experimental substructure to the rigid diaphragm in the numerical substructure. The link between the numerical substructure and the experimental substructure is illustrated in Figure 4.9 with blue arrows.

The geometry and configuration of the existing prototype specimen designed by Gilbert (2016) did not permit laboratory testing of the vertical and rotational degrees of freedoms of the second storey joint. The second storey joint is illustrated in green in Figure 4.9. Since the vertical and rotational degrees of freedoms were linked between the experimental and numerical substructures, a second column was added to the model to maintain the curvature of the column and transfer gravity loading to the ground. This second column is illustrated in black to the right of the experimental column in Figure 4.9. Accounting for the rotational and vertical degrees of freedoms in the numerical substructure was conservative. This assumption was warranted as the column element in the experimental substructure would experience more tension forces than would be actually expected. Failure of the glued-in rod was more critical than compression of the column. The beam and rigid stub elements in the numerical substructure were maintained for the tests. The period of the Two Bay OpenSees Model and this Hybrid Model were the same. 


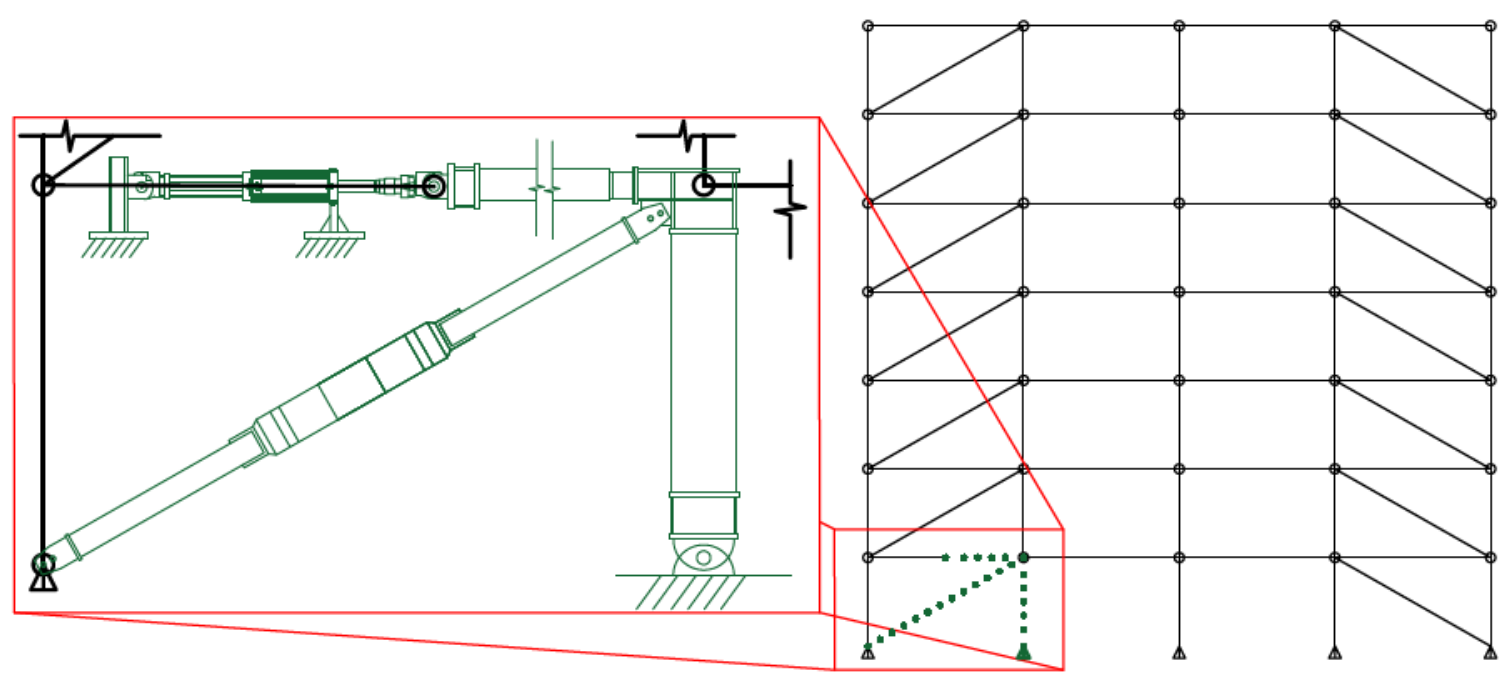

Figure 4.8: Experimental Substructure Green and Numerical Substructure Black

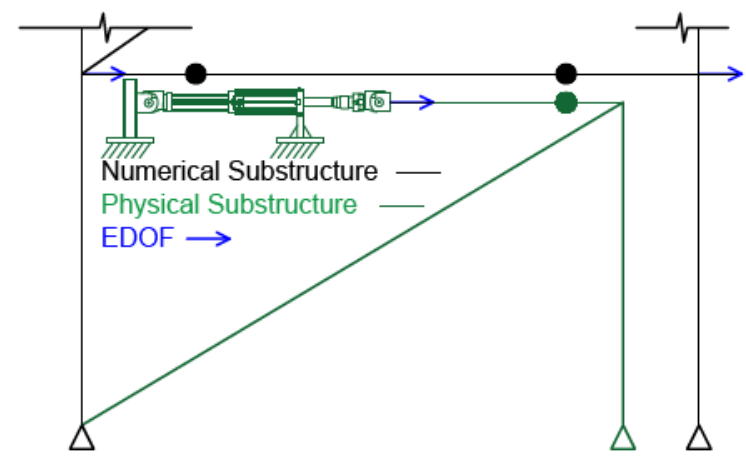

Figure 4.9: Substructured Equal Degrees of Freedom (EDOF) Between Numerical and Physical Substructure 


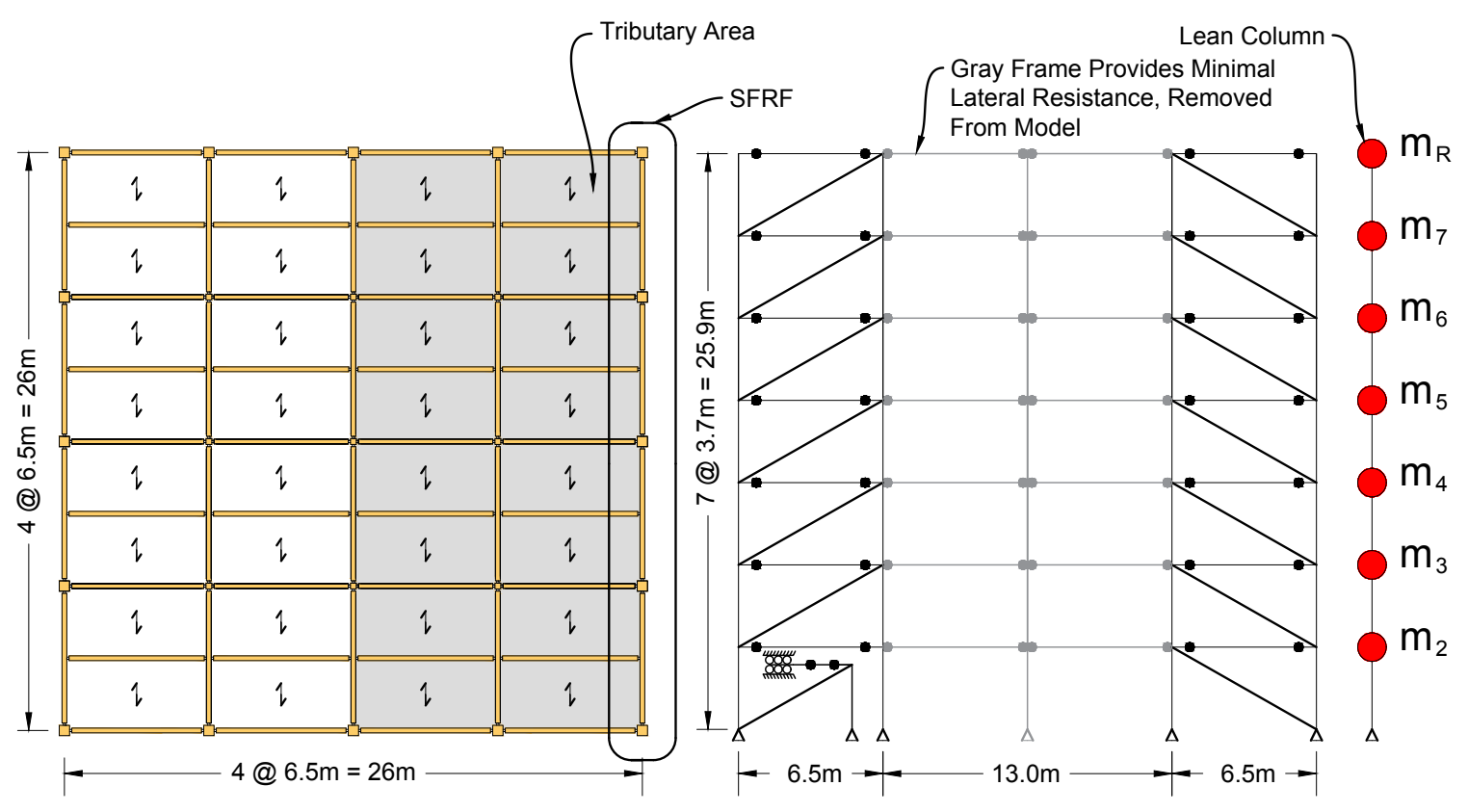

Figure 4.10: Hybrid Model of Two Bay OpenSees Model

The Hybrid Model analytically simulated the experimental substructure and the data acquisition systems in the laboratory through OpenFresco. The link between OpenSees, OpenFresco and the analytically modeled control and data acquisition systems in the laboratory is illustrated in Figure 4.11. The finite element software OpenSees contained the numerical substructure. The analytically modeled experimental substructure was modeled in OpenFresco through 4 main commands: an experimental element, an experimental site, an experimental setup and an experimental control. These four commands generated the analytically modeled experimental substructure. These commands also generated the link between the experimental substructure and the numerical substructure, the location where displacements were applied and forces were measured. The analytically modeled control and data acquisition systems in the laboratory were generated using the experimental control command in OpenFresco. This facilitated scaling between the numerical and experimental substructures. At each time step when the Hybrid Model was run, this command would scale down displacements into the analytically modeled experimental substructure in OpenFresco and scale up the measured resisting force on the return. 


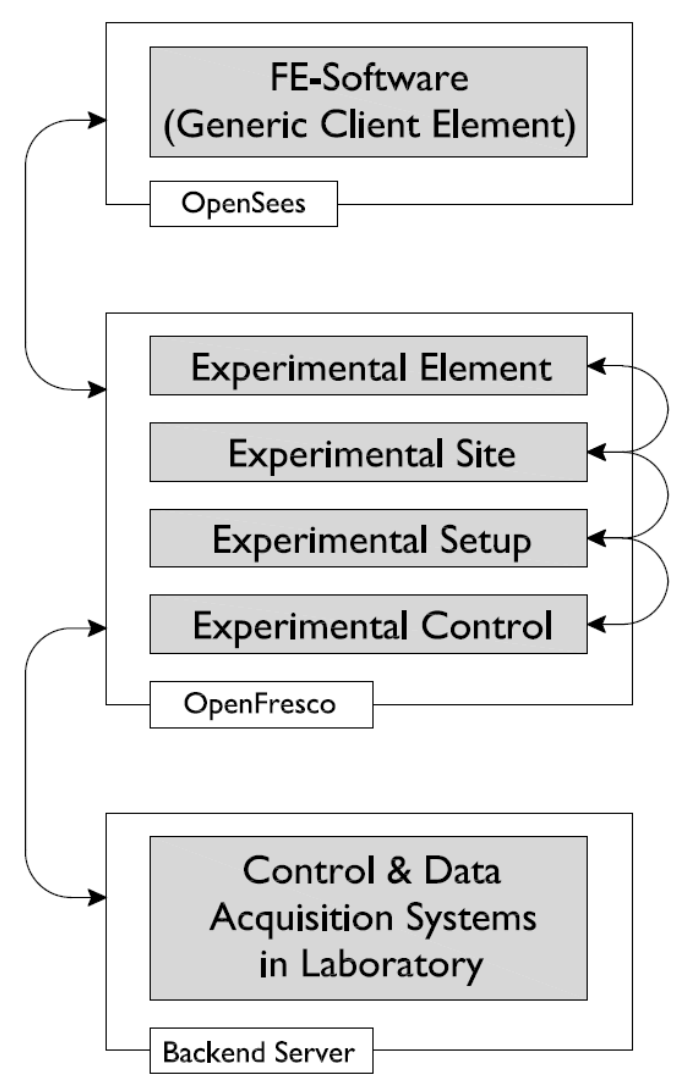

Figure 4.11: Communication Link between OpenSees, OpenFresco and Data and Control in Laboratory for Local Hybrid Test (Woods, 2016)

The development of the analytically modeled experimental substructure developed in OpenFresco is discussed below. The experimental control command simulated the material and behaviour properties of the prototype specimen. In this model, the prototype specimen was modeled as a single biaxial element. The element is illustrated in Figure 4.12. Its stiffness matrix is illustrated in Equation 4.1. 


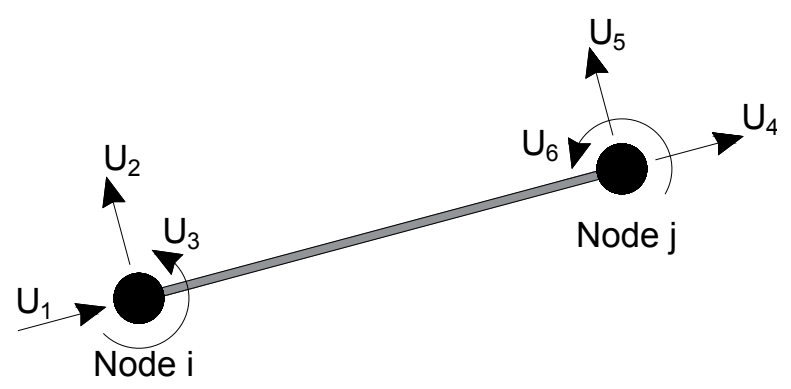

Figure 4.12: Degrees of Freedoms in Standard 2D Beam Column Element

$$
\left[\begin{array}{l}
f_{1} \\
V_{1} \\
M_{1} \\
f_{2} \\
V_{2} \\
M_{2}
\end{array}\right]=\left[\begin{array}{cccccc}
\frac{E A}{L} & 0 & 0 & \frac{-E A}{L} & 0 & 0 \\
0 & \frac{12 E I}{L^{3}} & \frac{6 E I}{L^{2}} & 0 & \frac{-12 E I}{L^{3}} & \frac{6 E I}{L^{2}} \\
0 & \frac{6 E I}{L^{2}} & \frac{4 E I}{L} & 0 & \frac{-6 E I}{L^{2}} & \frac{2 E I}{L} \\
\frac{-E A}{L} & 0 & 0 & \frac{E A}{L} & 0 & 0 \\
0 & \frac{-12 E I}{L^{3}} & \frac{-6 E I}{L^{2}} & 0 & \frac{12 E I}{L^{3}} & \frac{-6 E I}{L^{2}} \\
0 & \frac{6 E I}{L^{2}} & \frac{2 E I}{L} & 0 & \frac{-6 E I}{L^{2}} & \frac{4 E I}{L}
\end{array}\right]\left[\begin{array}{l}
u_{1} \\
v_{1} \\
\theta_{1} \\
u_{2} \\
v_{2} \\
\theta_{2}
\end{array}\right]
$$

The stiffness and force displacement behaviour of this single element matched that of the 4 elements it represented. The experimental setup was controlled by the previously defined control object; this simulated the actuator. The direction the actuator applied displacements onto the element as defined above is specified; for this test the direction is in the $U_{1}$ direction as illustrated in Figure 4.13. 


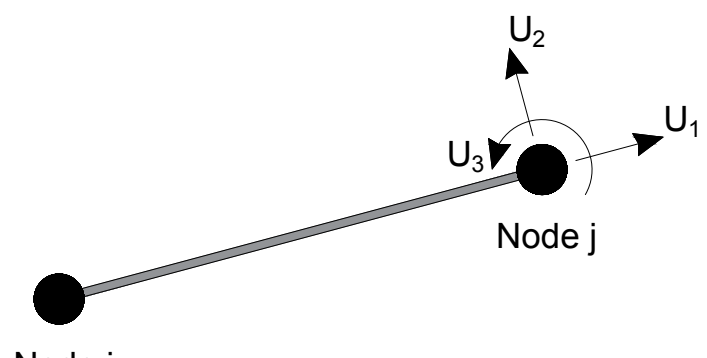

Node i

Figure 4.13: Experimental Degrees of Freedom Beam Column Element

The experimental site is local in this model and only relays the information from the experimental setup to the experimental element. The experimental site command is used in actual hybrid tests that contain multiple experimental substructures located in different laboratories. The command links multiple experimental sites to the numerical substructure. The experimental element command was used to simulate the prototype specimen in the laboratory. Within this command, the information regarding experimental control is received from the experimental site, as well as, the geometric transformation of the element, in this case PDelta effects. The initial stiffness of the prototype specimen was also provided in the experimental element command. This was required during the first time step of the hybrid simulation. The analysis utilized the initial stiffness since the tangent stiffness could not be practically determined during testing.

\subsubsection{Hybrid Model Verification}

A series of earthquake records were chosen to compare the Hybrid Model illustrated in Figure 4.10 to the Two Bay OpenSees Model illustrated in Figure 4.3. This was performed to verify that the boundary conditions utilized to link the numerical and experimental substructures in the Hybrid Model produced similar results to the Two Bay OpenSees Model. Both models were run with the same analysis parameters: a time step of 0.002 seconds, convergence tolerance of 0.001 and a maximum number of iterations for convergence of 2000 . The results from the simulations were very similar. Figure 4.14 illustrates the structural response of the Hybrid Model 
and the Two Bay OpenSees Model subjected to the 1994 Northridge earthquake record scaled by 1.18 .
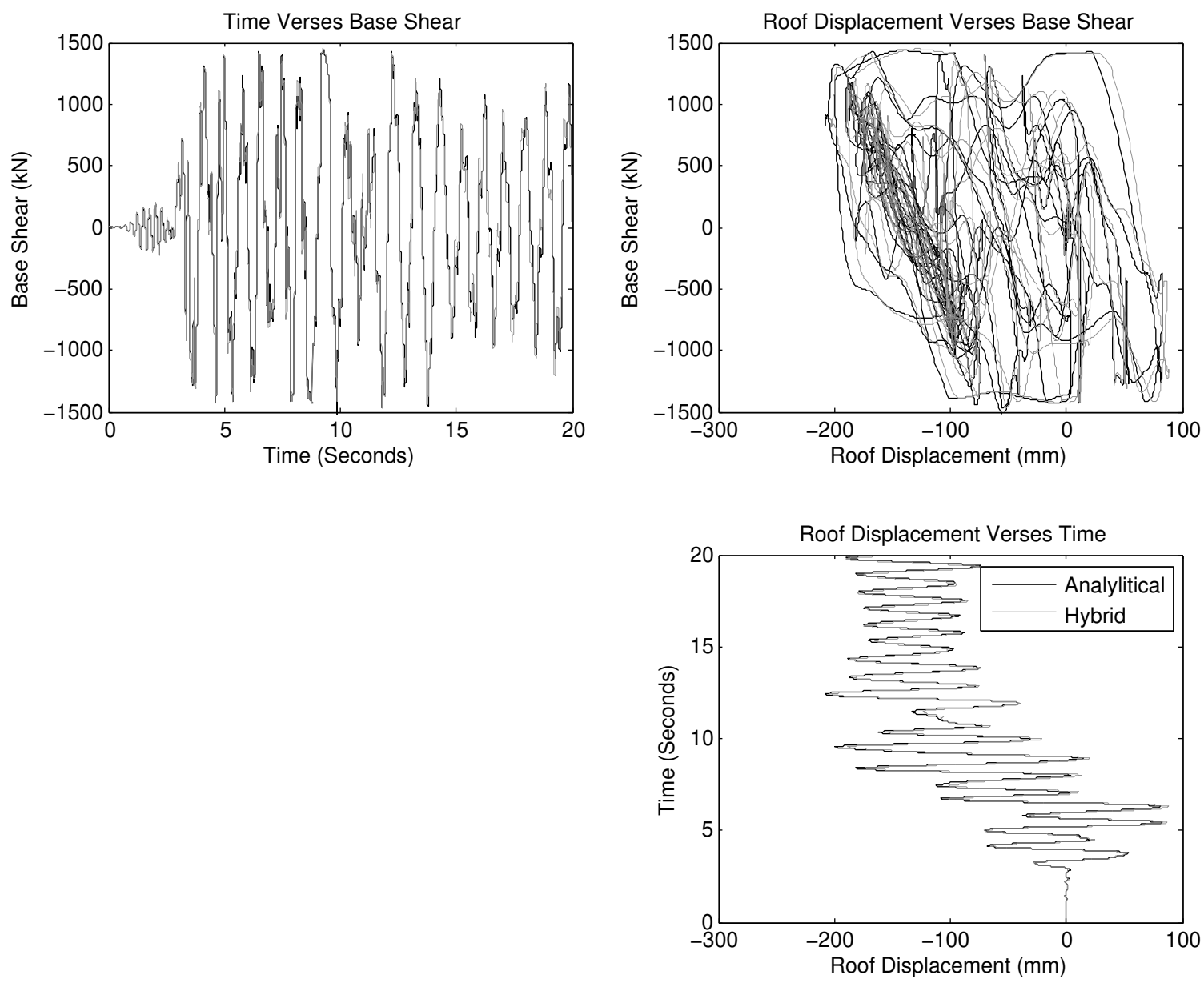

Figure 4.14: Response of Hybrid Model and OpenSees Model

The response of the Two Bay OpenSees Model and Hybrid Model are comparable. It can be seen that the base shear verses time response and roof displacement verses time response of the two models only deviated slightly at the extreme ends by a couple of $\mathrm{mm}$ or $\mathrm{kN}$. This is more visible in the roof displacement verses base shear response plot. The difference in response is due to the vertical disconnect between the physical substructure and the numerical substructure. In the Hybrid Model, during the initial stage when the gravity loads were applied, the experimental substructure's brace did not resist any gravity loading since there was a disconnect. As a result, 
there was a small axial force in the right side storey brace in the numerical substructure and no force in the brace in the experimental substructure. This resulted in a small initial base shear force that is not present in the Two Bay OpenSees Model. This slight difference in the system is what caused variability in the response between the two models. It should be noted that the model execution times are comparable. The actual hybrid test in the laboratory utilized the same boundary conditions in the experimental substructure and links between the numerical and experimental degrees of freedoms. The actual hybrid test is discussed in Chapter 6.

\subsection{Earthquake Record Scaling}

In this study, an incremental dynamic analysis was performed analytically using the Two Bay OpenSees Model discussed above and an IDA was performed experimentally in the laboratory through hybrid testing. The structure's performance at the Design Basis Earthquake (DBE) and at the Maximum Considered Earthquake (MCE) hazard levels was determined using the IDA results.

Modern performance based seismic design codes for buildings are typically measured against three seismic hazard levels: Frequent Earthquake (FE), Design Basis Earthquake (DBE) and Maximum Considered Earthquake (MCE) hazard levels. A structure's performance under these seismic hazard levels is used to evaluate if the structure meets specified performance requirements such as drifts and accelerations. A FE seismic hazard level has a 100 year return period or probability of $50 \%$ exceedance in 50 years. A DBE seismic hazard level has a 475 year return period or probability of $10 \%$ exceedance in 50 years. A MCE seismic hazard level has a 2475 year return period or probability of $2 \%$ exceedance in 50 years.

The first part of this study used a suite of far field earthquake records to evaluate the prototype structure's performance at the DBE and MCE hazard levels. The suite of far field records consisted of 22 individual records; each record contained 2 independent horizontal direction ground motion records. In this study "A" records correspond to component 1 horizontal ground motions and "B" records correspond to component 2 horizontal ground motions. For example, ATC-02A is the 1994 Northridge record component 1 horizontal ground motion. ATC-02B is the 
1994 Northridge record component 2 horizontal ground motion. This convention is the same for all records. Table 4.1 illustrates the suite of 22 records. These records were previously velocity normalized to the mean peak ground velocity of the 44 records (Applied Technology Council, 2009). The median spectra response and the 44 individual components of the normalized far field earthquake records are illustrated in Figure 4.15.

Using the previously normalized records allowed all records to be scaled by the same scale factors as opposed to scaling each record individually to evaluate building performance. The response spectra of the 44 far field earthquake records normalized is illustrated in Figure 4.16. The normalized records are scaled to the MCE hazard level by multiplying each record by the scale factor $S F$ illustrated in Equation 4.2, based on FEMA P695 2009 methodology (Applied Technology Council, 2009).

$$
\begin{aligned}
S F & =\frac{S_{M T}}{S_{N R T}} \\
& =\frac{0.45}{0.38} \\
& =1.18
\end{aligned}
$$

where $S_{M T}$ is the maximum credible spectral response acceleration at the fundamental period of the structure from the National Building Code of Canada for Victoria, British Columbia (National Research Council of Canada, 2010). $S_{N R T}$ is the median value of the normalized record set spectral response acceleration at the building's fundamental period (Applied Technology Council, 2009). $S_{M T}$ and $S_{N R T}$ were both determined considering the structures fundamental period of 0.917 seconds. This resulted in $S_{M T}$ and $S_{N R T}$ equaling 0.45 and 0.38 , respectively. This produced a scaling factor $S F$ of 1.18 at the maximum credible return period. The scale factor for the design basis earthquake is approximately $2 / 3$ of the maximum credible hazard scale factor, resulting in a factor of 0.79. Equation 4.2 from FEMA-P695 is from the American code not the Canadian code, but $S_{M T}$ and $S_{N R T}$ have the same parameters in both the National Building code of Canada (National Research Council, 2011) and in FEMA-P695 (Applied Technology Council, 
Table 4.1: ATC Far Field Ground Motions (Applied Technology Council, 2009)

\begin{tabular}{|c|c|c|c|c|c|}
\hline Excitation ID & Year & Station & Fault Type & Magnitude & PGA Normalized (g) \\
\hline ATC-F01 & 1994 & Northridge & Thrust & 6.7 & 0.34 \\
\hline ATC-F02 & 1994 & Northridge & Thrust & 6.7 & 0.40 \\
\hline ATC-F03 & 1999 & Duzce, Turkey & Strike-Slip & 7.1 & 0.52 \\
\hline ATC-F04 & 1999 & Hector Mine & Strike-Slip & 7.1 & 0.37 \\
\hline ATC-F05 & 1979 & Imperial Valley & Strike-Slip & 6.5 & 0.46 \\
\hline ATC-F06 & 1979 & Imperial Valley & Strike-Slip & 6.5 & 0.39 \\
\hline ATC-F07 & 1995 & Kobe, Japan & Strike-Slip & 6.9 & 0.53 \\
\hline ATC-F08 & 1995 & Kobe, Japan & Strike-Slip & 6.9 & 0.26 \\
\hline ATC-F09 & 1999 & Kocaeli, Tukey & Strike-Slip & 7.5 & 0.25 \\
\hline ATC-F10 & 1999 & Kocaeli, Turkey & Strike-Slip & 7.5 & 0.30 \\
\hline ATC-F11 & 1992 & Landers & Strike-Slip & 7.3 & 0.24 \\
\hline ATC-F12 & 1992 & Landers & Strike-Slip & 7.3 & 0.48 \\
\hline ATC-F13 & 1989 & Loma Prieta & Strike-Slip & 6.9 & 0.58 \\
\hline ATC-F14 & 1989 & Loma Prieta & Strike-Slip & 6.9 & 0.49 \\
\hline ATC-F15 & 1990 & Manjil, Iran & Strike-Slip & 7.4 & 0.40 \\
\hline ATC-F16 & 1987 & Superstition Hills & Strike-Slip & 6.5 & 0.31 \\
\hline ATC-F17 & 1999 & Superstition Hills & Strike-Slip & 6.5 & 0.53 \\
\hline ATC-F18 & 1992 & Cape Mendocino & Thrust & 7.0 & 0.45 \\
\hline ATC-F19 & 1999 & Chi-Chi, Taiwan & Thrust & 7.6 & 0.18 \\
\hline ATC-F20 & 1994 & Chi-Chi, Taiwan & Thrust & 7.6 & 0.49 \\
\hline ATC-F21 & 1971 & San Fernando & Thrust & 6.6 & 0.44 \\
\hline ATC-F22 & 1976 & Friuli, Italy & Thrust & 6.5 & 0.50 \\
\hline
\end{tabular}


2009).

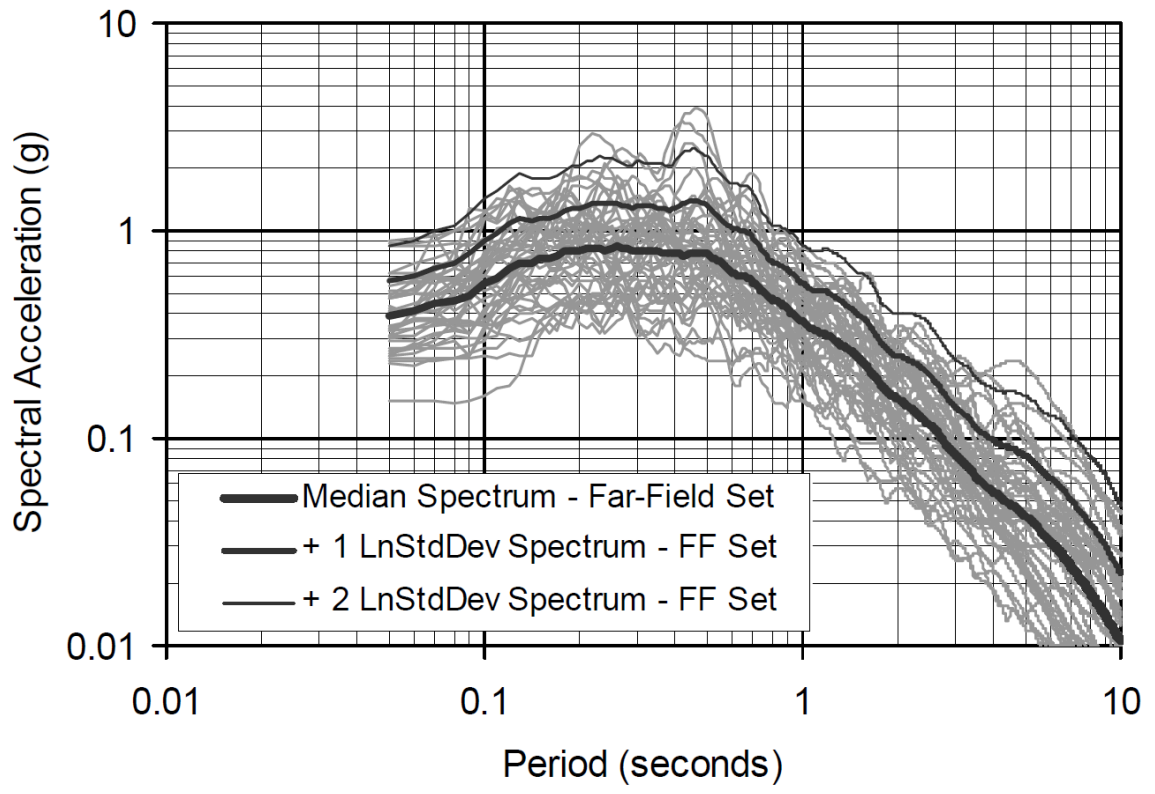

Figure 4.15: Individual and Median Response Spectra of Normalized Far Field Record Set (Applied Technology Council, 2009)

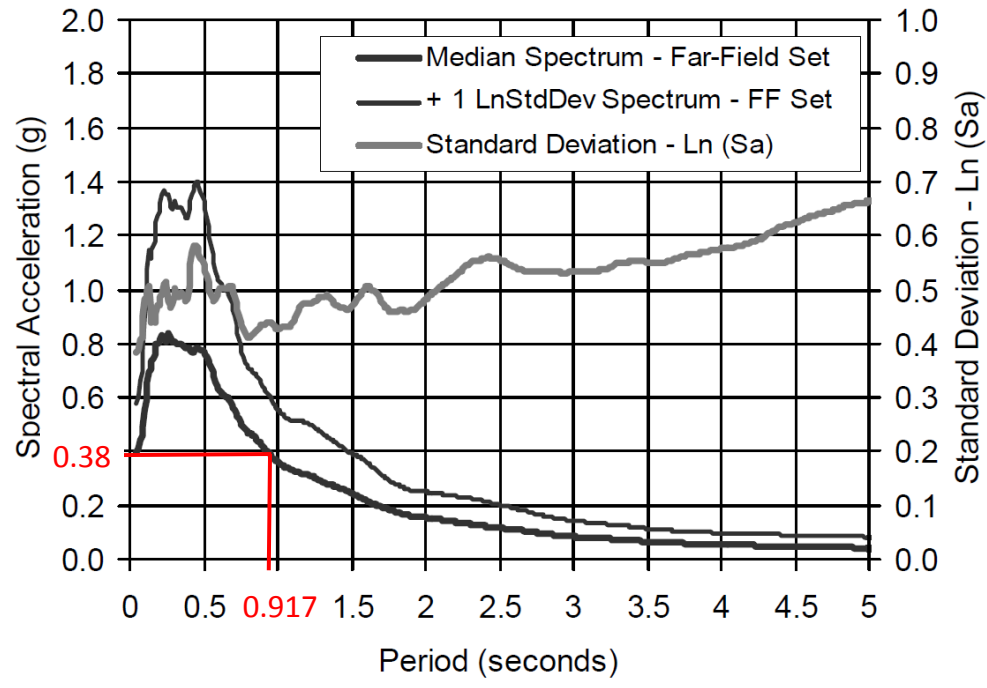

Figure 4.16: Response Spectra of Normalized Far Field Record Set (Applied Technology Council, 2009) 
The scaled response of all 44 earthquake records to MCE and DBE hazard levels for Victoria is illustrated in Figures 4.17 and 4.18. It can be seen that there is a lot of variability in spectral acceleration from individual record to individual record over the target period of 0.917 seconds. As a result, the response of the prototype structure varies from record to record depending on what frequency content is exciting the structure at any specific time.

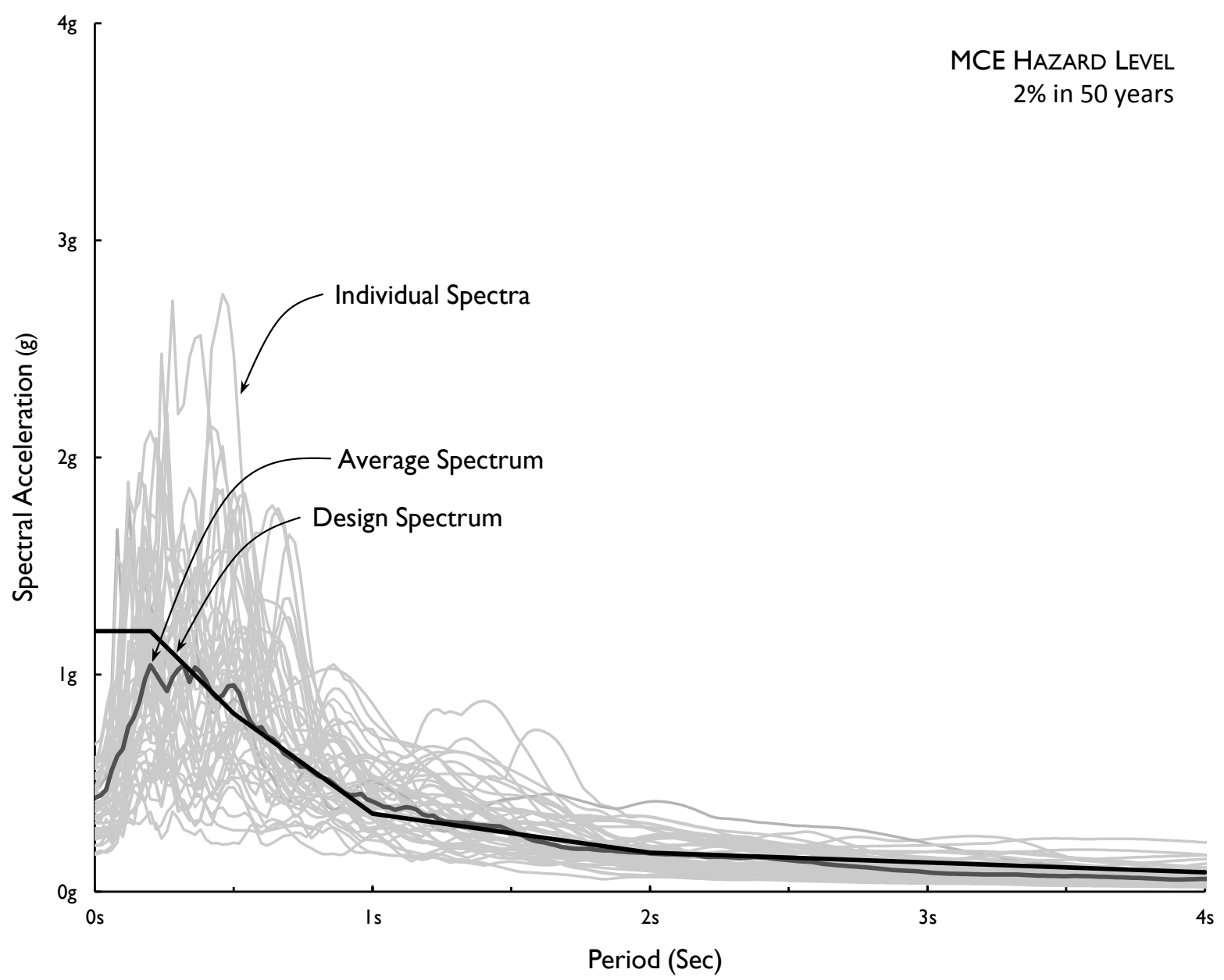

Figure 4.17: Suite of 44 Records Scaled to MCE Hazard Level 


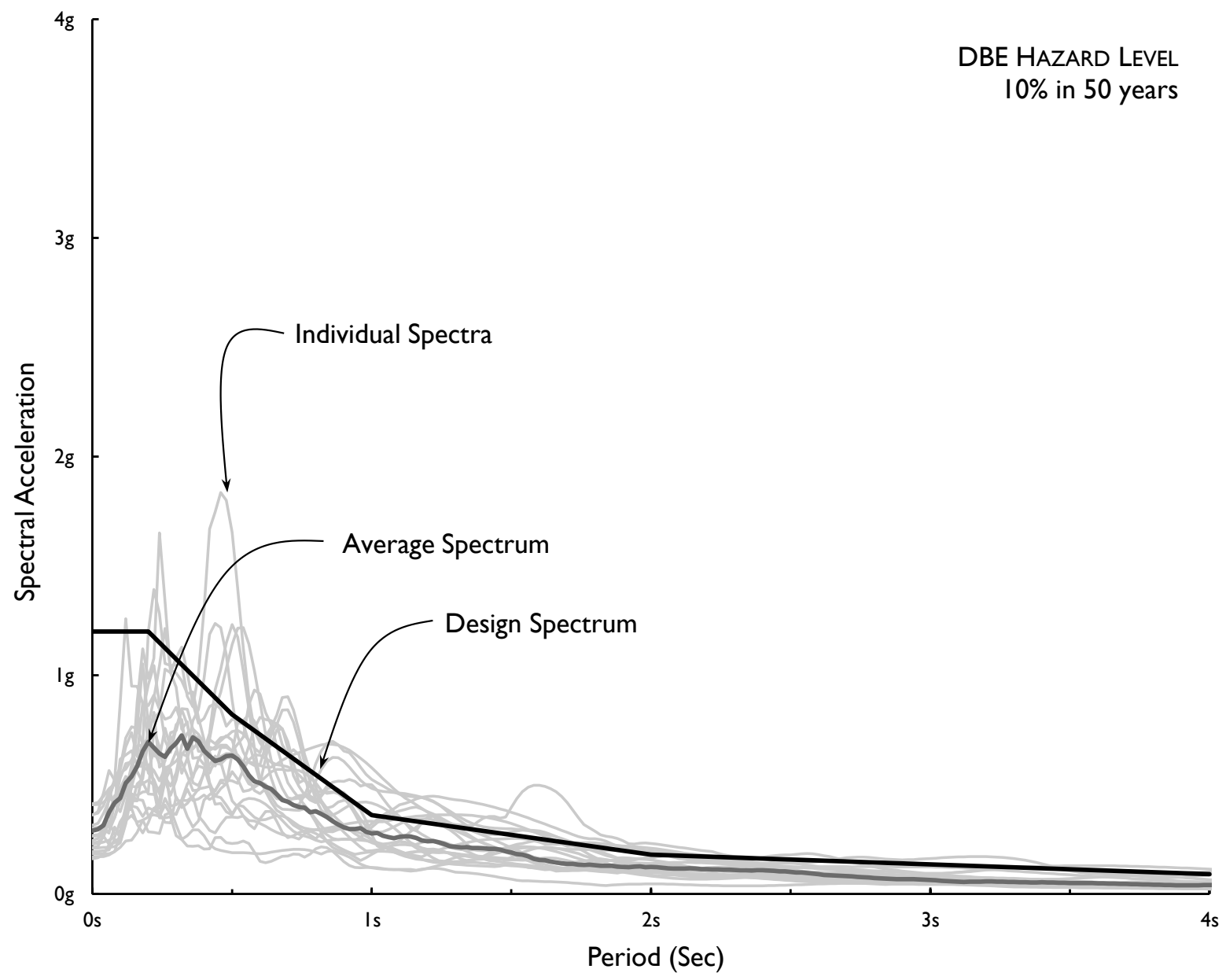

Figure 4.18: Suite of 44 Records Scaled to DBE Hazard Level

The analytical IDA utilized the suite of 44 earthquake records discussed above. The entire suite of records was scaled 295 times and applied to the Two Bay OpenSees Model. The scaling factors ranged between 0.025 and 7.40. The scaling factors increased by 0.025 with each subsequent analysis beginning at a scaling factor of 0.025 . The results of the analytical IDA performed using the Two Bay OpenSees Model were required prior to selecting the ground motions and scale factors for the experimental IDA through hybrid testing. The analytical IDA results using the Two Bay OpenSees Model are illustrated in Chapter 6. The selection of the 11 earthquake records and each record's 15 unique scale factors used in the experimental IDA through hybrid testing is discussed in Chapter 6. The scaling method utilized to complete the analytical IDA was a brute 
force approach. This approach was selected since the behaviour of friction braced structures often exhibit significant weaving behaviour. The analytical IDA analysis was performed with a fine mesh of data points to capture as much of the weaving behaviour as possible. Using the results of the analytical IDA, scale factors for each of the 11 records selected for the experimental IDA through hybrid testing were determined. 


\section{Chapter 5: Numerical Modeling Results and Discussion}

\subsection{Summary}

This chapter summarizes the analytical incremental dynamic analysis of the Two Bay OpenSees Model and the model's performance at maximum interstorey drifts and maximum interstorey residual drifts. IDA curve failure parameters are discussed within this chapter. The behaviour of the Two Bay OpenSees Model was evaluated against the ASCE 41-06 Standard (ASCE, 2007). The ASCE 41-06 Standard categorizes a structure's performance into one of three categories: collapse prevention, life safety or immediate occupancy (ASCE, 2007). Fragility curves are used to evaluate the probability of each performance level. Collapse Prevention performance level maximum interstorey drifts are $2 \%$ and above, transient and or permanent, resulting in interior spaces completely in shambles, with severe damage to sensitive equipment (ASCE, 2007). Life safety performance level drifts are expected to be between $0.5 \%$ and $2.0 \%$ transient and between $0.5 \%$ and $2.0 \%$ permanent; under these conditions, furniture will be toppled over and some damage is expected to sensitive equipment (ASCE, 2007). Immediate occupancy performance level drifts are expected to be $0.5 \%$ transient and permanent, leaving some furniture tipping (ASCE, 2007). The results from the Two Bay OpenSees Model IDA were used to develop fragility curves at various drift levels and were used to predict the structure's performance at the ASCE 41-06 Standard (ASCE, 2007). In addition, the structure's performance at a maximum interstorey drift of $2.5 \%$, which corresponds to the National Building code of Canada (National Research Council, 2011) drift limit, is presented. The results from the analytical IDA of the 
Two Bay OpenSees Model are compared with the experimental IDA performed through hybrid testing in Chapter 6.

\subsection{Incremental Dynamic Analysis}

The Two Bay OpenSees Model was subjected to all 44 earthquake records at increasing spectral accelerations ranging from $0.0 \mathrm{~g}$ to $5.0 \mathrm{~g}$. The maximum interstorey drift IDA response from all records is illustrated in Figure 5.4. The maximum interstorey residual drift IDA response is illustrated in Figure 5.5. Each line on the plots represents the prototype structure's interstorey drift response over a spectral acceleration range of $0 \mathrm{~g}$ to $5.0 \mathrm{~g}$. Each response line consists of 295 maximum interstorey drift points corresponding to 295 record scale factors. Each of these scale factors was converted to a spectral acceleration value based on the record's spectral acceleration at the structure's fundamental period. All response points are connected linearly. In both plots, the response lines increase as spectral acceleration increases. Some response lines contain horizontal lines, this indicates assumed collapse of the structure. Results after collapse are not shown. The parameters set to determine collapse of the structure are discussed in the following subsection. Maximum interstorey drifts were plotted up to $5 \%$. The reason for this limit is discussed in the following subsection as well. The MCE and DBE hazard level spectral accelerations are indicated in each figure by a thick and thin dashed line, respectively. The intersection of the MCE and DBE hazard lines with the 44 individual response curves indicates the structure's performance at each specific hazard level.

\subsubsection{Analysis Parameters for Analytical Incremental Dynamic Analysis}

The failure parameters for the IDA curve results generated for maximum interstorey residual drift followed the same criteria as the IDA curve failure parameters for maximum interstorey drift. The collapse parameters for the analytical IDA were based on 3 parameters: a maximum interstorey drift exceedance of $5 \%$, a tangent stiffness loss of the response greater than $80 \%$ of the initial elastic tangent stiffness response, and model dynamic instability. However, for the maximum interstorey residual drift IDA, the response was terminated if the structure exceeded 
the $5 \%$ drift limit due to maximum interstorey drift even if the maximum interstorey residual drift did not exceed 5 percent.

A 5\% drift limit was set in this study since the prototype specimen's friction brace designed by Gilbert was detailed with slotted holes that permitted maximum interstorey drifts up to $5 \%$. This limit facilitated comparison of analytical and experimental IDA results. Behaviour of the system past the $5 \%$ drift limit was not modeled. Exceedance of the $5 \%$ drift limit in the laboratory would have resulted in the friction brace being fully elongated or compressed and no longer able to slide. At this point, the pretensioned bolts which clamped the faying surfaces together would have beared on the ends of the friction brace's slotted holes. Any additional seismic loads would begin to yield the friction brace's gusset plates and thus damage the setup.

Tangent stiffness failure occurred in 3 basic forms in this IDA. Figure 5.1 illustrates an example of each case from this study. The tangent slope limit in this study was set at $20 \%$ of the elastic initial slope at a spectral acceleration of 0.05 gravity. This limit was set since it is generally assumed that the accuracy of the model is limited once the tangent slope exceeds $20 \%$ (Vamvatsikos and Cornell, 2002). At this point collapse is assumed. Record ATC-F11A in Figure 5.1 illustrates a $20 \%$ tangent slope exceedance, collapse of the structure is depicted by the flat line portion in black. The final response curve for the record is also depicted by the black line. 


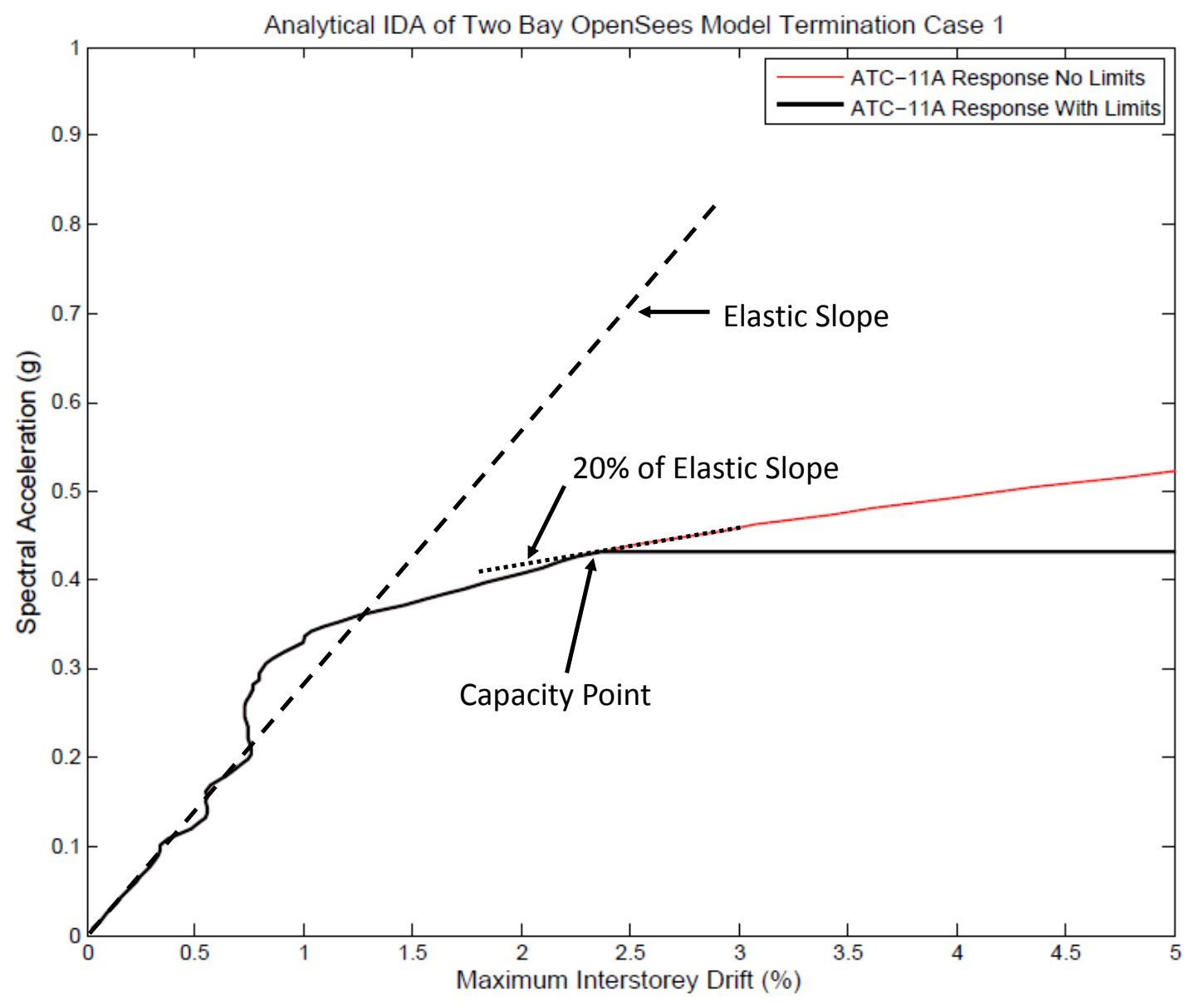

Figure 5.1: Incremental Dynamic Analysis Response Limits Case 1

Due to the behaviour of this system, some IDA curve responses reached the tangent slope limit over several points in a vertical plane at the same drift level. Record ATC-F05B in Figure 5.2 presents one such instance where the recorded tangent slope was less than $20 \%$ over multiple points. In such cases, it was conservative to assume failure of the structure at the lowest point as indicated by the horizontal line in black since any slight increase in drift could cause failure of the structure. 


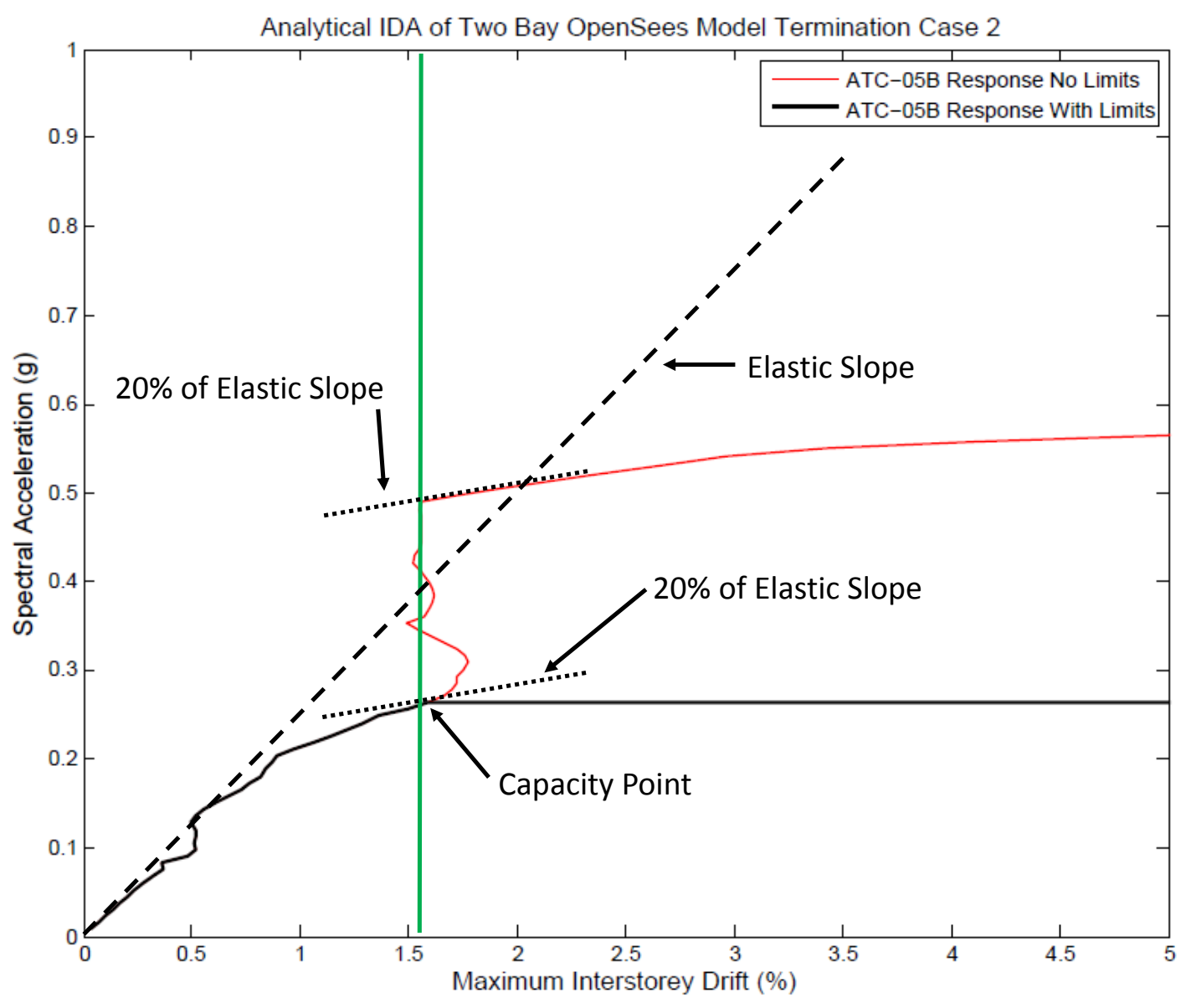

Figure 5.2: Incremental Dynamic Analysis Response Limits Case 2

In response locations with weaving patterns, the $20 \%$ tangent stiffness rule may not be valid for all weaving response locations if a general direction through the weave is followed. Figure 5.3 presents one such case. The tangent slope through the weave exceeded the initial stiffness in regions of negative slope but the general direction of the weave followed the initial elastic slope. In this study, most weaving responses were not present at the location of collapse. The response slope gradually decreased after the weaving response until the tangent slope exceeded the $20 \%$ limit. 


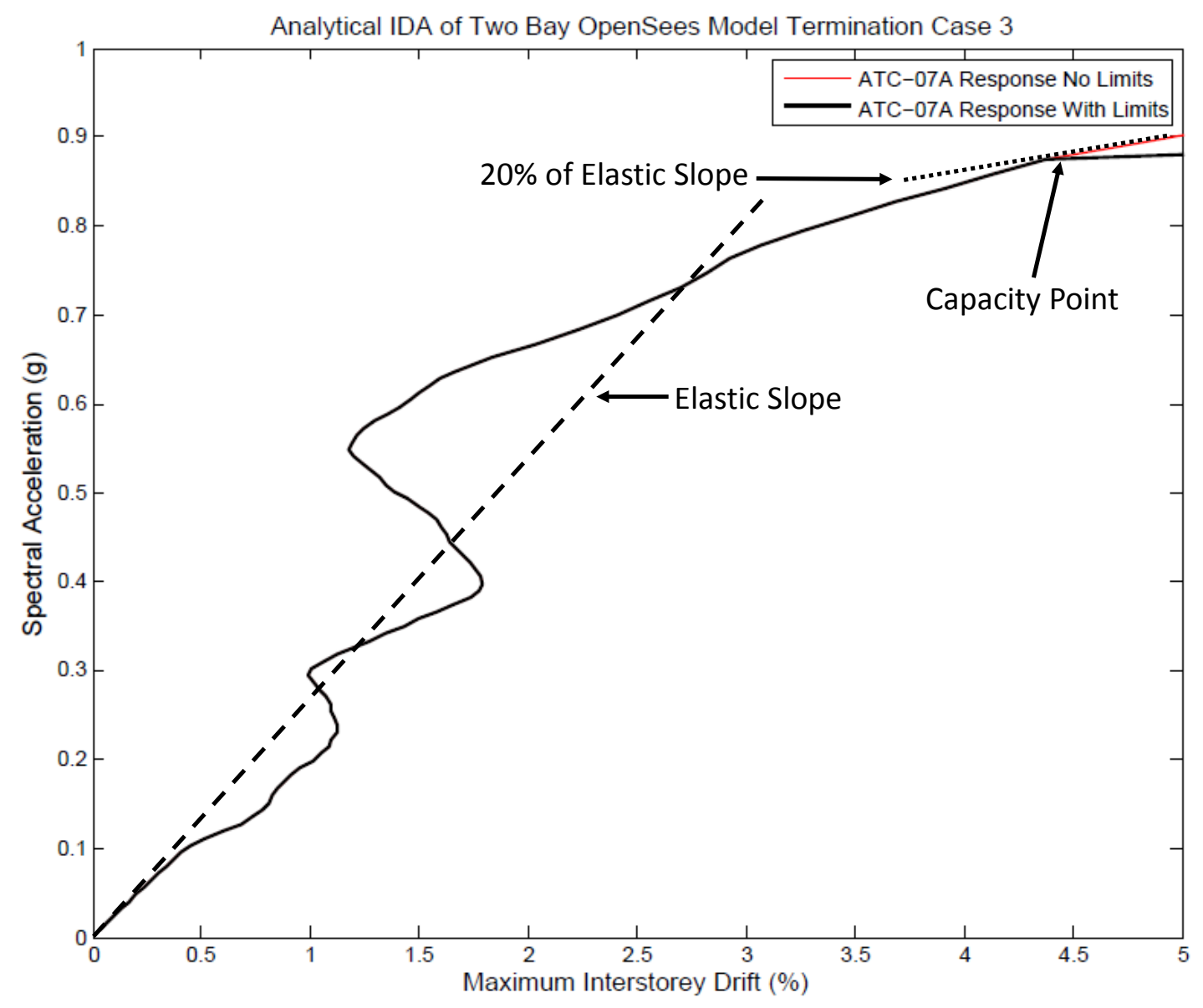

Figure 5.3: Incremental Dynamic Analysis Response Limits Case 3

Model dynamic instability did not occur in the IDA of the Two Bay OpenSees Model. If this had occurred, the response of the record in question would have been terminated with a horizontal line to indicate collapse of the structure.

The faliure parameters for each record are illustrated in Tables 5.1 and 5.2. Termination limits were set at $80 \%$ reduction in initial stiffness, maximum interstorey drift exceeding $5 \%$ and model dynamic instability. 


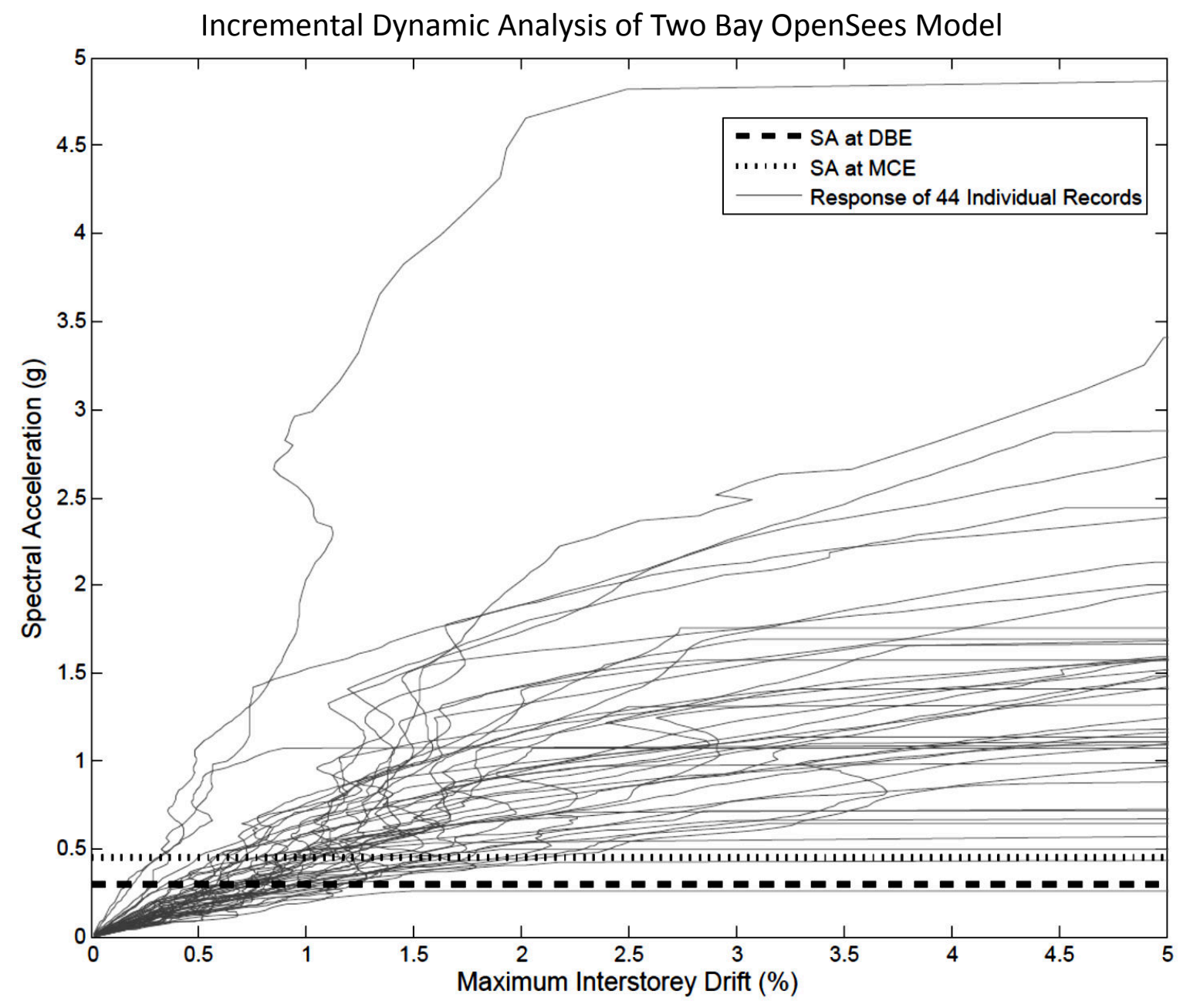

Figure 5.4: Incremental Dynamic Analysis of Two Bay OpenSees Model 


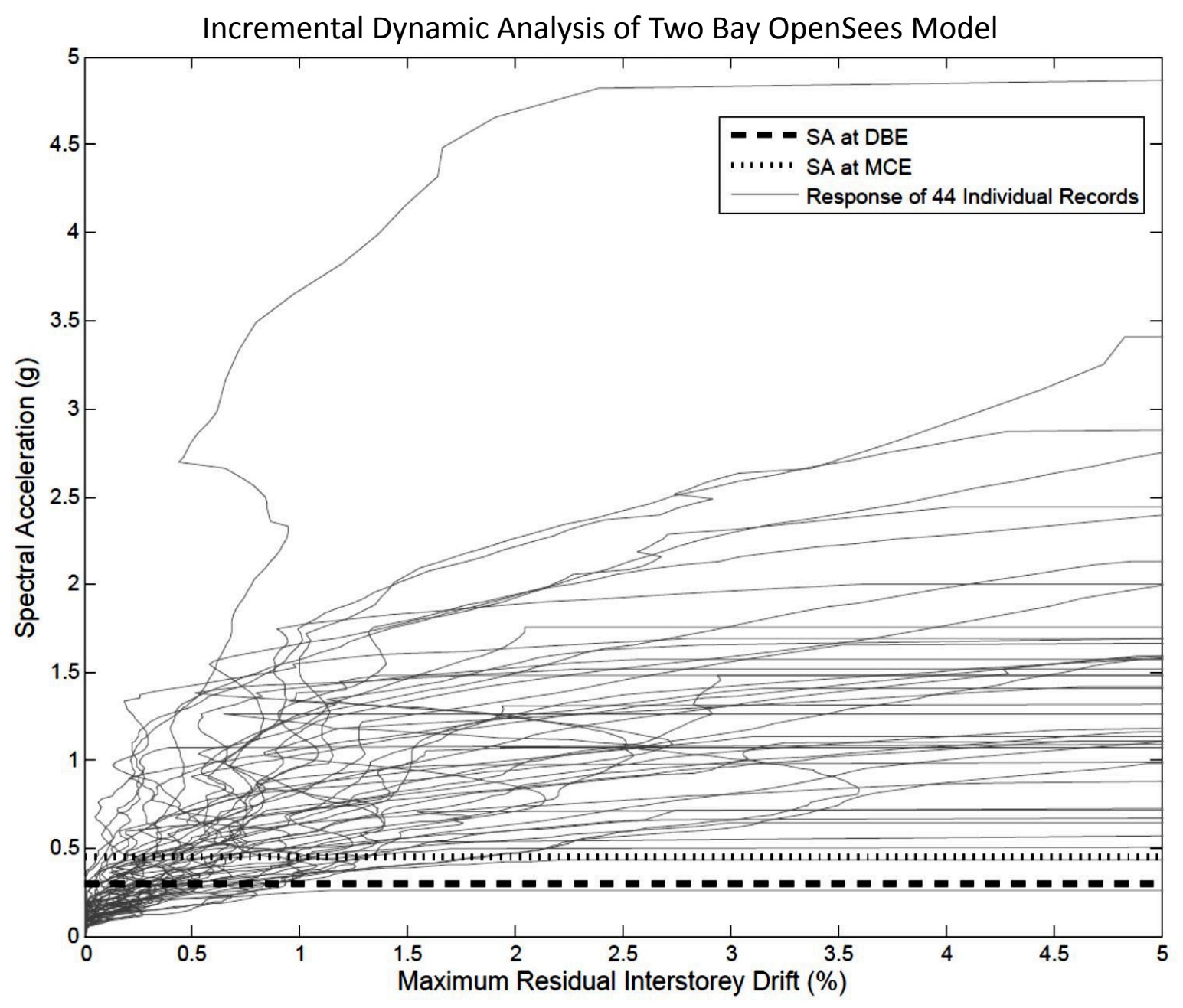

Figure 5.5: Incremental Dynamic Analysis of Two Bay OpenSees Model for Residual Drifts 
Table 5.1: ATC A Far Field Ground Motions Termination Response

\begin{tabular}{|c|c|c|}
\hline Excitation ID & Station & Termination Limit \\
\hline ATC-F01A & Northridge & $5 \%$ Drift Limit \\
\hline ATC-F02A & Northridge & $80 \%$ Stiffness Reduction \\
\hline ATC-F03A & Duzce, Turkey & $80 \%$ Stiffness Reduction \\
\hline ATC-F04A & Hector Mine & $80 \%$ Stiffness Reduction \\
\hline ATC-F05A & Imperial Valley & $80 \%$ Stiffness Reduction and SA Reduction \\
\hline ATC-F06A & Imperial Valley & $80 \%$ Stiffness Reduction and SA Reduction \\
\hline ATC-F07A & Kobe, Japan & $80 \%$ Stiffness Reduction \\
\hline ATC-F08A & Kobe, Japan & $80 \%$ Stiffness Reduction \\
\hline ATC-F09A & Kocaeli, Tukey & $80 \%$ Stiffness Reduction \\
\hline ATC-F10A & Kocaeli, Turkey & $80 \%$ Stiffness Reduction \\
\hline ATC-F11A & Landers & $80 \%$ Stiffness Reduction \\
\hline ATC-F12A & Landers & $5 \%$ Drift Limit \\
\hline ATC-F13A & Loma Prieta & $80 \%$ Stiffness Reduction \\
\hline ATC-F14A & Loma Prieta & $80 \%$ Stiffness Reduction \\
\hline ATC-F15A & Manjil, Iran & $80 \%$ Stiffness Reduction and SA Reduction \\
\hline ATC-F16A & Superstition Hills & $5 \%$ Drift Limit \\
\hline ATC-F17A & Superstition Hills & $80 \%$ Stiffness Reduction \\
\hline ATC-F18A & Cape Mendocino & $80 \%$ Stiffness Reduction and SA Reduction \\
\hline ATC-F19A & Chi-Chi, Taiwan & $80 \%$ Stiffness Reduction \\
\hline ATC-F20A & Chi-Chi, Taiwan & $80 \%$ Stiffness Reduction \\
\hline ATC-F21A & San Fernando & $5 \%$ Drift Limit \\
\hline ATC-F22A & Friuli, Italy & $5 \%$ Drift Limit \\
\hline
\end{tabular}


Table 5.2: ATC B Far Field Ground Motions Termination Response

\begin{tabular}{|c|c|c|}
\hline Excitation ID & Station & Termination Limit \\
\hline ATC-F01B & Northridge & $5 \%$ Drift Limit \\
\hline ATC-F02B & Northridge & $5 \%$ Drift Limit \\
\hline ATC-F03B & Duzce, Turkey & $5 \%$ Drift Limit \\
\hline ATC-F04B & Hector Mine & $80 \%$ Stiffness Reduction \\
\hline ATC-F05B & Imperial Valley & $80 \%$ Stiffness Reduction and SA Reduction \\
\hline ATC-F06B & Imperial Valley & $5 \%$ Drift Limit \\
\hline ATC-F07B & Kobe, Japan & $80 \%$ Stiffness Reduction \\
\hline ATC-F08B & Kobe, Japan & $80 \%$ Stiffness Reduction \\
\hline ATC-F09B & Kocaeli, Tukey & $80 \%$ Stiffness Reduction \\
\hline ATC-F10B & Kocaeli, Turkey & $80 \%$ Stiffness Reduction \\
\hline ATC-F11B & Landers & $80 \%$ Stiffness Reduction \\
\hline ATC-F12B & Landers & $5 \%$ Drift Limit \\
\hline ATC-F13B & Loma Prieta & $80 \%$ Stiffness Reduction \\
\hline ATC-F14B & Loma Prieta & $5 \%$ Drift Limit \\
\hline ATC-F15B & Manjil, Iran & $80 \%$ Stiffness Reduction \\
\hline ATC-F16B & Superstition Hills & $80 \%$ Stiffness Reduction \\
\hline ATC-F17B & Superstition Hills & $80 \%$ Stiffness Reduction and SA Reduction \\
\hline ATC-F18B & Cape Mendocino & $80 \%$ Stiffness Reduction and SA Reduction \\
\hline ATC-F19B & Chi-Chi, Taiwan & $5 \%$ Drift Limit \\
\hline ATC-F20B & Chi-Chi, Taiwan & $5 \%$ Drift Limit \\
\hline ATC-F21B & San Fernando & $80 \%$ Stiffness Reduction \\
\hline ATC-F22B & Friuli, Italy & $5 \%$ Drift Limit \\
\hline
\end{tabular}




\subsubsection{Response Behaviour of Prototype Structure}

The individual response of the system varied from record to record but weaving, softening, a bit of hardening and severe hardening responses were observed. Figure 5.6 illustrates an example of each behaviour from this study. Softening behaviour occurred when the base storey of the structure experienced the maximum interstorey drifts. This was present for all softening responses in the structure. Weaving responses generally occurred below $2.5 \%$ maximum interstorey drift. In all cases, the failure of the structure did not occur during a weaving response. In all cases after the weaving response, the response of the structure slowly softened to failure or the 5\% drift limit was met. Hardening and severe hardening responses of the structure were observed in roughly half of the the record's IDA's. 


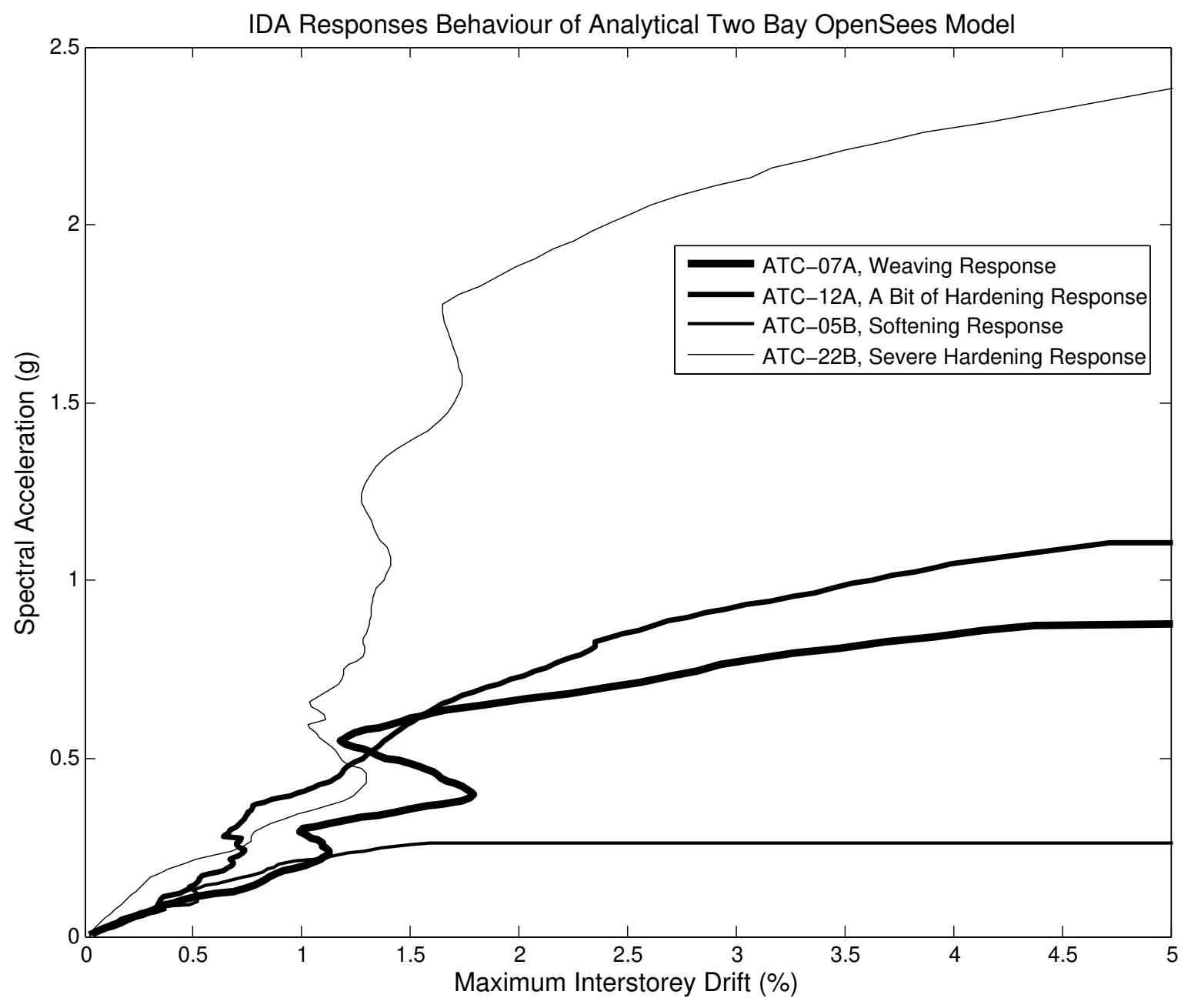

Figure 5.6: Incremental Dynamic Analysis Response Curves: Weaving, A Bit of Hardening, Severe Hardening (Vamvatsikos and Cornell, 2002)

It can be seen that under both DBE and MCE hazard levels of spectral acceleration, the maximum interstorey drifts were below $2.580 \%$, with the exception of 2 records. Figure 5.7 illustrates the 2 records that collapsed based on the failure criteria discussed above prior to reaching the MCE hazard level. 


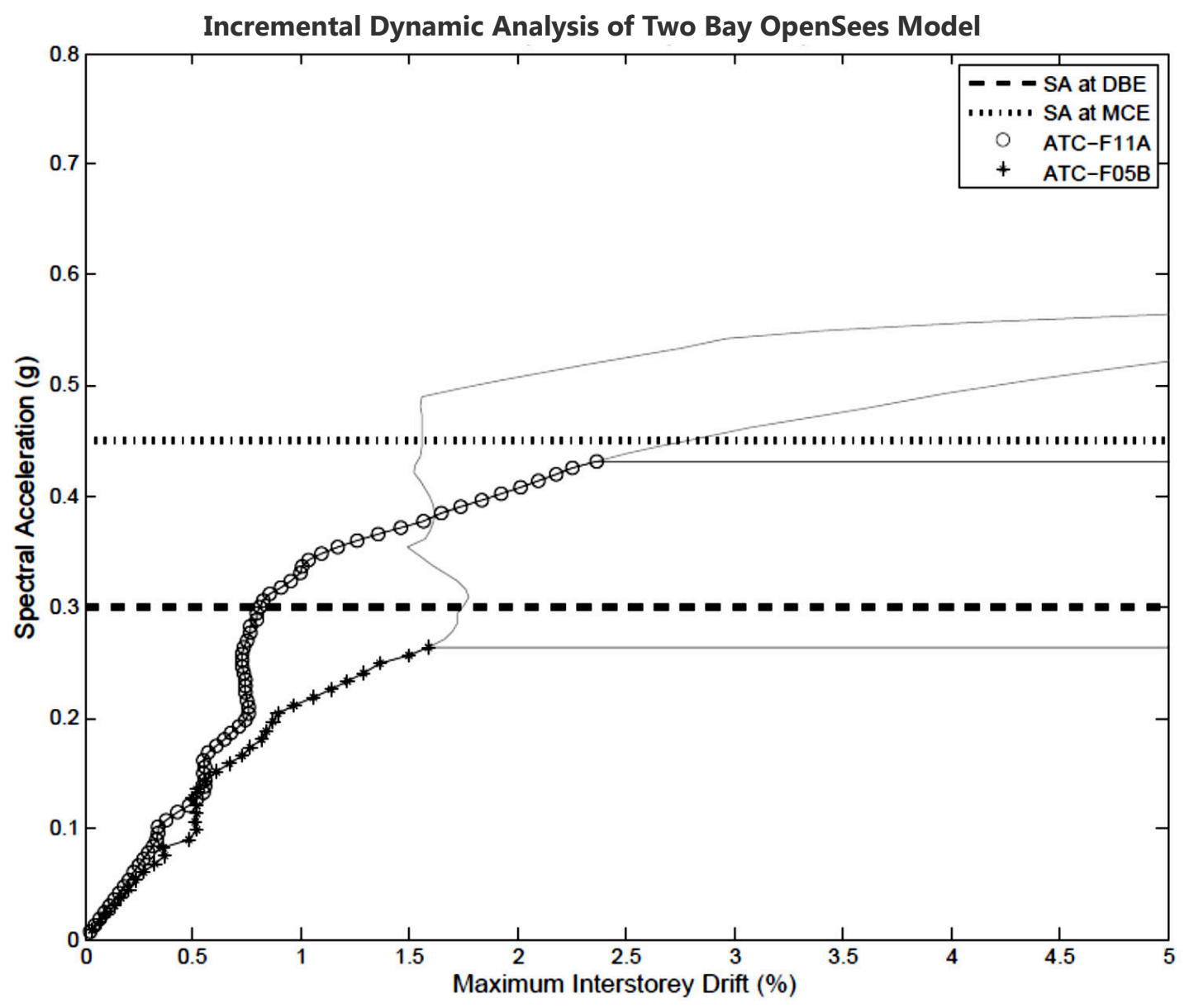

Figure 5.7: ATC-F11A and ATC-F05B IDA Response Two Bay OpenSees Model

\subsubsection{Fragility Curves for Two Bay OpenSees Model}

Fragility curves were developed from the Analytical Two Bay OpenSees Model IDA at $2.5 \%, 2.0 \%, 1.0 \%$ and $0.5 \%$ maximum interstorey and maximum interstorey residual drift levels corresponding to the ASCE 41-06 Standard limits for collapse prevention, life safety and immediate occupancy (ASCE, 2007). Figure 5.8 illustrates the fragility curves for maximum interstorey drift. Figure 5.9 illustrates the fragility curves for maximum interstorey residual drift. The curves from left to right increase in drift from $0.5 \%$ to $2.5 \%$. The intersection of the fragility curve with the specified hazard level, either MCE or DBE, indicates the probability of occurrences of each intensity measurement. In this study, maximum interstorey and maximum interstorey residual drifts are the intensity measure. The curves were fitted with a log normal distribution curve fit 
based on the set's mean and standard deviation.

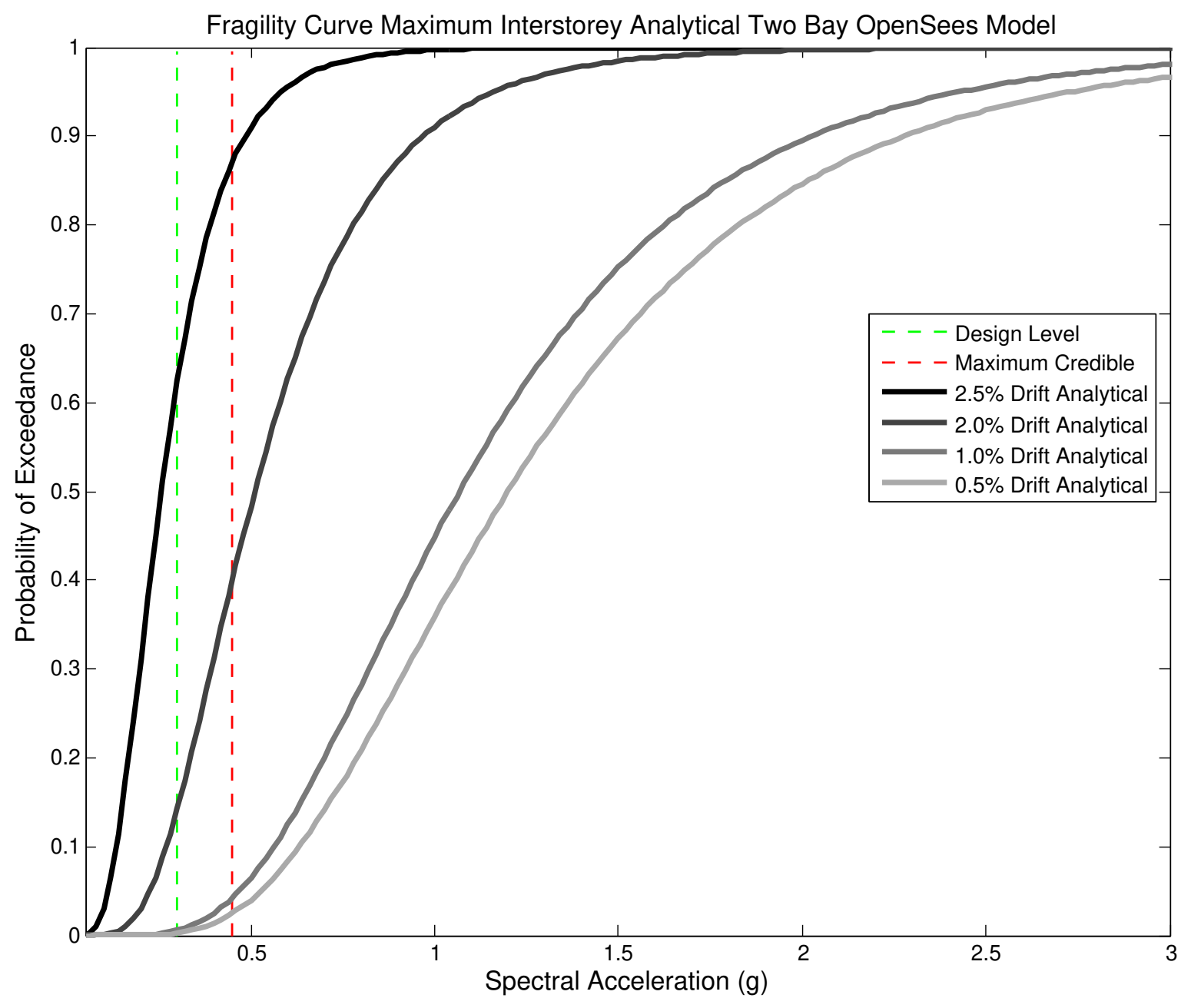

Figure 5.8: Fragility Curve of Two Bay OpenSees Model For Maximum Interstorey Drift 


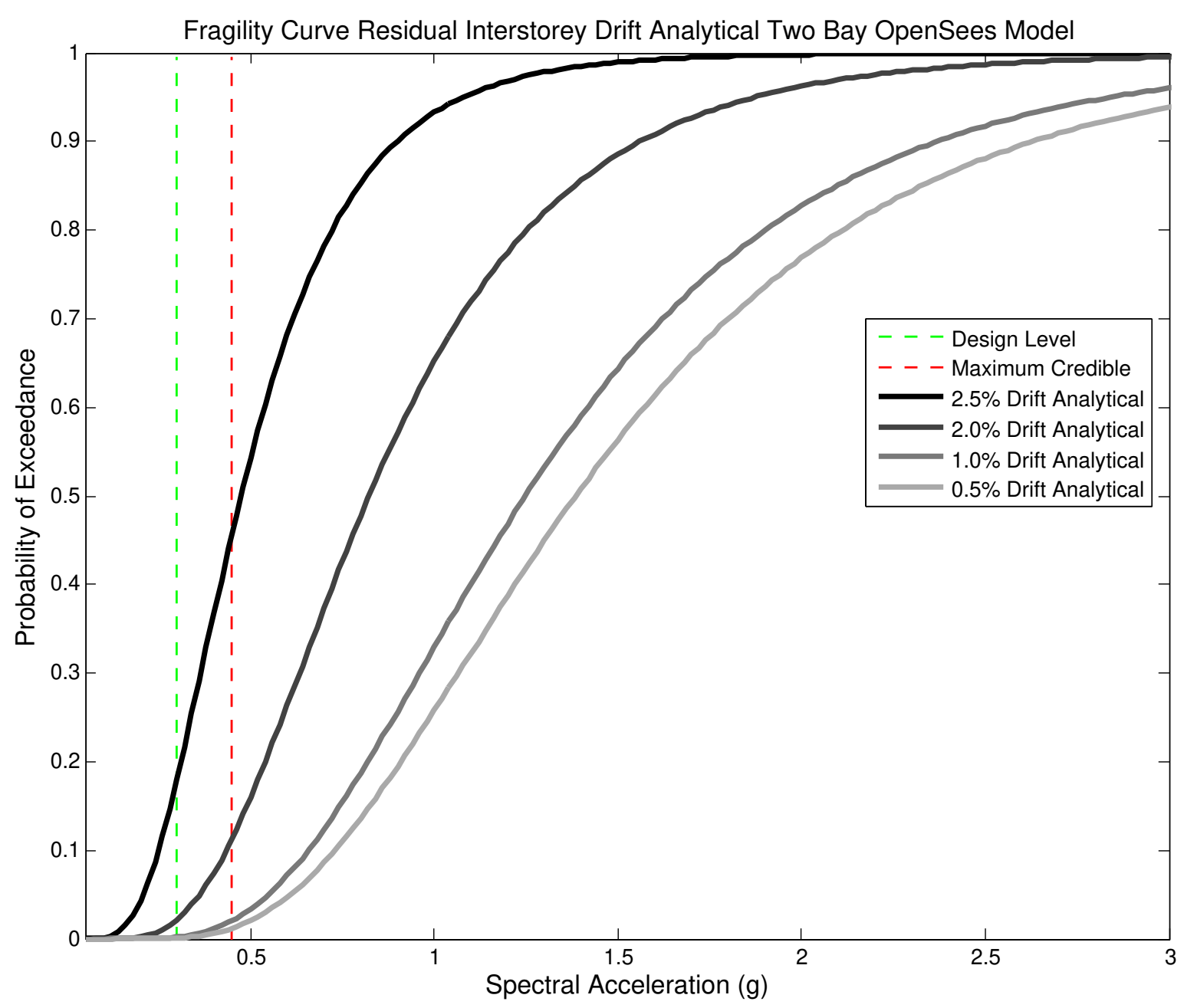

Figure 5.9: Fragility Curve of Two Bay OpenSees Model For Maximum Interstorey Residual Drift

Based on the fragility curves, the structure's performance in terms of probability of occurrence at the MCE and DBE hazard levels was determined. At the MCE hazard level, the probability of occurrence of $2.5 \%, 2.0 \%, 1.0 \%$ and $0.5 \%$ maximum interstorey drift levels were $2.5 \%, 4 \%, 41 \%$ and $87 \%$, respectively. The probability of the structure experiencing $2.5 \%, 2.0 \%$, $1.0 \%$ and $0.5 \%$ maximum interstorey residual drifts at the MCE hazard level were $1 \%, 1.5 \%$, $11 \%$ and $46 \%$, respectively. Based on these values, the structure had a $2.5 \%$ chance of experiencing a maximum interstorey drift over $2.5 \%$. The National Building code of Canada (National 
Research Council, 2011) limit is $2.5 \%$. Based on the results presented, the structure had a $4 \%$ chance of reaching the collapse prevention performance category and an $87 \%$ chance of reaching the life safety performance category. Chapter 6 will compare results of the experimental IDA and it's fragility curves with these results. 


\section{Chapter 6: Experimental Results and Discussion}

\subsection{Introduction}

This chapter discusses the experimental IDA of the prototype structure, record selection, record scaling, and compares experimental results with the analytical IDA results from Chapter 5. The experimental IDA was performed through hybrid testing. Hybrid tests were conducted using a suite of 11 earthquake records. Each record was applied multiple times at gradually increasing record spectral acceleration magnitudes. In total, 165 hybrid tests were performed on the prototype structure. The ground motion records were selected such that their mean response spectra approximately matched the uniform hazard spectra for Victoria, British Columbia. The response from these tests were used to develop IDA curves for the 11 records. The IDA results were used to develop fragility curves for maximum interstorey and maximum interstorey residual drift levels. The fragility curves assessed the prototype structure's performance at $0.5 \%, 1.0 \%$, $2.0 \%$ and $2.5 \%$ maximum interstorey drift and maximum interstorey residual drift. Experimental results are compared with analytical results in this chapter.

\subsection{Experimental IDA Earthquake Record Selection}

Eleven earthquake records with a mean response spectrum matching the MCE design spectrum of Victoria, British Columbia, Canada for the prototype structure are illustrated in Figure 6.1. Table 6.1 illustrates the 11 records selected for the experimental IDA. The 11 records selected 
for the experimental IDA are a subset of the 44 records used in the analytical IDA. These records were hand picked from the set of 44 records so that the mean spectrum of the subset matched the design spectrum as closely as possible. It can be seen in Figure 6.1 that the red line indicating the mean response spectrum of the subset of records approximately matched the design spectrum from $0.4 \mathrm{~s}$ to $4.0 \mathrm{~s}$. The mean response spectrum was slightly less than the design spectrum from 0.0 s to $0.4 \mathrm{~s}$. Ideally, the mean of the 11 records should match the design spectrum. The National Building Code of Canada requirements state that the spectrum of the subset should match the design spectrum between 0.15 and 1.5 times the first mode period of the structure when only 11 records are selected for a time history analysis at a return period of $2 \%$ in 50 years or roughly the MCE hazard level (National Research Council, 2015). For this structure to meet the National Building Code requirements, the subset of records should match the design spectra between $0.135 \mathrm{~s}$ and $1.4 \mathrm{~s}$. Since the spectra matched well between $0.4 \mathrm{~s}$ and $1.5 \mathrm{~s}$ and was close between $0.135 \mathrm{~s}$ and $0.4 \mathrm{~s}$, the subset of records was used as is. 


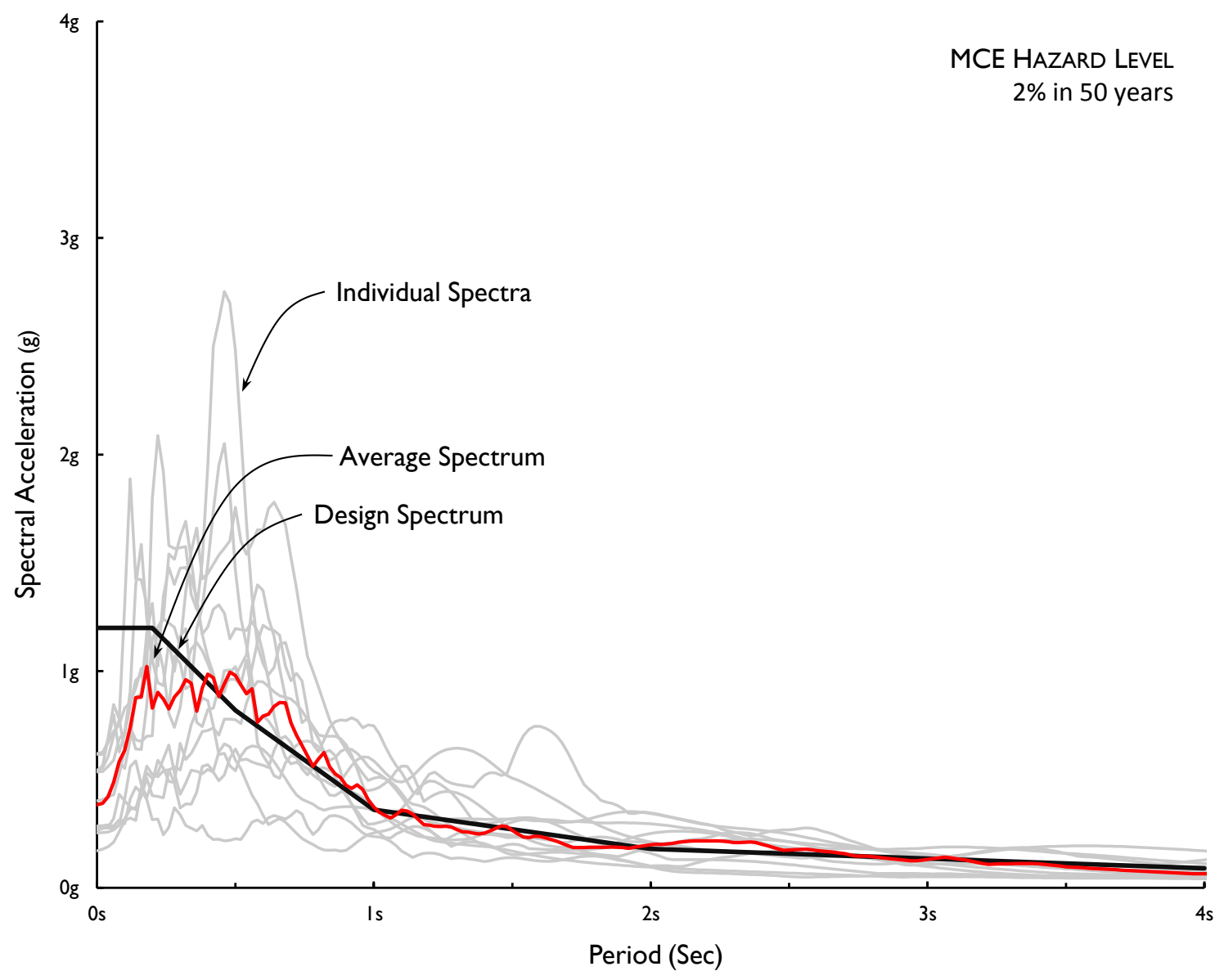

Figure 6.1: Response Spectra of Records used in Hybrid Tests 
Table 6.1: ATC Far Field Ground Motions Used in Experimental IDA (Applied Technology

Council, 2009)

\begin{tabular}{c|ccccc}
\hline Excitation ID & Year & Station & Fault Type & Magnitude & PGA Normalized (g) \\
\hline ATC-F02A & 1994 & Northridge & Thrust & 6.7 & 0.40 \\
ATC-F05A & 1979 & Imperial Valley & Strike-Slip & 6.5 & 0.46 \\
ATC-F07A & 1995 & Kobe, Japan & Strike-Slip & 6.9 & 0.53 \\
ATC-F09A & 1999 & Kocaeli, Tukey & Strike-Slip & 7.5 & 0.25 \\
ATC-F11A & 1992 & Landers & Strike-Slip & 7.3 & 0.24 \\
ATC-F12A & 1992 & Landers & Strike-Slip & 7.3 & 0.48 \\
ATC-F17A & 1999 & Superstition Hills & Strike-Slip & 6.5 & 0.53 \\
ATC-F19A & 1999 & Chi-Chi, Taiwan & Thrust & 7.6 & 0.18 \\
ATC-F05B & 1979 & Imperial Valley & Strike-Slip & 6.5 & 0.46 \\
ATC-F08B & 1995 & Kobe, Japan & Strike-Slip & 6.9 & 0.26 \\
ATC-F22B & 1976 & Friuli, Italy & Thrust & 6.5 & 0.50 \\
\hline
\end{tabular}

The maximum interstorey drift and maximum interstorey residual drift IDA curves from the analytical analysis are illustrated in Figures 6.2 and 6.3. Using the analytical IDA curve response of each record, 15 unique scale factors were selected for each record for use in the experimental IDA in this study. In most IDA's, approximately 12 unique scale factors are used in the analysis (Vamvatsikos and Cornell, 2002). Since the response of this system is not widely understood, 15 unique scale factors were chosen for the experimental IDA. These points were selected to best represent the response behaviour of the analytical IDA. Increased density of points were added around areas with weaving behaviour or sudden changes in slope. Table 6.2 illustrates the 15 scale factors for each record. 
CHAPTER 6. EXPERIMENTAL RESULTS AND

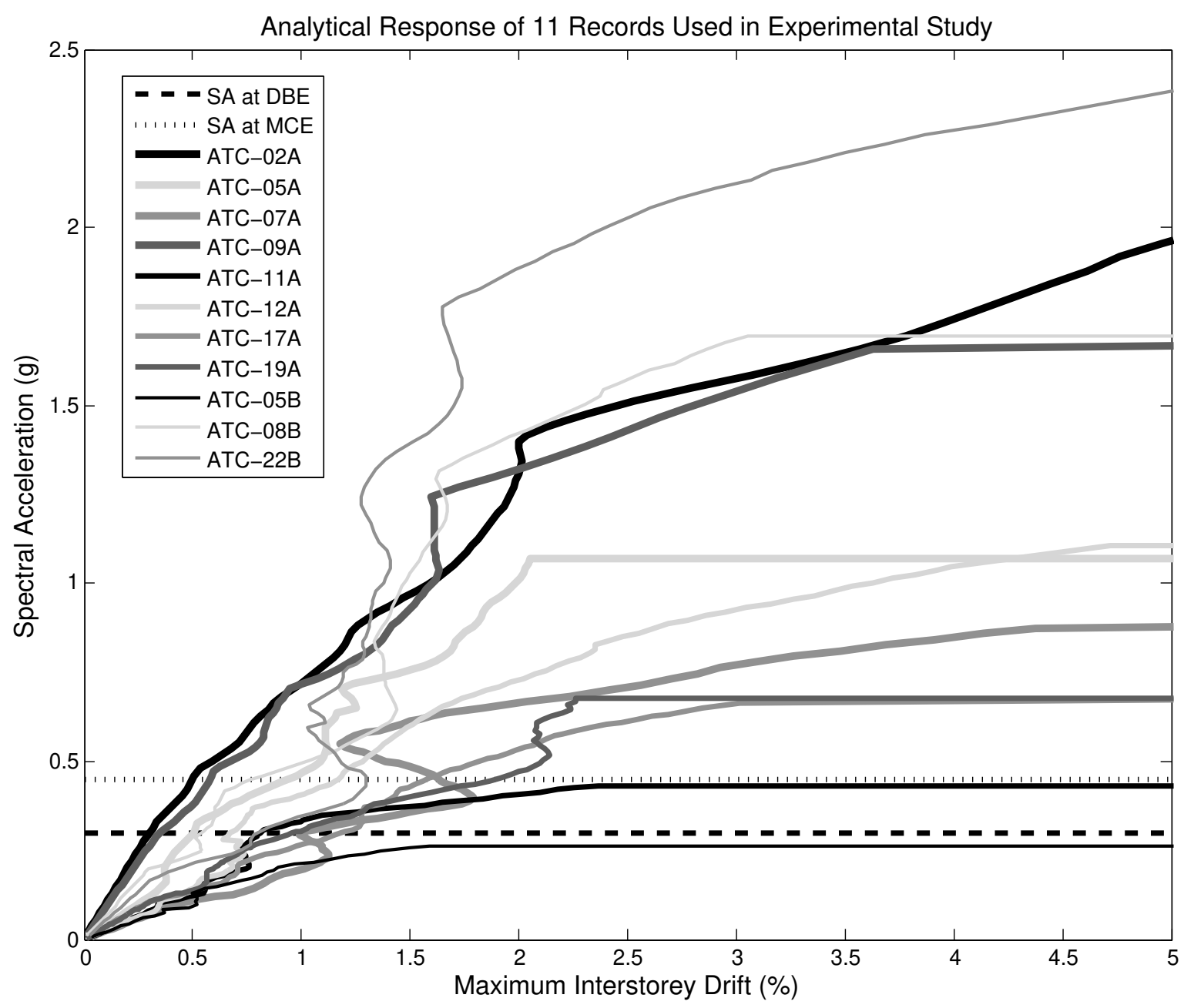

Figure 6.2: Analytical Maximum Interstorey Drift IDA Curves of 11 Selected Records 


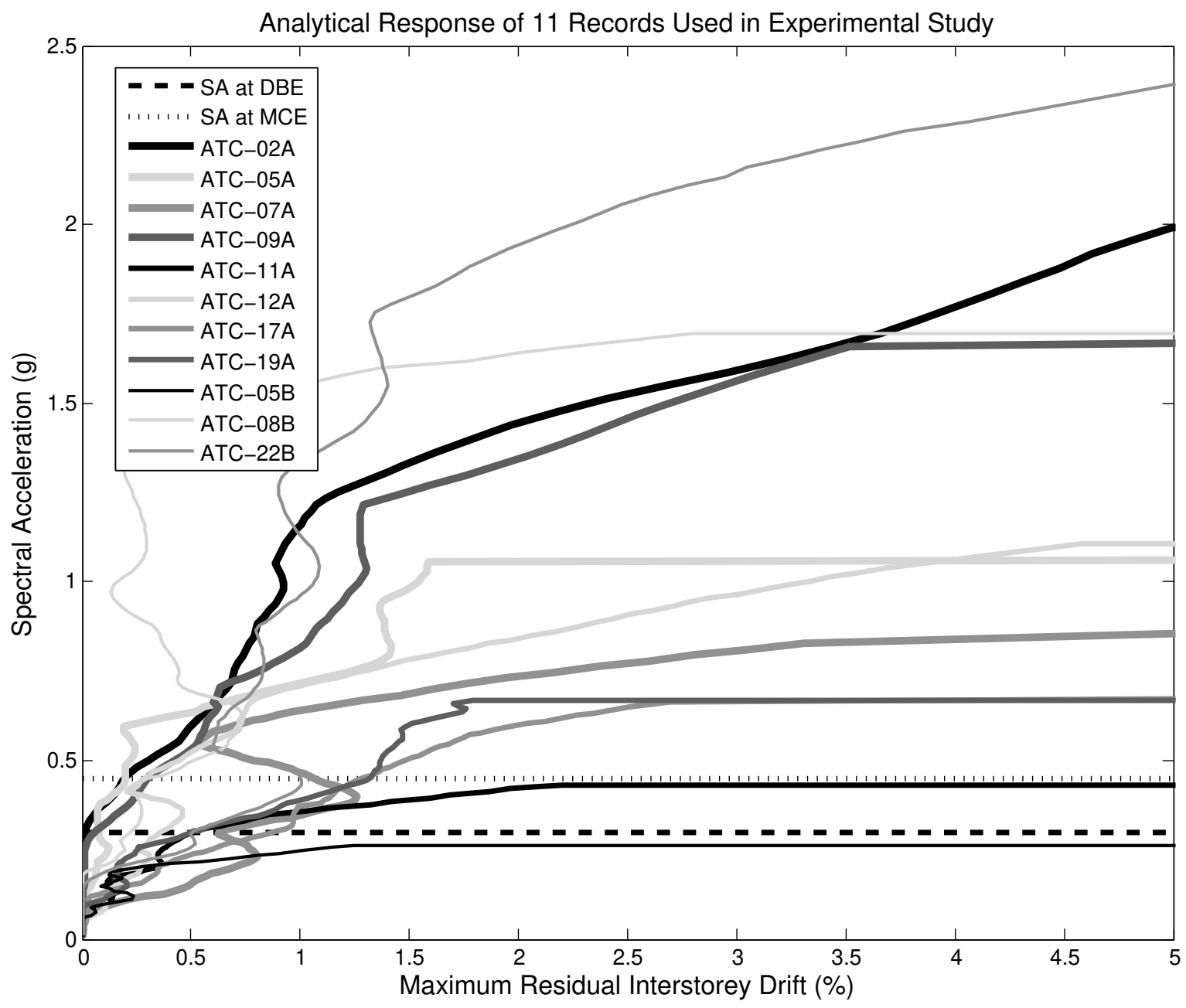

Figure 6.3: Analytical Maximum Interstorey Residual Drift IDA Curves of 11 Selected Records

\subsubsection{Analytical Fragility Curve Comparison \\ Suite of 44 Records and Subset of 11 Records}

The analytical fragility curves developed from the entire suite of 44 far field records and from the subset of 11 records selected for use in the hybrid tests are illustrated in Figures 6.4 and 6.5 for maximum interstorey drift and maximum interstorey residual drift, respectively. The analytical fragility curves developed from the subset of 11 selected records produced a different response than the fragility curves developed from the suite of 44 records despite the mean spectral accelerations of the suites approximately matching each other between $0.4 \mathrm{~s}$ and $4.0 \mathrm{~s}$. The 


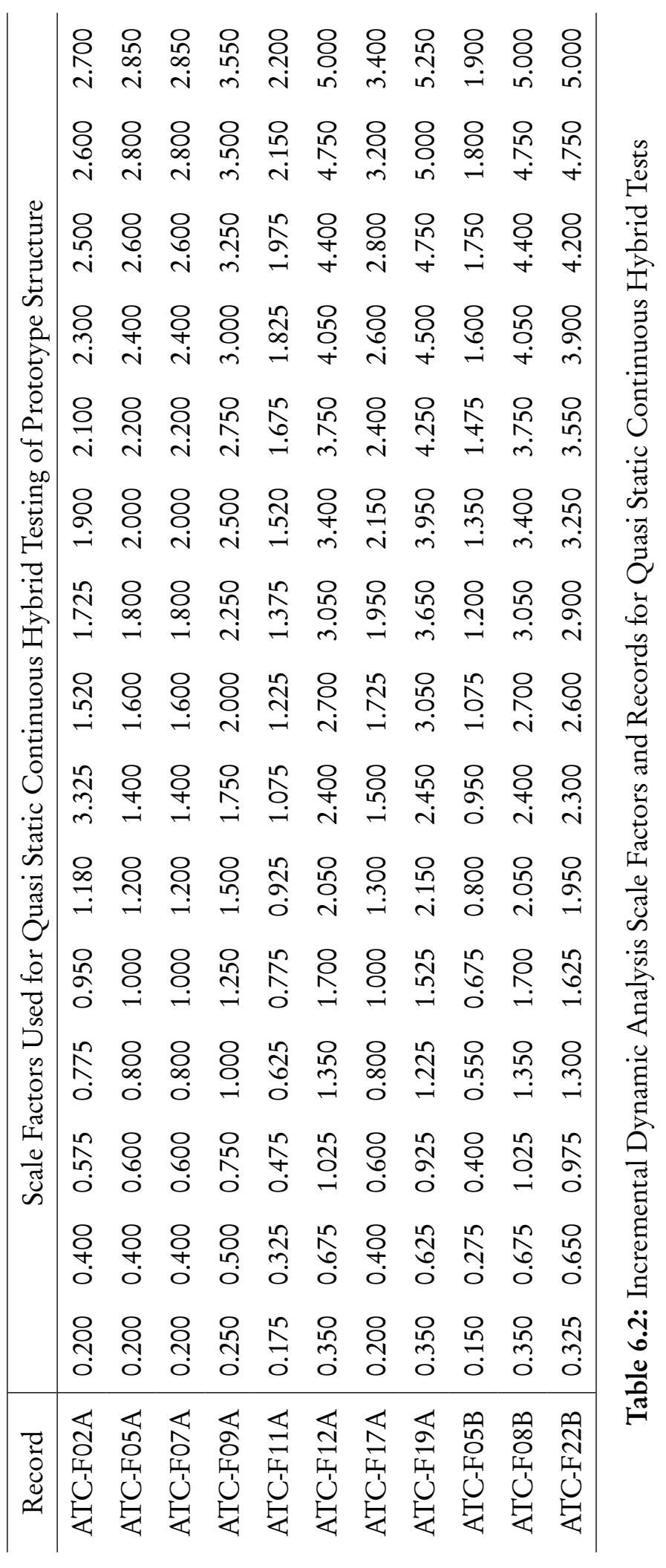


response spectrum of the suite of 44 records is illustrated in Figure 6.6. The fragility curves indicate that the subset of 11 records were more demanding on the structure than the suite of 44 records. The dashed lines in Figures 6.4 and 6.5 represent the subset of the 11 record's fragility curves; the solid lines represent the suite of the 44 record's fragility curves. The subset of 11 records at all drifts generally had more demand. This makes sense since between $0.45 \mathrm{~s}$ and $0.75 \mathrm{~s}$, the response spectra was slightly higher in the subset of 11 records than in the suite of 44 records, as illustrated in Figures 6.1 and 6.6. However, the demand was higher in the suite of 44 records between $0.15 \mathrm{~s}$ and $0.4 \mathrm{~s}$ as illustrated in Figures 6.1 and 6.6. This means the frequency content between $0.45 \mathrm{~s}$ and $0.75 \mathrm{~s}$ was exciting the structure more than the frequency content between $0.15 \mathrm{~s}$ and $0.4 \mathrm{~s}$. Since the fragility curves for the subset of 11 records was more demanding than the suite of 44 records, the analytical and experimental results were compared using the subset of 11 records. 


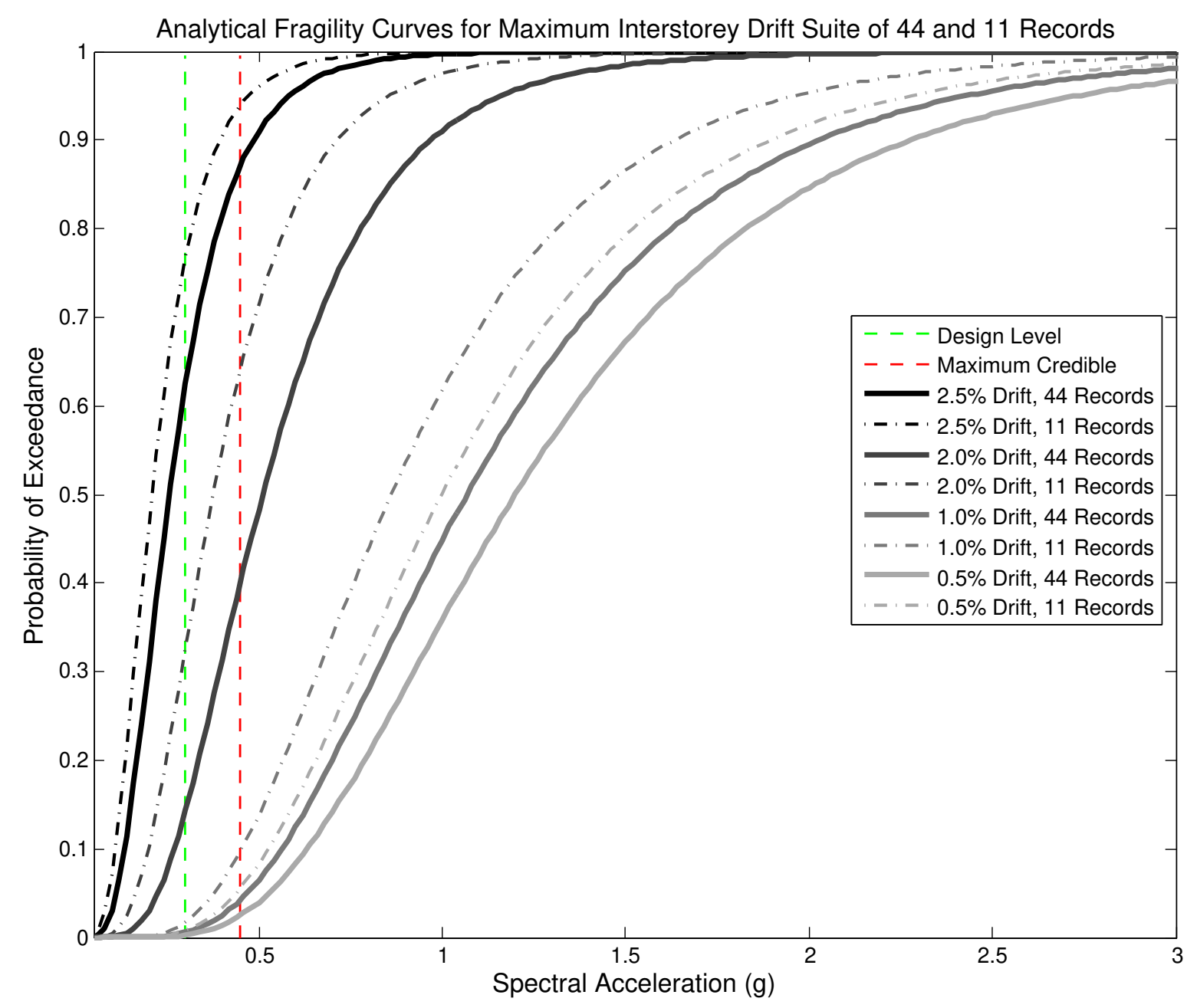

Figure 6.4: Fragility Curve Comparison Between Suite of 11 Records Selected for Experimental Testing and Entire Suite of 44 Records for Maximum Interstorey Drift 


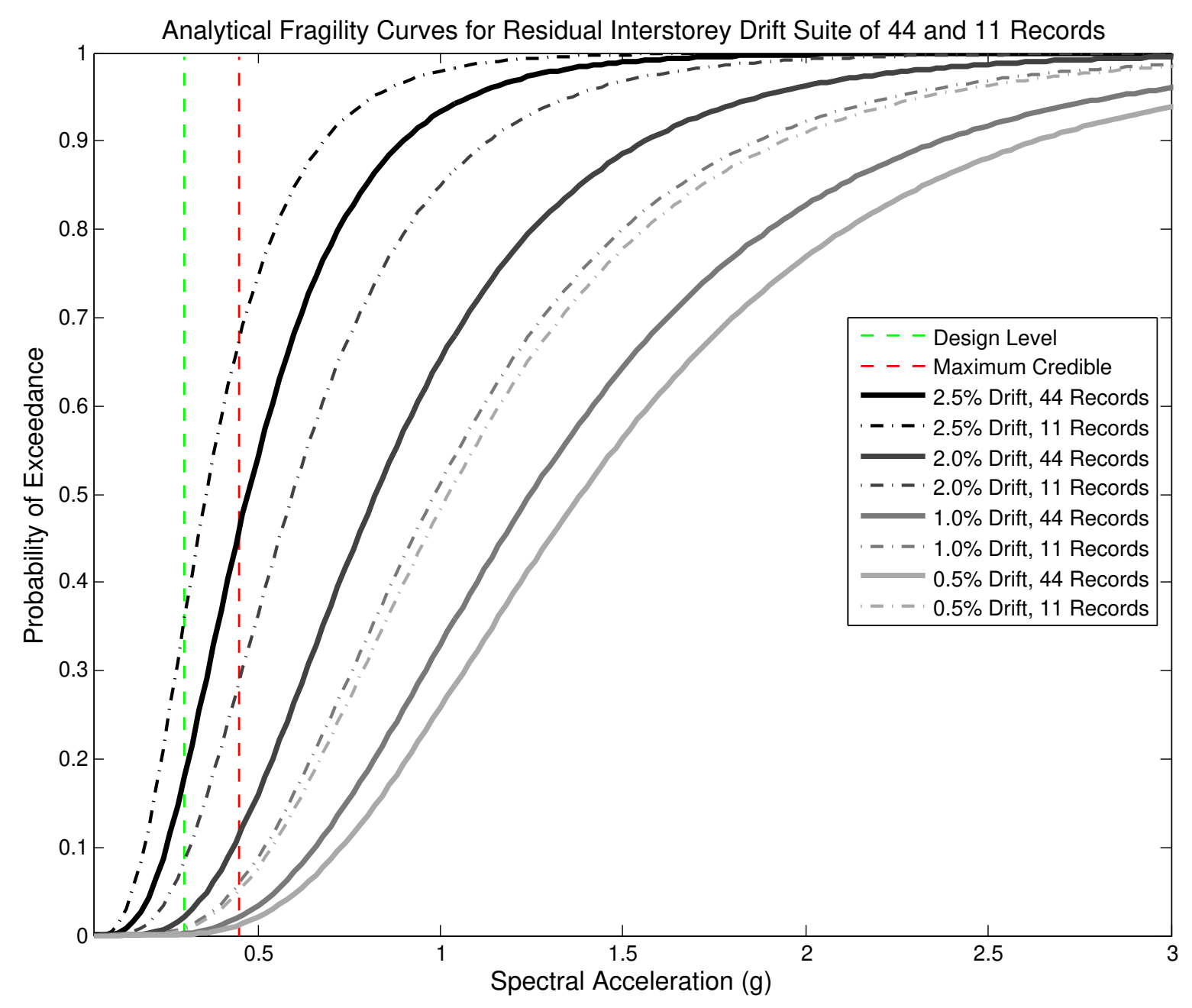

Figure 6.5: Fragility Curve Comparison Between Suite of 11 Records Selected for Experimental Testing and Entire Suite of 44 Records for Residual Interstorey Drift 


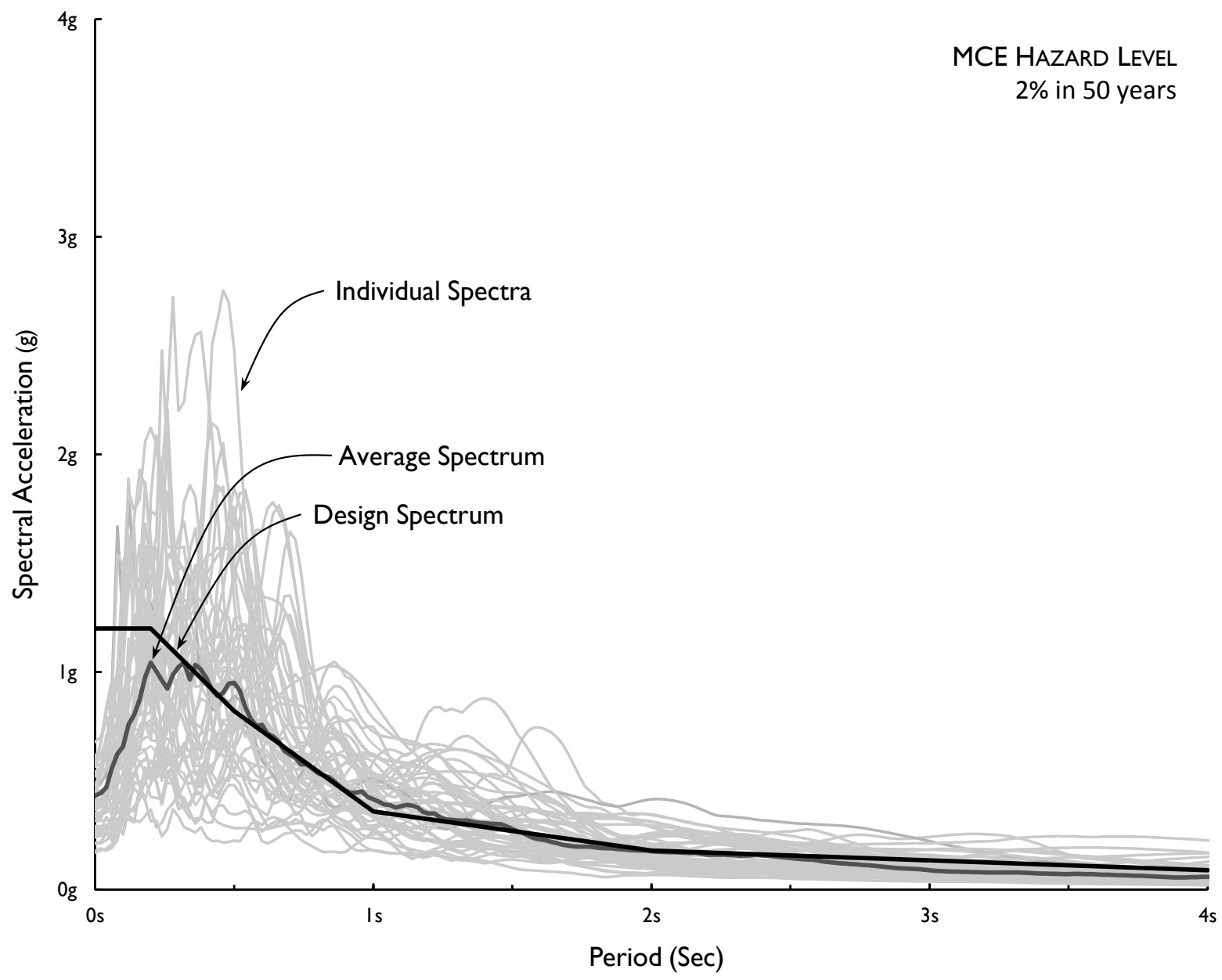

Figure 6.6: Suite of 44 Records Scaled to MCE Hazard Level

\subsection{Experimental Hybrid Test Analysis Parameters}

All hybrid tests were run at an extended time step to ensure the equation of motion was solved and convergence requirements were met. This was required due to equipment problems in the laboratory limiting processing speed of the model. Each time step was extended by a factor of 12, which was conservative. This ensured convergence at each time step was met prior to beginning the next time step and maintained a consistent time step throughout all tests. Since the only way to increase the speed of the tests was to reduce the number of time steps, a sensitivity analysis was performed to determine the time step that would accurately capture results but 
maintain velocity in the experiment. Figure 6.7 illustrates the results from the sensitivity analysis. The analysis was performed using record ATC-02A at a scale factor of 1.18. The time step selected for these tests was 0.02 seconds. It is clear that a time step greater than 0.05 seconds would have introduced a lot of error.

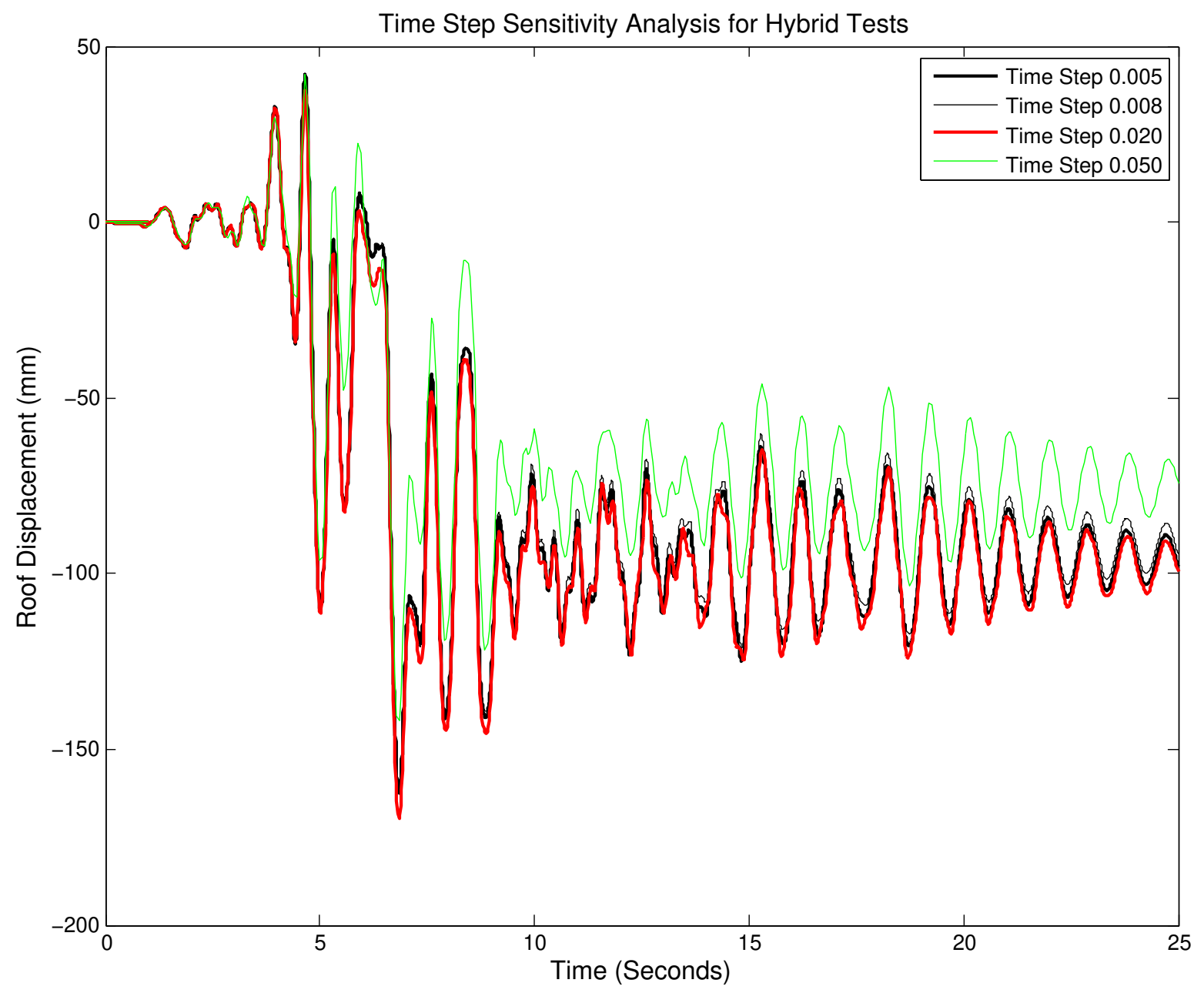

Figure 6.7: Hybrid Test Time Step Sensitivity Analysis

A predictor corrector function was used in these tests to maintain velocity. At the beginning of each time step, the function would predict actuator displacement, and once the final displacement was solved, the actuator would correct it's motion to achieve the correct displacement. The actuator velocity was linear in both the predictor and corrector phase of motion. The convergence tolerance in this test was 0.000001 with a maximum number of iterations of 25 . This 
maintained the same tolerance as the analytical analysis. The maximum number of iterations sensitivity analysis is illustrated in Figure 6.8. It can be seen that the maximum number of iterations never exceeded 5 in the record used in the study, thus 25 steps was conservative.

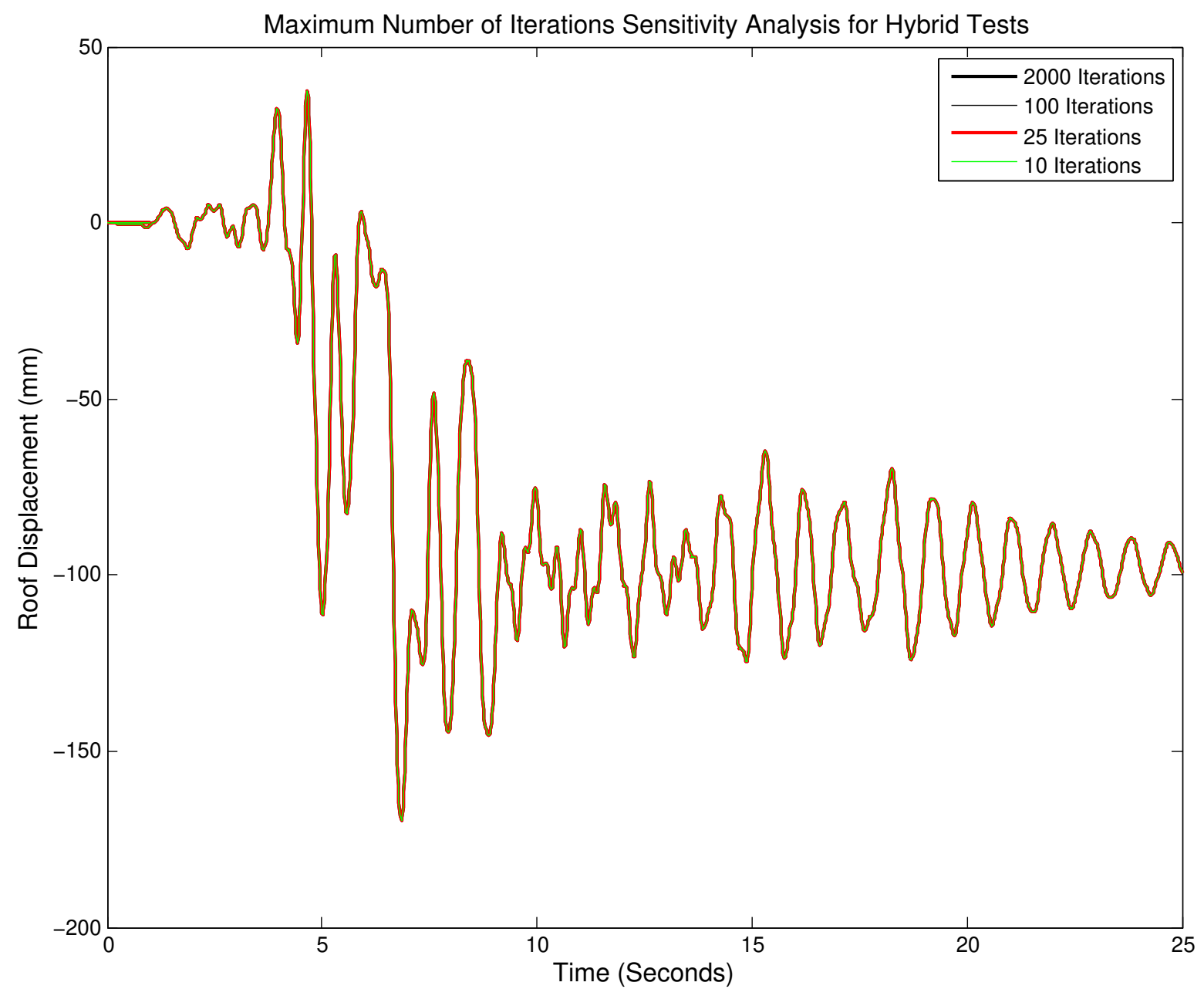

Figure 6.8: Hybrid Test Maximum Number of Iterations Sensitivity Analysis

The integrator used in the hybrid tests was AlphaOSGeneralized. The AlphaOSGeneralized integrator was used in combination with NewmarkGamma equal to 0.5. The integrator is unconditionally stable and used for hybrid tests (Al-Mahaidi and Hashemi, 2017). 


\subsection{Prototype Specimen Brace Slip Force Calibration}

A torque of $178 \mathrm{ft}$ lbs or $241 \mathrm{Nm}$ applied to each structural bolt achieved the specified slip force of $206 \mathrm{kN}$. This torque was applied using a torque wrench. The slip force was determined using two methods: strain gauges on the friction brace and the actuators load cell. Resolving both of these methods into force measurements axially in the friction brace accurately measured the slip force. The coefficient of friction was measured to be 0.45 , the same as in Gilbert (2016) tests.

\subsubsection{Gravity Load Application in Numerical Substructure}

Gravity loading on the numerical substructure was applied over the first 10 time steps, then the structure was allowed to vibrate freely with high damping for an additional 90 time steps to eliminate any free vibration. Earthquake loading was initiated on the 91st time step. Test results showed that applying gravity loading over more time steps did not have an effect on the system.

\subsection{Experimental Hybrid Test Termination Parameters}

The friction brace slip force was monitored during each test; if the activation force was higher or lower than the specified slip force of $206 \mathrm{kN}$ by more than $5 \%$, the test was restarted.

\subsection{Experimental Hybrid Test Temperature Monitoring}

The temperature of the friction brace was monitored during each test. The temperature of the friction brace's faying surfaces never exceeded 30 degrees Celsius. Under the most intense ground motions, the temperature of the system only increased by a couple of degrees. This was a direct result of slow loading rates. 


\subsection{Experimental Hybrid Test and Analytical Response Comparison}

A sample response of the structure is illustrated in Figures 6.9 and 6.10 comparing the experimental and analytical results of the prototype structure subjected to earthquake record ATC-F11A scaled by a magnitude of 1.375 (SA 0.95g). Results showed good agreement between the experimental and analytical hysteretic response of the friction brace. The stiffness of the physical assembly was approximately $73 \mathrm{kN} / \mathrm{mm}$ while the analytical model stiffness was $105 \mathrm{kN} / \mathrm{mm}$. The storey drift response was nearly identical at the first storey while the roof displacement response consistently illustrated a reduction in drift. This was observed in all test results. These results indicated that the difference in stiffness did not dictate the behaviour of the system, but slip behaviour of the braces did. These results were typical when the scaled spectral acceleration of the record was below 1g. This was the point when significant activation of the friction braces began to occur. Below 1g, the friction braces were not in constant motion but exhibited stick slip behaviour. Above 1g, continuous motion for extended periods of time was not uncommon. The friction brace was observed to cycle, slipping in extension and then compression up to 5 times without stopping. Figures 6.11 and 6.12 display the nodal response of the prototype structure's second floor and roof diaphragm under moderate and intense seismic loading for record ATCF12A. This was representative of the behaviour of the system above 1g. The storey displacement results deviated from the analytical results. It is clear in both plots that the response between analytical and experimental results was quite close under moderate loading up until the point of an abrupt change in displacement. In both cases, the response was nearly identical until the 15 second mark. This behaviour was present under all records. In zero stiffness systems, such as this one, it is not uncommon that small changes to the system can have a large effect on the results. How far and what direction the brace slips greatly depends on when the brace slips; a small change can have a large impact on the overall response of the system. 

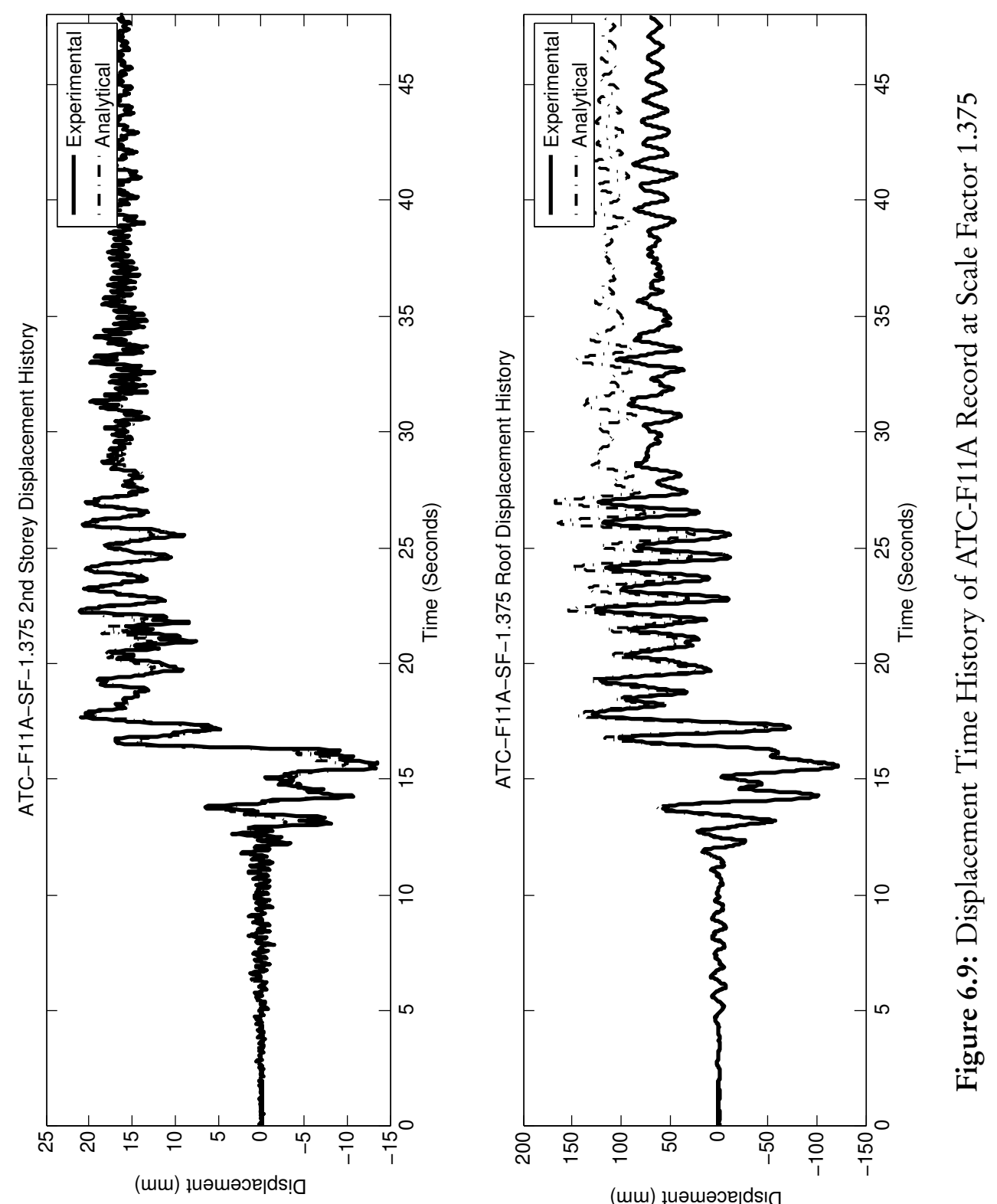


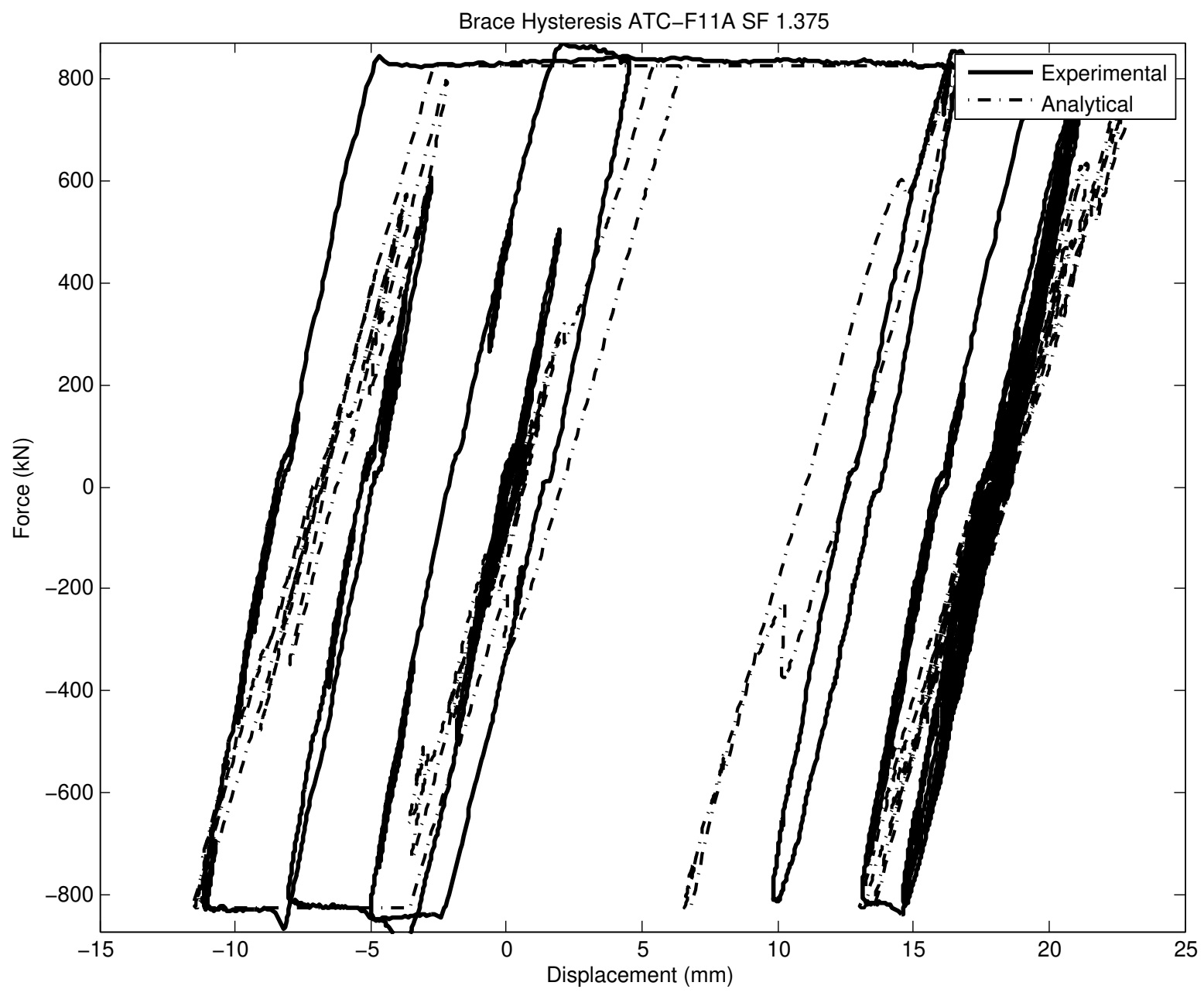

Figure 6.10: Brace Hysteresis ATC-F11A at Scale Factor 1.375 

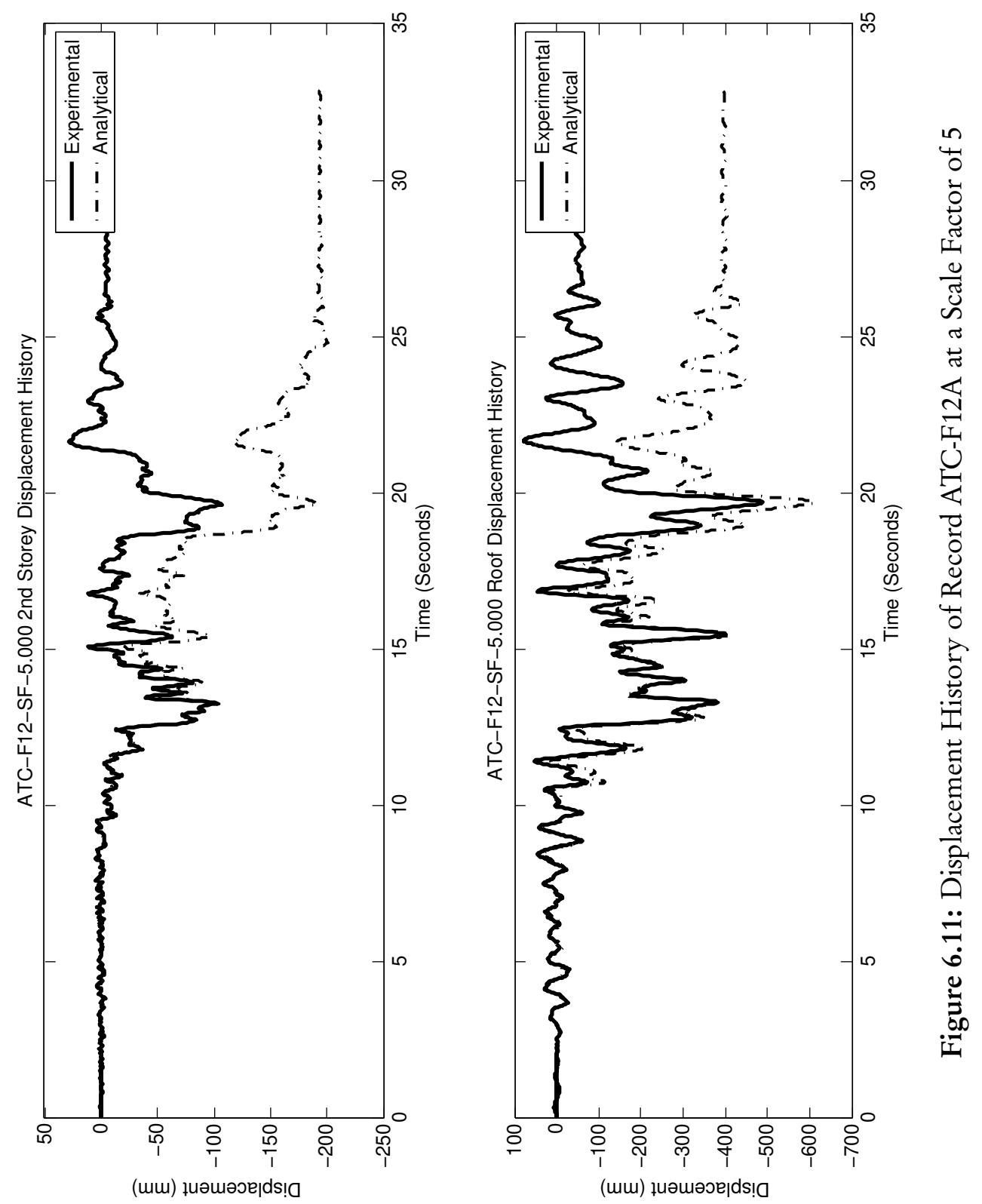

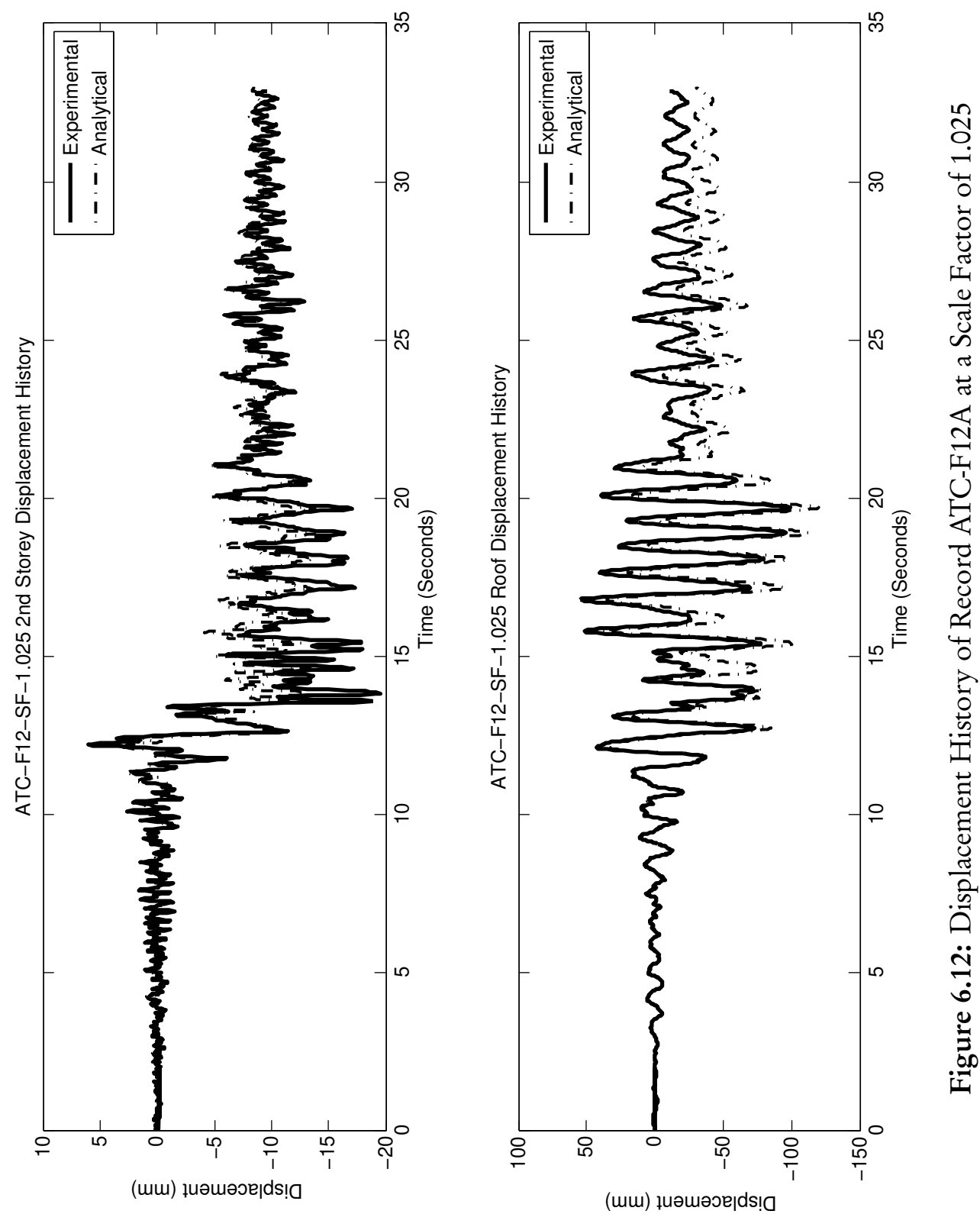


\subsection{Experimental Incremental Dynamic Analysis Results}

The IDA curves for each of the 11 records used in the experimental tests are illustrated in Figures 6.13 to 6.17 for maximum interstorey drifts and maximum interstorey residual drifts. It can be seen that the elastic response under all records was almost exactly the same between analytical and experimental IDA results. Once the intensity of the record began to cause inelastic behaviour in the bracing system, the experimental results began to deviate from the analytical results. This was especially evident when the maximum interstorey drifts were not occurring in the first storey. An example of this is illustrated in Figure 6.13, record ATC-F05A. In contrast, however, when the first storey was experiencing the maximum interstorey drifts, the response was much closer. An example of this is illustrated in Figure 6.14, record ATC-F11A. 

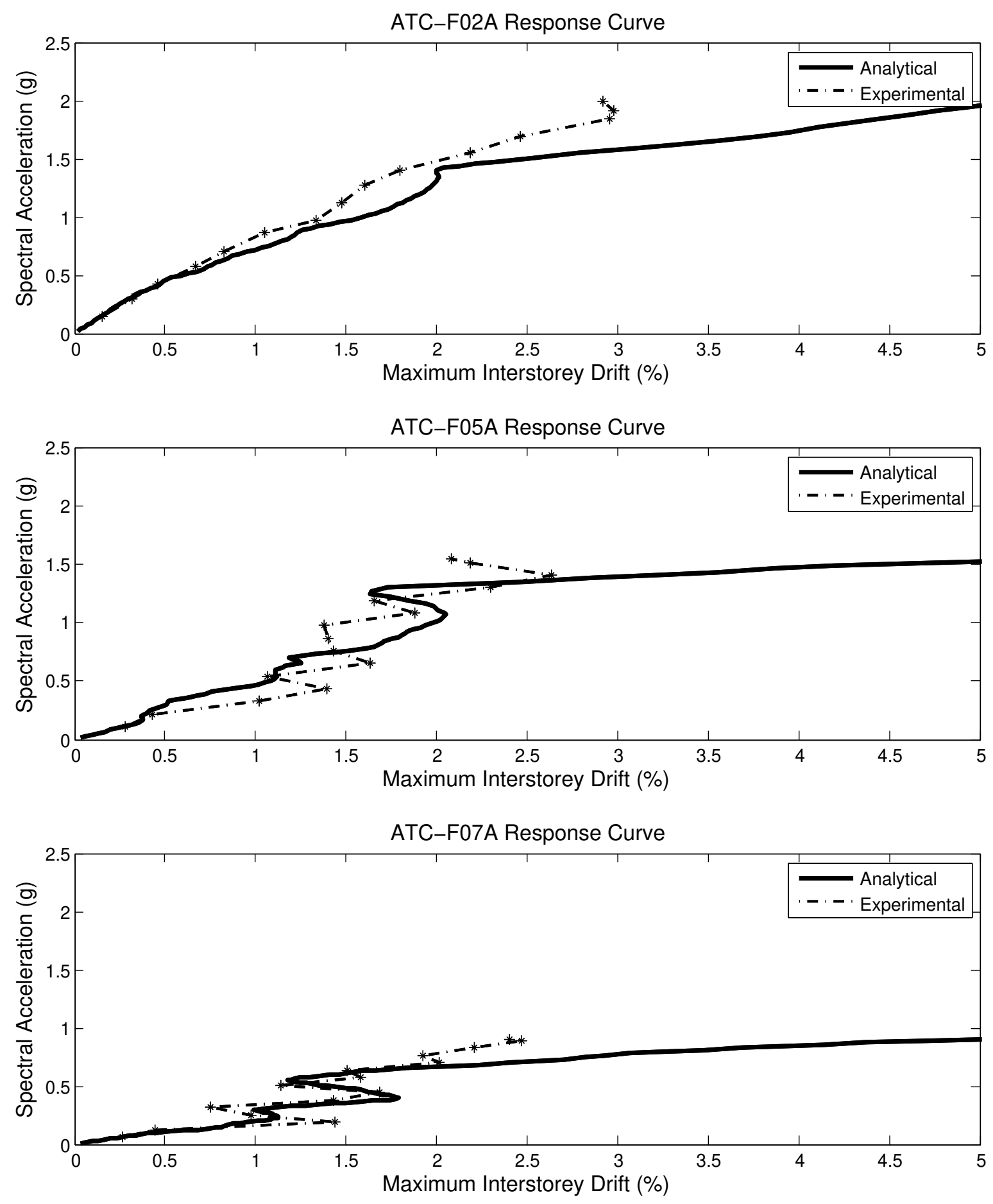

Figure 6.13: IDA Maximum Interstorey Drift Response of ATC-F02A, ATC-F05A and ATC-F07A Records Analytical and Experimental 

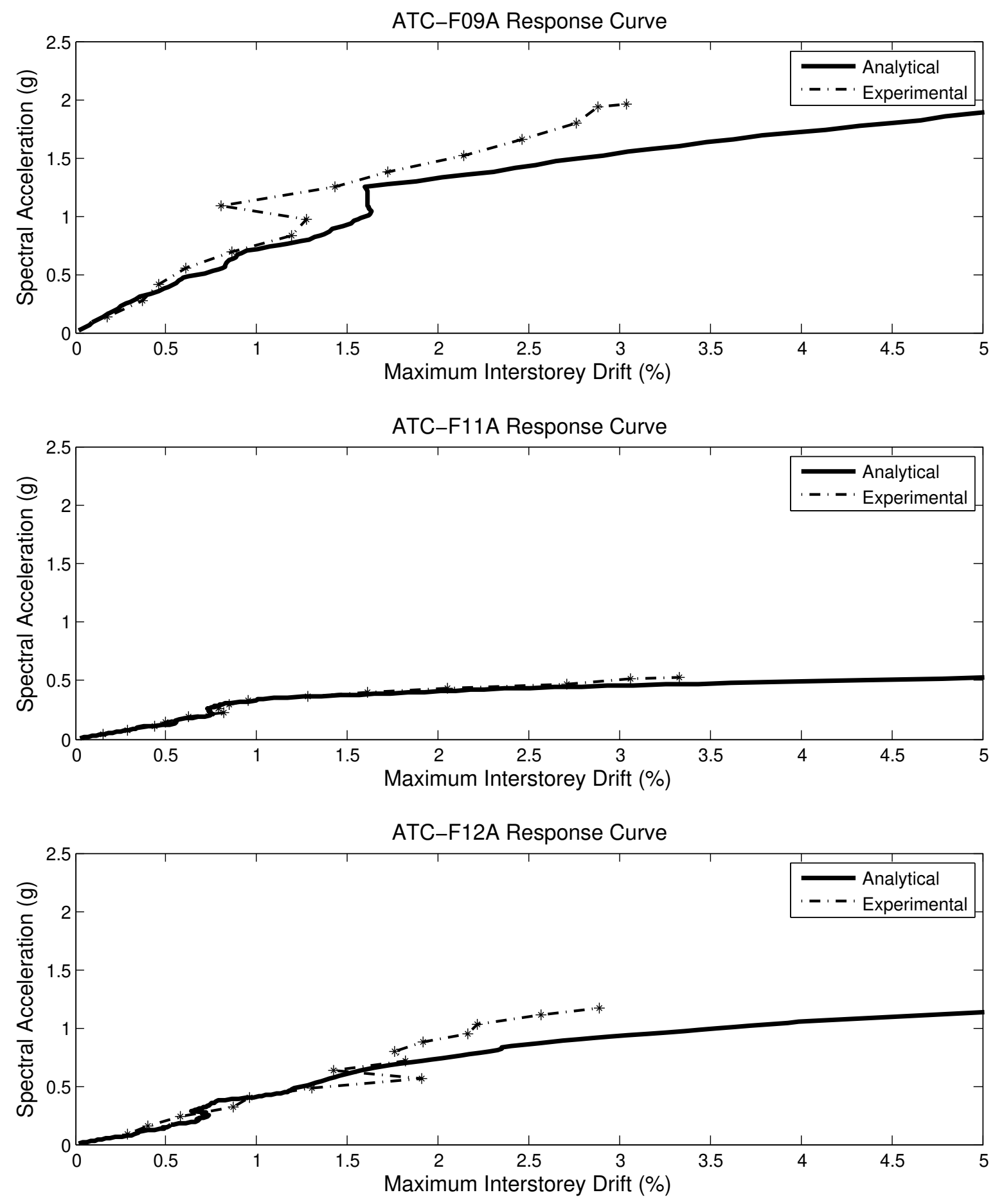

Figure 6.14: IDA Maximum Interstorey Drift Response of ATC-F09A, ATC-F11A and ATC-F12A Records Analytical and Experimental 

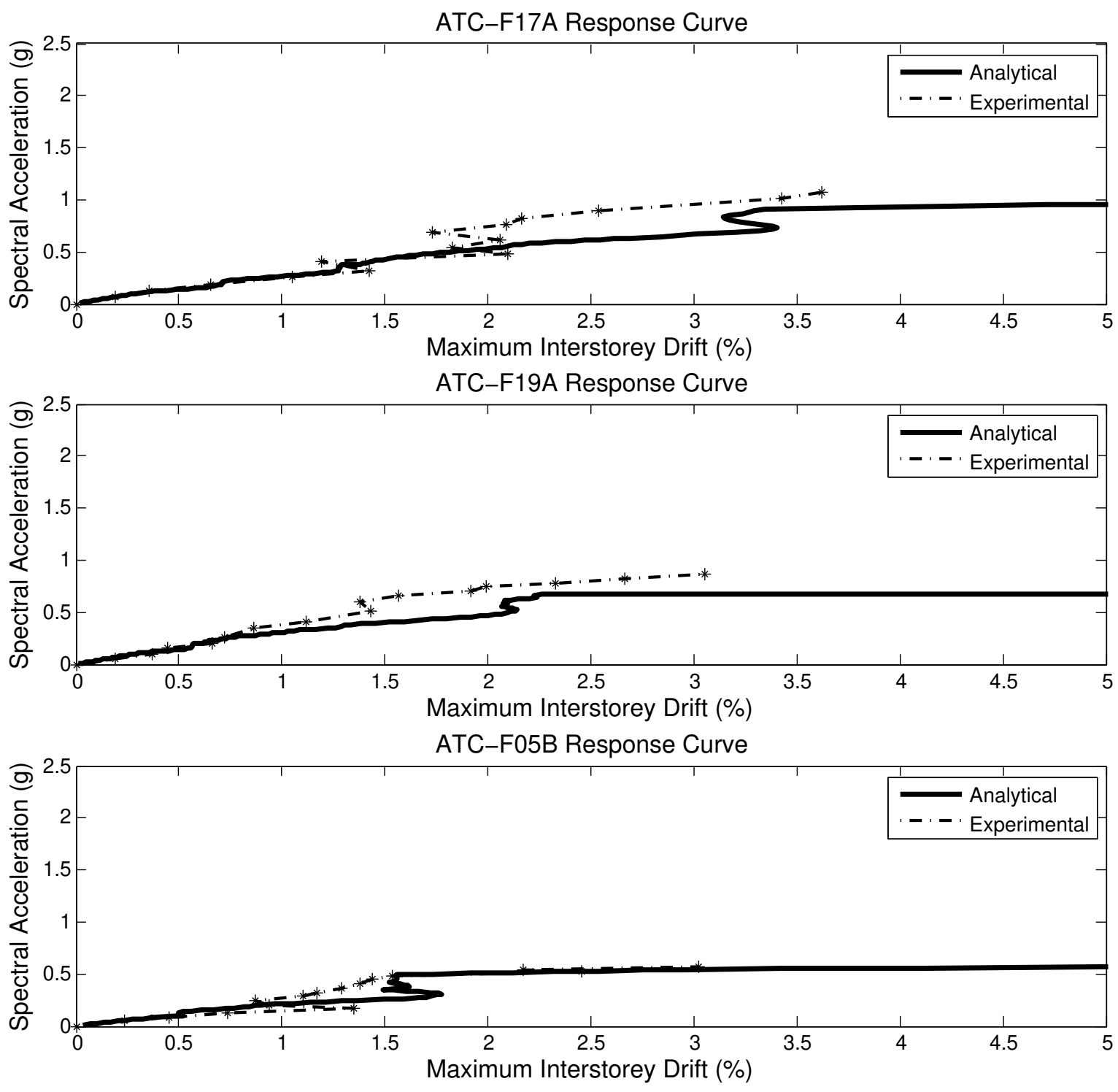

Figure 6.15: IDA Maximum Interstorey Drift Response of ATC-F17A, ATC-F19A and ATC-F05B Records Analytical and Experimental 

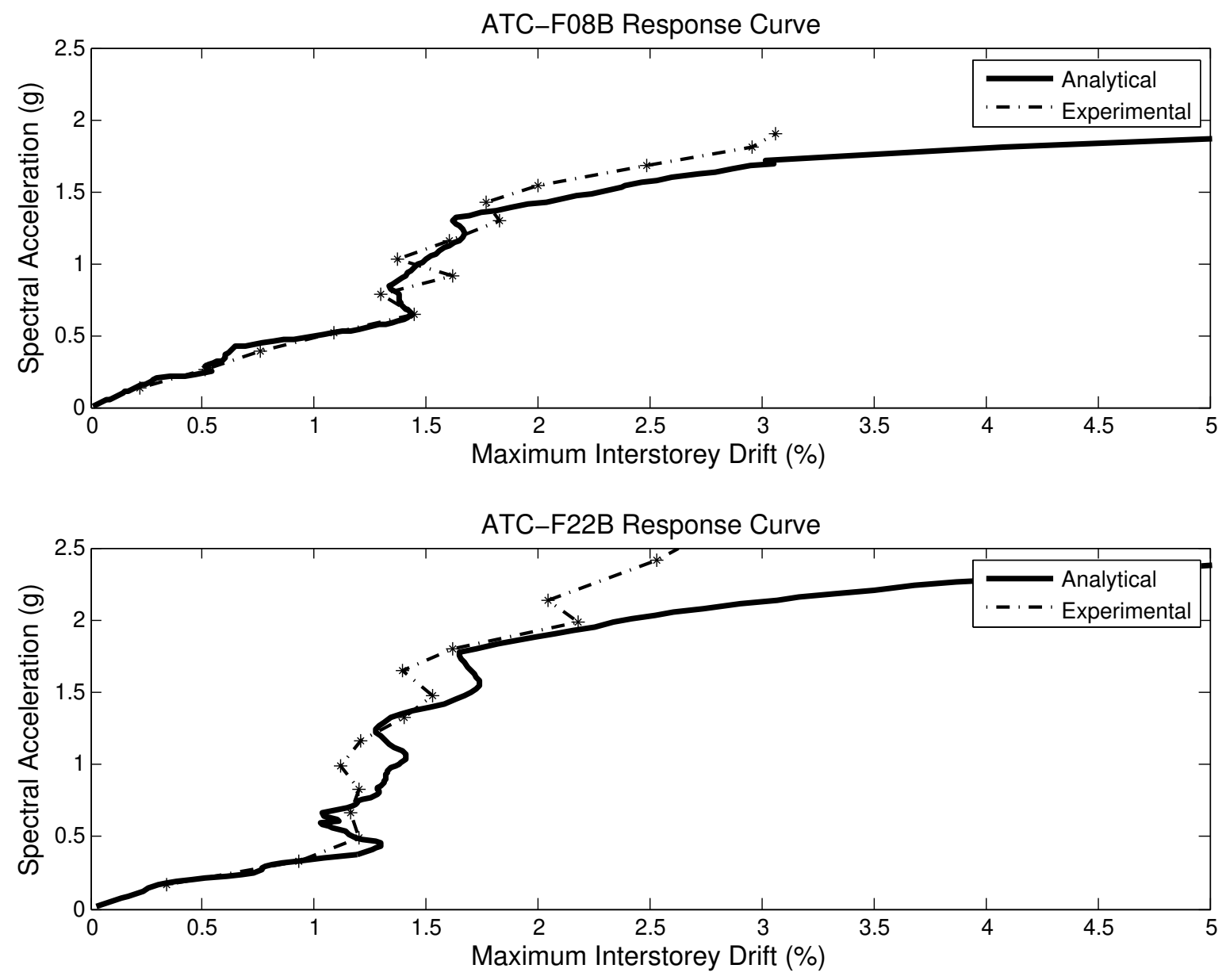

Figure 6.16: IDA Maximum Interstorey Drift Response of ATC-F08B and ATC-F22B Records Analytical and Experimental 

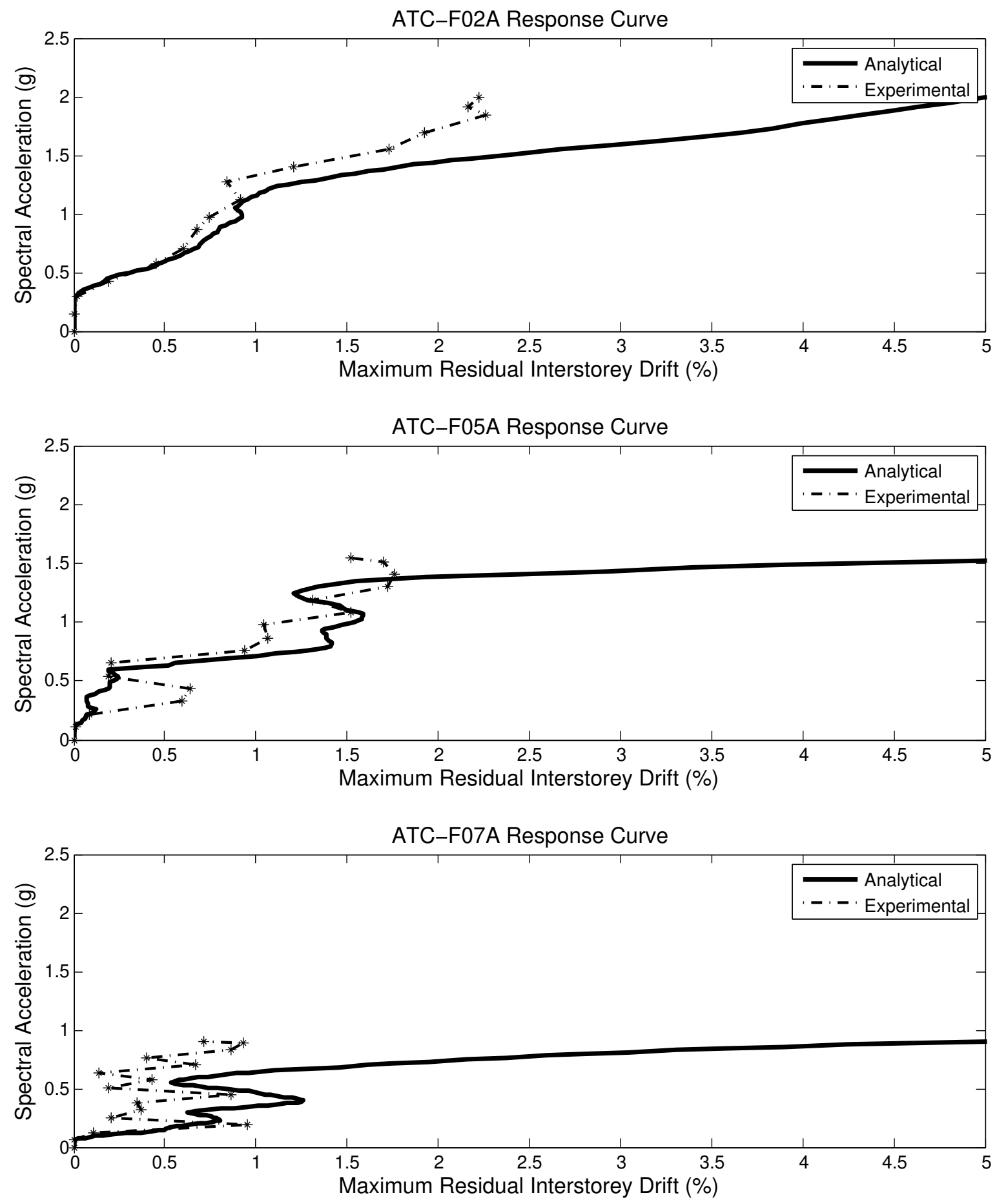

Figure 6.17: IDA Maximum Residual Interstorey Drift Response of ATC-F02A, ATC-F05A and ATC-F07A Records Analytical and Experimental 

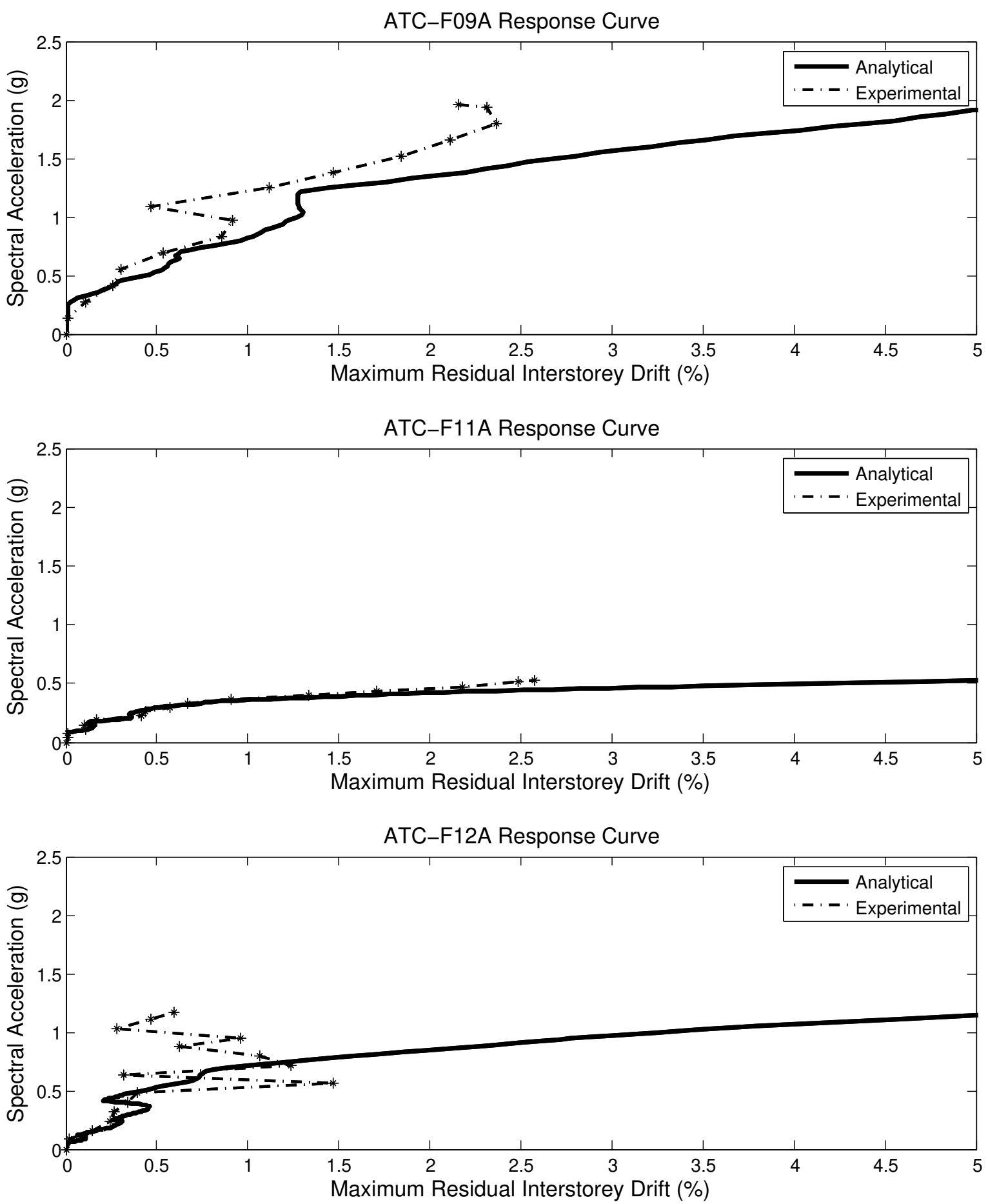

Figure 6.18: IDA Maximum Residual Interstorey Drift Response of ATC-F09A, ATC-F11A and ATC-F12A Records Analytical and Experimental 

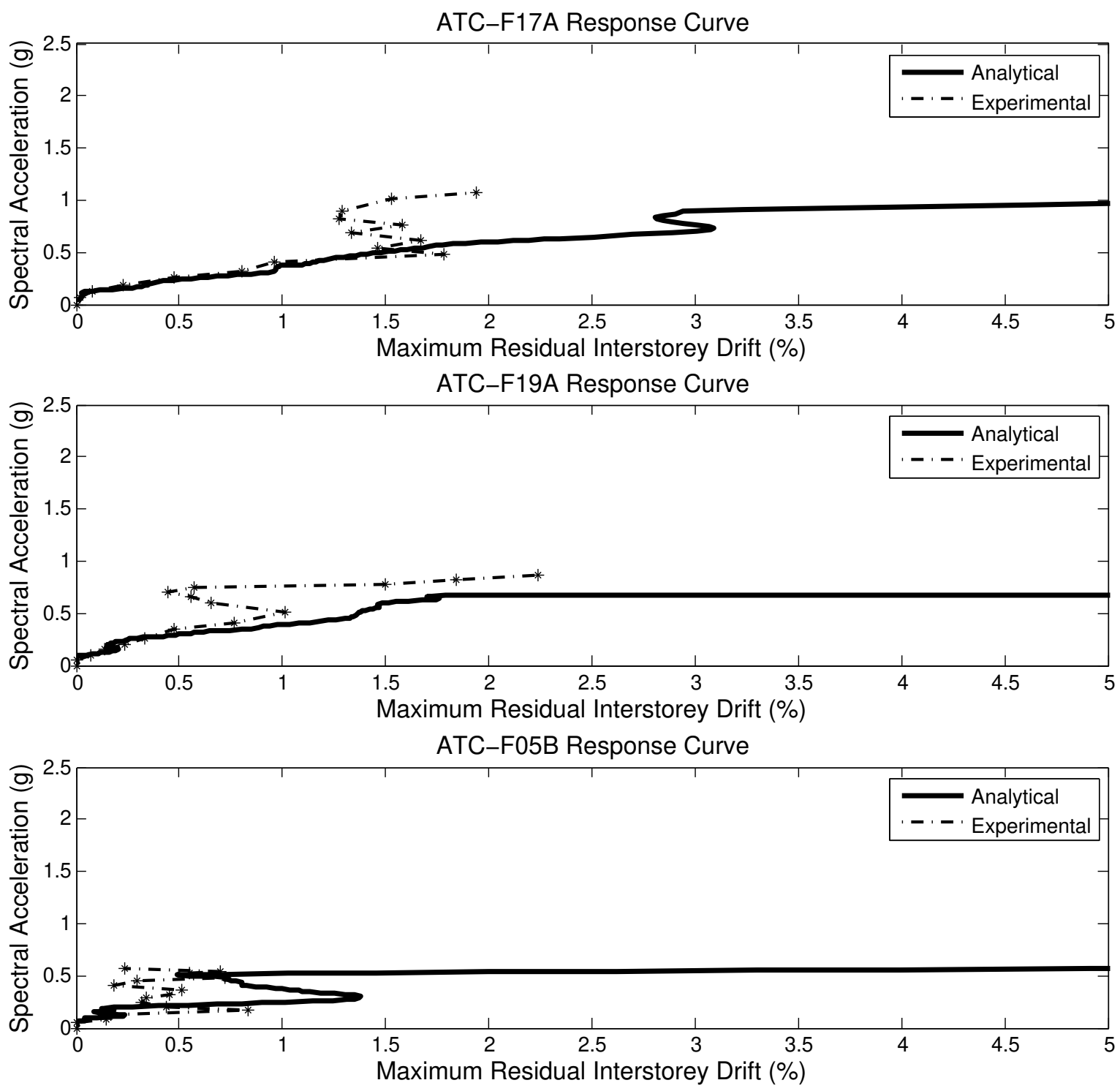

Figure 6.19: IDA Maximum Residual Interstorey Drift Response of ATC-F17A, ATC-F19A and ATC-F05B Records Analytical and Experimental 

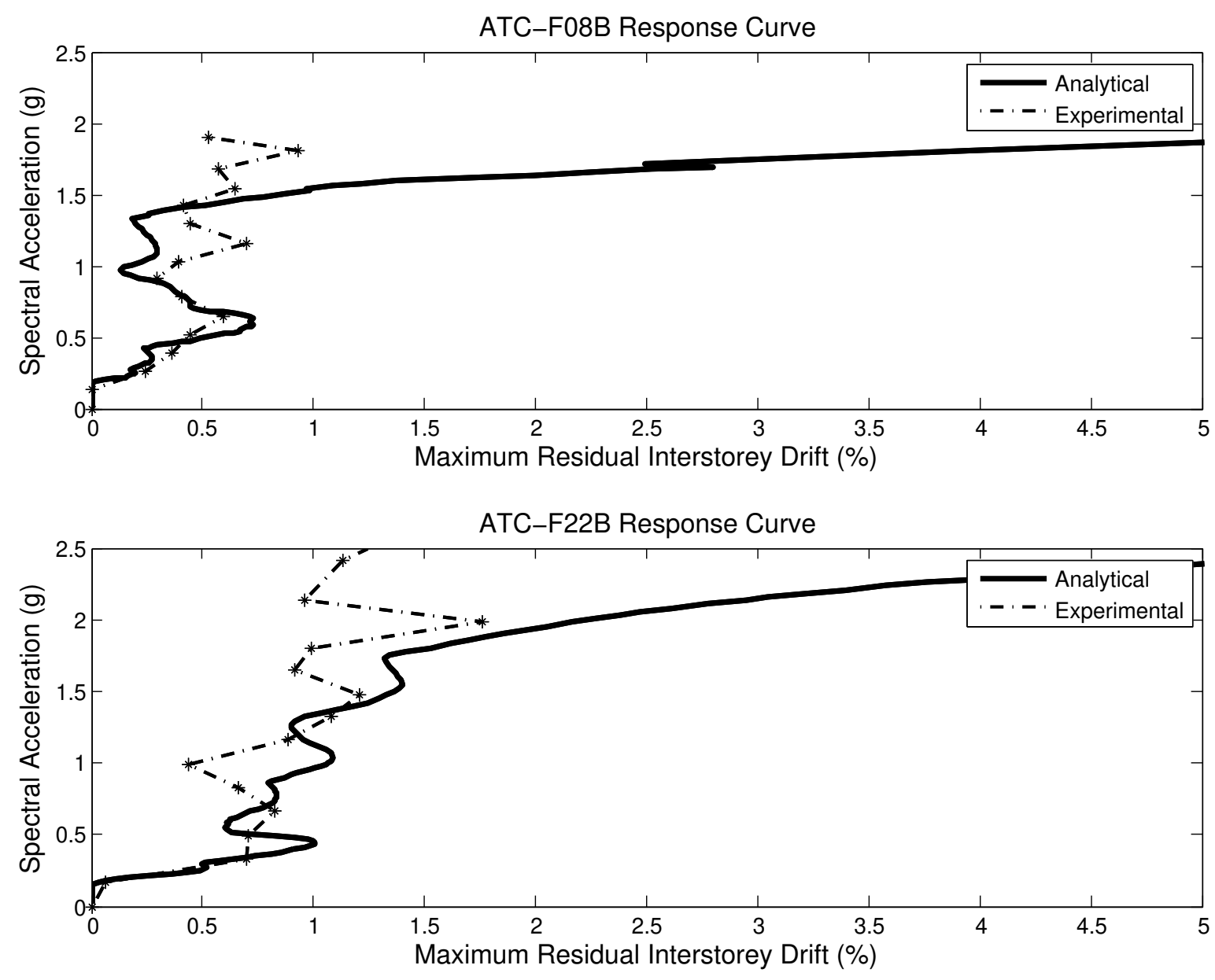

Figure 6.20: IDA Maximum Residual Interstorey Drift Response of ATC-F08B and ATC-F22B Records Analytical and Experimental

\subsubsection{Maximum Interstorey Drift Results}

The maximum interstorey drift IDA responses between the analytical study and the experimental study showed many interesting results. Between 0 and $0.5 \%$ maximum interstorey drift, the IDA response in both experimental and analytical studies contained no weaving behaviour, as illustrated in Figures 6.13 to 6.16. At this point, friction braces were only activated a small amount, less than $20 \mathrm{~mm}$ in extension or compression. Motion in the braces was stick slip. The term stick slip behaviour in this system refers to the behaviour of the braces when motion is stop start; the braces slide a small amount, stop, then slide a small amount, and stop again repetitively. 
Motion is never constant and full cycle motion in extension then compression without stopping does not occur.

Below $1.0 \%$ maximum interstorey drift, the response did not exhibit weaving behaviour as illustrated in both the experimental and analytical IDA results. The response between the analytical and experimental studies were also nearly identical. Between $1.0 \%$ and $2.0 \%$ maximum interstorey drift, weaving patterns in both the experimental and analytical results were present. This can be seen in 5 of the 11 analytical and experimental record IDA results: ATC-F05A, ATCF07A, ATC-F05B, ATC-F08B and ATC-F22B. Above 2.0\%, most analytical weaving responses dissipated, slight weaving behaviour was exhibited by ATC-F17A and ATC-F19A, while no weaving behaviour was present in the experimental results.

Softening behaviour was exhibited following weaving behaviour in all IDA responses leading to the response either exceeding the tangent slope failure limit or the $5 \%$ drift limit. This behaviour was most evident in analytical IDA record responses: ATC-05A, ATC-F07A and ATCF22B. Similarly, this was observed in the experimental results. A shift in responses between analytical and experimental results above a maximum interstorey drift of $1.5 \%$ are illustrated in Figures 6.15 and 6.16. IDA results for ATC-F17A, ATC-F19A, ATC-F05B and ATC-F22B exhibited this behaviour. In all cases, the observable weaving behaviour response or sudden changes in the response in the analytical results were closely matched by the experimental results at slightly lower levels of drift. These results complemented the discussion in Section 6.8.

In all IDA responses, considering maximum interstorey drift results, the experimental curves consistently exhibited less drift at the same magnitudes of spectral acceleration than the analytical results. In each record, the separation or shift between analytical and experimental IDA responses increased with increasing levels of drift once maximum interstorey drifts exceeded approximately $1.5 \%$ drift. Considering the low tangent slope of the responses at drifts in excess of $2.5 \%$, it is understandable that the experimental IDA results lagged behind the analytical results as drifts increased. At the same magnitude of spectral acceleration that caused the analytical curves to meet the $5 \%$ drift limit, the experimental results only reached a drift of approximately $3.0 \%$. If the trend observed was maintained, it is possible that the maximum interstorey drift limit could have been reached experimentally if an additional point was added with a spectral acceleration 
magnitude slightly greater than the analytical 5\% maximum interstorey drift spectral acceleration magnitude.

\subsubsection{Maximum Interstorey Residual Drift Results}

The maximum interstorey residual drift IDA responses between the analytical study and the experimental study displayed many interesting results. Maximum interstorey residual drift IDA curves are illustrated for the 11 records in Figures 6.17 to 6.20. All records, at low magnitudes of spectral acceleration, displayed no interstorey residual drift. This makes sense since the structure is behaving elastically. Similar to the maximum interstorey drift responses discussed in Section 6.8.1, the analytical maximum interstorey residual drift responses between 0 and $0.5 \%$ drift, did not exhibit weaving behaviour with the exception of record ATC-08B. However, unlike the experimental results in Section 6.8.1, weaving behaviour between 0 and $0.5 \%$ maximum interstorey residual drift was exhibited. This behaviour was expected and can be explained by the lag in experimental results. Since the magnitude of spectral acceleration required to achieve the same level of residual interstorey drifts was higher than that to achieve the same maximum interstorey drift, the onset of the lag in the experimental curve results occurred sooner. This separation between experimental and analytical results was illustrated well in records ATC-F07A, ATC-F09A, ATC-F17A, ATC-F19A and ATC-F05B.

Weaving behaviour was exhibited in 7 of the 11 records experimentally and analytically. Four records exhibited strong weaving behaviour both experimentally and analytically. Records ATC-F05A, ATC-F07A, ATC-F08B and ATC-F22B were characteristic of the response weaving multiple times within the IDA response. Similar to the maximum interstorey drift IDA response, the maximum interstorey residual drift response weaving behaviour only occurred between certain drift levels. Weaving behaviour, both experimentally and analytically, generally occurred between $0.2 \%$ and $1.5 \%$ maximum interstorey residual drift with the exception of record ATCF17A. This weaving behaviour occurred at a drift of approximately $0.5 \%$ sooner than was observed in the maximum interstorey drift IDA responses. Unlike the maximum interstorey drift IDA analysis, the experimental IDA curves did not soften as obviously as the analytical IDA curves predicted. Based on these results, it is not evident that an additional IDA point for each 
record at a slightly higher magnitude of spectral acceleration would have caused the responses to soften and match the response of the analytical IDA.

\subsubsection{Comparison of Maximum Interstorey Drift and Maximum Interstorey Residual Drift Results}

The maximum interstorey drift and maximum interstorey residual drift IDA results, both experimentally and analytically, demonstrated weaving, hardening and softening behaviours. Figures 6.13 and 6.17 for record ATC-F07A displayed clear weaving behaviour in which the structure weaved around the elastic slope and displayed successive segments of softening and hardening under different earthquake intensities. This behaviour was also illustrated in the maximum interstorey drift IDA response curves for records: ATC-F05A, ATC-F17A, ATC-F19A, ATC-F05B, ATC-F08B and ATC-F22B. Similarly, weaving behaviour was present in the same records, both experimentally and analytically, in the maximum interstorey residual drift IDA curves.

Figures 6.16 and 6.20 for records ATC-F08B and ATC-F22B illustrated typical hardening behaviour in which the structure initially followed the elastic slope and then hardened under larger ground motion intensity. In addition, the IDA response of both records weaved while hardening. Although this appears counter-intuitive, studies have found that this behaviour occurs as a result of the pattern and timing of the record, as opposed to the intensity (Zareian and Krawinkler, 2007). For example, a strong ground motion may cause earlier slip of a friction brace at a single storey relative to the same record at a lower intensity. This storey then acts as a fuse relative to other storeys in the structure.

Softening behaviour, both experimentally and analytically, is illustrated in Figures 6.13 and 6.19 for record ATC-F11A. Softening responses were generally exhibited in all maximum interstorey drift IDA record curves once drifts exceeded $2.5 \%$ experimentally and analytically. Softening responses also occurred in the analytical IDA results for maximum interstorey residual drifts over $2.5 \%$. The experimental study did not capture maximum interstorey residual drifts in excess of $2.5 \%$.

Sean Miller, Department of Civil and Environmental Engineering, Carleton University 


\subsubsection{Sources of Error Between Analytical and Experimental Results}

The experimental results at the highest levels of spectral acceleration for each individual record produced lower drifts than the analytical results predicted. In all cases, the drifts never exceeded 3.6\%. Interestingly, the fundamental period of the structure was virtually unchanged despite the stiffness of the prototype specimen being slightly lower than anticipated. This was due to the size of the model. The differences in responses between the analytical and experimental results may also have been due to the behaviour in the prototype specimen that was not modeled analytically. Some of these differences could have been due to a slightly higher static slip force than dynamic slip force, movement in connections, as well as, dis-similar behaviour between compression and tension of the glued-in rod connections regarding gap closure and opening. Additionally, the inclusion of the beam element in the prototype specimen softened the response of the structure since it was able to elongate and shorten, unlike the rigid diaphragm in the model. The beam element and it's glued-in rod connections in both tension and compression loading, shortened and elongated by approximately $3 \mathrm{~mm}$ and $4.5 \mathrm{~mm}$, respectively. Figure 6.21 compares the hysteretic behaviour of the assembly at the actuator interface to the hysteretic behaviour of the friction brace. 

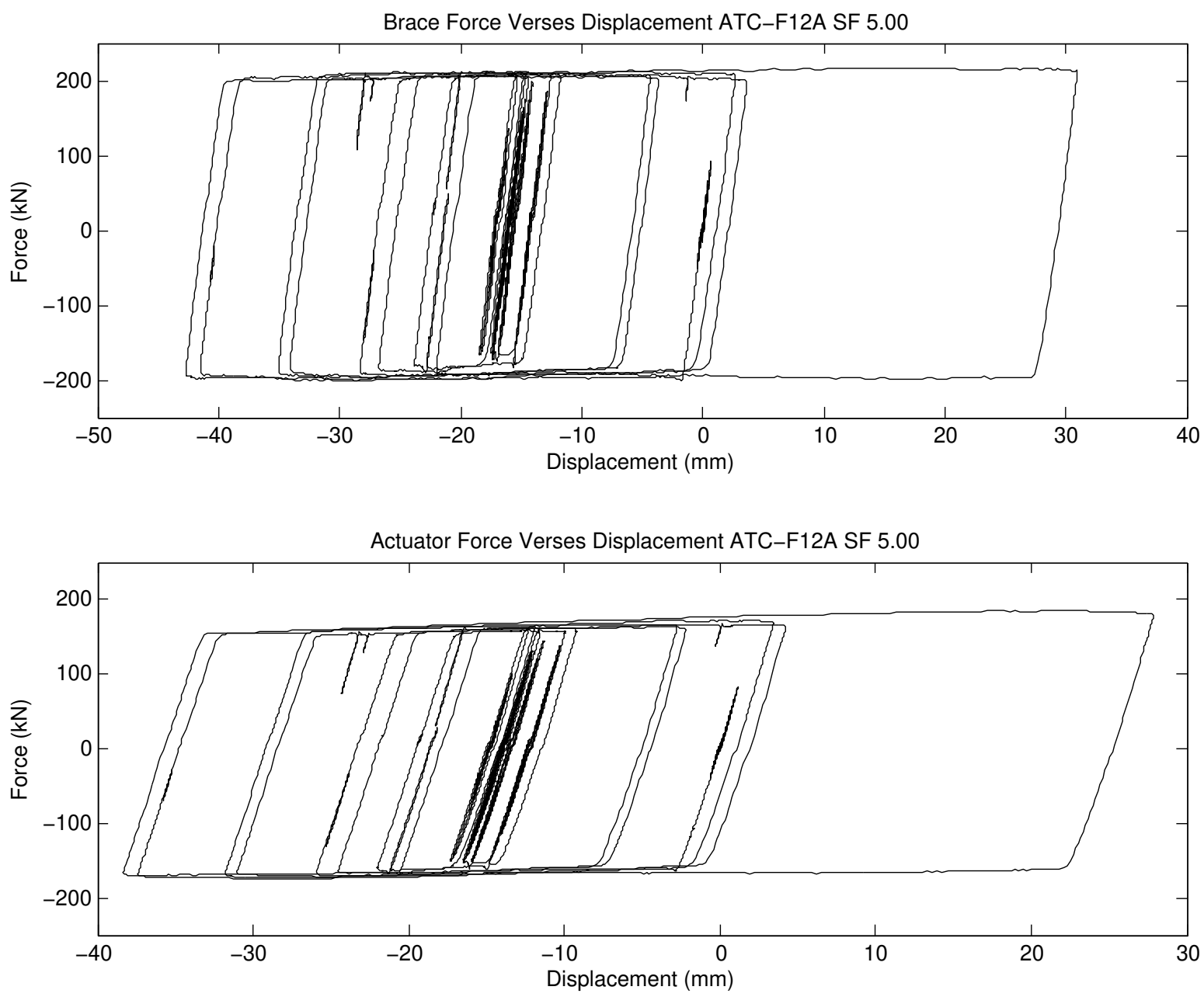

Figure 6.21: Hysteretic Response of Prototype Specimen at Actuator Interface and at Friction Brace Slip Location

\subsection{Prototype Specimen Post Test Condition}

The post test condition of the prototype specimen is illustrated in Figures 6.22 to 6.27. All components of the specimen were in good condition with only minor row shear occurring on the thin gusset plate. The brass and stainless steel wearing surfaces of the friction brace performed as expected with only minor wear. Strain gauges and white washing on all steel components indicated elastic behaviour. Wearing on the brass friction surfaces is illustrated in Figure 6.25. The stainless steel friction surface is illustrated in Figure 6.26. The brass discoloration on the stainless steel friction surfaces is brass that has worn off the brass friction surface and bonded 
to the harder stainless steel friction surface. All wear was confined to the softer brass friction surfaces; this behaviour was expected.

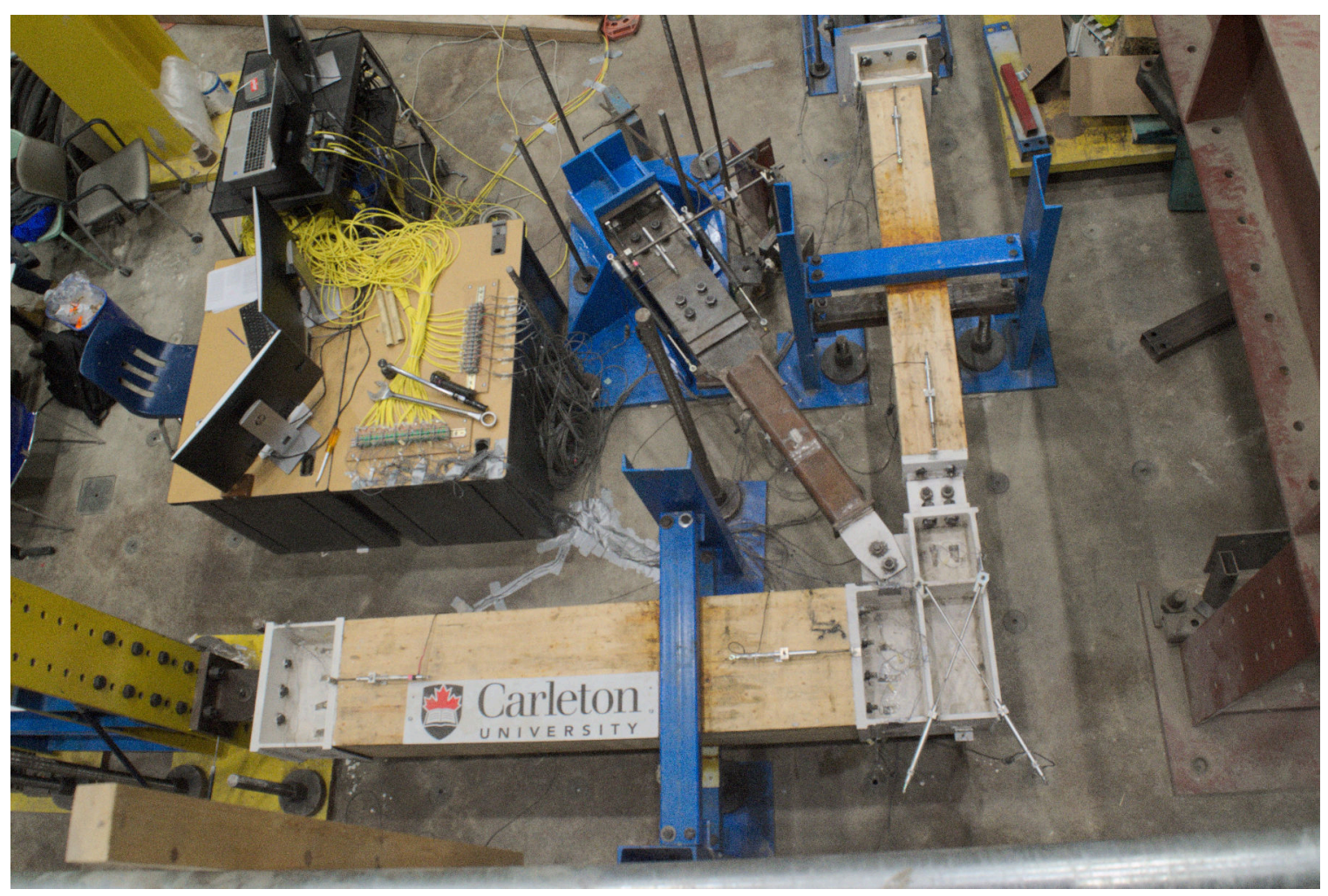

Figure 6.22: Overhead View of Prototype Specimen in Laboratory 
CHAPTER 6. EXPERIMENTAL RESULTS AND

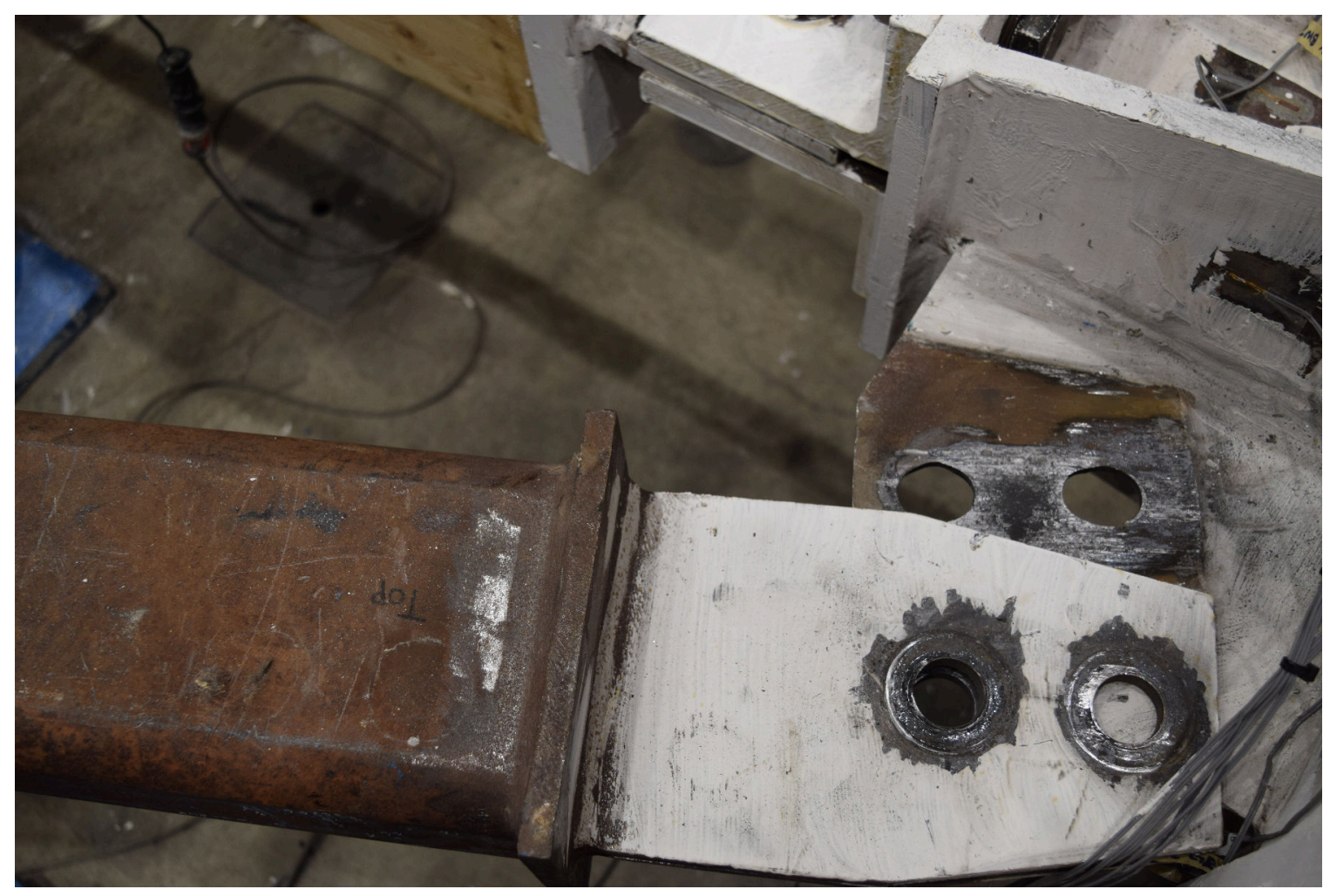

Figure 6.23: Gusset Condition Post Testing 
CHAPTER 6. EXPERIMENTAL RESULTS AND

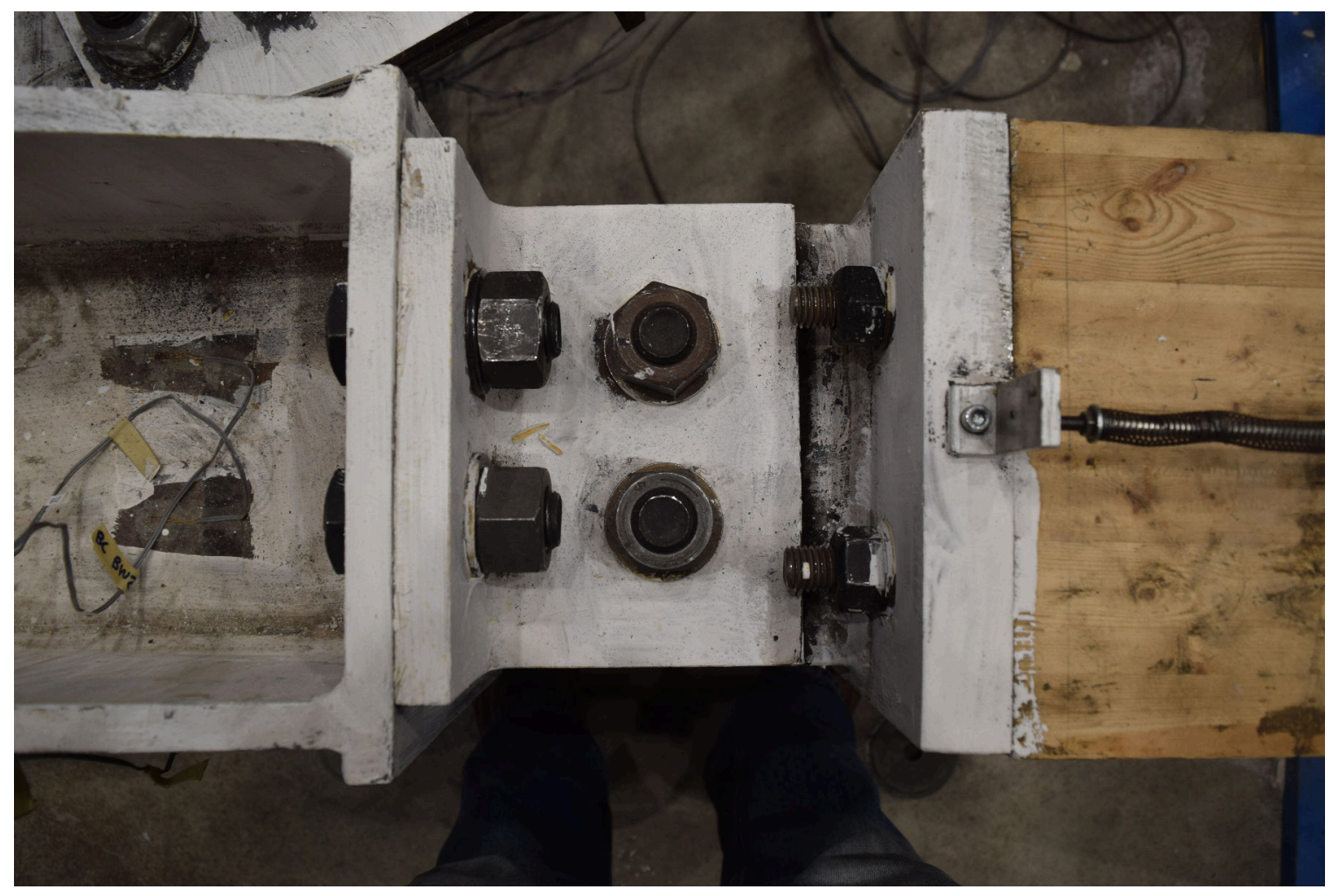

Figure 6.24: Beam Joint Condition Post Testing 


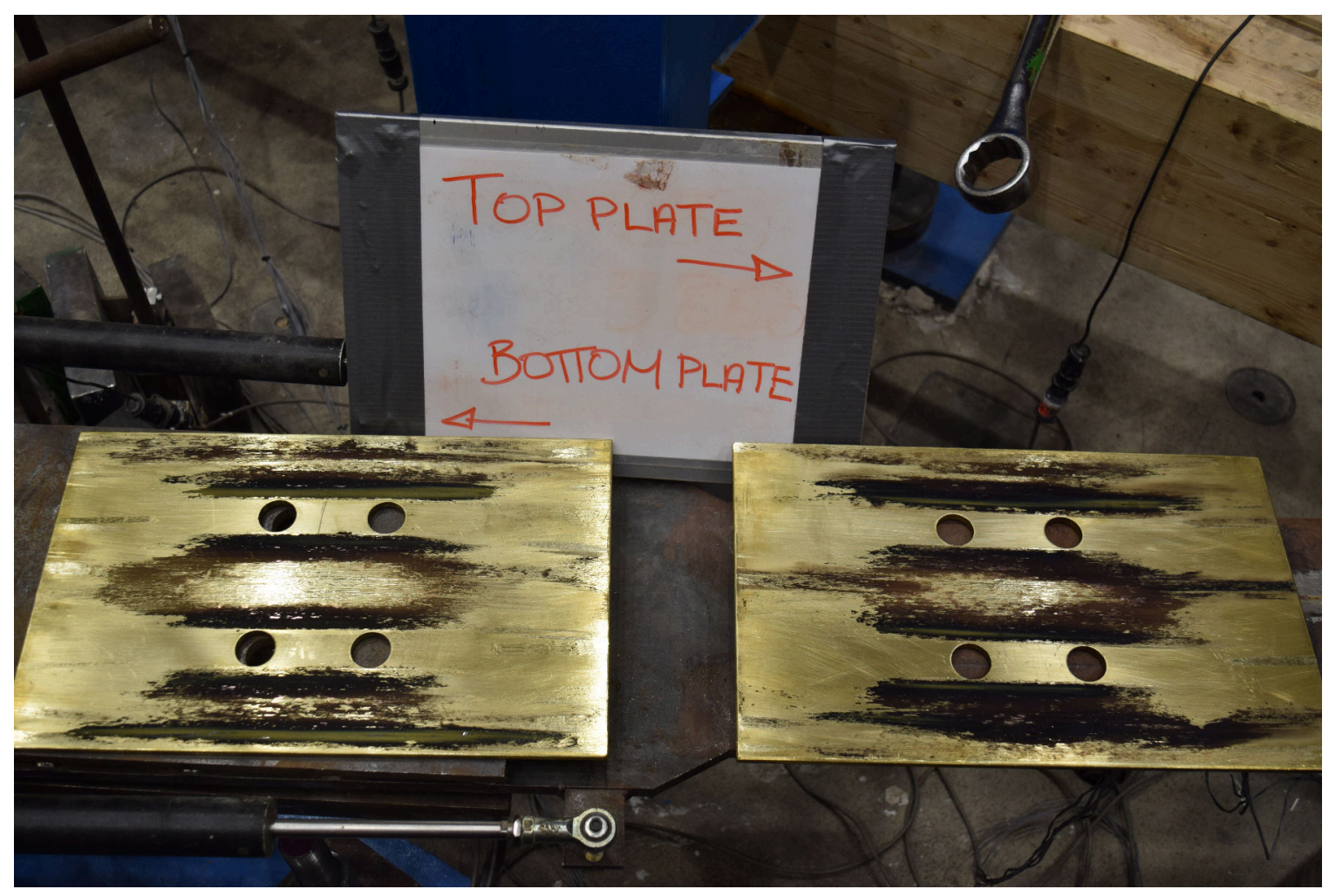

Figure 6.25: Brass Friction Plates Condition Post Testing 


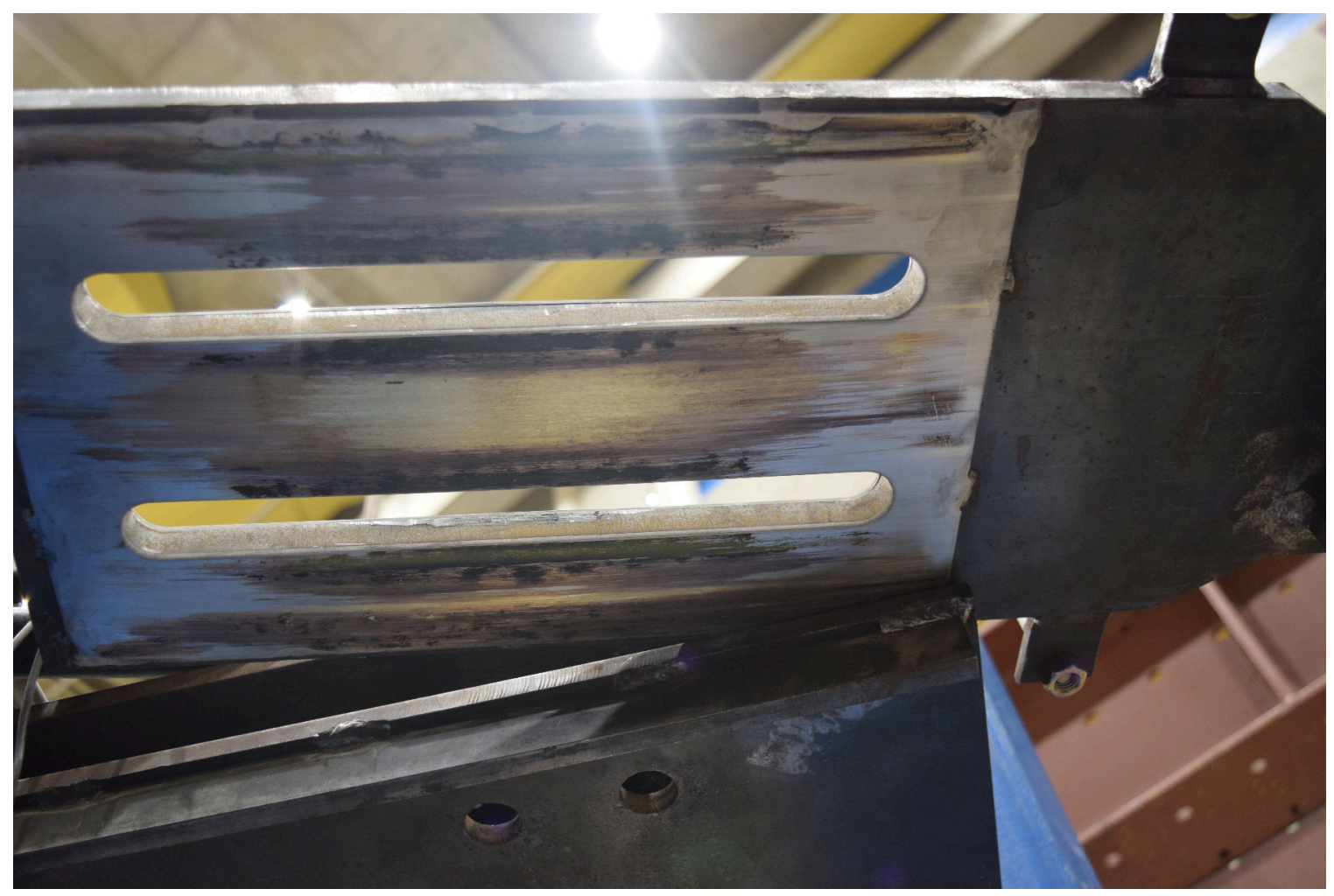

Figure 6.26: Bottom Stainless Steel Friction Plate Condition Post Testing 


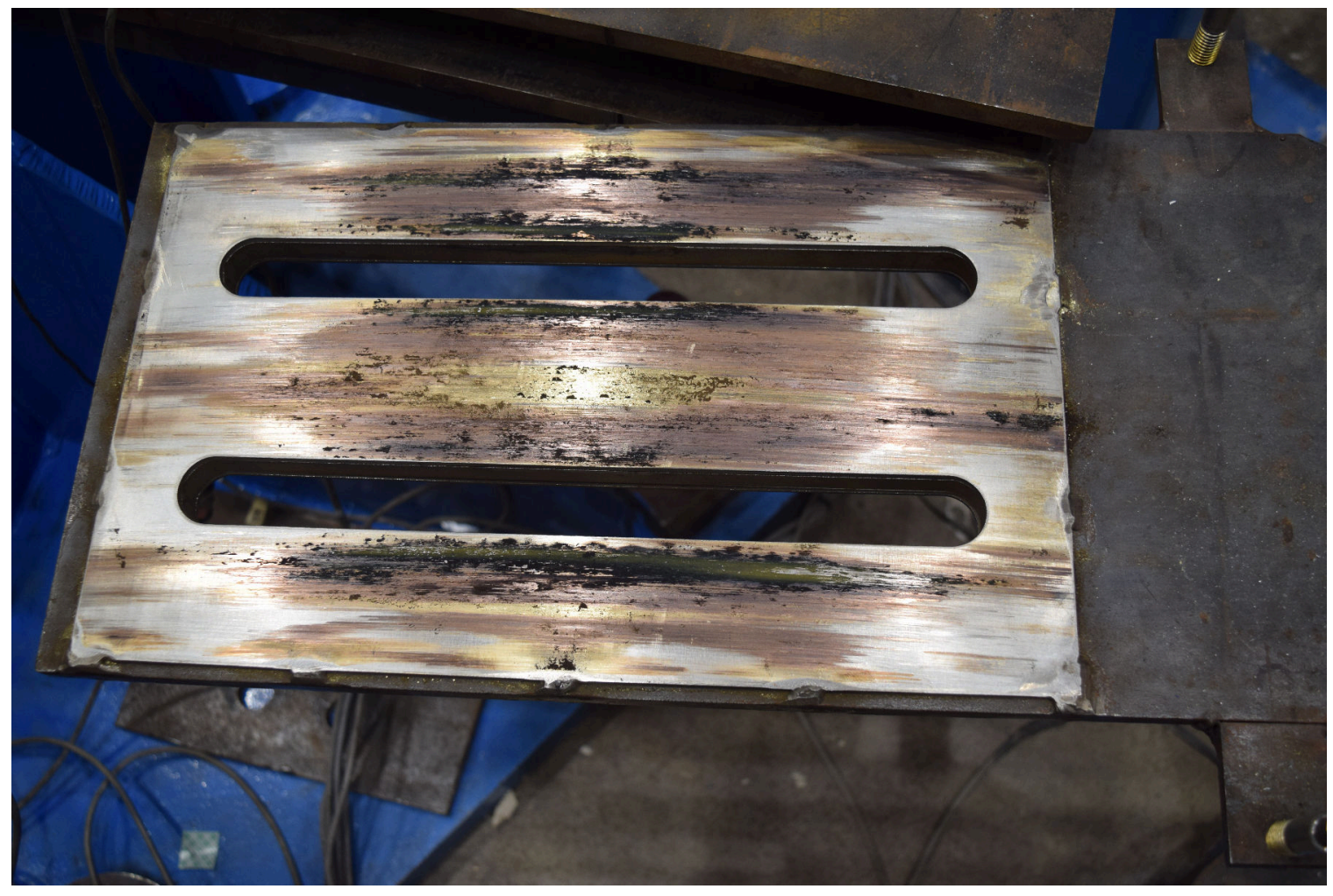

Figure 6.27: Top Stainless Steel Friction Plate Condition Post Testing

\subsection{Experimental and Analytical Fragility Curves}

The results from the experimental IDA curves were used to develop fragility curves to assess the seismic performance of the proposed SFRS. Figures 6.28 and 6.29 illustrate the fragility curves in terms of maximum interstorey drift and maximum interstorey residual drift, respectively, for the prototype structure. Fragility curves were derived for different performance levels based on drift levels of $0.5 \%, 1 \%, 2 \%$, and $2.5 \%$, according to the ASCE 41-06 (ASCE, 2007) Standard. These performance levels include collapse prevention ( $>2 \%$ drift), life safety $(0.5 \%$ $2.0 \% \mathrm{drift}$ ), and immediate occupancy ( $<0.5 \% \mathrm{drift})$. The limit associated with the MCE hazard level shown on the fragility curve plot for maximum interstorey drift was based on the design spectral acceleration at the structure's fundamental period for Victoria, British Columbia (National Research Council of Canada, 2010). This resulted in a MCE spectral acceleration of 0.45g. The DBE hazard level was assumed to be $2 / 3$ of the maximum credible earthquake resulting in 
a spectral acceleration of $0.3 \mathrm{~g}$. Dashed lines in both figures represent experimental results while solid lines illustrate analytical results. The curves from left to right increased in drift from $0.5 \%$ to $2.5 \%$. The intersection of the fragility curve with the specified hazard level, either MCE or DBE, indicated the probability of occurrence of each intensity measurement. In this study, maximum interstorey and maximum interstorey residual drifts are the intensity measure. The curves were fitted with a log normal distribution curve fit based on the sets mean and standard deviation.

The analytical and experimental fragility curves demonstrated excellent seismic performance of the structural system. In all cases, the experimental fragility curves indicated conservative results over the analytical fragility curves in terms of maximum interstorey drift and maximum interstorey residual drift. The maximum interstorey drift fragility curves at $0.5 \%$ and $1.0 \%$ drift levels were nearly identical. This makes sense since the individual IDA curves were very similar. At $2.0 \%$ and $2.5 \%$ drift, the analytical curves illustrated slightly more conservative results than the analytical curves predicted. This result is also in line with the individual IDA results and the separation observed in behaviour. The gap in fragility curve drifts between the experimental and analytical curves also increased with drift; this is illustrated well in the fragility curves. The gap between analytical and experimental fragility curves was larger at $2.5 \%$ drifts than at $2.0 \%$ drifts. The maximum interstorey residual drift fragility curves also displayed conservative results experimentally. At $0.5 \%$ maximum drift, the analytical and experimental results were virtually identical which makes sense since the IDA results illustrated similar responses. However, the fragility curves at $1.0 \%$ maximum interstorey residual drift exhibited much more conservative results. This is in direct agreement with the lag between the experimental and analytical responses.

The probability of reaching the life safety performance limit at the MCE hazard level was approximatively 95\% analytically and experimentally, as illustrated in Figure 6.28. This corresponded to exceeding a maximum interstorey drift of $0.5 \%$. Similarly, the lower limit for the life safety performance category was met when maximum interstorey residual drifts exceeded $0.5 \%$. The probability of reaching this limit was approximately $68 \%$ both analytically and experimentally. The upper limit of the life safety category is $2.0 \%$ for both maximum interstorey drift and maximum interstorey residual drift. The probability of reaching the upper limit of the life safety 
performance category was predicted analytically to be $10 \%$ while experimental results predicted $8 \%$ probability of occurrence. The experimental study did not capture maximum interstorey drifts at $2.0 \%$, but analytical results predicted an $7 \%$ probability of occurrence. These results showed the high seismic performance potential for the combined timber-steel bracing system.

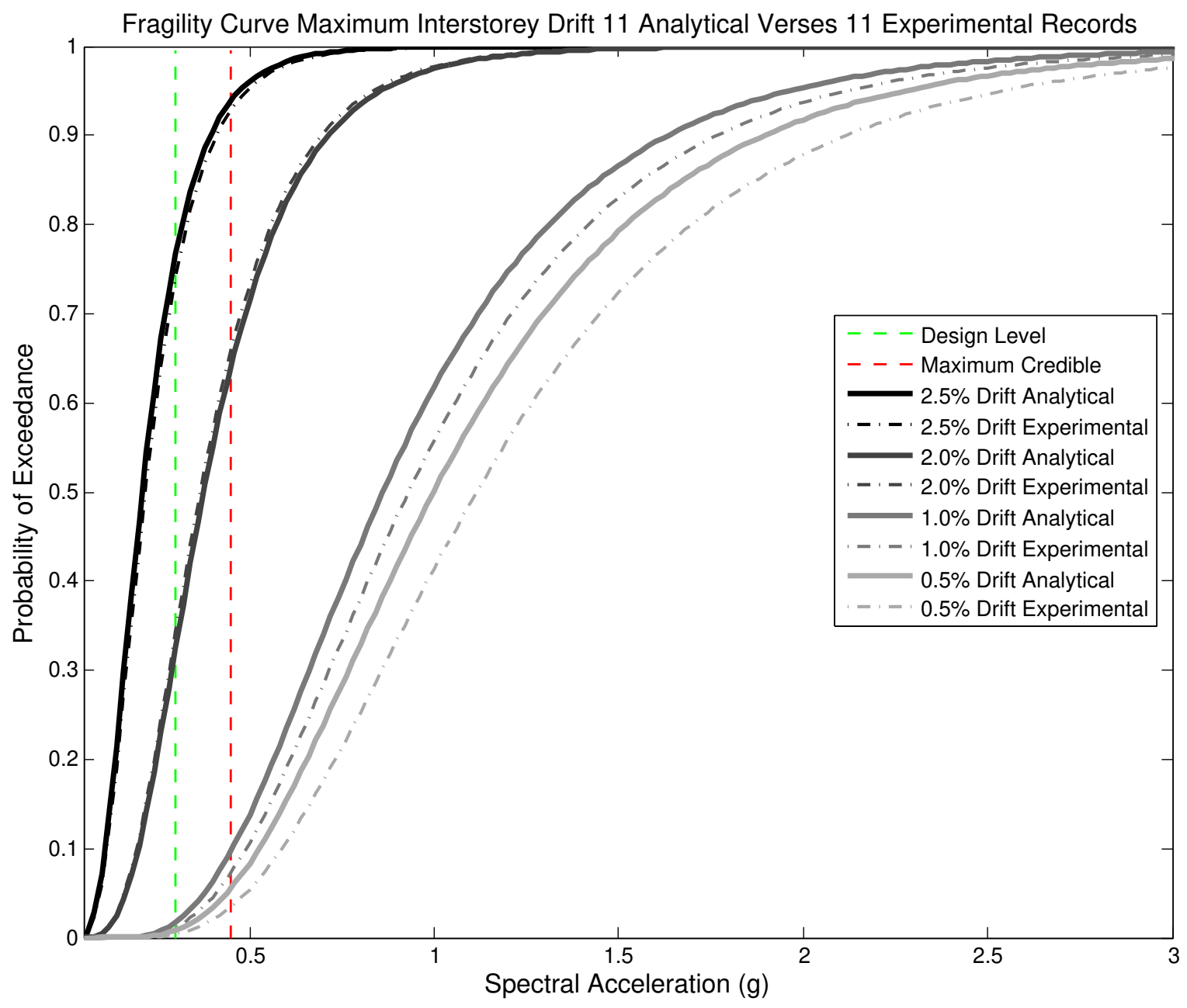

Figure 6.28: Fragility Plot of 11 Analytical and Experimental Record Responses at Maximum Interstorey Drifts 


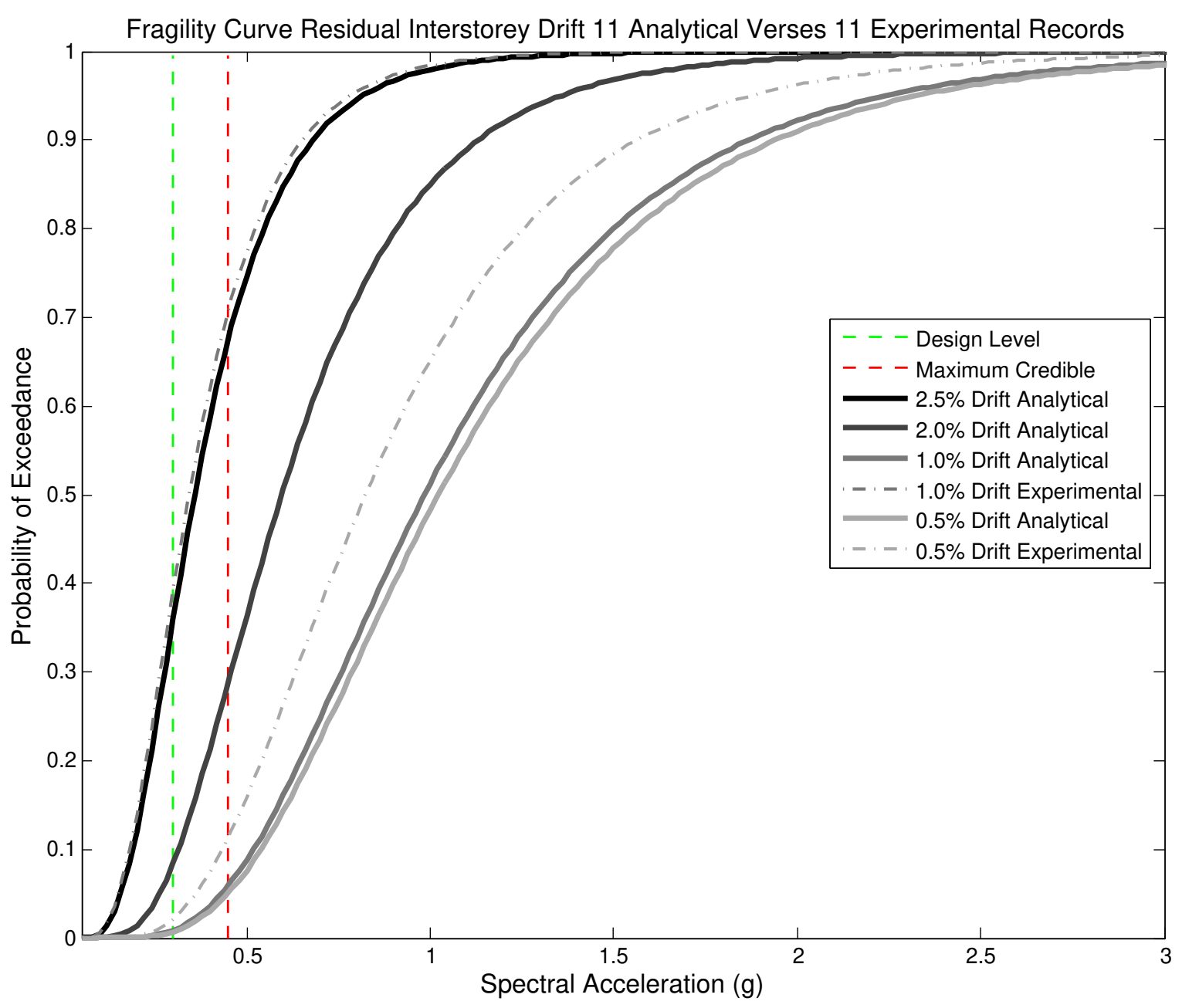

Figure 6.29: Fragility Plot of 11 Analytical and Experimental Record Responses at Maximum Residual Interstorey Drifts

Analytical and experimental IDA curves and subsequent fragility curves for maximum interstorey residual drifts are generally not developed since they require that each record in the study be run fully plus additional time for free vibration. In most cases, the analysis is terminated once the maximum interstorey drift is observed since significant time during the analysis can be saved. In this study, the development of IDA curves and subsequent fragility curves allowed conclusions to be drawn regarding convergence of maximum interstorey drifts and maximum interstorey residual drifts. In Figure 6.30, the maximum interstorey drifts began to converge with maximum interstorey residual drifts as the intensity measure increased from $0.5 \%$ to $2.5 \%$. The maximum interstorey drift converged to the maximum interstorey residual drift at approximately 
$2.5 \%$ drift. Convergence began when weaving behaviour transitioned to softening behaviour responses; this generally occurred around 2.0\% maximum interstorey drift. At $2.5 \%$ drift, all response behaviours exhibited softening, and convergence was almost met.

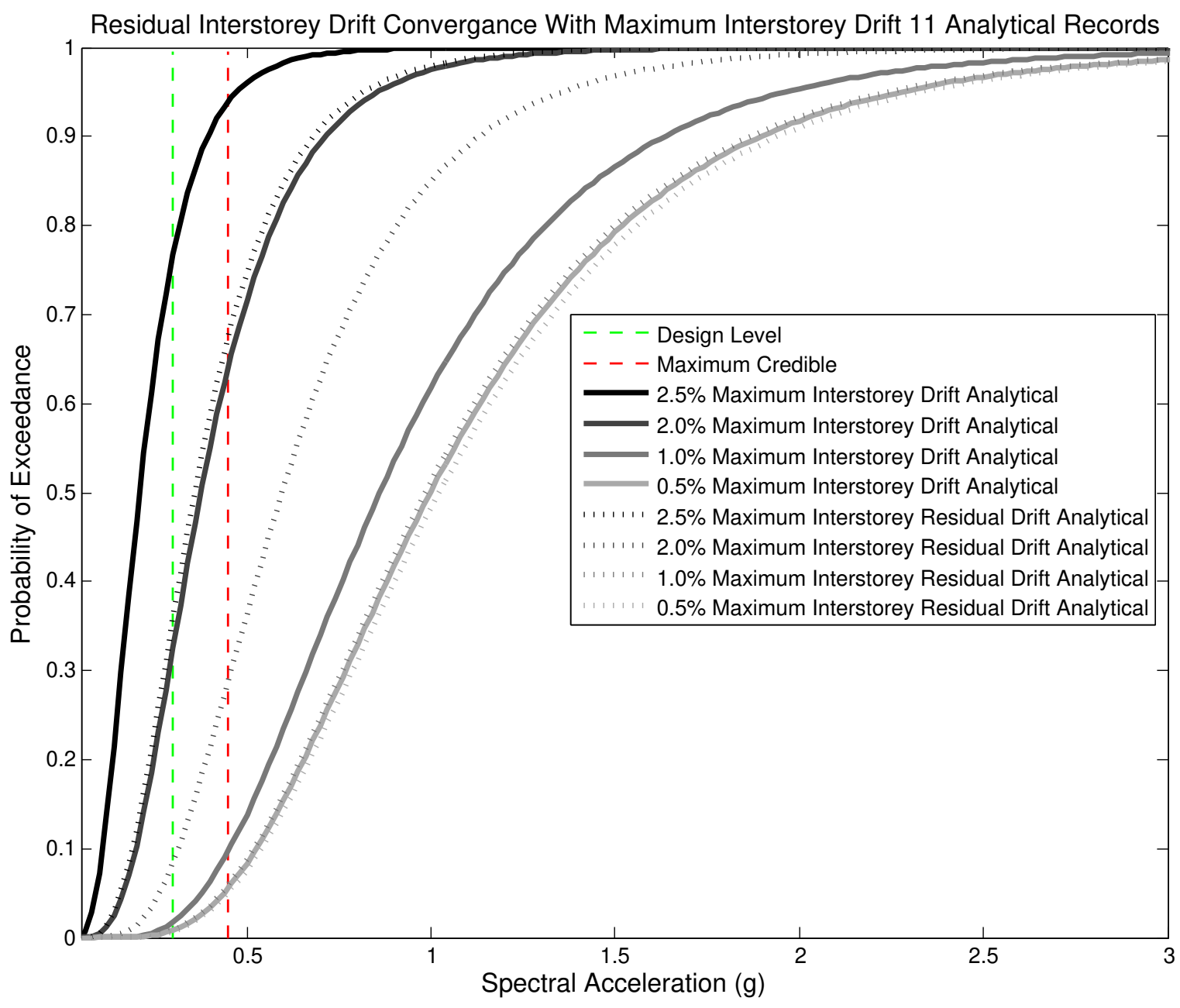

Figure 6.30: Maximum Interstorey Drift Convergence with Maximum Interstorey Residual Drift

\subsection{Results Summary}

IDA curves for maximum interstorey drift and maximum interstorey residual drift were developed using 11 far field earthquake records. An analytical model of the prototype structure developed in OpenSees was used to perform the analytical IDA to predict performance. 
An experimental IDA was performed through hybrid testing to compare model predictions to experimental results. In general, both analytical and experimental results agreed at maximum interstorey drifts of $0.5 \%, 1.0 \%$ and $2.0 \%$. Maximum interstorey drifts began to deviate at and above $2.5 \%$. Maximum interstorey residual drifts were very similar at $0.5 \%$ both experimentally and analytically. Deviation between analytical and experimental results began to occur around $1.0 \%$ drift. Complementing these results, the gap between analytical and experimental results increased with increasing drifts suggesting the separation in response was magnified at higher drift levels. This behaviour was likely due to the unpredictable behaviour of the friction braces while in motion for long periods of time or the slightly lower experimental prototype specimen stiffness than the analytical model predicted.

The probability of reaching the lower limit of the ASCE 41-06 (ASCE, 2007) life safety performance category for the prototype structure at the MCE hazard level was $95 \%$ as analytically and experimentally predicted. The probability of reaching the life safety upper limit was $10 \%$ as analytically predicted and $8 \%$ as experimentally predicted. At these performance levels the structure itself would be undamaged, the friction braces could be simply loosened, the structure straightened and the friction braces re-torqued. In addition, maximum interstorey drifts converged on maximum interstorey residual drifts at approximately $2.5 \%$ drift. The structure's behaviour was somewhat random in that softening, hardening and weaving behaviour responses were all observed. It was also noted that all responses gradually softened to collapse. Overall, the analytical model predicted the experimental results well.

Based on the results of this study, modeling friction braces as biaxial elements is an effective means of capturing the full behaviour of friction braces. In addition, the response behaviour of the friction brace used in this study with a brass on stainless steel friction interface displayed repeatable and predictable behaviour throughout the entire study. This type of friction braced system also exhibited convergence of maximum interstorey and maximum interstorey residual drifts at approximately $2.5 \%$ drift. The combined heavy-timber steel SFRS containing friction braces as the primary source of lateral resistance is an effective means of reducing seismic damage to this type of structure. The modeling system exhibited predictable behaviour for drifts less than $2.5 \%$. Results indicated the model was conservative. 
The ductility of this structure showed improvements over modern heavy timber SFRS. The ductility of this SFRS was in excess of 10 , however, more work is needed to quantify the values of over strength and ductility for this type of SFRS. 


\section{Chapter 7: Concluding Remarks}

In this study, the combined timber-steel system developed by Gilbert (2016) was modified and utilized in a friction braced structure. The 7 storey prototype structure contained glulam frame elements, cross laminated timber floor diaphragms and friction braces. The behaviour of the structure was quantified through an incremental dynamic analysis. An analytical model of the structure was developed in OpenSees and used to perform an analytical IDA to predict the structure's response. Complementing this, an experimental IDA through hybrid testing, was performed to compare the accuracy of the analytical predictions. The hybrid tests used a substructured model consisting of a physical and a numerical substructure. The physical substructure consisted of a lower portion of the prototype structure that was physically tested in the laboratory while the remainder of the structure was modeled analytically in the numerical substructure. Additional highlights include:

- The physical substructure consisted of a first storey corner bay beam, column and friction brace

- The prototype specimen used as the physical substructure in hybrid tests was half scale

- Axial and rotational effects were not applied to the prototype specimen's column element in hybrid tests

- 165 experimental earthquake tests were performed through hybrid testing on the prototype as part of the experimental IDA 


\subsection{Summary of Findings}

IDA curves for maximum interstorey drift and maximum interstorey residual drift were developed using 11 far field earthquake records. An analytical model of the prototype structure developed in OpenSees was used to perform the analytical IDA to predict performance. An experimental IDA was performed through hybrid testing to compare model predictions to experimental results. In general, both analytical and experimental results agreed at maximum interstorey drifts of $0.5 \%, 1.0 \%$ and $2.0 \%$. Maximum interstorey drifts began to deviate at and above $2.5 \%$. Maximum interstorey residual drifts were very similar at $0.5 \%$ both experimentally and analytically. Deviation between analytical and experimental results began to occur around $1.0 \%$ drift. Complementing these results, the gap between analytical and experimental results increased with increasing drifts suggesting the separation in response was magnified at higher drift levels. This behaviour was likely due to the chaotic behaviour of the friction braces while in motion for long periods of time or the slightly lower experimental prototype specimen stiffness than the analytical model predicted.

The probability of reaching the lower limit of the ASCE 41-06 (ASCE, 2007) life safety performance category for the prototype structure at the MCE hazard level was $95 \%$ as analytically and experimentally predicted. The probability of reaching the life safety upper limit was $10 \%$ as analytically predicted and $8 \%$ as experimentally predicted. At these performance levels the structure itself will be undamaged, the friction braces can be simply loosened, the structure straightened and the friction braces re-torqued. In addition, maximum interstorey drifts converged on maximum interstorey residual drifts at approximately $2.5 \%$ drift. The structure's behaviour was somewhat random in that softening, hardening and weaving behaviour responses were all observed. It was also noted that all responses gradually softened to collapse. Overall, the analytical model predicted the experimental results well.

Based on the results of this study, modeling friction braces as biaxial elements is an effective means of capturing the full behaviour of friction braces. In addition, the response behaviour of the friction brace used in this study with a brass on stainless steel friction interface displayed repeatable and predictable behaviour throughout the entire study. This type of friction 
braced system also exhibited convergence of maximum interstorey and maximum interstorey residual drifts at approximately $2.5 \%$ drift. The combined heavy-timber steel SFRS containing friction braces as the primary source of lateral resistance is an effective means of reducing seismic damage to this type of structure. The modeling system exhibited predictable behaviour for drifts less than $2.5 \%$. Results indicated the model was conservative.

The following key findings are highlighted:

- The developed model is accurate at predicting results below $2.0 \%$ maximum interstorey drift

- Results indicated that the model was conservative

- Analytically, this type of friction braced system exhibited convergence of maximum interstorey and maximum interstorey residual drifts at approximately $2.5 \% \mathrm{drift}$

- Analytical and experimental IDA results showed good agreement at $0.5 \%$ for maximum interstorey residual drifts

- Fragility curves demonstrated excellent seismic performance of the structural system at the MCE hazard level

- The gap between analytical and experimental results increased with increasing drifts, suggesting the separation in response was magnified at higher drift levels

- Depending on an earthquake's frequency content, the structure's response behaviour will vary (i.e. softening, hardening, weaving), gradually softening to collapse

- The structures response always softened following weaving behaviour

- It is difficult to predict performance of zero post yield structures in motion for long periods of time as their response behaviour can be unpredictable

- Supporting previous research findings, modeling friction brace's as biaxial elements is an effective means to capture friction braces full behaviour 
- Supporting previous research findings, a brass on stainless steel friction interface has predictable, repeatable behavior

- Supporting previous research findings, remaining within the design parameters for the slotted hole length of friction braces allows for the structure's braces to be loosened, straightened, and re-torqued

- The proposed SFRS limited excessive force on frame elements up to $5 \%$ drift

\subsection{Key Conclusions}

This research demonstrates that:

- The results of the analytical model are similar to the results of the hybrid tests under $2.0 \%$ maximum interstorey drift, which suggests that the analytical model captures the behaviour of the real structure

- Combined heavy timber-steel friction braced SFRS is a feasible method to resist seismic loads and reduce seismic damage to structures

- This combined type of SFRS offers higher ductility than modern heavy timber systems, increasing design efficiency

- This wood-based system offers a more sustainable alternative to more energy-intensive conventional SFRSs (e.g. concrete)

\subsection{Future Research}

Based on the findings and shortcomings of this research, the following directions are presented as areas for future research.

- Investigate the ways in which a near field suite of earthquake records might change the behaviour of the SFRS 
- Explore approaches to capture behaviour of the SFRS up to the 5\% drift limit (e.g. increase stiffness of reaction supports, perform additional IDA points, etc.)

- Evaluate the extent to which structure height affects the behaviour exhibited by the system

- Perform experimental tests in real time, compare these results with those of the current study

- Investigate the extent to which multi degrees of freedom hybrid test with the prototype specimen would increase the reliability of results

- Experimentally test the system to failure 


\section{References}

Aktan, H. (1986). Pseudo dynamic testing of structures. Journal of Engineering Mechanics, 112(2):183-197.

Al-Mahaidi, R. and Hashemi, M. (2017). Advanced hybrid experimental-numerical strategies for safer structures. In on Smart Monitoring Assessment, F. C. and of Civil Structures, R., editors, Fourth Conference on Smart Monitoring Assessment and Rehabilitation of Civil Structures. Second European Conference on Earthquake Engineering and Seismology.

Andreolli, M., Piazza, M., Tomasi, R., and Zandonini, R. (2011). Ductile moment resistant steel timber connections. In Proceedings of the Institution of Civil Engineers Structures and Buildings, pages 64-78. Institution of Civil Engineers Structures and Buildings.

Applied Technology Council (2009). Quantification of Building Seismic Performance Factors. U.S. Dept. of Homeland Security, FEMA.

ASCE (2007). Seismic Rebabilitation of Existing Building ASCE Standard 41-06. ASCE.

Balendra, T., Lam, K., Liaw, C., and Lee, S. (1987). Behaviour of eccentrically braced frame by pseudo dynamic test. Structural Engineering, 4(113):673-688.

Bauwesen, N. (2004). Design of Timber Structures General Rules and Rules of Building. Normenausschuss Bauwesen.

Bazzurro, P. and Cornell, C. (1994a). Seismic hazard analysis for nonlinear structures i methodology. ASCE Journal of Structural Engineering, 120(11):3320-3344.

Bazzurro, P. and Cornell, C. (1994b). Seismic hazard analysis for nonlinear structures ii applications. ASCE Journal of Structural Engineering, 120(11):3345-3365.

Bengtsson, C. and Johanssan, C. (2002). Glued in rods for timber structures. Technical report, Swedish National Testing and Research Institute, Boras, Sweden.

Bertero, V. (1977). Strength and deformation capacities of buildings under extreme environments. Structural Engineering and Structural Mechanics, pages 211-215.

Borzouie, J., MacRae, G., Chase, J., Rodgers, G., and Clifton, G. (2015). Experimental studies on cyclic performance of column base weak axis aligned asymmetric friction connection. Journal of Constructional Steel Research, 112(215):252-262. 
Bowden, P. and Tabor, D. (1973). Friction: An Introduction to Tribology. Anchor Press.

Butterworth, J. (2000). Ductile concentrically braced frames using slotted bolted joints. Journal of the Structural Engineering Society New Zealand, 13(1):39-48.

Christopoulos, C. and Filiatrault, A. (2006). Principles of Passive Supplemental Damping and Seismic Isolation. Iuss Press.

Christopoulos, C., Tremblay, R., Kim, H., and Lacerte, M. (2008). Self centering energy dissipative bracing system for the seismic resistance of structures: Development and validation. Journal of Structural Engineering, 134(1):96-107.

Closen, M. (2012). Self tapping screw assemblies under monotonic and reverse cyclic load. Master's thesis, University of British Columbia, British Columbia Canada.

Computers and Structures Inc. (2013). Etabs (2013).

Connolly, T. and Mettem, C. (2003). Low intrusion conservation system for timber structures (licons). Technical report, Timber Research and Development Association.

Constantinou, M., Tsopelas, P., Kasalanati, A., and Wolff, E. (1999). Property Modification Factors for Seismic Isolation Bearings. Technical Report MCEER-99-0012, Multidisciplinary Center for Earthquake Engineering Research.

CSA 086-14 (2014). Wood Design Manual. CSA 086-14.

CSA A23.3 (2010). CSA A23.3-04 Design of Concrete Structures Standards. CSA A23.3. CSA S16 (2010). CAN/CSA S16-09 Limit States Design of Steel Structures. CSA S16.

Delgado, M. (2014). Hybrid Simulation With Distributed Substructures Including Overlapping Domains. PhD thesis, State University of New York at Buffalo, Buffalo New York.

Doudak, G. (2016). Design of cross laminated timber.

Dubina, D., Ciutina, A., Stratan, A., and Dinu, F. (2000). Ductility demand for semi-rigid joint frames. Moment Resistant Connections of Steel Frames in Seismic Areas, pages 371-408.

Duff, S. (1999). New strategies in seismic design for timber frame structures. In Technology Conference Montreal. ACSA CIB.

Eatherton, M. and Hajjar, J. (2014). Hybrid simulation testing of a self centering rocking steel braced frame system. Earthquake Engineering and Structural Dynamics, 43(11):1725-1742.

Erick, O., Jones, F., Horton, H., and Ryffel, H. (2008). Machinery's Handbook 28th Edition. 
Industrial Press.

Erochko, J. (2013). Improvements to the Design and Use of Post-Tensioned Self Centering Energy Dissipative (SCED) Braces. PhD thesis, Department of Civil Engineering University of Toronto, Toronto Canada.

Filiatrault, A. (1988). Seismic Design of Friction Damped Braced Steel Plane Frames by Energy Methods. PhD thesis, University of British Columbia, British Columbia.

Gilbert, C. (2016). Development of an Innovative Method for the Adaption of Advanced Structural Bracing Systems into Heavy Timber Structures for Seismic Applications. Master's thesis, Carleton University, Ottawa Canada.

Gohlich, R. (2015). Development of an Innovative Hybrid Timber Steel Moment Resisting Frame for Seismic Resistant Heavy Timber Structures. Master's thesis, Carleton University, Ottawa Canada.

Griffith, C., Shao, X., Van de Lindt, J., Bahmani, P., Pang, W., Ziaei, E., and Dao, T. (2013). Hybrid simulation of a wood shear wall frame. In ASCE, editor, Structural Congress, pages 2421-2432. Structures Congress.

Grigorian, C. (1994). Energy Disipaction With Slotted Bolt Connections. PhD thesis, University of California Berkeley, Berkeley California United States.

Humbert, J., Lee, S., Park, L., and Park, M. (2014). Moment resistance of post-and-beam joints with concealed metallic connectors. In World Conference on Timber Engineering Quebec City Canada. World Conference on Timber Engineering.

Javad, H. (2013). Collapse Simulation of Multi Story Buildings Through Hybrid Testing with Substructuring Techniques. PhD thesis, State University of New York at Buffalo, Buffalo New York. Jennings, E., Van de Lindt, J., Shao, X., Pang, W., and Ziaei, E. (2013). Full scale hybrid testing of a soft story woodframe building seismically retrofited using shape memory alloy devices in scissor jack braces. In 10th U.S. National Conference on Earthquake Engineering: Frontiers of Earthquake Engineering, Proceedings, pages 21-25. Tenth U.S. National Conference on Earthquake Engineering Frontiers of Earthquake Engineering.

Kammula, V., Erochko, J., Kwon, O., and Christopoulos, C. (2013). Application of hybrid simulation to fragility assessment of the telescoping self centering energy dissipative bracing 
system. Earthquake Engineering and Structural Dynamics, 43(6):811-830.

Karavasillis, T., Ricles, J., Sause, R., and Chen, C. (2011). Experimental evaluation of the seismic performance of steel mrfs with compressed elastomer dampers using large scale real time hybrid simulation. Engineering Structures, 33(6):1859-1869.

Kim, H., Christopoulos, C., and Tremblay, R. (2004). Experimental Characterization of BoltStressed Non-Asbestos Organic Material-to-Steel Interfaces. Report No. UT2004-3, Department of Civil Engineering.

Komatsu, K., Mori, T., Kitamori, A., and Araki, Y. (2014). Evaluation on dynamic performance of glulam frame structure composed of slotted bolted connection system. In World Conference on Timber Engineering Quebec City Canada. World Conference on Timber Engineering.

Kulak, G., Fisher, J., and Struik, J. (2001). Guide to Design Criteria for Bolted and Riveted Joints 2nd Edition. AISC.

Latour, M., Piluso, V., and Rizzano, G. (2013). Experimental behaviour of friction t stub beam to column joints under cyclic loads. Journal of Steel Construction, 6(1).

Lee, S., Park, E., Min, K., Lee, S., Chung, L., and Park, J. (2007). Real time hybrid shaking table testing method for the performance evaluation of a tuned liquid damper controlling seismic response of building structures. Sound and Vibration, 302(3):596-612.

Lin, P., Tsai, K., Wang, K., Yu, Y., Wei, C., Wu, A., Tsai, C., Lin, C., Chen, J., Schellenberg, A., Mahin, S., and Roeder, C. (2011). Seismic design and hybrid tests of a full scale three storey buckling restraining braced frame using welded end connections and thin profile. Earthquake Engineering and Structural Dynamics, 41(5):1001-1020.

Luco, N. and Cornell, C. (1988). Effects of random connection fractures on demands and reliability for a 3-storey pre northridge smrf structure. In Proceedings of the 6th U.S. National Conference on Earthquake Engineering, page paper 244. Proceedings of the 6th U.S. National Conference on Earthquake Engineering.

Luco, N. and Cornell, C. (2000). Effects of connection fractures on smrf seismic drift demands. ASCE Journal of Structural Engineering, 126:127-136.

Matteis, G., Landolfo, R., Dubina, D., and Stratan, A. (2000). Insuence of the structural typology on the seismic performance of steel framed buildings. Moment Resistant Connections of Steel 
Frames in Seismic Areas, pages 513-538.

McCrum, D. and Williams, M. (2016). An overview of seismic hybrid testing of engineering structures. Engineering Structures, 118:240-261.

McKenna, F., Fenves, G., Scott, M., and Jeremic, B. (2000). Open system for earthquake engineering simulation pacific earthquake engineering research center.

Mehanny, S. and Deierlein, G. (2000). Modeling and assessment of seismic performance of composite frames with reinforced concrete columns and steel beams report no 136. Technical report, Stanford University.

Molina, F., Verzeletti, G., Magonette, G., Buchet, P., and Geradin, M. (1999). Bi directional pseudodynamic test of a full size three storey building. Earthquake Engineering and Structural Dynamics, 28(12):1541-1566.

Nassar, A. and Krawinkler, H. (1991). Seismic demands for sdof and mdof systems report no 95. Technical report, Stanford University.

National Research Council (2011). User's Guide NBC 2010 Structural Commentaries (Part 4 of Division B). Institute for Research in Construction.

National Research Council (2015). 2015 Structural Commentaries Users Guide NBC (Part 4 of Division B). National Research Council.

National Research Council of Canada (2010). National Building Code of Canada 2010. National Research Council Canada Institute for Research in Construction.

Negrao, J., Brito, L., Dias, A., Junior, C., and Lahr, F. (2016). Numerical and experimental study of small scale moment resistant reinforced concrete joints for timber frames. Journal of Construction and Building Materials, 118(2016):89-103.

Pall, S. and Marsh, C. (1982). Response of friction damped braced frames. Journal of Structural Division, 108(ST6):1313-1323.

Psycharis, I., Papastamatiou, D., and Alexandris, A. (2000). Parametric investigation of the stability of classical columns under harmonic and earthquake excitations. Earthquake Engineering and Structural Dynamics, 29:1093-1109.

Rabinowicz, E. (1966). Friction and Wear of Materials. John Wiley and Sons, Inc. 
Schellenberg, A., Mahin, S., and Fenves, G. (2009). Advanced implementation of hybrid simulation pacific earthquake engineering research center university of california berkeley, ca.

Shao, X. and Griffith, C. (2013). An overview of hybrid simulation implementations in nees projects. Engineering Structures, 56(2013):1439-1451.

Shao, X., Pang, W., Griffith, C., Ziaei, E., and Lindt, J. (2016). Development of a hybrid simulation controller for full scale experimental investigation of seismic retrofits for soft story wood frame buildings. Earthquake Engineering and Structural Dynamics, 45(8):1233-1249.

Shao, X., Van de Lindt, J., Bahmani, P., Pang, W., Ziaei, E., Symans, M., Tian, J., Jennings, E., and Dao, T. (2014). Real time hybrid simulation of a stacked wood shear wall with viscous damper. In on Earthquake Engineering, T. U. N. C., editor, Frontiers of Earthquake Engineering, pages -. Tenth U.S. National Conference on Earthquake Engineering.

Shing, B., Bursi, O., and Vannan, M. (1994). Pseudodynamic tests of a concentrically braced frame using substructuring techniques. Journal of Constructional Steel Research, 29(1):121-148.

Shome, N. and Cornell, C. (2004). Probabilistic seismic demand analysis of nonlinear structures. Technical report, Stanford University.

Structurlam Products LP (2016). Crosslam CLT Technical Design Guide. Structurlam Products LP.

Tirca, L., Serban, O., Wang, M., and Modica, D. (2013). Incremental dynamic analysis of existing steel braced frame buildings in moderate seismic zones. Structures Congress.

Tjahyadi, A. (2002). Slotted bolted friction damper as a seismic energy dissipator in a braced timber frame. Master's thesis, Oregon State University, Oregon United States.

Tremblay, T. (1993). Seismic Behavior and Design of Friction Concentrically Braced Frames for Steel Buildings. PhD thesis, University of British Columbia, British Columbia.

Tsai, K. and Hsiao, P. (2008). Pseudo dynamic tests of a full scale cft brb frame part ii specimen performance of buckling restraining braces and connections. Earthquake Engineering and Structural Dynamics, 37(7):1099-1115.

Tsai, K., Hsiao, P., Wang, K., Weng, Y., Lin, M., Lin, K., Chen, C., Lai, J., and Lin, S. (2008). Pseudo dynamic tests of a full scale cft brb frame part i specimen design experiment and analysis. Earthquake Engineering and Structural Dynamics, 37(7):1081-1098. 
Vamvatsikos, D. and Cornell, C. (2002). Incremental dynamic analysis. Earthquake Engineering and Structural Dynamics, 31(3):491-514.

Vamvatsikos, D. and Cornell, C. (2004). Applied incremental dynamic analysis. Earthquake Spectra, 20(2):523-553.

Welch, D., Sullivan, T., and Filiatrault, A. (2014). Equivalent Structural Damping of DriftSensitive Nonstructural Building Components. Tenth U.S. National Conference on Earthquake Engineering Frontiers of Earthquake Engineering.

Woods, J. (2016). Hybrid Simulation of a Multi Storey Reinforced Concrete Shear Wall Structure Doctoral Thesis Proposal. PhD thesis, Carleton University, Ottawa Canada.

Yun, S. (2002). Seismic performance for steel moment frames. ASCE Journal of Structural Engineering.

Zareian, F. and Krawinkler, H. (2007). Assessment of probability of collapse and design for collapse safety. Earthquake Engineering and Structural Dynamics, 36:1901-1914.

Zargar, S. and Medina, R. (2014). Hybrid simulation of an exterior steel column in a 20 storey moment resisting frame. In on Earthquake Engineering, S. E. C. and Seismology, editors, 2nd European Conference on Earthquake Engineering and Seismology 2014 (2nd ECEES): Joint Event of the 15th European Conference on Earthquake Engineering and the 34th General Assembly of the European Seismological Commission. Second European Conference on Earthquake Engineering and Seismology.

Sean Miller, Department of Civil and Environmental Engineering, Carleton University 


\section{Appendix A: Design of Prototype Structure}

The design of the prototype structure described in this Appendix outlines the assumptions, methods and calculations used in the structural analysis of the combined heavy timber-steel structure located in Victoria, British Columbia, Canada. The structure contained friction braces as the primary force resisting system. The structure was analyzed using the 3-dimensional structural analysis program ETABS (Computers and Structures Inc., 2013). The 3-dimensional model was used to determine the seismic design forces and storey drift responses. The structure was designed in accordance with the requirements of the National Building Code of Canada (National Research Council, 2011). Glulam structural members were designed in accordance with the Canadian Wood Design Manual CSA 089-14 (CSA 086-14, 2014) and glued-in rod connections in accordance with procedures outlined in GIROD Report (2002) (Bengtsson and Johanssan, 2002), LICONS Report (2003) (Connolly and Mettem, 2003) and the German Design Code DIN 1052 (2004) (Bauwesen, 2004).

The seven storey structure contained two identical braced friction frames in the east west and north south direction. The structure was 4 bays wide by 4 bays deep, each spaced at $6.5 \mathrm{~m}$ with $3.7 \mathrm{~m}$ tall storeys. Friction braces were located in the outer bays of the seismic force resisting system. The flooring and roof system was a $245 \mathrm{~mm}$ thick cross laminated timber slab running in the north south direction to transfer beams running in the east west direction to columns.

\section{A.0.1 Loads on the Structure}

The structure was designed as an office building resulting in a live load of $2.4 \mathrm{kPa}$ on

all floor diaphragms. The snow load requirements were based on the National Building code requirements (National Research Council, 2011) resulting in a uniform snow load of $1.08 \mathrm{kPa}$ 
on the roof. A parapet height of $0.5 \mathrm{~m}$ was assumed for the analysis. The wind load analysis did not govern the design of the structure and was in accordance with the National Building Code (National Research Council, 2011). Earthquake loads were determined first using the static procedure and refined using the response spectrum analysis (National Research Council, 2011). A summary of the dead, live, snow, wind and earthquake loads is illustrated in Table A.1. The following subsections present the procedures used to determine loading on the structure.

Table A.1: Storey and Roof Pressures

\begin{tabular}{c|cccccc}
\hline $\begin{array}{c}\text { Load } \\
\text { Units }\end{array}$ & $\begin{array}{c}\text { Snow } \\
(\mathrm{kPa})\end{array}$ & $\begin{array}{c}\text { Live } \\
(\mathrm{kPa})\end{array}$ & $\begin{array}{c}\text { Dead } \\
(\mathrm{kPa})\end{array}$ & $\begin{array}{c}\text { Facade Dead } \\
(\mathrm{kN} / \mathrm{m})\end{array}$ & $\begin{array}{c}\text { Wind } \\
(\mathrm{kN})\end{array}$ & $\begin{array}{c}\text { Earthquake } \\
(\mathrm{kN})\end{array}$ \\
\hline Roof & 1.08 & 1.0 & 2.53 & 0.703 & 86 & 765 \\
Floor 7 & 0 & 2.4 & 3.32 & 1.41 & 254 & 1321 \\
Floor 6 & 0 & 2.4 & 3.32 & 1.41 & 415 & 1669 \\
Floor 5 & 0 & 2.4 & 3.35 & 1.41 & 569 & 1756 \\
Floor 4 & 0 & 2.4 & 3.35 & 1.41 & 715 & 2225 \\
Floor 3 & 0 & 2.4 & 3.42 & 1.41 & 849 & 2364 \\
Floor 2 & 0 & 2.4 & 3.42 & 1.41 & 977 & 2868 \\
\hline
\end{tabular}

\section{A.0.2 Dead Loads}

The dead loads on the floor and roof diaphragms are illustrated in Table A.2. The CLT slab floor density was determined based on the density of SPF cross laminated timber slabs manufactured by Structurlam Products LP (Structurlam Products LP, 2016). The building facade load included windows, glass, frames and sash and were determined from CSA A23.3 (2010). All other dead loads were determined from the National Building Code (National Research Council, 2011). 
Table A.2: Storey - Roof - Wall loads

\begin{tabular}{c|c|c|c}
\hline $\begin{array}{c}\text { Location } \\
\text { Units }\end{array}$ & $\begin{array}{c}\text { Floor } \\
(\mathrm{kPa})\end{array}$ & $\begin{array}{c}\text { Roof } \\
(\mathrm{kPa})\end{array}$ & $\begin{array}{c}\text { Exterior Wall } \\
(\mathrm{kN} / \mathrm{m})\end{array}$ \\
\hline Floor Coverings & 0.10 & 0.00 & 0 \\
Fire Proofing & 0.10 & 0.10 & 0 \\
Ceiling & 0.24 & 0.24 & 0 \\
Insulation & 0.00 & 0.10 & 0 \\
Mech Elec & 0.48 & 0.48 & 0 \\
CLT Slab & 1.17 & 1.17 & 0 \\
Partitions & 1.00 & 0.00 & 0 \\
Roofing & 0.00 & 0.24 & 0 \\
Building Facade & 0.00 & 0.00 & 1.41 \\
\hline Total & 3.09 & 2.33 & 1.41 \\
\hline
\end{tabular}

\section{A.1 Snow Loads}

The procedure used to determine snow loading on the structure was from the National Building Code (National Research Council, 2011). Equations A.1 to A.3 and Table A.3 illustrate the procedure and assumptions made. The parapet height on the structure was $500 \mathrm{~mm}$. The resulting snow load on the structure was $1.08 \mathrm{kPa}$ uniformly over the entire roof area.

$$
\begin{gathered}
S=I_{s}\left[S_{s}\left(C_{b} C_{w} C_{s} C_{a}\right)+S_{r}\right] \\
C_{b}=0.8 \text { forl } l_{c} \leq\left[\frac{70}{C_{w}^{2}}\right] \\
l_{c}=2 w-\frac{w^{2}}{l}
\end{gathered}
$$


Table A.3: Snow Load Variables

\begin{tabular}{c|ccc}
\hline Item & Value & Units & Note \\
\hline$I_{s}$ & 1.0 & $(-)$ & Importance Factor \\
$S_{s}$ & 1.1 & $(\mathrm{kPa})$ & 1 in 50 probability ground snow load \\
$C_{b}$ & 0.8 & $(-)$ & Basic roof snow load factor \\
$C_{w}$ & 1.0 & $(-)$ & Wind exposure factor \\
$C_{s}$ & 1.0 & $(-)$ & Roof slope factor \\
$C_{a}$ & 1.0 & $(-)$ & Shape factor \\
$S_{r}$ & 0.2 & $(\mathrm{kpa})$ & Associated Rain Load less than $S_{s} C_{b} C_{w} C_{s} C_{a}$ \\
$w$ & 26.0 & $(\mathrm{~m})$ & Smaller plan dimension \\
$l_{c}$ & 26.0 & $(\mathrm{~m})$ & Characteristic length of Roof \\
$l$ & 26.0 & $(\mathrm{~m})$ & Larger Plan Dimension \\
$S$ & 1.08 & $(\mathrm{kpa})$ & Snow Load \\
\hline
\end{tabular}

\section{A.1.1 Wind Loads}

The procedure used to determine wind loading on the structure was from the National Building Code (National Research Council, 2011). Equations A.4 to A.5 and Table A.4 illustrate the procedure and assumptions made. The cumulative wind loads on the center of each floor and roof diaphragm are illustrated in Table A.5. Wind loading did not govern the design of the structure.

$$
\begin{gathered}
p=I_{w} \cdot q \cdot C_{e} \cdot C_{g} \cdot C_{p} \\
C_{e}=\left(\frac{h}{10}\right)^{0.2}
\end{gathered}
$$


Table A.4: Wind Load Variables

\begin{tabular}{c|c}
\hline variable & Description \\
\hline$p$ & Specified external pressure acting statically \\
$h$ & Height of the floor \\
$C_{e}$ & Exposure factor for open terrain \\
$I_{w}$ & Importance factor for wind load 1.0 \\
$q$ & Reference velocity 0.57 \\
$C_{g}$ & Gust effect factor 2.0 \\
$C_{p}$ & External pressure coefficient 0.8 windward -0.5 leeward \\
\hline
\end{tabular}

Table A.5: Wind Load Calculation

\begin{tabular}{|c|c|c|c|c|c|c|}
\hline Height & $C_{e}$ & $\begin{array}{c}P \\
\text { Windward } \\
(\mathrm{kPa})\end{array}$ & $\begin{array}{c}P \\
\text { Leeward } \\
(\mathrm{kPa})\end{array}$ & $\begin{array}{l}\text { Total } \\
\text { forces } \\
(\mathrm{kN})\end{array}$ & $\begin{array}{c}\text { Cumulative } \\
\text { Frame Load } \\
(\mathrm{kN})\end{array}$ & $\begin{array}{c}\text { Individual } \\
\text { Brace Force } \\
(\mathrm{kN})\end{array}$ \\
\hline 25.9 & 1.21 & 1.10 & -0.69 & 86 & 86 & 24 \\
\hline 22.2 & 1.17 & 1.07 & -0.67 & 167 & 254 & 71 \\
\hline 18.5 & 1.13 & 1.03 & -0.64 & 161 & 415 & 116 \\
\hline 14.8 & 1.08 & 0.99 & -0.62 & 154 & 569 & 159 \\
\hline 11.1 & 1.02 & 0.93 & -0.58 & 146 & 715 & 200 \\
\hline 7.4 & 0.94 & 0.86 & -0.54 & 134 & 849 & 237 \\
\hline 3.7 & 0.90 & 0.82 & -0.51 & 128 & 977 & 273 \\
\hline
\end{tabular}

\section{A.1.2 Seismic Design}

\section{A.1.2.1 Equivalent Static Design Method}

The equivalent static seismic design procedure was used to establish the preliminary design forces and an upper limit on the seismic force resisting system. The elastic seismic design was in accordance with the National Building Code (National Research Council, 2011). Equation A.6 to A.12 and Table A.7 illustrate the procedure used to calculate the earthquake forces in all braces in the structure.

Site class $\mathrm{C}$ soil conditions were assumed, and the acceleration and velocity factors $F_{a}$ 
and $F_{v}$ were 1.0 and 1.0, respectively. Five percent supplemental damping for the structure was assumed. The $5 \%$ supplemental damped design spectrum and factored ordinates for Victoria are illustrated in Table A.6. The concentrically braced frame design period Ta was determined from Equation A.6 (National Research Council, 2011).

$$
T_{a}=0.025 h_{n}=0.025(25.9)=0.65 \mathrm{sec}
$$

Where $h_{n}$ is the total height of the structure. This period was used to calculate the elastic design base shear $V_{e d}$ at maximum spectral acceleration of $0.69 \mathrm{~g}$ and a corresponding upper limit of $2 T_{a}$ of 1.3 seconds and spectral acceleration of $0.32 \mathrm{~g}$. The seismic weight of the structure was determined from the total dead load plus $25 \%$ of the snow load. The storey breakdown of seismic weight is illustrated in Table A.7. Ductility and over strength factors $R_{d}$ and $R_{o}$ for friction braced structures are not codified and were assumed to be the same as for a buckling restrained braced structure at 4.0 and 1.2, respectively. The importance factor for the structure was set at 1.0 and the higher mode effect factor $M_{v}$ is equal to 1.0 for structures with a fundamental period less than 1.0 second. The seismic design base shear force was calculated using Equation A.7 (National Research Council, 2011),

Table A.6: Design Spectrum For Victoria British Columbia Canada

\begin{tabular}{c|c}
\hline $\mathrm{T}(\mathrm{s})$ & $S_{a}(\mathrm{~T})$ \\
Units & $(\mathrm{g})$ \\
\hline 0.2 & 1.20 \\
0.5 & 0.82 \\
1.0 & 0.38 \\
2.0 & 0.18 \\
4.0 & - \\
\hline
\end{tabular}




$$
V=\frac{S\left(T_{a}\right) M_{v} I_{E} W}{R_{d} R_{o}}
$$

The vertical distribution of seismic forces was distributed using Equation A.8 based on relative seismic weight and storey height (National Research Council, 2011).

$$
F_{x}=\frac{\left(V-F_{t}\right) W_{x} h_{x}}{\left(\left(\sum_{i=1}^{n}\right) W_{i} h_{i}\right)}
$$

where $F_{t}$ accounts for the higher mode effects applied at the roof level presented in Equation A.9.

$$
F_{t}=0.07 T_{a} V
$$

To account for accidental eccentricity in the structure, a notional load, $N_{x}$, was applied to the lateral direction of the structure. Equation A.10 illustrates the notional load participation at each storey and roof level, where $P_{x}$ is the total gravity load on the storey in question. Table A.7 illustrates the notional load contribution.

$$
N_{x}=0.005 P_{x}
$$

P-Delta effects increase lateral displacements under earthquake loading. This phenomena was accounted for by magnifying the lateral load by a factor of $U_{2}$, illustrated in Equation A.11. The seismic magnification factor for each floor level is illustrated in Table A.7.

$$
U_{2}=(1+\theta)
$$

Where $\theta$ is the stability coefficient illustrated in Equation A.12.

$$
\theta=\frac{P_{x} \Delta}{R_{o} V_{x} h_{s} x}
$$

Where $P_{x}$ is the axial gravity load in the columns, $\theta$ is the anticipated storey drift assumed to be $1.0 \%$ of the storey height which equals $0.037 \mathrm{~m}, R_{o}$ is the over strength factor $1.2, h_{s x}$ is the storey 
height $3.7 \mathrm{~m}$ and $V_{x}$ is the seismic force at the storey in question. An additional magnification factor of $10 \%$ was considered to account for structural irregularities and accidental eccentricity in the building due to torsion. Due to the symmetric layout of the structure, this factor could be exempt. This magnification factor is illustrated under heading $1.1 F_{x}$ in Table A.7. A summary of the total lateral seismic design forces per brace is illustrated in Table A.7. 


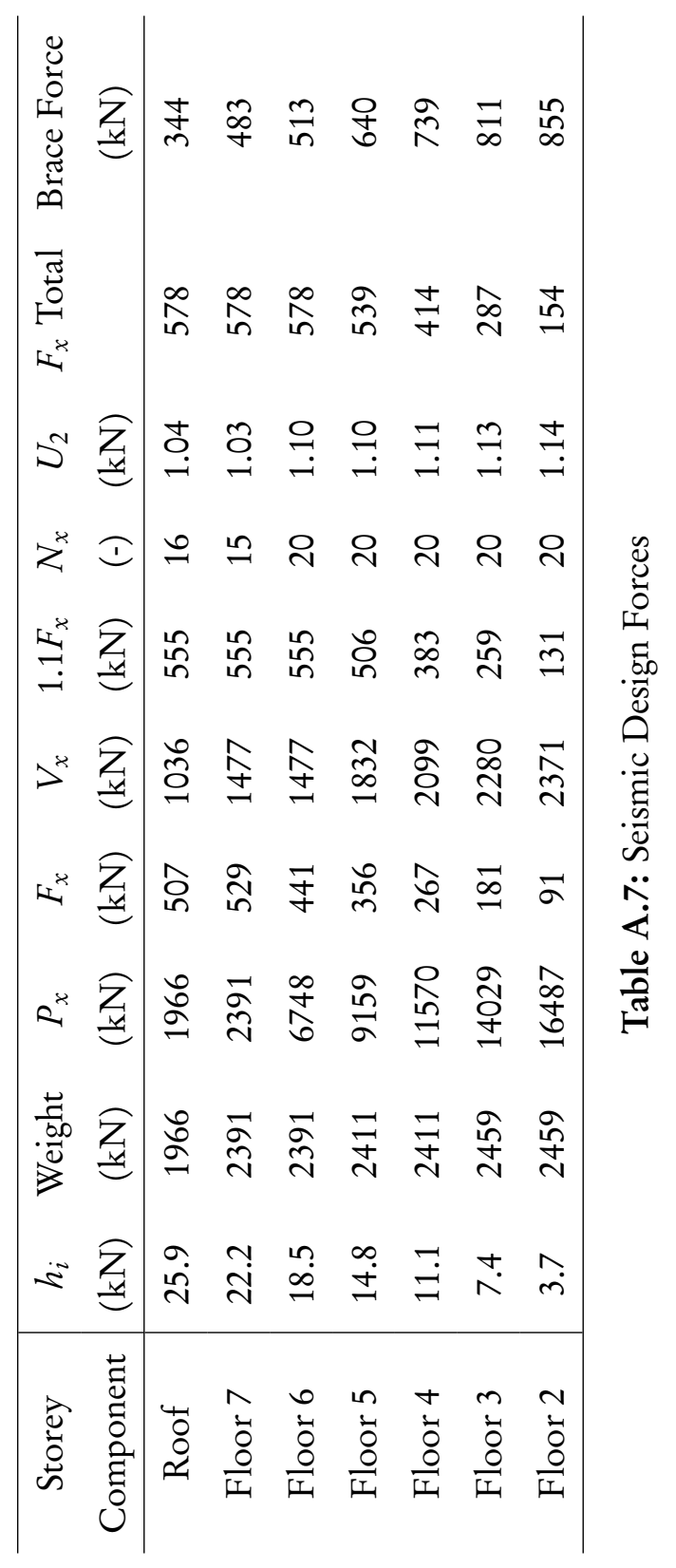




\section{A.1.2.2 Response Spectrum Analysis}

The iterative response spectrum analysis was completed following the equivalent static seismic design to reduce brace forces and improve the overall design of the structure. The analysis followed the procedure outlined in the Canadian National Building Code (National Research Council, 2011). The analysis was carried out using a 3 dimensional ETABS model of the structure (Computers and Structures Inc., 2013). The glulam beam and column elements were modeled as Douglas Fir-Larch 24F-EX members using an orthotropic material type with a modulus of elasticity of $12800 \mathrm{MPa}$ as per CSA 086, 2014 (CSA 086-14, 2014). The friction braces were modeled as steel hollow structural section members provided by the program. The floor and roof slabs were modeled as shell elements and assigned their corresponding properties. The analysis was carried out in the north south direction where rotations in each storey perpendicular to the plane of movement were restrained. To account for accidental eccentricity, the center of rigidity and center of mass were separated by $5 \%$. Using this model, the fundamental period $\left(T_{a}\right)$, seismic weight $(W)$ and elastic base shear $\left(V_{e}\right)$ were determined using the National Building code (National Research Council, 2011) spectral load case. Since the ductility factor $R_{d}$ is greater than 1.5 and the structure was located on soil of site class less than F, Equation A.13 was multiplied by the elastic base shear, $V_{e d}$. Note the, spectral acceleration $S_{a}$ at the fundamental period of the restrained model was determined from Table A.6.

The first six modes were considered in the response spectrum analysis, see Figure A.1. This accounted for approximately $90 \%$ mass participation in the two orthogonal directions and rotation. A breakdown of the mass participation is illustrated in Table A.8. 

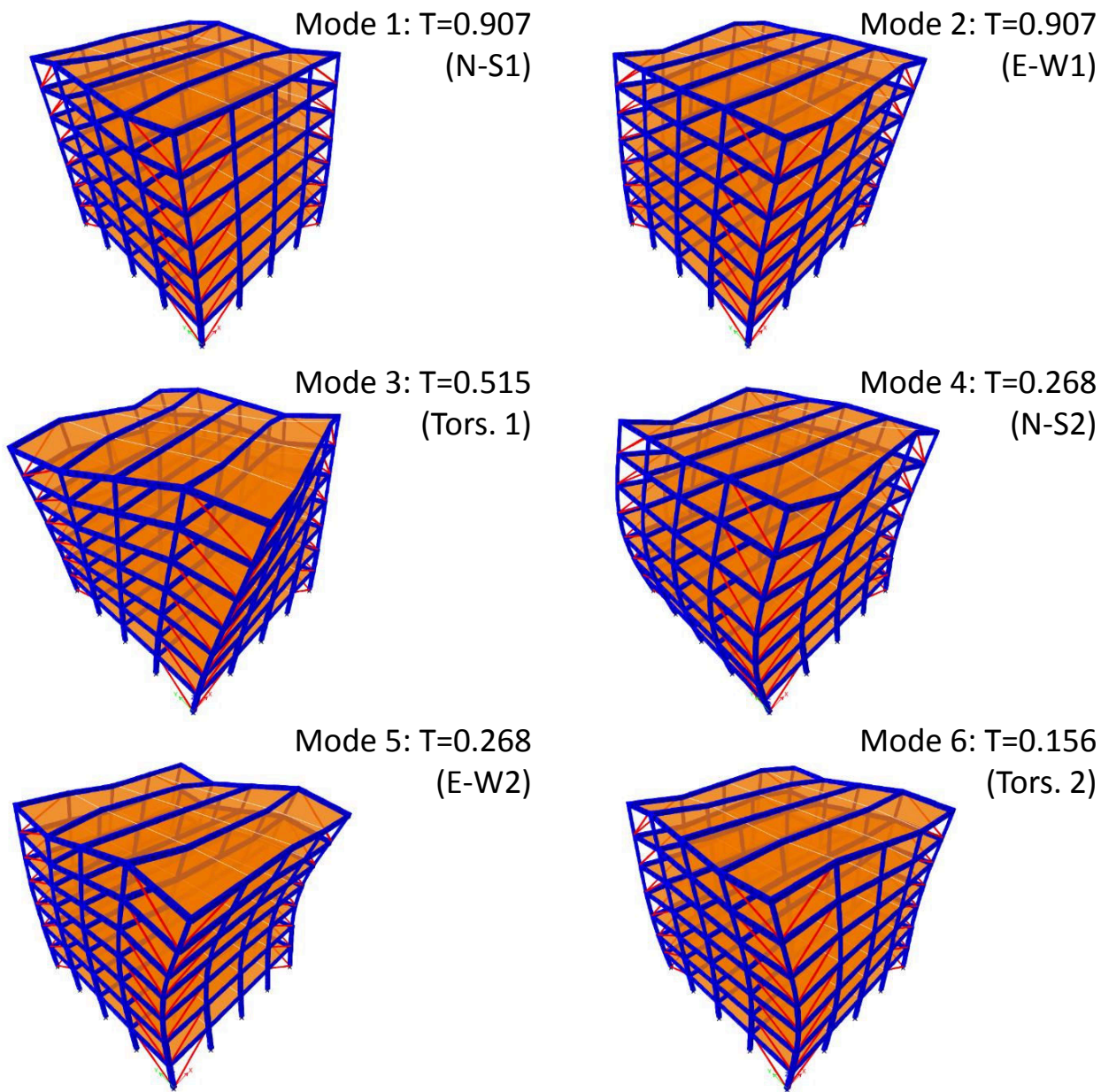

(E-W2)

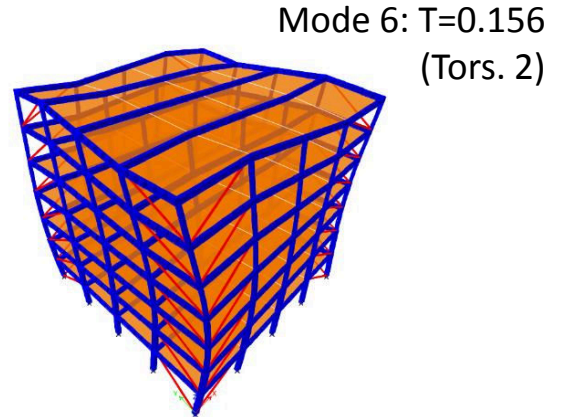

Figure A.1: Structures First 6 Mode Shapes and Associated Periods 
Table A.8: Modal Mass Participation Ratio of Structure

\begin{tabular}{|c|c|c|c|c|}
\hline \multirow{3}{*}{$\begin{array}{l}\text { Mode } \\
\text { Units }\end{array}$} & \multirow{3}{*}{$\begin{array}{c}\text { Period } \\
(s)\end{array}$} & \multicolumn{3}{|c|}{ Modal Mass Participation } \\
\hline & & N-S & E-W & Rotation \\
\hline & & $\%$ & $\%$ & $\%$ \\
\hline 1 & 0.907 & 69.5 & 0 & 0 \\
\hline 2 & 0.907 & 0 & 69.5 & 0 \\
\hline 3 & 0.515 & 0 & 0 & 73.9 \\
\hline 4 & 0.268 & 21.1 & 0 & 0 \\
\hline 5 & 0.268 & 0 & 21.1 & 0 \\
\hline \multirow[t]{2}{*}{6} & 0.156 & 0 & 0 & 19.3 \\
\hline & Total \% & 90.6 & 90.6 & 93.2 \\
\hline
\end{tabular}

$$
\frac{2 S(0.2)}{3 S\left(T_{a}\right)}
$$

The minimum design base shear $V$ from the equivalent static method is illustrated in Equation A.14. The fundamental period $\mathrm{Ta}$ is the lesser of the model period or the upper limit period of $2 T_{a}$.

$$
V=\frac{S\left(T_{a}\right) M_{v} I_{E} W}{R_{d} R_{o}}
$$

The fundamental period of the restrained structure was 0.907 seconds and the corresponding upper limit was 1.3 seconds. The design base shear was then calculated as illustrated in Equation A.15 with the limit of $80 \%$ of base shear present in Equation A.13.

$$
V_{d}=\frac{I_{E} V_{e d}}{R_{d} R_{o}}
$$

Following this, the rotational restraints were removed from the model. Results from the unrestrained ETABS model were scaled by the ratio of $V_{d}$ to $V_{e}$. Drift results in the lateral direction were magnified by $R_{d} R_{o}$. Table A.9 illustrates the axial force in the friction braces from the response spectrum analysis and Table A.10 illustrates the anticipated storey drifts. The dynamic 
slip activation force in the braces was the same as the axial force found from the response spectrum analysis illustrated in Table A.9.

Table A.9: Force in Friction Braces From Response Spectrum Analysis

\begin{tabular}{c|c}
\hline $\begin{array}{c}\text { Brace Location } \\
\text { Units }\end{array}$ & $\begin{array}{c}\text { Axial Force } \\
(\mathrm{kN})\end{array}$ \\
\hline Storey 7 - Roof & 220 \\
Storey 6 - Storey 7 & 380 \\
Storey 5 - Storey 6 & 480 \\
Storey 4 - Storey 5 & 505 \\
Storey 3 - Storey 4 & 640 \\
Storey 2 - Storey 3 & 680 \\
Ground - Storey 2 & 825 \\
\hline
\end{tabular}

Table A.10: Storey Drift Response

\begin{tabular}{c|c}
\hline Floor Location & Interstorey Drift (\%) \\
\hline Storey 7 - Roof & 1.08 \\
Storey 6 - Storey 7 & 1.12 \\
Storey 5 - Storey 6 & 1.07 \\
Storey 4 - Storey 5 & 0.95 \\
Storey 3 - Storey 4 & 0.85 \\
Storey 2 - Storey 3 & 0.64 \\
Ground - Storey 2 & 0.53 \\
\hline
\end{tabular}

\section{A.2 Final Member Sizing}

The final member sizes of the prototype structure are illustrated in Table A.11. Table A.13 to A.16 illustrate the tensile, compression parallel to grain, shear and moment capacity of all frame elements. 
Table A.11: Member Sizes

\begin{tabular}{|c|c|c|c|c|c|c|}
\hline location & $\begin{array}{c}\text { Exterior } \\
\text { Column } \\
\mathrm{mm}\end{array}$ & $\begin{array}{c}\text { Interior } \\
\text { Column } \\
\mathrm{mm}\end{array}$ & $\begin{array}{c}\text { Exterior } \\
\text { Beam } \\
\mathrm{mm}\end{array}$ & $\begin{array}{c}\text { Interior } \\
\text { Beam } \\
\text { mm }\end{array}$ & $\begin{array}{l}\text { CLT Floor } \\
\text { \# 35mm plys } \\
-\end{array}$ & $\begin{array}{l}\text { Friction Brace } \\
\text { mm }\end{array}$ \\
\hline Roof & & & $265 \times 494$ & $265 \times 494$ & 7 & \\
\hline Storey 7 - R & $265 \times 265$ & $265 \times 265$ & & & & HSS152x $203 \times 13$ \\
\hline Floor 7 & & & $265 \times 494$ & $265 \times 494$ & 7 & \\
\hline Storey 6 - 7 & $265 \times 265$ & $342 \times 342$ & & & & HSS $152 \times 203 \times 13$ \\
\hline Floor 6 & & & $265 \times 494$ & $265 \times 494$ & 7 & \\
\hline Storey 5 - 6 & $265 \times 265$ & $265 \times 265$ & & & & HSS152x203x13 \\
\hline Floor 5 & & & $265 \times 494$ & $265 \times 494$ & 7 & \\
\hline Storey 4 - 5 & $342 \times 342$ & $342 \times 342$ & & & & HSS152x203x13 \\
\hline Floor 4 & & & $265 \times 494$ & $265 \times 494$ & 7 & \\
\hline Storey 3 - 4 & $342 \times 342$ & $342 \times 342$ & & & & HSS152x $203 \times 13$ \\
\hline Floor 3 & & & $265 \times 494$ & $265 \times 494$ & 7 & \\
\hline Storey 2 - 3 & $465 \times 465$ & $465 \times 465$ & & & & HSS152x203×13 \\
\hline Floor 2 & & & $265 \times 494$ & $265 \times 494$ & 7 & \\
\hline Ground - 2 & $465 \times 465$ & $465 \times 465$ & & & & HSS152x $203 \times 13$ \\
\hline
\end{tabular}




\section{A.2.1 Capacities of Glulam Beam and Column Elements}

The shear, moment and axial capacity of the beam and column elements is illustrated in this section. Table A.12 illustrates and describes the variables used. All equations illustrated in this section are from the Canadian Wood Design Manual (CSA 086-14, 2014). 
Table A.12: Variables and Descriptions for Timber Design Equations A.16 to A.23

\begin{tabular}{|c|c|c|}
\hline Variable & Units & Description \\
\hline$A_{g}$ & $\left(\mathrm{~mm}^{2}\right)$ & Gross area of cross section \\
\hline$K_{D}$ & $(-)$ & Duration factor \\
\hline$K_{H}$ & $(-)$ & System factor \\
\hline$K_{S c}$ & $(-)$ & Service condition factor compression parallel to grain \\
\hline$K_{T}$ & $(-)$ & Treatment factor \\
\hline$K_{X}$ & $(-)$ & Curvature factor \\
\hline$K_{L}$ & $(-)$ & Lateral stability factor \\
\hline$K_{C}$ & $(-)$ & Slenderness factor \\
\hline$f_{t g}$ & $(\mathrm{MPa})$ & Tension strength parallel to grain gross \\
\hline$f_{t}$ & $(\mathrm{MPa})$ & Tension strength parallel to grain \\
\hline$f_{v}$ & $(\mathrm{MPa})$ & Specified strength in shear \\
\hline$f_{b}$ & $(\mathrm{MPa})$ & Specified strength in bending \\
\hline$I$ & $\left(\mathrm{~mm}^{4}\right)$ & Moment of inertia in the plane of the applied moment \\
\hline$L_{e}$ & $(\mathrm{~mm})$ & Effective length in the plane of the applied moment \\
\hline$E$ & $(\mathrm{MPa})$ & Specified modulus of elasticity \\
\hline$E_{05}$ & $(\mathrm{MPa})$ & Modulus of elasticity 5 percent \\
\hline$C_{c}$ & $(\mathrm{MPa})$ & Slenderness ratio \\
\hline$C_{v}$ & $(-)$ & Shear load coefficient \\
\hline$Z$ & $\left(\mathrm{~m}^{3}\right)$ & Beam volume \\
\hline$b$ & $(\mathrm{~mm})$ & Beam width / lamination width \\
\hline$d$ & $(\mathrm{~mm})$ & Beam depth \\
\hline$L$ & $(\mathrm{~mm})$ & Length of beam segment \\
\hline$T_{r}$ & $(\mathrm{kN})$ & Tensile resistance parallel to grain \\
\hline$T_{f}$ & $(\mathrm{kN})$ & Factored axial load in tension \\
\hline$P_{r}$ & $(\mathrm{kN})$ & Factored compressive resistance parallel to grain \\
\hline$P_{f}$ & $(\mathrm{kN})$ & Factored axial load in compression \\
\hline$P_{E}$ & $(\mathrm{kN})$ & Euler buckling load in the plane of the applied moment \\
\hline$V_{r}$ & $(\mathrm{kN})$ & Shear resistance \\
\hline$M_{r 1}$ & $(\mathrm{kN} \cdot \mathrm{m})$ & Factored moment resistance \\
\hline$M_{r 2}$ & $(\mathrm{kN} \cdot \mathrm{m})$ & Factored moment resistance \\
\hline$S$ & $\left(\mathrm{~mm}^{3}\right)$ & Section modulus \\
\hline
\end{tabular}




\section{A.2.1.1 Timber Elements in Tension}

The tensile capacity of the beam and column elements is illustrated in Table A.13. Equations A.16 to A.18 are used to calculated the tensile capacity of each element illustrated in Table A.13.

$$
\begin{gathered}
T_{r}=\phi F_{t g} A_{g} \\
F_{t g}=f_{t g} K_{D} K_{H} K_{S t} K_{T} \\
A_{g}=w h
\end{gathered}
$$




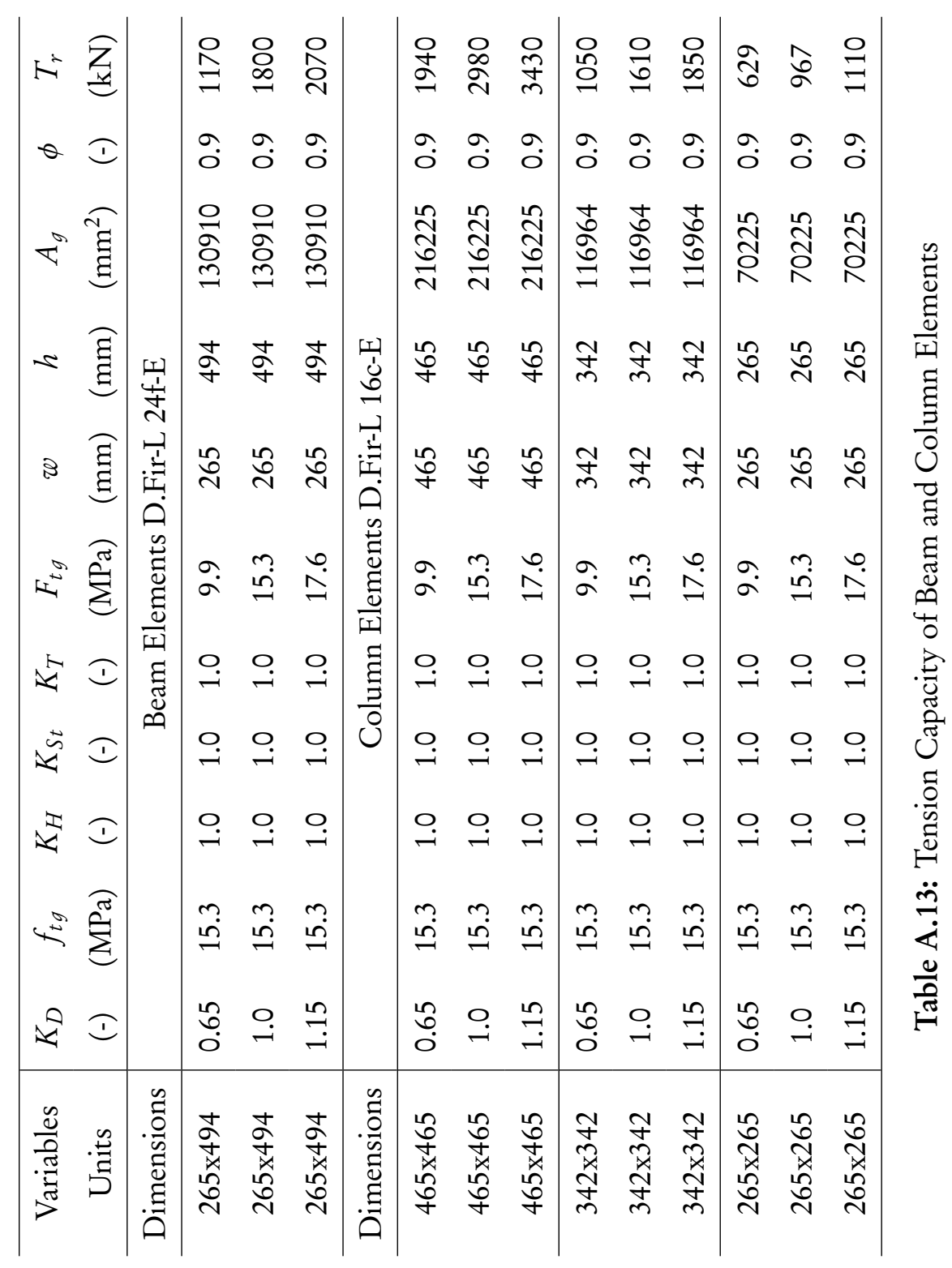




\section{A.2.1.2 Timber Elements in Compression}

The compression capacity parallel to grain of the beam and column element is illustrated in Table A.14. Equations A.19 to A.23 were used to calculated the compression parallel to grain capacity of each element illustrated in Table A.14.

$$
\begin{gathered}
P_{r}=\phi F_{c} A K_{Z c g} K_{C} \\
F_{c}=f_{c} K_{D} K_{H} K_{S c} K_{T} \\
K_{Z c g}=0.68 Z^{-0.13} \leq 1.0 \\
K_{c}=\left[1.0+\frac{F_{c} K_{Z c g} C_{c}^{3}}{35 E_{05} K_{S E} K_{T}}\right]^{-1} \\
C_{c}=\frac{k L}{w} \leq 50.0
\end{gathered}
$$




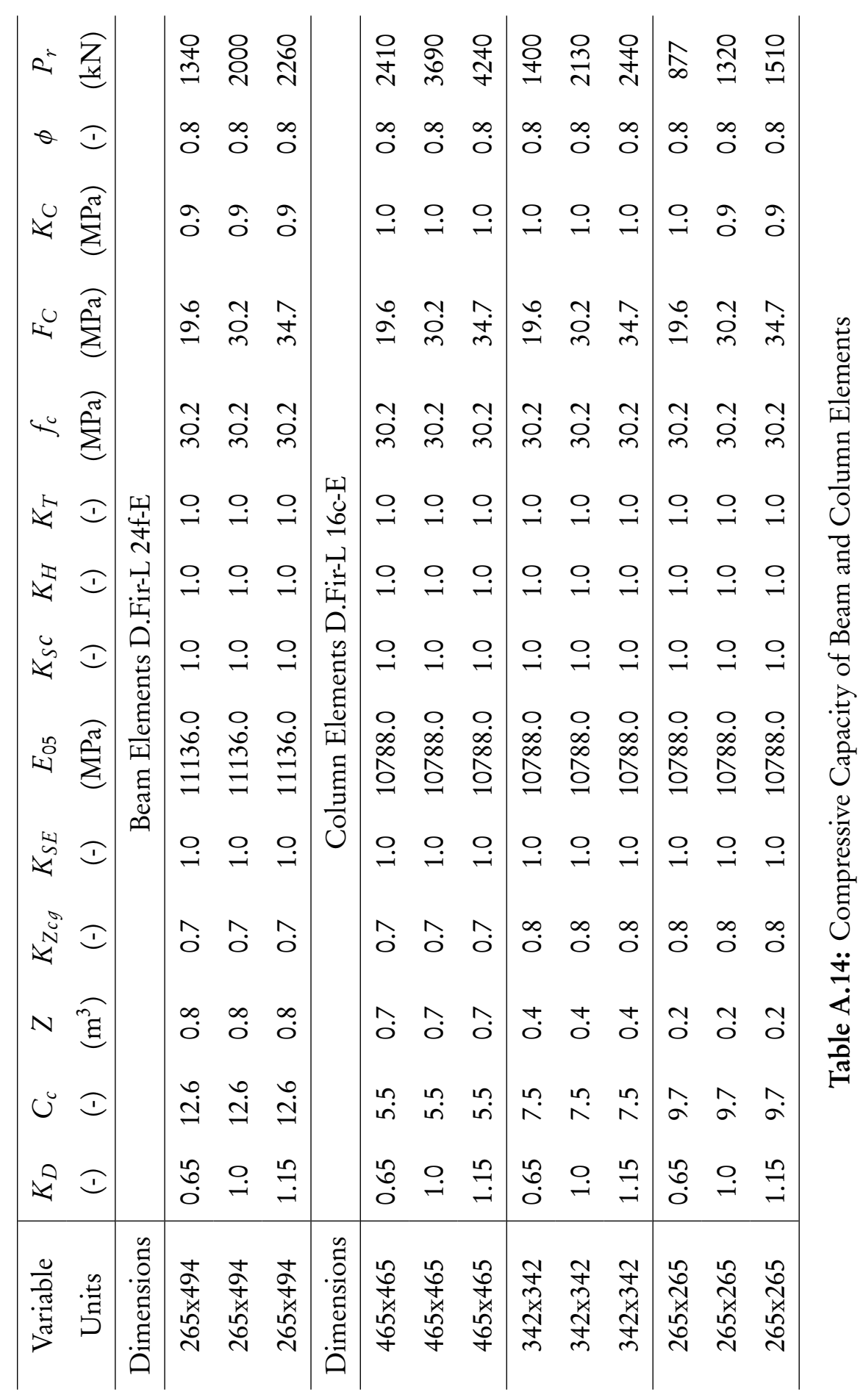




\section{A.2.1.3 Timber Elements in Shear}

The shear capacity of the beam and column elements is illustrated in Table A.15. Equations A.24 to A.25 were used to calculated the shear capacity of each element illustrated in Table A.15.

$$
\begin{gathered}
V_{r}=\phi F_{v} \frac{2 A_{g}}{3} \\
F_{v}=f_{v}\left(K_{D} K_{H} K_{S v} K_{T}\right)
\end{gathered}
$$

\begin{tabular}{|c|c|c|c|c|c|c|c|c|}
\hline $\begin{array}{c}\text { Variables } \\
\text { Units }\end{array}$ & $\begin{array}{c}K_{D} \\
(-)\end{array}$ & $\begin{array}{r}K_{H} \\
(-)\end{array}$ & $\begin{array}{r}K_{T} \\
(-)\end{array}$ & $\begin{array}{c}K_{S v} \\
(-)\end{array}$ & $\begin{array}{c}f_{v} \\
(\mathrm{MPa})\end{array}$ & $\begin{array}{c}F_{v} \\
(\mathrm{MPa})\end{array}$ & $\begin{array}{c}A_{g} \\
\left(\mathrm{~mm}^{2}\right)\end{array}$ & $\begin{array}{c}V_{r} \\
(\mathrm{kN})\end{array}$ \\
\hline Dimension & \multicolumn{8}{|c|}{ Beam Elements D.Fir-L 24f-E } \\
\hline $265 \times 494$ & 1.0 & 1.0 & 1.0 & 1.0 & 1.0 & 2.0 & 130910 & 157.1 \\
\hline Dimension & \multicolumn{8}{|c|}{ Column Elements D.Fir-L 16c-E } \\
\hline $465 \times 465$ & 1.15 & 1.0 & 1.0 & 1.0 & 1.0 & 2.0 & 216225 & 298.4 \\
\hline $342 \times 342$ & 1.15 & 1.0 & 1.0 & 1.0 & 1.0 & 2.0 & 116964 & 161.4 \\
\hline $265 \times 265$ & 1.15 & 1.0 & 1.0 & 1.0 & 1.0 & 2.0 & 70225 & 96.9 \\
\hline
\end{tabular}

Table A.15: Shear Capacity of Beam and Column Elements

\section{A.2.1.4 Timber Elements Moment Capacity}

The moment capacity of the beam and column element is illustrated in Table A.16. Equations A.26 to A.29 were used to calculate the moment capacity of each element illustrated in Table A.16.

$$
\begin{gathered}
M_{r 1}=\phi F_{b} S K_{X} K_{Z b g} \\
M_{r 2}=\phi F_{b} S K_{X} K_{L}
\end{gathered}
$$




$$
\begin{gathered}
F_{b}=f_{b}\left(K_{D} K_{H} K_{S b} K_{T}\right) \\
K_{Z b g}=\left(\frac{130}{b}\right)^{\frac{1}{10}}\left(\frac{610}{d}\right)^{\frac{1}{10}}\left(\frac{9100}{L}\right)^{\frac{1}{10}} \leq 1.3
\end{gathered}
$$




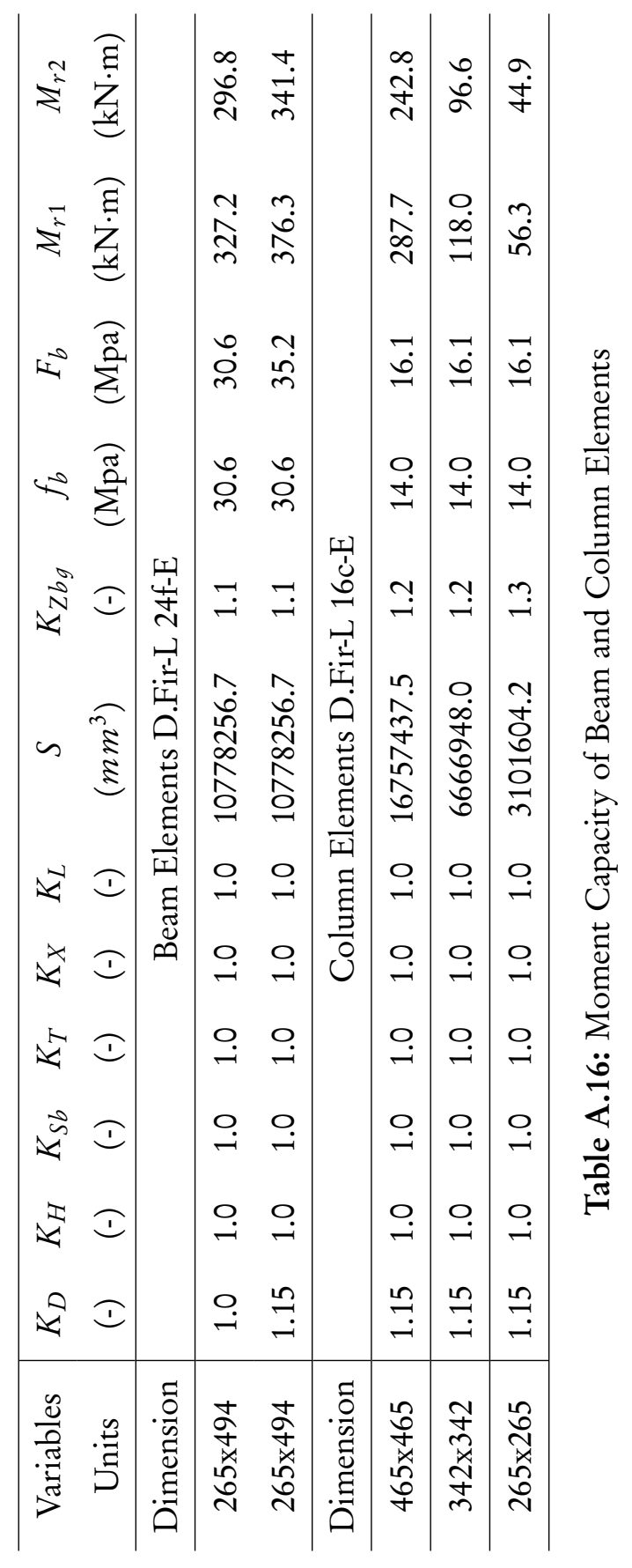




\section{A.2.1.5 Combined Bending and Axial Resistance}

The combined axial tension and bending and the combined axial compression and bending capacity of the beam elements was determined using Equations A.30 to A.32 and Table A.17.

$$
\begin{gathered}
\left(\frac{P_{f}}{P_{r}}\right)^{2}+\frac{M_{f}}{M r}\left(\frac{1}{1-\frac{P_{f}}{P_{E}}}\right) \leq 1 \\
\frac{T_{f}}{T_{r}}+\frac{M_{f}}{M_{r}} \leq 1 \\
P_{E}=\frac{\pi^{2} E_{05} K_{S E} K_{T} I}{L_{e}^{2}}
\end{gathered}
$$

\begin{tabular}{|c|c|c|c|c|c|c|c|}
\hline Case & \multicolumn{7}{|c|}{ Combined Axial Tension and Bending Case 265x494 D.Fir-L Beam } \\
\hline Variable & $K_{D}$ & $T_{f}$ & $T_{r}$ & $P_{E}$ & $M_{f}$ & $M_{r}$ & Equation A.31 \\
\hline Units & $(-)$ & $(\mathrm{kN})$ & $(\mathrm{kN})$ & $(\mathrm{kN} \cdot \mathrm{m})$ & $(\mathrm{kN} . \mathrm{m})$ & $(\mathrm{kN} . \mathrm{m})$ & $(-)$ \\
\hline Value & 1.15 & 1051 & 2073 & 7604 & 72.1 & 341.4 & 0.72 \\
\hline Case & \multicolumn{7}{|c|}{ Combined Axial Compression and Bending Case 265x494 D.Fir-L Beam } \\
\hline Variable & $K_{D}$ & $P_{f}$ & $P_{r}$ & $P_{E}$ & $M_{f}$ & $M_{r}$ & Equation A.30 \\
\hline Units & $(-)$ & $(\mathrm{kN})$ & $(\mathrm{kN})$ & $(\mathrm{kN})$ & $(\mathrm{kN} . \mathrm{m})$ & $(\mathrm{kN} . \mathrm{m})$ & $(-)$ \\
\hline Value & 1.15 & 1051 & 2263 & 7604 & 72.1 & 341.4 & 0.46 \\
\hline
\end{tabular}

Table A.17: Combined Axial Tension / Axial Compression and Bending Resistance of Beam Elements

\section{A.2.2 Beam Deflection}

The beam deflection under static loading was calculated using Equations A.33 and A.34 and Table A.18. Under both dead and live, as well as, dead and snow load cases there was sufficient stiffness.

$$
\Delta=\frac{5 w l^{4}}{384 E_{s} I}
$$




$$
E_{s}=E\left(K_{S E} K_{T}\right)
$$

Table A.18: Static Beam Deflections

\begin{tabular}{|c|c|c|c|c|c|c|}
\hline Case & \multicolumn{6}{|c|}{ 1.0D + 1.0L 265x494 D.Fir-L 24f-E Beam } \\
\hline Variable & $w$ & $E_{s}$ & $L$ & $I$ & Limit L/180 & $\Delta$ \\
\hline Value & 37.8 & 12800 & 6200 & $2.66 \times 10^{9}$ & 34.4 & 21.3 \\
\hline Units & $(\mathrm{kN} / \mathrm{m})$ & $(\mathrm{MPa})$ & $(\mathrm{mm})$ & $\left(\mathrm{mm}^{4}\right)$ & $(\mathrm{mm})$ & $(\mathrm{mm})$ \\
\hline Case & \multicolumn{6}{|c|}{ 1.0D + 1.0S 265x494 D.Fir-L 24f-E Beam } \\
\hline Variable & $w$ & $E_{s}$ & $L$ & $I$ & Limit L/240 & $\Delta$ \\
\hline Units & $(\mathrm{kN} / \mathrm{m})$ & $(\mathrm{MPa})$ & $(\mathrm{mm})$ & $\left(\mathrm{mm}^{4}\right)$ & $(\mathrm{mm})$ & $(\mathrm{mm})$ \\
\hline Value & 23.5 & 12800 & 6200 & $2.66 \times 10^{9}$ & 23.5 & 13.3 \\
\hline
\end{tabular}

\section{A.3 CLT Floor Design}

The cross laminated timber floor design is illustrated in Figure A.2. The floor consisted of 7 plys of SPF No1/No2. The properties are illustrated in Table A.19 and a cross section is illustrated in Figure A.2. Table A.20 summarizes the capacity and deflections of a typical floor section from the structure. Equations A. 35 to A.45 follow the draft procedure outlined in CSA O86 (Doudak, 2016).

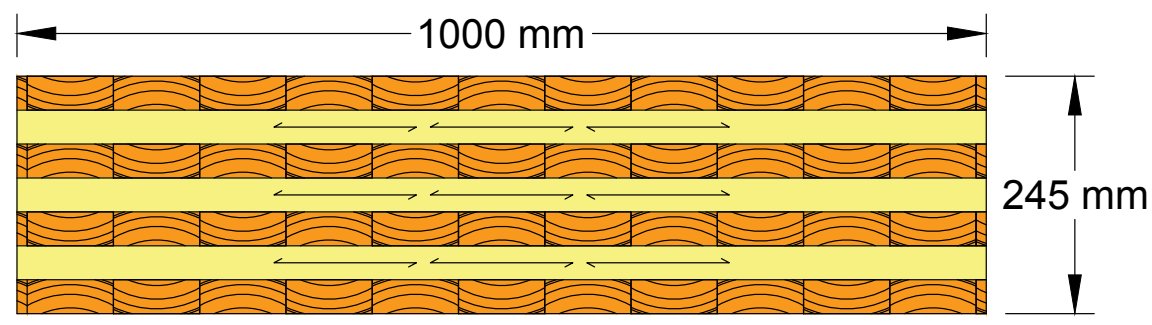

Figure A.2: Cross Laminated Timber Cross Section 
Table A.19: CLT Floor Variables

\begin{tabular}{c|cc||c|cc}
\hline Property & Value & Units & Property & Value & Units \\
\hline$E_{0}$ & 9500 & $(\mathrm{Mpa})$ & $Z_{1}$ & 105.0 & $(\mathrm{~mm})$ \\
$E_{90}$ & 316.7 & $(\mathrm{Mpa})$ & $Z_{2}$ & 70.0 & $(\mathrm{~mm})$ \\
$f_{b 0}$ & 11.5 & $(\mathrm{Mpa})$ & $Z_{3}$ & 35.0 & $(\mathrm{~mm})$ \\
$f_{b 90}$ & 11.5 & $(\mathrm{Mpa})$ & $Z_{4}$ & 0.0 & $(\mathrm{~mm})$ \\
$f_{v r 0}$ & 1.5 & $(\mathrm{Mpa})$ & $Z_{5}$ & 35.0 & $(\mathrm{~mm})$ \\
$f_{v r 90}$ & 1.5 & $(\mathrm{Mpa})$ & $Z_{6}$ & 70.0 & $(\mathrm{~mm})$ \\
$G_{0}$ & 593.8 & $(\mathrm{Mpa})$ & $Z_{7}$ & 105.0 & $(\mathrm{~mm})$ \\
$G_{90}$ & 59.4 & $(\mathrm{Mpa})$ & $t_{1}$ & 35.0 & $(\mathrm{~mm})$ \\
$f_{t 0}$ & 5.5 & $(\mathrm{Mpa})$ & $t_{2}$ & 35.0 & $(\mathrm{~mm})$ \\
$f_{s}$ & 0.5 & $(\mathrm{Mpa})$ & $t_{3}$ & 35.0 & $(\mathrm{~mm})$ \\
$h$ & 245 & $(\mathrm{~mm})$ & $t_{4}$ & 35.0 & $(\mathrm{~mm})$ \\
$b_{y}$ & 1000.0 & $(\mathrm{~mm})$ & $t_{5}$ & 35.0 & $(\mathrm{~mm})$ \\
$\rho$ & 420 & $\left(\mathrm{~kg} / \mathrm{m}^{3}\right)$ & $t_{6}$ & 35.0 & $(\mathrm{~mm})$ \\
$\phi$ & 0.9 & $(-)$ & $t_{7}$ & 35.0 & $(\mathrm{~mm})$ \\
$K_{r b y}$ & 0.85 & $(-)$ & $w_{L T}$ & 3.09 & $(\mathrm{kN} / \mathrm{m})$ \\
$K_{D}$ & 1.0 & $(-)$ & $w_{S T}$ & 2.4 & $(\mathrm{kN} / \mathrm{m})$ \\
$K_{H}$ & 1.0 & $(-)$ & $L_{1}$ & 6235 & $(\mathrm{~mm})$ \\
$K_{T}$ & 1.0 & $(-)$ & $K_{s b}$ & 1.0 & $(-)$ \\
\hline & & & & &
\end{tabular}




\section{A.3.1 CLT Floor Design Moment Resistance}

$$
\begin{array}{rl}
(E I)_{e f f, y} & =\sum_{i=1}^{n} E_{i} b_{y} \frac{t_{i}^{3}}{12}+\sum_{i=1}^{2} E_{i} b_{y} t_{i} z_{i}^{2} \\
& =2 * 9500 * 1000 * \frac{35^{3}}{12}+2 * 9500 * 1000 * 35 * 105^{2}+\ldots \\
& 2 * 9500 * 1000 * \frac{35^{3}}{12}+2 * 9500 * 1000 * 35 * 35^{2}+\ldots \\
2 & * 316.7 * 1000 * \frac{35^{3}}{12}+2 * 316.7 * 1000 * 35 * 70^{2}+\ldots \\
& 316.7 * 1000 * \frac{35^{3}}{12} \\
& =8.39404 \times 10^{12}
\end{array}
$$

$$
\begin{aligned}
F_{b} & =f_{b} k_{D} K_{H} K_{s} b K_{T} \\
& =11.8 * 1 * 1 * 1 * 1 \\
& =11.8
\end{aligned}
$$

$$
\begin{aligned}
M_{r, y} & =\phi F_{b} S_{e f f, y} K_{r b y} \\
& =0.9 * 11.8 * 7.2129 \times 10^{6} * 0.85 \\
& =65.1
\end{aligned}
$$




\section{A.3.2 CLT Floor Design Shear Resistance}

$$
\begin{aligned}
V_{r, z y} & =\phi F_{s} \frac{2 A_{g, z y}}{3} \\
& =\frac{0.9 * 0.5 * 2 * 1000 * 245}{3} \\
& =73.5
\end{aligned}
$$

\section{A.3.3 CLT Floor Design Deflection Check}

$$
\begin{aligned}
(G A)_{e f f, z y} & =\frac{\left[h-\frac{t_{1}}{2}-\frac{t_{n}}{2}\right]^{2}}{\frac{t_{1}}{2 G_{1} b_{y}} \sum_{i=2}^{n-1} \frac{t_{i}}{G_{i} b_{i}}+\frac{t_{n}}{2 G_{n} b_{y}}} \\
& =\frac{\left[245-\frac{35}{2}-\frac{35}{2}\right]^{2}}{\frac{2 * 35}{2 * 593.8 * 1000}+\frac{3 * 35}{59.34 * 1000}+\frac{2 * 35}{593.8 * 1000}} \\
& =22.729 \times 10^{6} \\
\Delta_{U D L, L T} & =\frac{5 w L^{4}}{384(E I)_{e f f}}+\frac{w L^{2} k}{8(G A)_{e f f}} \\
& =\frac{5 * 3.09 * 6235^{4}}{384 * 8.39404 \times 10^{12}}+\frac{3.09 * 6235^{2} * 1.2}{8 * 22.729 \times 10^{6}} \\
& =8.04 \\
& =\frac{5 * 2.4 * 6235^{4}}{384 * 8.39404 \times 10^{12}}+\frac{2.4 * 6235^{2} * 1.2}{8 * 22.729 \times 10^{6}} \\
= & 6.24 \\
\Delta_{U D L, S T} & =\frac{5 w L^{4}}{384(E I)_{e f f}}+\frac{w L^{2} k}{8(G A)_{e f f}} \\
& \\
& \\
& \\
&
\end{aligned}
$$




$$
\begin{aligned}
\Delta_{\max } & =\Delta_{S T}+\Delta_{L T} K_{\text {creep }} \\
& =6.24+8.04 * 2.0 \\
& =22.3
\end{aligned}
$$

\section{A.3.4 CLT Floor Design Vibration}

$$
\begin{aligned}
& m=\frac{\rho b_{y} h}{1000^{2}} \\
& =\frac{420 * 1000 * 245}{1000^{2}} \\
& =102.9 \\
& l_{v}=\frac{0.11\left[\frac{((E I))_{e f f}}{10^{6}}\right]^{0.29}}{m^{0.12}} \\
& =\frac{0.11\left[\frac{\left(\left(8.39404 \times 10^{12}\right)\right)_{e f f}}{10^{6}}\right]^{0.29}}{102.9^{0.12}} \\
& =6.42
\end{aligned}
$$

Table A.20: CLT Floor Loads and Capacity Summary

\begin{tabular}{c|cccc}
\hline $\begin{array}{c}\text { Load Type } \\
\text { Units }\end{array}$ & $\begin{array}{c}\text { Moment } \\
(\mathrm{kNm})\end{array}$ & $\begin{array}{c}\text { Shear } \\
(\mathrm{kN})\end{array}$ & $\begin{array}{c}\text { Deflection } \\
(\mathrm{mm})\end{array}$ & $\begin{array}{c}\text { Vibration } \\
(\mathrm{m})\end{array}$ \\
\hline Capacity & 65.1 & 73.5 & 34.6 & 6.42 \\
Load & 26.7 & 17.8 & 22.3 & 6.33 \\
\hline
\end{tabular}




\section{A.4 Friction Brace Design}

The friction brace assembly consisted of a series of sliding surfaces pretensioned together on slotted holes connected to two hollow structural steel sections. The activation force in the friction braces is defined as the dynamic slip forces of the friction interface and is illustrated in Table A.21. The tube section was a HSS203 $\times 152 \times 13$. The activation force of the friction braces was the same as the forces expected under earthquake loading determined from the response spectrum analysis. The stiffness of the braces was $248 \mathrm{kN} / \mathrm{m}$. This was determined using Equation A.3. Where $A$ is the area of the hollow structural section, $E$ is the modulus of elasticity of steel and $L$ is the unbraced stiffened length of the member. It was assumed that $1628 \mathrm{~mm}$ of the total length of the brace was significantly more rigid than the than the rest of the brace; this included the portion of the brace contained in the rigid panel zone and the friction assembly in the middle of the brace. All braces were assumed to contain the same stiffness. Figure A.3 illustrates the dimension of the friction brace, it's components and their associated stiffness.

$$
\begin{aligned}
K & =\frac{E A}{L} \\
& =\frac{200 \times 10^{3} * 7270}{7479.30478-1628} \\
& =248.5
\end{aligned}
$$

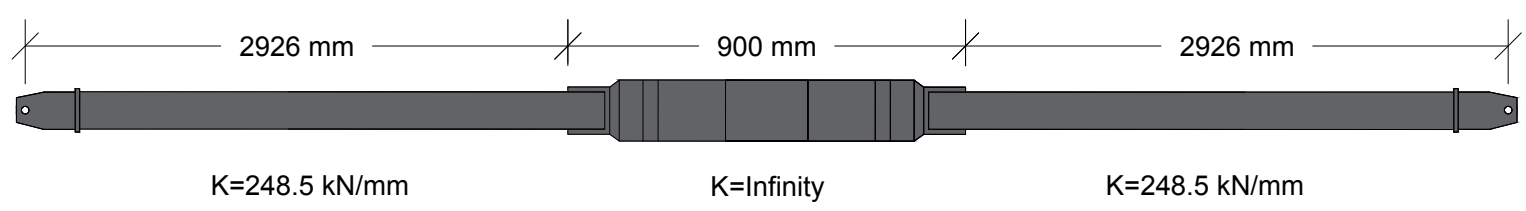

Figure A.3: Typical Brace Stiffness and Length Properties 
Table A.21: Activation Force in Friction Braces

\begin{tabular}{c|c}
\hline $\begin{array}{c}\text { Brace Location } \\
\text { Units }\end{array}$ & $\begin{array}{c}\text { Activation Force } \\
(\mathrm{kN})\end{array}$ \\
\hline Storey 7 - Roof & 220 \\
Storey 6 - Storey 7 & 380 \\
Storey 5 - Storey 6 & 480 \\
Storey 4 - Storey 5 & 505 \\
Storey 3 - Storey 4 & 640 \\
Storey 2 - Storey 3 & 680 \\
Ground - Storey 2 & 825 \\
\hline
\end{tabular}

\section{A.5 Glued-in Rod Design}

The axial capacity of all glued-in rod column connections was calculated using the procedure outlined in the German Design Code DIN 1052. This method is the most conservative and thus yielded the safest results. The embedment depth was assumed to be $600 \mathrm{~mm}$. An ultimate strength of $860 \mathrm{mPa}$ was also assumed. Minimum edge spacing requirements of $2 d$ and internal spacing of $5 d$ were used in the design. The tensile capacity of the glued-in rod connection using the methodology in the German Design Code DIN 1052 is illustrated in Equations A.47, A.48, A.49 and Table A.22 The capacity of all columns using the EUROCODE approach produced much larger capacity results. The EUROCODE estimates the axial capacity of the following

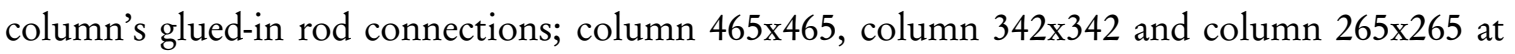
$2370 \mathrm{kN}, 1330 \mathrm{kN}$ and $720 \mathrm{kN}$, respectively.

$$
\begin{gathered}
R_{a x, d}=\pi d l_{a d} f_{k 1, d} \\
f_{k 1, d}= \begin{cases}4.0 & \text { if } l_{a d} \leq 250 \mathrm{~mm} \\
5.25-0.005 l_{a d} & \text { if } 250>l_{a d} \leq 500 \mathrm{~mm} \\
3.5-0.0015 l_{a d} & \text { if } 500>l_{a d} \leq 1000 \mathrm{~mm}\end{cases}
\end{gathered}
$$




$$
l_{d a, \max }=\left\{\begin{array}{l}
0.5 d^{2} \\
10 d
\end{array}\right.
$$

Table A.22: Glued-in Rods Tensile Capacity DIN 1052 Method Beam and Column

\begin{tabular}{c|cccccc}
\hline $\begin{array}{c}\text { Item } \\
\text { Units }\end{array}$ & $\begin{array}{c}d \\
(\mathrm{~mm})\end{array}$ & $\begin{array}{c}l_{\text {da,max }} \\
(\mathrm{mm})\end{array}$ & $\begin{array}{c}f_{k 1, d} \\
(\mathrm{Mpa})\end{array}$ & $\begin{array}{c}R_{\text {ax,d.Individual }} \\
(\mathrm{kN})\end{array}$ & $\begin{array}{c}\text { \# Rods } \\
(-)\end{array}$ & $\begin{array}{c}R_{\text {ax,d.total }} \\
(\mathrm{kN})\end{array}$ \\
\hline Beam & 19 & 600 & 2.6 & 93.1 & 10 & 931 \\
Column 465x465 & 22 & 600 & 2.6 & 93.1 & 16 & 1725 \\
Column 342x342 & 22 & 600 & 2.6 & 93.1 & 9 & 970 \\
Column 265x265 & 25.4 & 600 & 2.6 & 93.1 & 4 & 500 \\
\hline
\end{tabular}

The shear capacity of the glued-in rods in the beam connection was determined using the methodology from the GIROD Report (2002) method and is illustrated in Equations A.50 to A.56 and in Tables A.23 and A.24. Figure 3.3 details each frame elements glued-in rod connection. The shear capacity of the glued-in rod connections in the column elements was significantly larger than the forces they were subjected too.

$$
\begin{gathered}
R_{90, d}=0.5 k_{s} k_{r}\left[6.5+\frac{18 a^{2}}{H^{2}}\right]\left[T_{e f} H\right]^{0.8} \\
T_{e f, \min }=\left\{\begin{array}{l}
B \\
6 d
\end{array}\right. \\
k_{s, \max }=\left\{\begin{array}{l}
1 \\
0.7+\frac{1.4 a_{r}}{H}
\end{array}\right. \\
k_{r}=\frac{n}{\sum_{i=1}^{n}\left(\frac{h_{1}}{h_{i}}\right)^{2}}
\end{gathered}
$$




$$
\begin{gathered}
a_{r}=-t+\sqrt{t^{2}+4\left(\frac{M_{y}}{f_{h, 1} d}\right)} \\
f_{h 1}=0.11 \rho_{k} d^{-} 0.3 \\
M_{y}=0.26 f_{u} d_{m}^{2.7}
\end{gathered}
$$


Table A.23: Variables Used in Glued-in Rod Shear Calculation

\begin{tabular}{c|ccc}
\hline Variable & Value & Units & Description \\
\hline$H$ & 494 & $(\mathrm{~mm})$ & Height of beam \\
$B$ & 265 & $(\mathrm{~mm})$ & Width of beam \\
$b$ & 19 & $(\mathrm{~mm})$ & Rod diameter \\
$f_{u}$ & 860 & $(\mathrm{mPm})$ & Ultimate strength of rod \\
$d_{m}$ & 19 & $(\mathrm{~mm})$ & Average rod diameter \\
$p_{k}$ & 510 & $\left(\mathrm{~kg} / \mathrm{m}^{3}\right)$ & Density of D.Fir-L \\
$t$ & 0 & $(\mathrm{~mm})$ & Space between wood and steel connection \\
$n$ & 10 & $(-)$ & Number of rods \\
$h 1$ & 50 & $(\mathrm{~mm})$ & Rod depth from bottom \\
$h 2$ & 145 & $(\mathrm{~mm})$ & Rod depth from bottom \\
$h 3$ & 240 & $(\mathrm{~mm})$ & Rod depth from bottom \\
$h 4$ & 335 & $(\mathrm{~mm})$ & Rod depth from bottom \\
$h 5$ & 430 & $(\mathrm{~mm})$ & Rod depth from bottom \\
$a$ & 65 & $(\mathrm{~mm})$ & Rod depth from top \\
\hline
\end{tabular}

Table A.24: Shear Capacity of Glued-in Rod Beam Connection

\begin{tabular}{c|ccccccc}
\hline Variable & $t_{e f}$ & $M_{y}$ & $f_{h 1}$ & $a_{r}$ & $k_{s}$ & $k_{r}$ & $R_{90, d}$ \\
\hline Value & 114 & 634025 & 23.2 & 75.9 & 1.0 & 8.35 & 180 \\
\hline
\end{tabular}




\section{A.6 Full and Half Scale Specimen Forces}

\section{A.6.1 Friction Slip Force}

The full scale and half scale tension and compression force in the friction braces were $825 \mathrm{kN}$ and $206 \mathrm{kN}$, respectively. There was no shear and moment on the friction brace.

\section{A.6.2 Gusset Plate}

The gusset plate was capacity designed by 1.1 over the friction brace slip force. This resulted in a full scale force of $909 \mathrm{kN}$ and half scale force of $227 \mathrm{kN}$. There was no shear and moment on the friction brace.

\section{A.6.3 Hybrid Connection}

The axial compression and tension force in the hybrid connection consisted of forces from the columns, the beams and the gusset plate at the joint. This resulted in a full scale tension and compression force in the hybrid connection of $1525 \mathrm{kN}$ and $2940 \mathrm{kN}$, respectively. The half scale forces in tension and compression were $381 \mathrm{kN}$ and $735 \mathrm{kN}$, respectively. The shear force in the hybrid connection was the vertical force component from the gusset, capacity designed by 1.1 plus the shear force from the beam framing into the connection. This resulted in a full scale shear force of $547 \mathrm{kN}$ and a half scale capacity design force of $136 \mathrm{kN}$. The full scale beam shear was $53 \mathrm{kN}$ and the half scale beam shear was $13 \mathrm{kN}$. There was no moment on the hybrid connection.

\section{A.6.4 Beam Connection}

The axial tension and compression force in the beam connection for the full scale and half scale frames were $868 \mathrm{kN}$ and $217 \mathrm{kN}$, respectively. The shear and moment on the beam was governed by the load case in Equation A.57. This resulted in a full scale shear and moment of $89 \mathrm{kN}$ and $145 \mathrm{kNm}$, respectively. The half scale shear and moment were $22 \mathrm{kN}$ and $18 \mathrm{kNm}$, respectively. 


$$
\text { Case }=1.25 D+1.5 L
$$

\section{A.6.5 Beam Fasteners}

The axial force in the beam fasteners was the axial force in the beam connection factored up by 1.1. This resulted in a full scale axial force in compression and tension of $955 \mathrm{kN}$ and half scale force of $239 \mathrm{kN}$. The shear was the same as in the beam connection and there was no moment.

\section{A.6.6 Beam}

The axial tension and compression force in the timber beam was the axial force in the fasteners scaled by 1.1. This resulted in a full scale tension and compression force of $1051 \mathrm{kN}$ and a half scale force of $263 \mathrm{kN}$. The shear in the beam remained the same for both full and half scale, while the moment was calculated using Equation A.57. This resulted in a full scale moment of $145 \mathrm{kNm}$ and half scale moment of $18 \mathrm{kNm}$.

\section{A.6.7 Timber Fasteners}

The axial force in the column's fasteners was the axial force in the hybrid connection scaled up by a factor of 1.1. This resulted in a full scale tension and compression force of $1668 \mathrm{kN}$ and $2242 \mathrm{kN}$, respectively. The half scale tension and compression forces were $419 \mathrm{kN}$ and $809 \mathrm{kN}$, respectively. There was minimal shear and moment in the timber column's fasteners.

\section{A.6.8 Timber Columns}

The axial force in the timber columns was the axial force in the column fasteners scaled up by a factor of 1.1 . This resulted in a full scale tension and compression force of $1835 \mathrm{kN}$ and $2467 \mathrm{kN}$, respectively. The half scale tension and compression forces were $461 \mathrm{kN}$ and $889 \mathrm{kN}$, respectively. There was minimal shear and moment in the timber columns. 


\section{Appendix B: Design of OpenSees and Hybrid Models}

\section{B.1 OpenSees and Hybrid Models Mass and Stiffness Properties}

The mass breakdown of the Two Bay OpenSees Model and the Four Bay OpenSees Model is presented in this section. In both cases, the tributary area of the seismic force resisting system was half of the structure. The mass break down in the lateral direction for the Four Bay OpenSees Model and Two Bay OpenSees Model is illustrated in Tables B.1 and B.2, respectively. The mass break down in the vertical direction for the Four Bay OpenSees Model and Two Bay OpenSees Model is illustrated in Tables B.3 and B.4, respectively. The lean column's elements modulus of elasticity, area and moment of inertia were representative of all columns within the tributary area of the seismic force resisting system that were not already modeled. A breakdown of the area and moment of inertia for each lean column in the Four Bay OpenSees Model and Two Bay OpenSees Model are illustrated in Tables B.5 and B.6. 
Table B.1: Nodal Mass Break Down in Four Bay OpenSees Model Lateral Direction

\begin{tabular}{cc|cccc}
\hline Location & $\begin{array}{c}\text { Node \# } \\
\text { Units }\end{array}$ & $\begin{array}{c}\text { Snow } \\
\mathrm{kN}\end{array}$ & $\begin{array}{c}\text { Storey Dead } \\
\mathrm{kN}\end{array}$ & $\begin{array}{c}\text { Facade Dead } \\
\mathrm{kN}\end{array}$ & $\begin{array}{c}\text { Sum } \\
\mathrm{kN}\end{array}$ \\
\hline Roof Level & 561 & 91 & 855 & 37 & 983 \\
7th Floor & 461 & 0.0 & 1122 & 73 & 1195 \\
6th Floor & 461 & 0.0 & 1122 & 73 & 1195 \\
5th Floor & 461 & 0.0 & 1132 & 73 & 1205 \\
4th Floor & 361 & 0.0 & 1132 & 73 & 1205 \\
3rd Floor & 261 & 0.0 & 1156 & 73 & 1229 \\
2nd Floor & 161 & 0.0 & 1156 & 73 & 1229 \\
\hline
\end{tabular}

Table B.2: Nodal Mass Break Down in Two Bay OpenSees Model Lateral Direction

\begin{tabular}{cc|cccc}
\hline Location & $\begin{array}{c}\text { Node \# } \\
\text { Units }\end{array}$ & $\begin{array}{c}\text { Snow } \\
\mathrm{kN}\end{array}$ & $\begin{array}{c}\text { Storey Dead } \\
\mathrm{kN}\end{array}$ & $\begin{array}{c}\text { Facade Dead } \\
\mathrm{kN}\end{array}$ & $\begin{array}{c}\text { Sum } \\
\mathrm{kN}\end{array}$ \\
\hline Roof Level & 761 & 91 & 855 & 36.8 & 983 \\
7th Floor & 661 & 0 & 1122 & 72.8 & 1195 \\
6th Floor & 561 & 0 & 1122 & 72.8 & 1195 \\
5th Floor & 461 & 0 & 1132 & 72.8 & 1205 \\
4th Floor & 361 & 0 & 1132 & 72.8 & 1205 \\
3rd Floor & 261 & 0 & 1157 & 72.8 & 1229 \\
2nd Floor & 161 & 0 & 1157 & 72.8 & 1229 \\
\hline
\end{tabular}




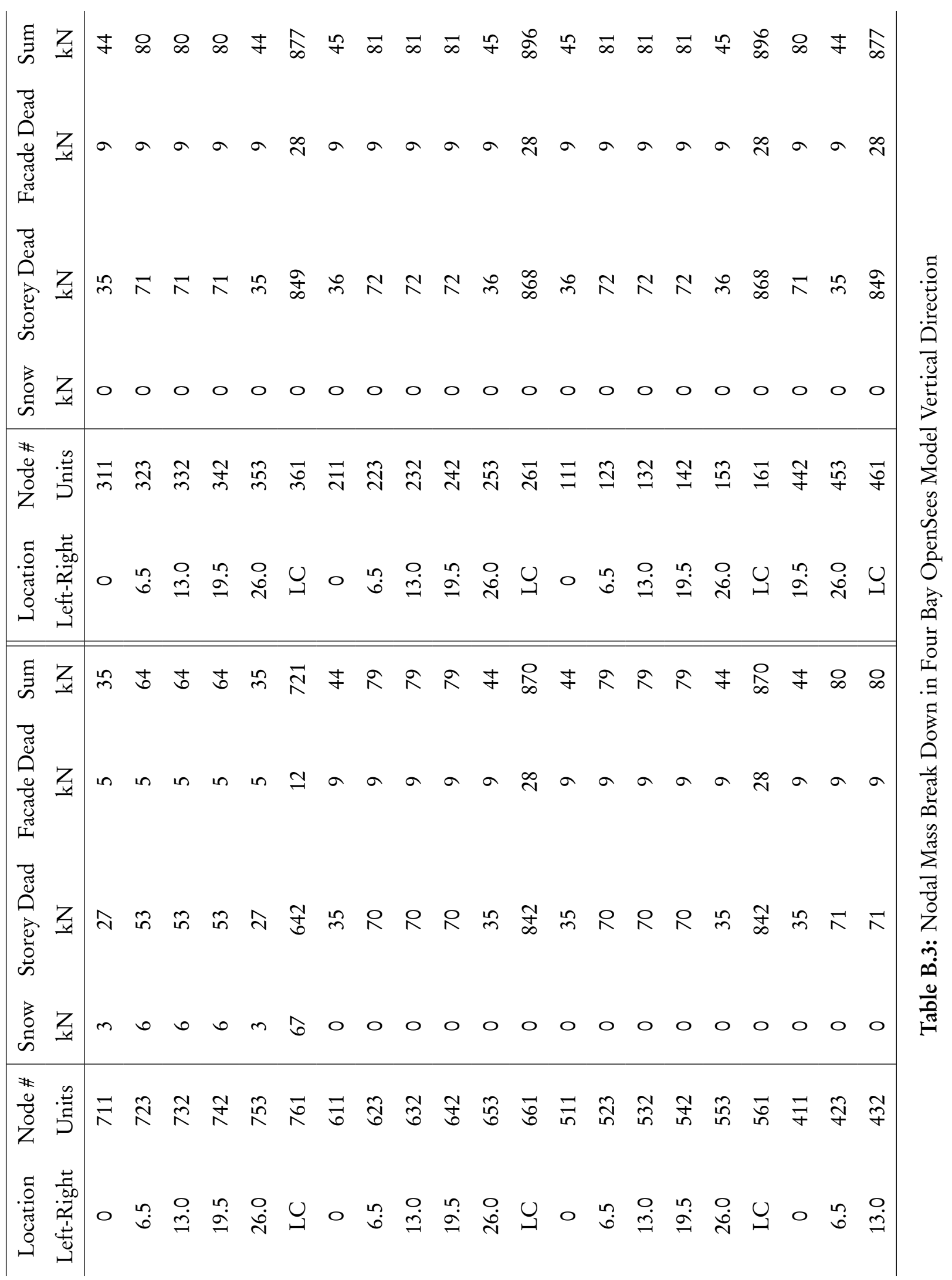




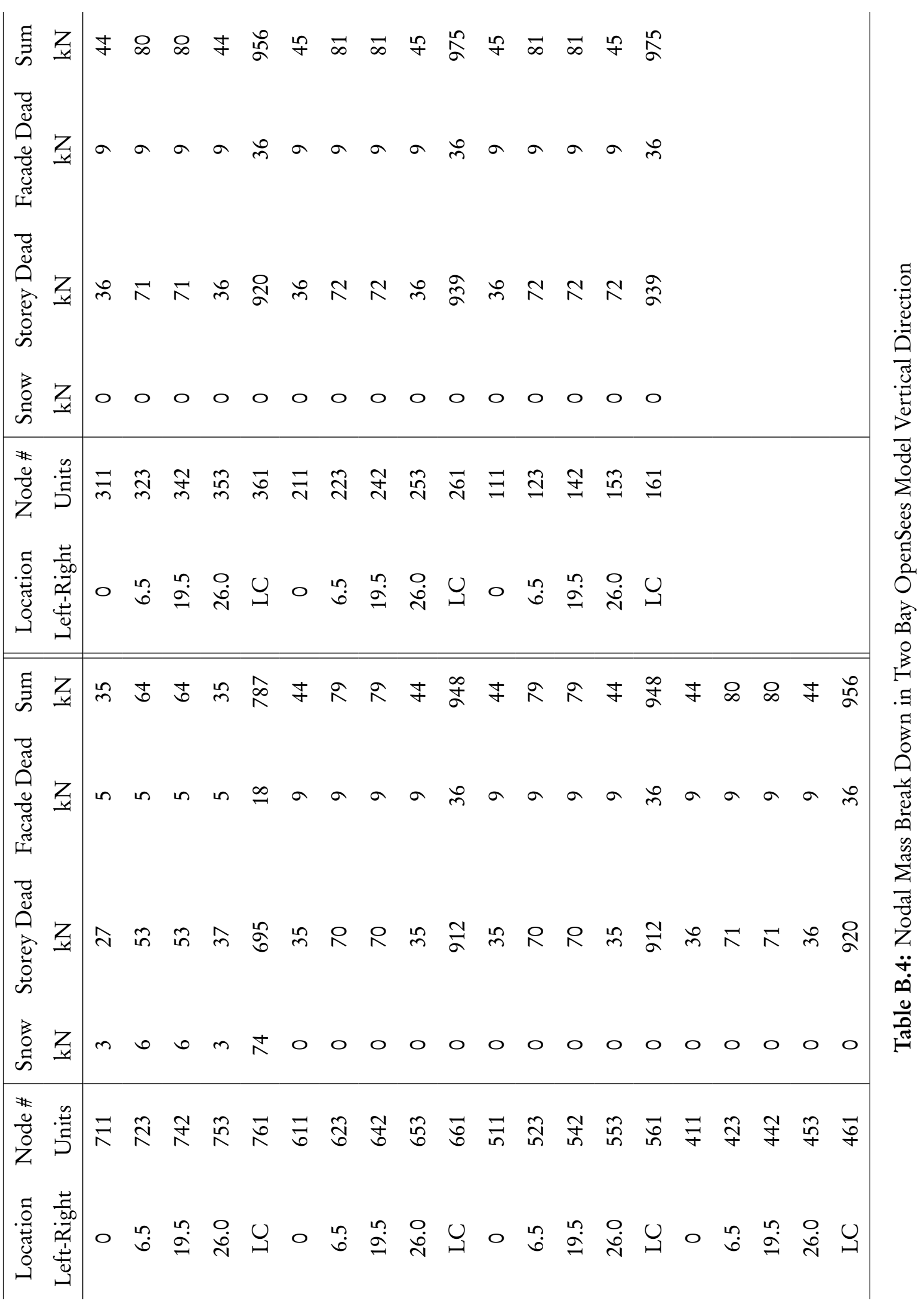


Table B.5: Properties of Lean Column in Four Bay OpenSees Model

\begin{tabular}{|c|c|c|c|c|c|c|}
\hline $\begin{array}{l}\text { Column } \\
\text { Item } \\
\text { units }\end{array}$ & $\begin{array}{l}\text { Interior } \\
\text { Area } \\
10^{3} \mathrm{~mm}^{2}\end{array}$ & $\begin{array}{c}\text { Exterior } \\
\text { Area } \\
10^{3} \mathrm{~mm}^{2}\end{array}$ & $\begin{array}{c}\text { Sum } \\
\text { Area } \\
10^{3} \mathrm{~mm}^{2}\end{array}$ & $\begin{array}{l}\text { Interior } \\
I_{X} \\
10^{6} \mathrm{~mm}^{4}\end{array}$ & $\begin{array}{c}\text { Exterior } \\
\qquad I_{X} \\
10^{6} \mathrm{~mm}^{4}\end{array}$ & $\begin{array}{c}\text { Sum } \\
I_{X} \\
10^{6} \mathrm{~mm}^{4}\end{array}$ \\
\hline storey 7-R & 70 & 7.5 & 525 & 411 & 7.5 & 3083 \\
\hline Storey 6-7 & 70 & 7.5 & 525 & 411 & 7.5 & 3083 \\
\hline Storey 5-6 & 70 & 7.5 & 525 & 411 & 7.5 & 3083 \\
\hline Storey 4-5 & 117 & 7.5 & 878 & 1140 & 7.5 & 8550 \\
\hline Storey 3-4 & 117 & 7.5 & 878 & 1140 & 7.5 & 8550 \\
\hline Storey 2-3 & 216 & 7.5 & 1620 & 3896 & 7.5 & 29220 \\
\hline Ground -2 & 216 & 7.5 & 1620 & 3896 & 7.5 & 29220 \\
\hline
\end{tabular}

Table B.6: Properties of Lean Column in Two Bay OpenSees Model

\begin{tabular}{c|ccc|ccc}
\hline $\begin{array}{c}\text { Column } \\
\text { Item }\end{array}$ & $\begin{array}{c}\text { Interior } \\
\text { Area }\end{array}$ & $\begin{array}{c}\text { Exterior } \\
\text { Area }\end{array}$ & $\begin{array}{c}\text { Sum } \\
\text { Area }\end{array}$ & $\begin{array}{c}\text { Interior } \\
I_{X}\end{array}$ & $\begin{array}{c}\text { Exterior } \\
I_{X}\end{array}$ & $\begin{array}{c}\text { Sum } \\
I_{X}\end{array}$ \\
units & $10^{3} \mathrm{~mm}^{2}$ & $10^{3} \mathrm{~mm}^{2}$ & $10^{3} \mathrm{~mm}^{2}$ & $10^{6} \mathrm{~mm}^{4}$ & $10^{6} \mathrm{~mm}^{4}$ & $10^{6} \mathrm{~mm}^{4}$ \\
\hline storey 7-R & 316.01 & 280.90 & 596.91 & 1849.33 & 1643.85 & 3493.18 \\
storey 6-7 & 316.01 & 280.90 & 596.91 & 1849.33 & 1643.85 & 3493.18 \\
storey 5-6 & 316.01 & 280.90 & 596.91 & 1849.33 & 1643.85 & 3493.18 \\
Storey 4-5 & 526.34 & 467.86 & 994.19 & 5130.21 & 4560.19 & 9690.41 \\
Storey 3-4 & 526.34 & 467.86 & 994.19 & 5130.21 & 4560.19 & 9690.41 \\
Storey 2-3 & 973.01 & 864.90 & 1837.91 & 17532.47 & 15584.42 & 33116.89 \\
Ground -2 & 973.01 & 864.90 & 1837.91 & 17532.47 & 15584.42 & 33116.89
\end{tabular}




\section{Appendix C: Prototype Specimen Design (Gilbert, 2016)}

\section{C.1 Physical Specimen Design by (Gilbert, 2016)}

The specimen was designed with the following codes and design procedures: CSA 08609 Wood Design Manual (CSA 086-14, 2014), CSA S16-09 Handbook of Steel Construction (CSA S16, 2010), German Design Code DIN 1052 (Bauwesen, 2004), GIRod Project Design Procedure (Bengtsson and Johanssan, 2002) and LICONS Report Design Procedure (Connolly and Mettem, 2003). The intermediate steel section was fabricated from CSA G40.21-300W steel plate with a yield strength of $300 \mathrm{MPa}$ and an ultimate strength of $400 \mathrm{MPa}$. The hollow structural section of the brace was fabricated from CSA G40.21350W steel, with a yield strength of $350 \mathrm{MPa}$ and an ultimate strength of $450 \mathrm{MPa}$. The adhesive chosen to anchor the glued-in rods was Sika AnchorFix-300, a two component epoxy resin characterized as a high strength and low volatile organic compound. The manufacturer's nominal properties are provided in Table C.1. The threaded rod specifications and timber products are illustrated in Tables C.2 and C.3. Gilbert (2016) concluded that the specimen's glued-in rod connection capacities exceeded the estimated capacities using the 3 European design methods. The friction brace utilized a brass on stainless steel friction contact surface and is detailed to activate at the scaled activation resistance of the lower bay brace from the prototype building. The brace's components were designed to remain

elastic at the probable yield force of the gusset plate. The following sections detail each aspect of the physical specimen. 
Table C.1: Adhesive Properties (Gilbert, 2016)

\begin{tabular}{|c|c|c|}
\hline Property & Strength $(\mathrm{MPa})$ & Modulus (GPa) \\
\hline \multicolumn{3}{|c|}{ Compression } \\
\hline 1 Day & 59 & - \\
\hline 7 Days & 85 & 5 \\
\hline \multicolumn{3}{|c|}{ Tension } \\
\hline 1 Day & 18 & 5.7 \\
\hline 7 Days & 23.5 & 5.5 \\
\hline \multicolumn{3}{|c|}{ Flexure } \\
\hline 1 Day & 45 & - \\
\hline
\end{tabular}

Table C.2: B7 Threaded Steel Rod Properties (Gilbert, 2016)

\begin{tabular}{c|cc}
\hline Property & Specified Value & Unit of Measure \\
\hline Tension Strength, $f_{u}$ & 860 & $\mathrm{MPa}$ \\
Yield Strength, $f_{y}$ & 725 & $\mathrm{MPa}$ \\
Elastic Modulus & 200000 & $\mathrm{MPa}$ \\
Thread Pitch & 10 & $\mathrm{~mm}$ \\
\hline
\end{tabular}

Table C.3: Nordic Glulam Material Properties (Gilbert, 2016)

\begin{tabular}{c|cc}
\hline Property & Specified Value & Unit of Measure \\
\hline Compression Parallel to Grain, $f_{c}$ & 33.0 & $\mathrm{MPa}$ \\
Compression Perpendicular to Grain, $f_{c p}$ & 7.5 & $\mathrm{MPa}$ \\
Tension Parallel to Grain, $f_{t}$ & 20.4 & $\mathrm{MPa}$ \\
Positive Bending, $f_{b p}$ & 30.7 & $\mathrm{MPa}$ \\
Negative Bending, $f_{b n}$ & 30.7 & $\mathrm{MPa}$ \\
Shear, $f_{v}$ & 2.2 & $\mathrm{MPa}$ \\
Elastic Modulus, $E$ & 13100 & $\mathrm{GPa}$ \\
Density, $\rho$ & 560 & $\frac{\mathrm{kg}}{\mathrm{m}^{3}}$ \\
\hline
\end{tabular}




\section{C.1.1 Friction Device Component Design}

The friction device designed by Gilbert (2016) contained a brass on stainless steel friction interface. This configuration was selected due to the corrosive resistant properties of the materials and the consistent and reliable energy dissipation properties when in friction contact with each other. The friction interface was designed to accommodate $5 \%$ drift to avoid failure of the brace under loading, exceeding MCE hazard level ground motions. The friction plates were detailed to be clamped with four 1 inch, $25.4 \mathrm{~mm}$ diameter A325 structural bolts. The results of Gilbert's tests indicated that there was not much variation between the dynamic and static coefficients of friction (Gilbert, 2016). In Gilbert's tests, it was determined that the dynamic coefficient of friction for brass on stainless steel in this interface is 0.45 (Gilbert, 2016). All components of the friction assembly and the brace itself were checked and detailed to avoid possible buckling of components under compressive loads if the friction interface was locked. Figure C.1 illustrates the friction brace.

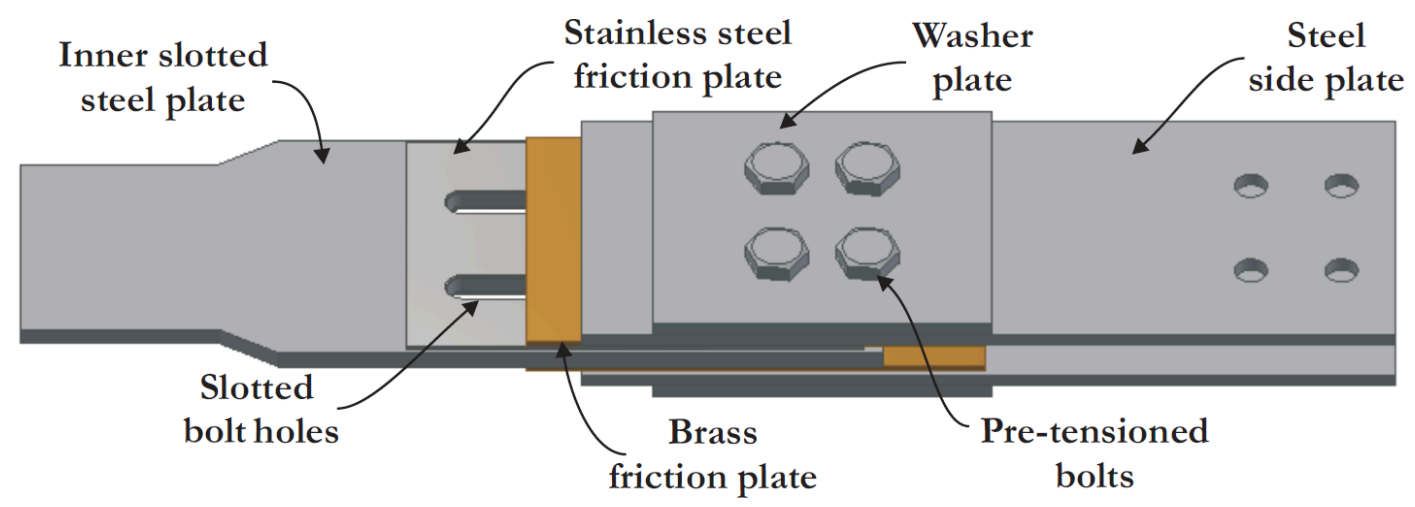

Figure C.1: Friction Brace Assembly (Gilbert, 2016)

To achieve the required activation force in the brace, the dynamic coefficient of friction was considered when calculating bolt axial force. This coefficient of friction was used to determine the torque requirements for the pretensioning bolts. Any additional resistances caused by a slightly higher static coefficient of friction above the dynamic slip force was resisted by the system, up to an axial unfactored force in the brace of $300 \mathrm{kN}$. At this point, the gusset plate may begin to experience nonlinear behaviour. From Equation C.1, the pretension axial force in each bolt of 57 
$\mathrm{kN}$ was determined (Christopoulos and Filiatrault, 2006).

$$
F_{N b}=\frac{F_{f, s t a t i c}}{n_{f s} n_{b} \mu_{s}}
$$

Where $n_{f s}$ is the number of faying surfaces, $n_{b}$ is the number of bolts, $\mu_{s}$ is the coefficient of static friction and $F_{f}$, dynamic is the slip force of the friction brace. To achieve the required pretension force in each bolt, the torque and elongation of the bolts were determined. Using both methods increased the accuracy and reduced the calibration time required before testing. Equation C. 2 to C.6 illustrates the required torque to achieve an axial force in each bolt of 57.2 $\mathrm{kN}$ (Erick et al., 2008). Parameter definitions can be found in Table C.4.

$$
T_{f}=K F_{b} d_{b}
$$

$$
K=\frac{1}{2 d_{b}}\left[\frac{P}{\pi}+\mu_{s} d_{2} \sec \alpha^{\prime}+\mu_{w} D_{w}\right]
$$

$$
\begin{gathered}
D_{w}=\frac{2}{3}\left[\frac{D_{o}^{3}-D_{i}^{3}}{D_{o}^{2}-D_{i}^{2}}\right] \\
\alpha^{\prime}=\tan ^{-1}(\tan \alpha \cos \beta) \\
\beta=\tan ^{-1}\left[\frac{l}{2 \pi r}\right]
\end{gathered}
$$


Table C.4: Torque Requirements (Erick et al., 2008)

\begin{tabular}{c|ccc}
\hline Property & Units & Value & Description \\
\hline$K$ & $(-)$ & 0.166 & Torque coefficient \\
$F_{b}$ & $(\mathrm{kN})$ & 57.2 & Pretension force in the bolt \\
$d_{b}$ & $(\mathrm{~mm})$ & 25.4 & Diameter of the bolt \\
$P$ & $(\mathrm{~mm})$ & 3.629 & Bolt thread pitch distance between threads \\
$\mu_{s}$ & $(-)$ & 0.125 & Thread surface friction lubricated bolts \\
$d_{2}$ & $(\mathrm{~mm})$ & 23.337 & Pitch diameter of the thread \\
$\alpha^{\prime}$ & $(-)$ & 26.0 & Flank angle at the ridge perpendicular section of the threaded ridge \\
$\mu_{w}$ & $(-)$ & 0.125 & Bearing surface friction lubricated surface \\
$D_{w}$ & $(\mathrm{~mm})$ & 35.310 & Equivalent diameter of the friction torque bearing surface \\
$D_{o}$ & $(\mathrm{~mm})$ & 41.275 & Outside diameter of the bearing surface contact area of the nut \\
$D_{i}$ & $(\mathrm{~mm})$ & 28.575 & Inside diameter of the bearing surface contact area of the nut \\
$\alpha$ & $(-)$ & 14.5 & Thread half angle \\
$\beta$ & $(-)$ & 2.604 & Thread helix, or lead angle \\
$l$ & $(-)$ & 3.629 & Thread lead \\
$r$ & $(\mathrm{~mm})$ & 12.7 & Thread radius, one half the nominal diameter $d$ \\
\hline
\end{tabular}

The torque was estimated to be $241 \mathrm{~N} \cdot \mathrm{m}$ or $178 \mathrm{ft} \cdot \mathrm{lbs}$.

The elongation of the bolt is estimated in Equations C.7 and C. 8 to be $0.053 \mathrm{~mm}$ at an axial force in the bolts of $57.2 \mathrm{kN}$. Parameter definitions can be found in Table C.5 and Figure C.2.

$$
\begin{gathered}
L_{b}=\left(\frac{d_{t s}}{d b}\right)^{2}\left(L_{S}+\frac{H_{B}}{2}\right)+L_{J}-L_{S}+\left(\frac{H_{N}}{2}\right) \\
\delta_{b}=\frac{F_{b} L_{b}}{A_{b} E}
\end{gathered}
$$

Using both torque and elongation of the bolts provided a good starting point to calibrate the 
friction brace to the anticipated dynamic activation force of $206 \mathrm{kN}$. Estimating bolt normal force using torque and elongation of the bolt is expected to produce accurate results within $20 \%$ and $3.5 \%$, respectively (Erick et al., 2008).

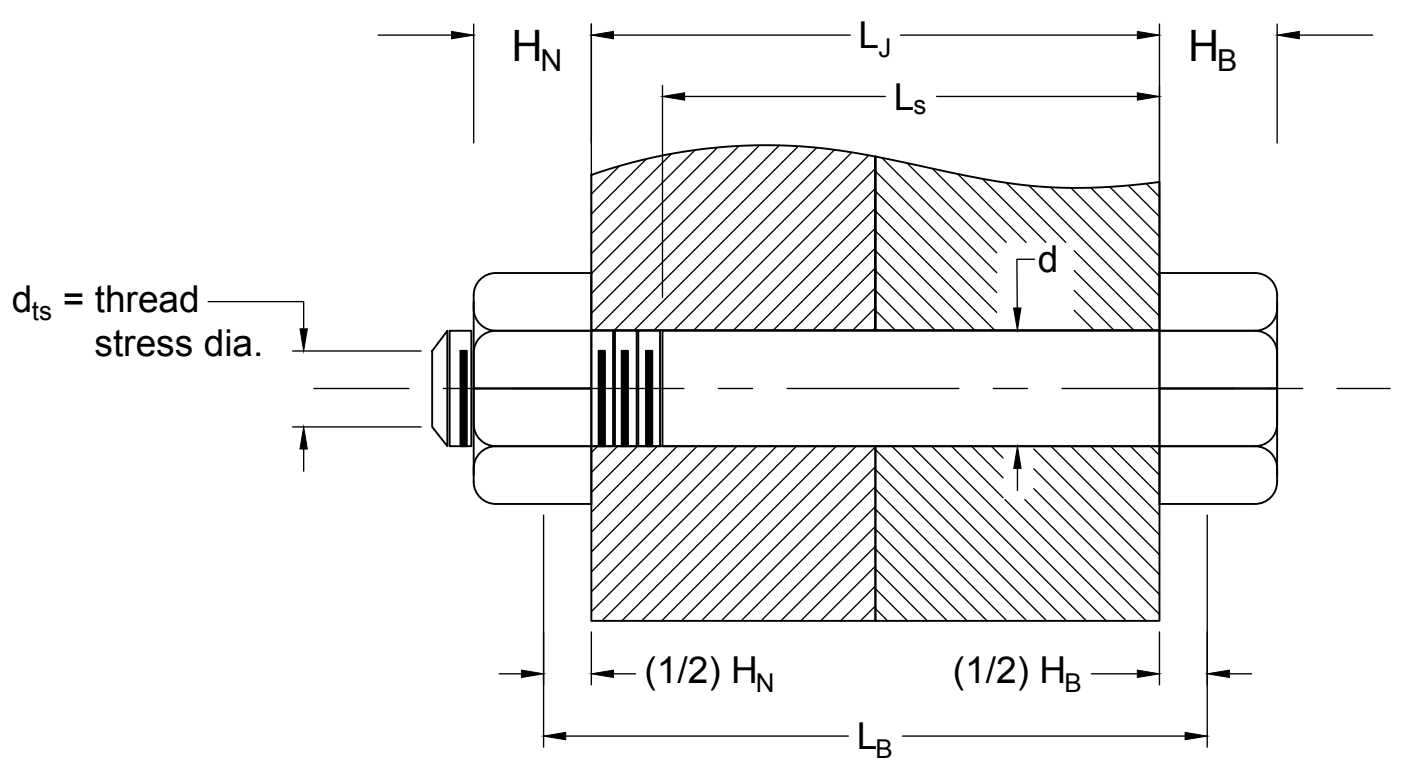

Figure C.2: Glued-in rod Detail for Each Frame Element

Table C.5: Elongation Requirements (Erick et al., 2008)

\begin{tabular}{c|ccc}
\hline Property & Units & Value & Description \\
\hline$L_{b}$ & $(\mathrm{~mm})$ & 96.398 & Effective length of bolt \\
$d_{t s}$ & $(\mathrm{~mm})$ & 22.00 & Minimum thread diameter \\
$d_{b}$ & $(\mathrm{~mm})$ & 25.4 & Nominal diameter of the bolt \\
$L_{S}$ & $(\mathrm{~mm})$ & 73.55 & Un-threaded bolt shank length \\
$H_{B}$ & $(\mathrm{~mm})$ & 15.50 & Bolt Head Thickness \\
$L_{J}$ & $(\mathrm{~mm})$ & 94.72 & Total grip length including 2 .177 inch thick washers \\
$H_{N}$ & $(\mathrm{~mm})$ & 25.00 & Nut thickness \\
$\delta_{b}$ & $(\mathrm{~mm})$ & 0.53 & Bolt elongation \\
$F_{b}$ & $(\mathrm{kN})$ & 57.2 & Normal force in bolt \\
$A_{b}$ & $\left.(\mathrm{~mm})^{2}\right)$ & 506.7 & Area of the nominal cross section of bolt \\
$E$ & $(\mathrm{mPa})$ & 200000 & Young's modulus of A325 steel bolt \\
\hline
\end{tabular}




\section{C.1.2 Gusset Plate Design (Gilbert, 2016)}

The gusset plate designed by Gilbert (2016) was detailed with an over strength factor of 1.1 in the horizontal component to allow for extra energy dissipation if necessary. The design consisted of a $6.4 \mathrm{~mm}$ gusset with a row shear failure mechanism. Figure C.3 illustrates the gusset plate. The design procedure used to determine the governing failure mechanism of the gusset plate is located in Appendix D, Sections D.0.3, D.0.4 and D.0.5 beginning on page 222.

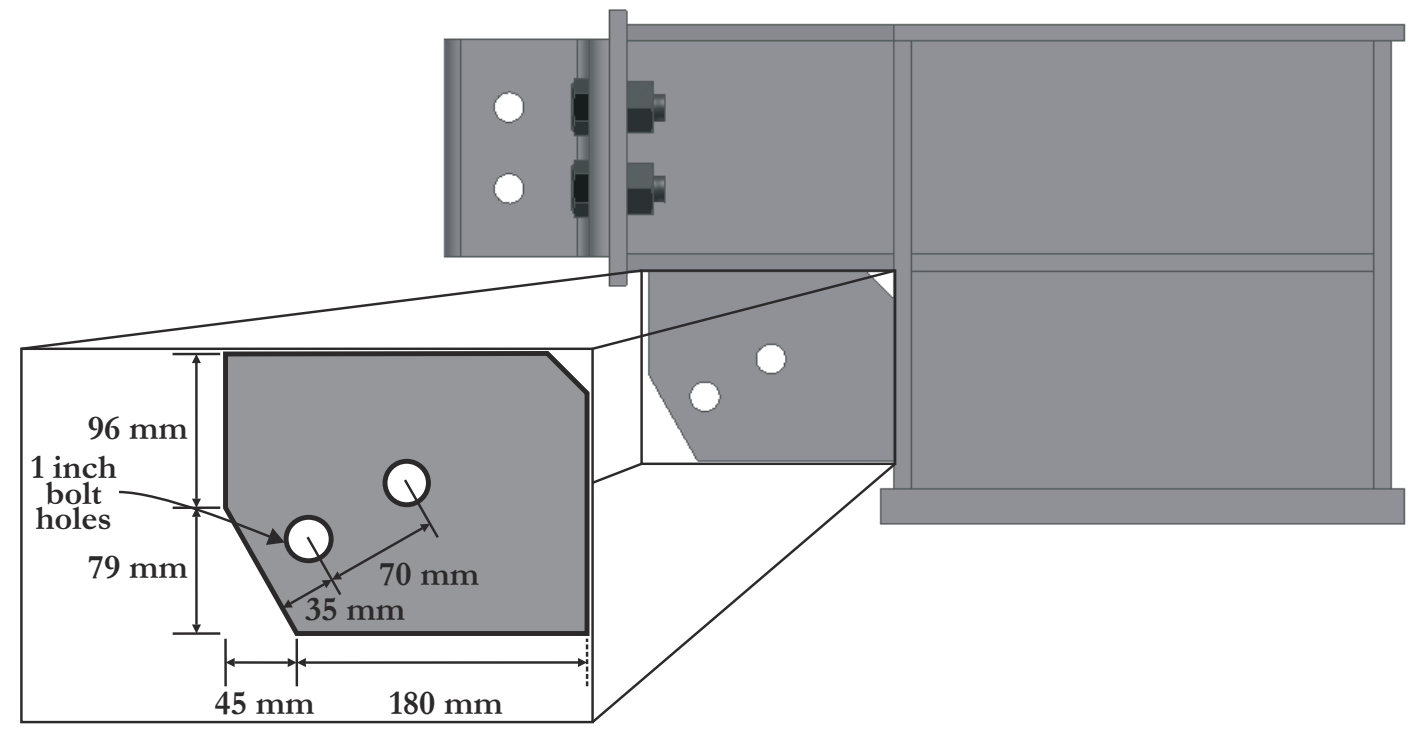

Figure C.3: Gusset Plate (Gilbert, 2016)

\section{C.1.3 Glued-in Rod Design (Gilbert, 2016)}

All glued-in rod connections were detailed to remain elastic to prevent stiffness properties from changing during Gilbert's testing procedures. The glued-in rods in the beam connection were detailed with an over strength factor of 1.1 while the glued-in rod connections in the column were detailed with an over strength factor of 1.21. This provided an additional over strength factor of 1.1 for the column connection over the gusset plate and thus provided an extra level of safety to the critical column element. All rods were detailed with an embedment length of $600 \mathrm{~mm}$. The resistance of the rods was expected to plateau at an embedment of $450 \mathrm{~mm}$ but was increased because it was believed that it would be beneficial in safeguarding the connection against high frequency vibrations. The beam element connection design contained 4 B7 glued-in 
rods that developed a total resistance of $452 \mathrm{kN}$ when snug tight. The column element connection design contained $8 \mathrm{~B} 7$ rods that developed a total resistance of $904 \mathrm{kN}$ when snug tight. Section views of the beam and column glued-in rods is illustrated in Figures C.4 and C.5. The design procedure used to determine the lateral and axial capacity of each glued-in rod connection is illustrated in Appendix D.0.7 beginning on page 224. The German Design Code DIN 1052 (Bauwesen, 2004), GIRod Project Design Procedure (Bengtsson and Johanssan, 2002) and LICONS Report Design Procedure (Connolly and Mettem, 2003) were each used to determine the axial capacity of the beam and column elements glued-in rod connections. Based on these different standards, the estimated glued-in rod strength lay between $492 \mathrm{kN}$ and $372 \mathrm{kN}$ and between $1000 \mathrm{kN}$ and $744 \mathrm{kN}$ for the beam and column elements, respectively. The shear capacity of the beam and column elements is not critical during these tests.

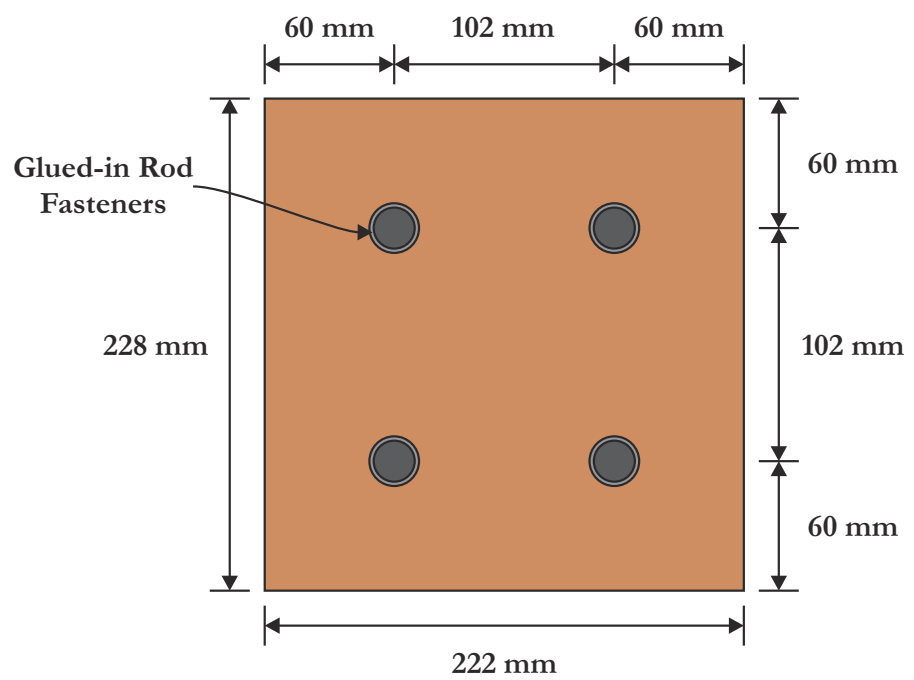

Figure C.4: Glued-in Rod Connection Beam Plan View (Gilbert, 2016) 


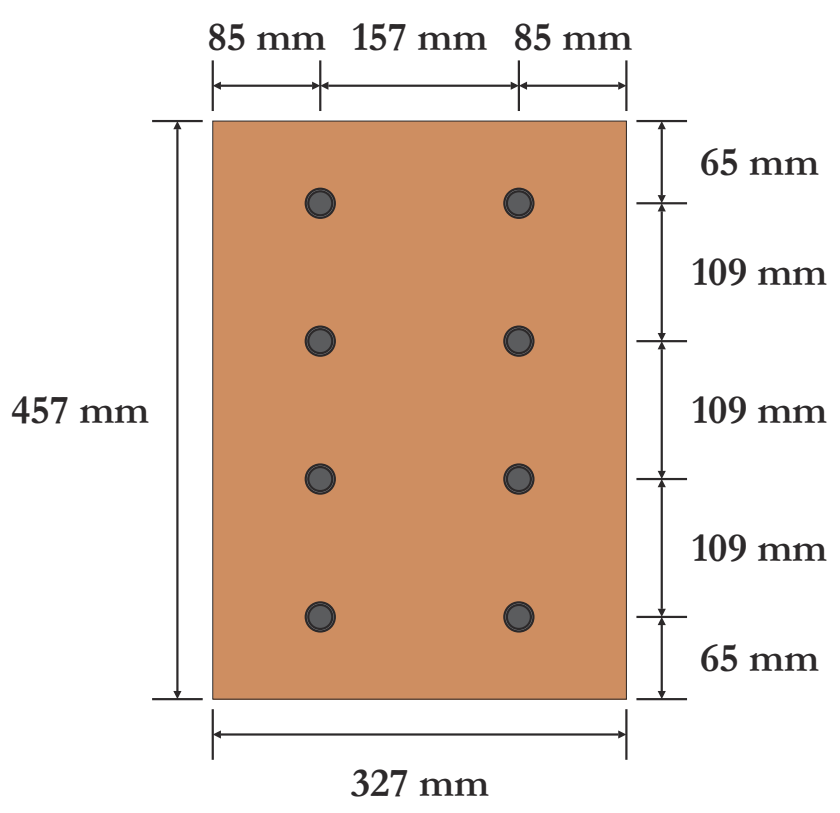

Figure C.5: Glued-in Rod Connection Column Plan View (Gilbert, 2016)

\section{C.1.4 Intermediate Steel Connection Component (Gilbert, 2016)}

An intermediate steel connection was chosen to replace the damage prone beam column interface of conventional heavy timber frames. The element was designed by Gilbert (2016) in accordance with CSA S16-09. The connection was designed to remain elastic under all loading.

\section{C.1.5 Timber Member Design (Gilbert, 2016)}

The design of the timber beam and column was governed by the spacing and edge distance requirements of the glued-in rod connections. The beam and column sizes were $228 \times 222 \mathrm{~mm}$ and $457 \times 327 \mathrm{~mm}$, respectively. Their capacities were more than adequate to provide elastic performance under all loading conditions. The design procedure used to determine the axial capacity of the beam and column elements is located in Appendix D.0.1 and Appendix D.0.2 beginning on page 221. The anticipated tensile capacity of the beam and column elements is $1039 \mathrm{kN}$ and $3155 \mathrm{kN}$, respectively. The compressive capacity of the beam and column elements was $1393 \mathrm{kN}$ and $3622 \mathrm{kN}$, respectively. The shear and moment capacity of the elements was not critical in these tests. 


\section{Appendix D: Capacity of Physical Specimen}

The capacity of all components within the prototype specimen are illustrated in this section including the beam and column elements, the friction brace, the gusset plate and the panel zone connection.

\section{D.0.1 Timber Elements in Tension}

The tensile capacity of the beam and column element is illustrated in Equations D.1 to D.3 and in Table D.1. All equations illustrated in this subsection are from the Canadian Wood Design Manual (CSA 086-14, 2014).

$$
\begin{gathered}
T_{r}=\phi F_{t g} A_{g} \\
F_{t g}=f_{t g} K_{D} K_{H} K_{S t} K_{T} \\
A_{g}=w h
\end{gathered}
$$

Table D.1: Timber Tension Capacity Forces Beam and Column

\begin{tabular}{c|ccccccccccc}
\hline Item & $f_{t g}$ & $K_{D}$ & $K_{H}$ & $K_{S t}$ & $K_{T}$ & $F_{t g}$ & $w$ & $h$ & $A_{g}$ & $\phi$ & $\begin{array}{c}T_{r} \\
\text { Units }\end{array}$ \\
$(\mathrm{Mpa})$ & $(-)$ & $(-)$ & $(-)$ & $(-)$ & $(\mathrm{Mpa})$ & $(\mathrm{mm})$ & $(\mathrm{mm})$ & $\left(\mathrm{mm}^{2}\right)$ & $(-)$ & $(\mathrm{kN})$ \\
\hline Beam & 20.4 & 1.15 & 1.0 & 1.0 & 1.0 & 23.46 & 222.0 & 228.0 & 50616.0 & 0.9 & 1038.6 \\
Column & 20.4 & 1.15 & 1.0 & 1.0 & 1.0 & 23.46 & 327.0 & 457.0 & 149439.0 & 0.9 & 3155.3 \\
\hline
\end{tabular}




\section{D.0.2 Timber Elements in Compression}

The capacity of the beam and column elements in compression are illustrated in Equations D.4 to D.8 and Table D.2.All equations illustrated in this subsection are from the Canadian Wood Design Manual (CSA 086-14, 2014).

$$
\begin{gathered}
P_{r}=\phi F_{c} A K_{Z c g} K_{C} \\
F_{c}=f_{c} K_{d} K_{H} K_{S c} K_{T} \\
K_{Z c g}=0.68 Z^{-0.13} \leq 1.0 \\
K_{c}=\left[1.0+\frac{F_{c} K_{Z c g} C_{c}^{3}}{35 E_{05} K_{S E} K_{T}}\right]^{-1} \\
C_{c}=\frac{k L}{w} \leq 50.0
\end{gathered}
$$

Table D.2: Timber Compressive Capacity Forces Beam and Column

\begin{tabular}{c|cccccccccccc}
\hline Item & $C_{c}$ & $Z$ & $K_{Z c g}$ & $K_{S E}$ & $E_{05}$ & $K_{S c}$ & $K_{d}$ & $f_{c}$ & $F_{C}$ & $K_{C}$ & $\phi$ & $P_{r}$ \\
Units & $(-)$ & $\left(\mathrm{m}^{3}\right)$ & $(-)$ & $(-)$ & $(\mathrm{Mpa})$ & $(-)$ & $(-)$ & $(\mathrm{Mpa})$ & $(\mathrm{Mpa})$ & $(-)$ & $(-)$ & $(\mathrm{kN})$ \\
\hline Beam & 7.7 & 0.086 & 0.93 & 1.0 & 11397 & 1.0 & 1.15 & 33.3 & 38.3 & 0.96 & 0.8 & 1393 \\
Column & 5.7 & 0.276 & 0.80 & 1.0 & 11397 & 1.0 & 1.15 & 33.3 & 38.3 & 0.98 & 0.8 & 3621 \\
\hline
\end{tabular}

\section{D.0.3 Group Tear out Steel Connections}

The group tear out of the steel connections are illustrated in Equations D.9 to D.10 and in Table D.3. All equations illustrated in this subsection are from the CAN/CSA S16-09 Limit States Design of Steel Structures Manual (CSA S16, 2010). 


$$
\begin{gathered}
T_{r}=\phi_{u}\left[U_{t} A_{n} F_{u}+0.6 A_{g v} \frac{F_{y}+F_{u}}{2}\right] \\
T_{r}=\phi_{u} A_{n e} F_{u}
\end{gathered}
$$

\begin{tabular}{|c|c|c|c|c|c|c|c|}
\hline $\begin{array}{l}\text { Item } \\
\text { Units }\end{array}$ & $\begin{array}{l}\phi_{u} \\
(-)\end{array}$ & $\begin{array}{l}U_{t} \\
(-)\end{array}$ & $\begin{array}{c}A_{n} \\
(\mathrm{~mm})\end{array}$ & $\begin{array}{c}F_{u} \\
(\mathrm{Mpa})\end{array}$ & $\begin{array}{c}A_{g v} \\
(\mathrm{~mm})\end{array}$ & $\begin{array}{c}F_{y} \\
(\mathrm{Mpa})\end{array}$ & $\begin{array}{c}T_{r} \\
(\mathrm{kN})\end{array}$ \\
\hline Gusset Plate & 0.75 & $(-)$ & 0.0 & 450.0 & 1344.0 & 300.0 & 226.8 \\
\hline Beam Pin Connection Plate & 0.75 & 0.6 & 1965.9 & 450.0 & 735.2 & 300.0 & 522.2 \\
\hline
\end{tabular}

Table D.3: Gusset Plate Capacity

\section{D.0.4 Bolts in Bearing}

The bolt's bearing capacity is illustrated in Equation D.11 and in Table D.4. All equations illustrated in this subsection are from the CAN/CSA S16-09 Limit States Design of Steel Structures Manual (CSA S16, 2010).

$$
B_{r}=3 \phi_{b r} n t d F_{u}
$$

Table D.4: Gusset Plate Capacity Bolt Bearing

\begin{tabular}{c|cccccc}
\hline Item & $\phi_{b r}$ & $n$ & $t$ & $d$ & $F_{u}$ & $B_{r}$ \\
Units & $(-)$ & $(-)$ & $(\mathrm{mm})$ & $(\mathrm{mm})$ & $(\mathrm{Mpa})$ & $(\mathrm{kN})$ \\
\hline Gusset Plate & 0.80 & 2 & 6.4 & 25.4 & 450.0 & 351.1 \\
Beam Pin Connection Plate & 0.80 & 2 & 15.88 & 25.4 & 450.0 & 871.2 \\
\hline
\end{tabular}

\section{D.0.5 Bolts in Shear}

The bolt's shear capacity is illustrated in Equation D.12 and in Table D.5. All equations illustrated in this subsection are from the CAN/CSA S16-09 Limit States Design of Steel Structures 
Manual (CSA S16, 2010).

$$
V_{r}=0.60 \phi_{b} n m A_{b} F_{u}
$$

Table D.5: Gusset Plate Capacity Bolt Shear

\begin{tabular}{c|cccccc}
\hline Item & $\phi_{b}$ & $n$ & $m$ & $A_{b}$ & $F_{u}$ & $V_{r}$ \\
Units & $(-)$ & $(-)$ & $(-)$ & $\left(\mathrm{mm}^{2}\right)$ & $(\mathrm{mPa})$ & $(\mathrm{kN})$ \\
\hline Gusset Plate & 0.80 & 2 & 2 & 506.7 & 450.0 & 437.8 \\
Beam Pin Connection Plate & 0.80 & 2 & 2 & 506.7 & 450.0 & 437.8 \\
\hline
\end{tabular}

\section{D.0.6 Axial Tension}

The axial tension capacity of the gusset plate and the beam pin connections are illustrated in Equation D.13 and in Table D.6. All equations illustrated in this subsection are from the CAN/CSA S16-09 Limit States Design of Steel Structures Manual (CSA S16, 2010).

$$
T_{r}=\phi_{u} A_{n e} F_{u}
$$

Table D.6: Gusset Plate Capacity Axial Tension

\begin{tabular}{c|cccc}
\hline $\begin{array}{c}\text { Item } \\
\text { Units }\end{array}$ & $\begin{array}{c}\phi_{u} \\
(-)\end{array}$ & $\begin{array}{c}A_{n e} \\
\left(\mathrm{~mm}^{2}\right)\end{array}$ & $\begin{array}{c}F_{u} \\
(\mathrm{mPa})\end{array}$ & $\begin{array}{c}T_{r} \\
(\mathrm{kN})\end{array}$ \\
\hline Gusset Plate & 0.90 & 1223.7 & 450.0 & 495.6 \\
Beam Pin Connection Plate & 0.90 & 2305.8 & 450.0 & 933.8 \\
\hline
\end{tabular}

\section{D.0.7 Glued-in Rods Tensile Resistance}

The tensile capacity of the glued-in rods for pretensioned and snug tight cases are illustrated in the following subsections, considering the GIRod Report, the EUROCODE, and the DIN 1052 Code. The capacity of the pretensioned rods was $70 \%$ of the snug tight case, since the 
formation of a gap between the steel plate and the bearing end grain on the glulam member should be avoided. $l_{a}$ was increased to 600 to ensure ductile yield failure of the rods and thus the embedment length used in all calculations below is $600 \mathrm{~mm}$.

\section{D.0.7.1 Rod Tensile Capacity}

The tensile capacity of an individual rod is illustrated in Equation D.14. The sung tight tensile capacity of the beam and column specimen's glued-in rods is illustrated in Table D.7. All equations illustrated in this subsection are from the CAN/CSA S16-09 Limit States Design of Steel Structures Manual (CSA S16, 2010).

$$
F u_{\text {rod }}=0.75 \phi_{A r} A_{n} f_{u}
$$

Table D.7: Glued-in Rods Tensile Capacity Beam and Column

\begin{tabular}{c|cccccc}
\hline Item & $\phi_{A r}$ & $A_{n}$ & $f_{u}$ & $F u_{\text {Rod,Individual }}$ & \# Rods & $P_{\text {f.total }}$ \\
Units & $(-)$ & $\left(\mathrm{mm}^{2}\right)$ & $(\mathrm{Mpa})$ & $(\mathrm{kN})$ & $(-)$ & $(k N)$ \\
\hline Beam & 0.8 & 283.5 & 860 & 146 & 4 & 585 \\
Column & 0.8 & 283.5 & 860 & 146 & 8 & 1170 \\
\hline
\end{tabular}

\section{D.0.7.2 GIRod Report Method}

The tensile capacity of the glued-in rod connection using the methodology presented in the GIRod Report (2002) is illustrated in Equations D.15, D.16, D.17 and Tables D.8 and D.9.

$$
\begin{gathered}
P_{f}=\pi d_{h} l_{a} \tau_{f} \frac{\tanh \varpi}{\varpi} \\
\varpi_{\text {member }}=\sqrt{\frac{l_{g e o, \text { member }}}{l_{m}}} \\
l_{\text {geo,member }}=\frac{\pi d_{r} l_{a}^{2}}{2}\left[\frac{1}{A_{r}}+\frac{\frac{E_{r}}{E_{w}}}{A_{w, \text { member }}}\right]
\end{gathered}
$$


Table D.8: Glued-in Rods Tensile Capacity GIRod Report 2002

\begin{tabular}{c|ccc}
\hline Item & Value & Units & Note \\
\hline$\phi$ & 0.75 & $(-)$ & Resistance Factor \\
$A_{n}$ & 283.5 & $(\mathrm{~mm})$ & Area of Rod \\
$\phi_{u}$ & 0.8 & $(-)$ & Resistance Factor \\
$f_{u}$ & 860 & $(\mathrm{Mpa})$ & Ultimate Strength of Rod \\
$d_{r}$ & 19 & $(\mathrm{~mm})$ & Rod Diameter \\
$l_{a}$ & 600 & $(-)$ & min of $25 d_{r}$ or 500 \\
$E_{r}$ & 200000 & $(\mathrm{Mpa})$ & Modulus of Elasticity of Rod \\
$l_{m}$ & 3600 & $(\mathrm{~mm})$ & Material Length Parameter for Epoxy Adhesives \\
$E_{w}$ & 13100 & $(\mathrm{Mpa})$ & Modulus of Elasticity of Wood \\
$A_{w, m e m b e r}$ & Varies & $\left(\mathrm{mm}{ }^{2}\right)$ & Area of Wood \\
$\tau_{f}$ & 10.5 & $(\mathrm{Mpa})$ & Bond Line Shear \\
$d_{h}$ & 23 & $(-)$ & min of $d_{r}+t_{b l}$ or $1.25 d_{r}$ \\
$t_{b l}$ & 4 & $(\mathrm{~mm})$ & Bond Line Thickness \\
\hline
\end{tabular}

Table D.9: Glued-in Rods Tensile Capacity GIRod Report 2002 Method Beam and Column

\begin{tabular}{c|cccccc}
\hline $\begin{array}{c}\text { Item } \\
\text { Units }\end{array}$ & $\begin{array}{c}l_{\text {geo,member }} \\
(-)\end{array}$ & $\begin{array}{c}A_{\text {w,member }} \\
\left(\mathrm{mm}^{2}\right)\end{array}$ & $\begin{array}{c}\varpi_{\text {member }} \\
(-)\end{array}$ & $\begin{array}{c}P_{\text {f,Individual }} \\
(\mathrm{kN})\end{array}$ & $\begin{array}{c}\text { \# Rods } \\
(-)\end{array}$ & $\begin{array}{c}P_{\text {f.total }} \\
(k N)\end{array}$ \\
\hline Beam & 49518 & 14117 & 3.71 & 123 & 4 & 492 \\
Column & 47770 & 16617 & 3.64 & 125 & 8 & 1000 \\
\hline
\end{tabular}

\section{D.0.7.3 EUROCODE Method}

The tensile capacity of the glued-in rod connection using the methodology in EUROCODE 5 is illustrated in Equations D.18, D.19 and Tables D.10 and D.11.

$$
\begin{gathered}
w=0.016 \frac{l_{a}}{\sqrt{d_{e q u}}} \\
F_{a x, R}=\pi d_{h} l_{a} f_{a x, k} \frac{\tanh (w)}{w}
\end{gathered}
$$


Table D.10: Glued-in Rods Tensile Capacity EUROCODE 5

\begin{tabular}{c|ccc}
\hline Item & Value & Units & Note \\
\hline$l_{a}$ & 600 & $(-)$ & min of $25 d_{r}$ or 500 \\
$d_{h}$ & 23 & $(-)$ & min of $d_{r}+t_{b l}$ or $1.25 d_{r}$ \\
$f_{a x, k}$ & 5.5 & $(-)$ & Timber Adhesive Shear Strength \\
\hline
\end{tabular}

Table D.11: Glued-in Rods Tensile Capacity EUROCODE 5 Method Beam and Column

\begin{tabular}{c|cccc}
\hline $\begin{array}{c}\text { Item } \\
\text { Units }\end{array}$ & $\begin{array}{c}F_{\text {ax,R,Individual }} \\
(-)\end{array}$ & $\begin{array}{c}\text { \# Rods } \\
\left(\mathrm{mm}^{2}\right)\end{array}$ & $\begin{array}{c}P_{\text {f.total }} \\
(-)\end{array}$ & $(\mathrm{kN})$ \\
\hline Beam & 2.0 & 115 & 4 & 460 \\
Column & 2.0 & 115 & 8 & 920 \\
\hline
\end{tabular}

\section{D.0.7.4 DIN German Design Code Method}

The tensile capacity of the glued-in rod connection using the methodology in the German Design Code DIN 1052 is illustrated in Equations D.20, D.21, D.22 and Table D.12.

$$
\begin{gathered}
R_{a x, d}=\pi d l_{a d} f_{k 1, d} \\
f_{k 1, d}= \begin{cases}4.0 & \text { if } l_{a d} \leq 250 \mathrm{~mm} \\
5.25-0.005 l_{a d} & \text { if } 250>l_{a d} \leq 500 \mathrm{~mm} \\
3.5-0.0015 l_{a d} & \text { if } 500>l_{a d} \leq 1000 \mathrm{~mm}\end{cases} \\
l_{d a, \text { max }}=\left\{\begin{array}{l}
0.5 d^{2} \\
10 d
\end{array}\right.
\end{gathered}
$$


Table D.12: Glued-in Rods Tensile Capacity DIN 1052 Method Beam and Column

\begin{tabular}{c|cccccc}
\hline $\begin{array}{c}\text { Item } \\
\text { Units }\end{array}$ & $\begin{array}{c}d \\
(\mathrm{~mm})\end{array}$ & $\begin{array}{c}l_{\text {da,max }} \\
(\mathrm{mm})\end{array}$ & $\begin{array}{c}f_{k 1, d} \\
(\mathrm{Mpa})\end{array}$ & $\begin{array}{c}R_{\text {ax,d.Individual }} \\
(\mathrm{kN})\end{array}$ & $\begin{array}{c}\text { \# Rods } \\
(-)\end{array}$ & $\begin{array}{c}R_{\text {ax,d.total }} \\
(\mathrm{kN})\end{array}$ \\
\hline Beam & 19 & 600 & 2.6 & 93.1 & 4 & 372 \\
Column & 19 & 600 & 2.6 & 93.1 & 8 & 745 \\
\hline
\end{tabular}

\section{D.0.7.5 Shear Capacity GIROD Report (2002) Method}

The lateral capacity of the glued-in rods using the methodology in the GIROD Report (2002) is illustrated in Equations D.23 to D.29 and in Table D.13. The shear capacity of the beam and column elements was $54 \mathrm{kN}$ and $134 \mathrm{kN}$, respectively.

$$
\begin{gathered}
R_{90, d}=0.5 k_{s} k_{r}\left[6.5+\frac{18 a^{2}}{H^{2}}\right]\left[T_{e f} H\right]^{0.8} \\
T_{e f, \text { min }}=\left\{\begin{array}{l}
B \\
6 d
\end{array}\right. \\
k_{s, m a x}=\left\{\begin{array}{l}
1 \\
0.7+\frac{1.4 a_{r}}{H}
\end{array}\right. \\
k_{r}=\frac{n}{\sum_{i=1}^{n}\left(\frac{h_{1}}{h_{i}}\right)^{2}} \\
a_{r}=-t+\sqrt{t^{2}+4\left(\frac{M_{y}}{f_{h, 1} d}\right)} \\
M_{y}=0.26 f_{u} d_{m}^{2.7} \\
f_{h 1}=0.11 \rho_{k} d^{-0.3}
\end{gathered}
$$


Table D.13: Glued-in Rods Shear Capacity GIROD (2002) Method Beam and Column

\begin{tabular}{|c|c|c|c|c|}
\hline Item & Beam & Column & Units & Notes \\
\hline$A_{r}$ & 77.0 & 77.0 & $(\mathrm{~mm})$ & Plastic hinge length, Refer to Equation D.27 \\
\hline$R_{90, d}$ & 54.3 & 134 & $(\mathrm{kN})$ & Shear strength, Refer to Equation D.23 \\
\hline$k_{s}$ & 1.17 & 1.0 & $(-)$ & Refer to Equation D.25 \\
\hline$k_{r}$ & 3.52 & 6.56 & $(-)$ & Refer to Equation D.26 \\
\hline$H$ & 228 & 457 & $(\mathrm{~mm})$ & Element height \\
\hline$T_{e f}$ & 114 & 114 & $(\mathrm{~mm})$ & Refer to Equation D.24 \\
\hline$d$ & 19 & 19 & $(\mathrm{~mm})$ & Rod diameter \\
\hline$B$ & 222 & 327 & $(\mathrm{~mm})$ & Element width \\
\hline$a$ & 60 & 65 & $(\mathrm{~mm})$ & Rod depth from tension face \\
\hline$n$ & 4 & 8 & $(\mathrm{~mm})$ & Number of Rods \\
\hline$h_{1}$ & 60 & 65 & $(\mathrm{~mm})$ & Rod depth from compression face \\
\hline$h_{2}$ & 162 & 174 & $(\mathrm{~mm})$ & Rod depth from compression face \\
\hline$h_{3}$ & 0 & 283 & $(\mathrm{~mm})$ & Rod depth from compression face \\
\hline$h_{4}$ & 0 & 392 & $(\mathrm{~mm})$ & Rod depth from compression face \\
\hline$t$ & 0 & 0 & $(\mathrm{~mm})$ & Space between wood and steel connection \\
\hline$M_{y}$ & 634025 & 634025 & $(-)$ & Refer to Equation D.29 \\
\hline$f_{h 1}$ & 22.5 & 22.5 & $(\mathrm{MPa})$ & Embedment strength of timber refer to Equation D.28 \\
\hline$\rho_{k}$ & 495 & 495 & $\left(\mathrm{~kg} / \mathrm{m}^{3}\right)$ & Raw density of SPF timber \\
\hline$d_{m}$ & 19 & 19 & $(\mathrm{~mm})$ & Average rod diameter \\
\hline$f_{u}$ & 860 & 860 & $(\mathrm{Mpa})$ & Ultimate Strength of rod \\
\hline
\end{tabular}

\section{D.0.8 Glued-in Rod Capacity Summary}

A summary of the beam and column glued-in rod connection capacities is illustrated in Table D.14. The glued-in rod connection snug tight case for the beam and column connections were between $492 \mathrm{kN}$ and $372 \mathrm{kN}$ and between $1000 \mathrm{kN}$ and $744 \mathrm{kN}$, respectively. The pretensioned capacity was between $344 \mathrm{kN}$ and $260 \mathrm{kN}$ and between $700 \mathrm{kN}$ and $521 \mathrm{kN}$ for the beam and column connections, respectively. 
Table D.14: Glued-in Rods Connection Summary Snug Tight and Pretensioned

\begin{tabular}{c|cccc}
\hline Tightening Method & \multicolumn{2}{|c}{ Snug Tight Capacity } & \multicolumn{2}{c}{ Pretensioned Capacity } \\
Item & Beam & Column & Beam & Column \\
Units & $(\mathrm{kN})$ & $(\mathrm{kN})$ & $(\mathrm{kN})$ & $(\mathrm{kN})$ \\
\hline Rod Tensile Capacity & 584 & 1168 & 409 & 818 \\
GIRod Report & 492 & 1000 & 344 & 700 \\
EUROCODE 5 & 460 & 920 & 322 & 644 \\
DIN 1052 & 372 & 744 & 260 & 521 \\
\hline
\end{tabular}




\section{Appendix E: Fabrication Drawings (Gilbert, 2016)}

\section{E.1 Prototype Specimen Shop Drawings (Gilbert, 2016)}

The prototype specimen shop drawings are presented below. The design of the prototype specimen was by Gilbert (2016). 


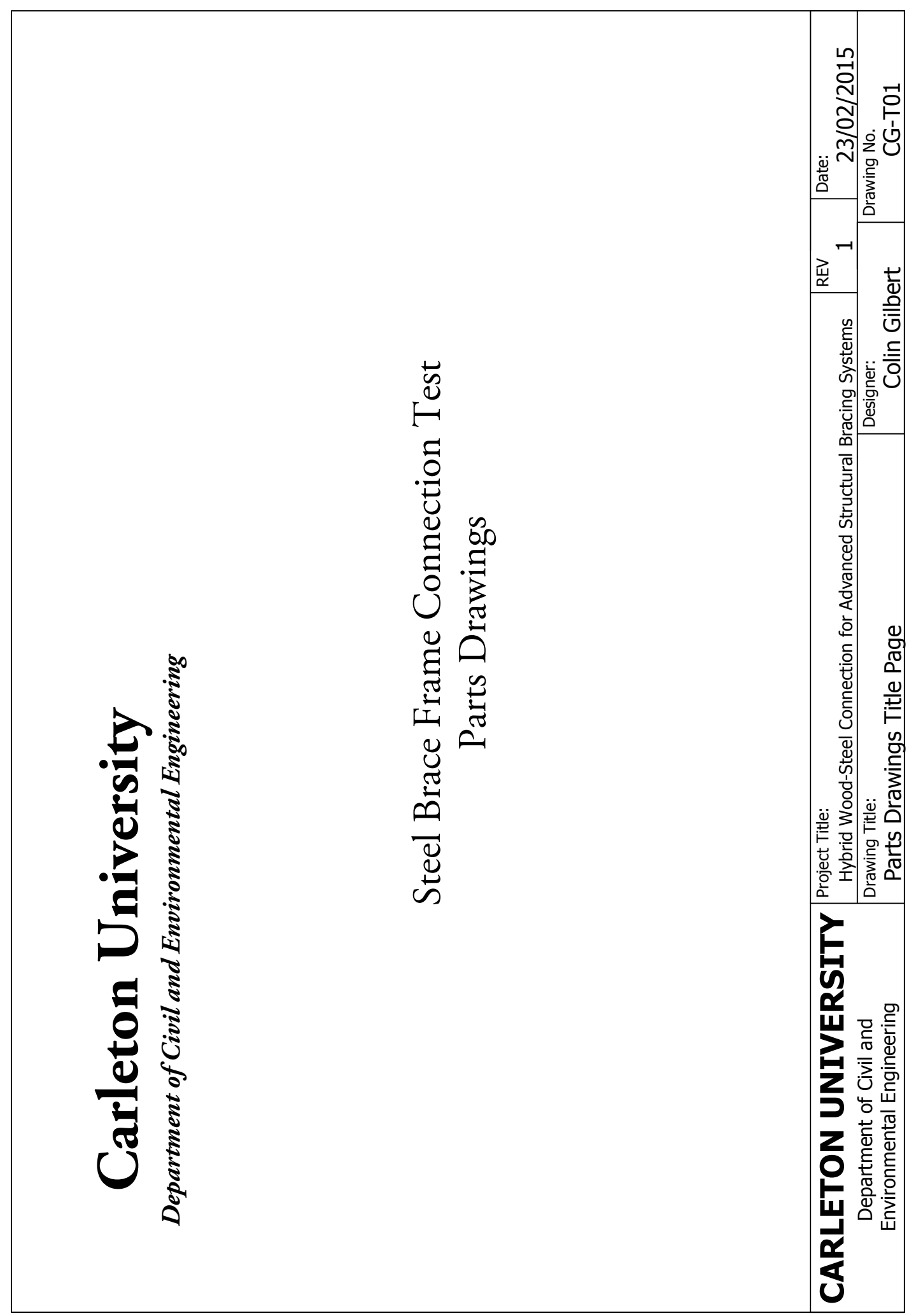




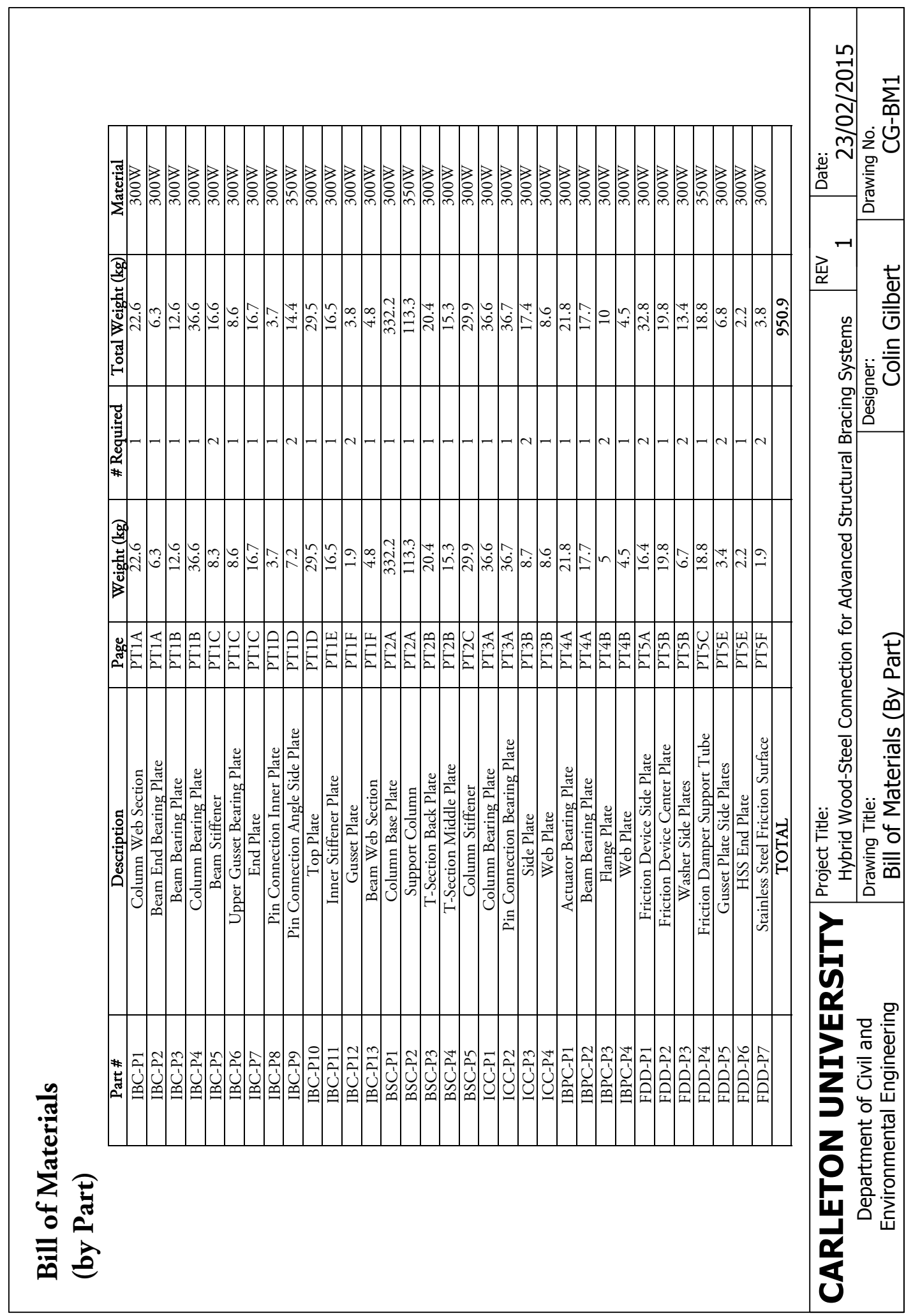




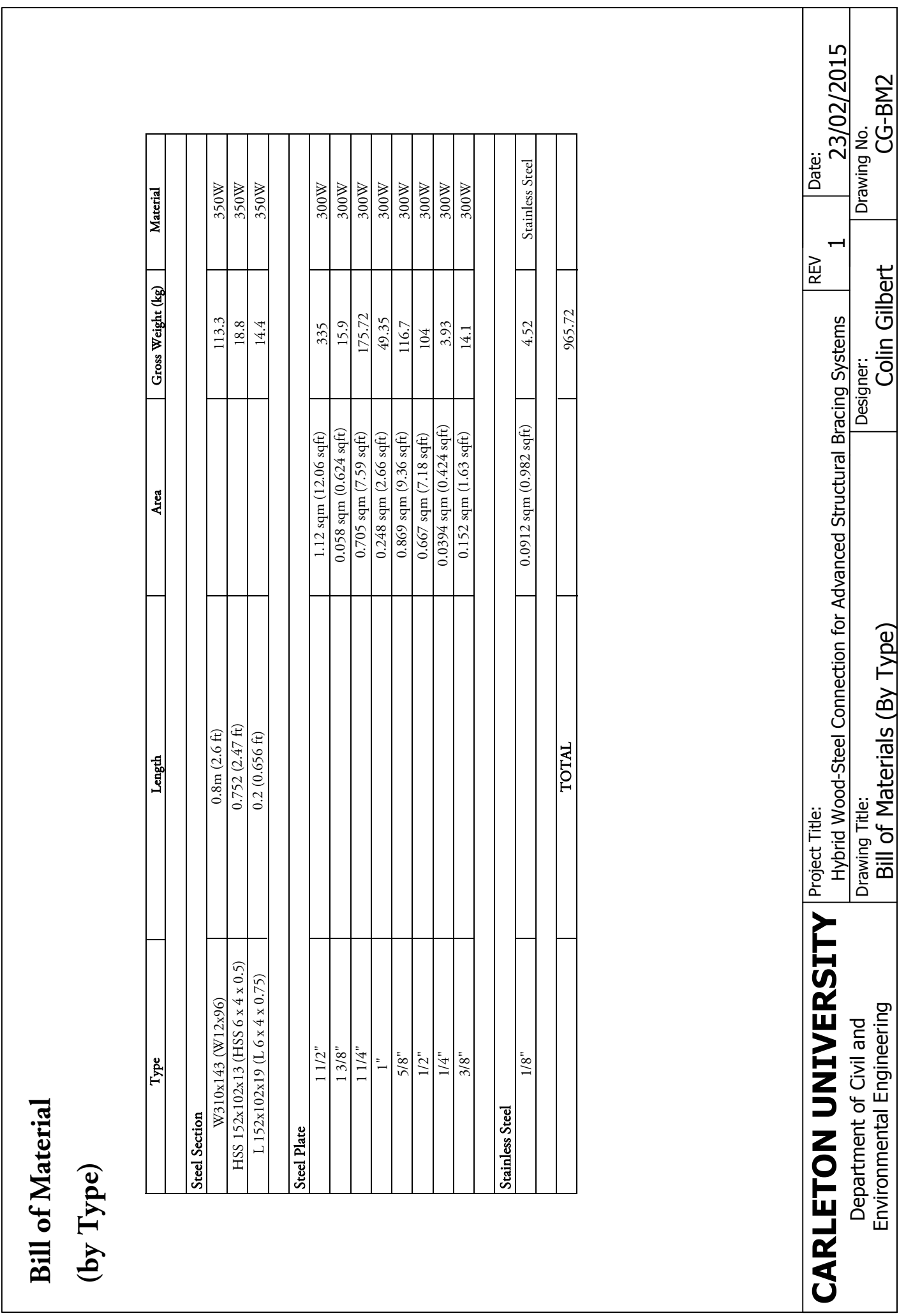




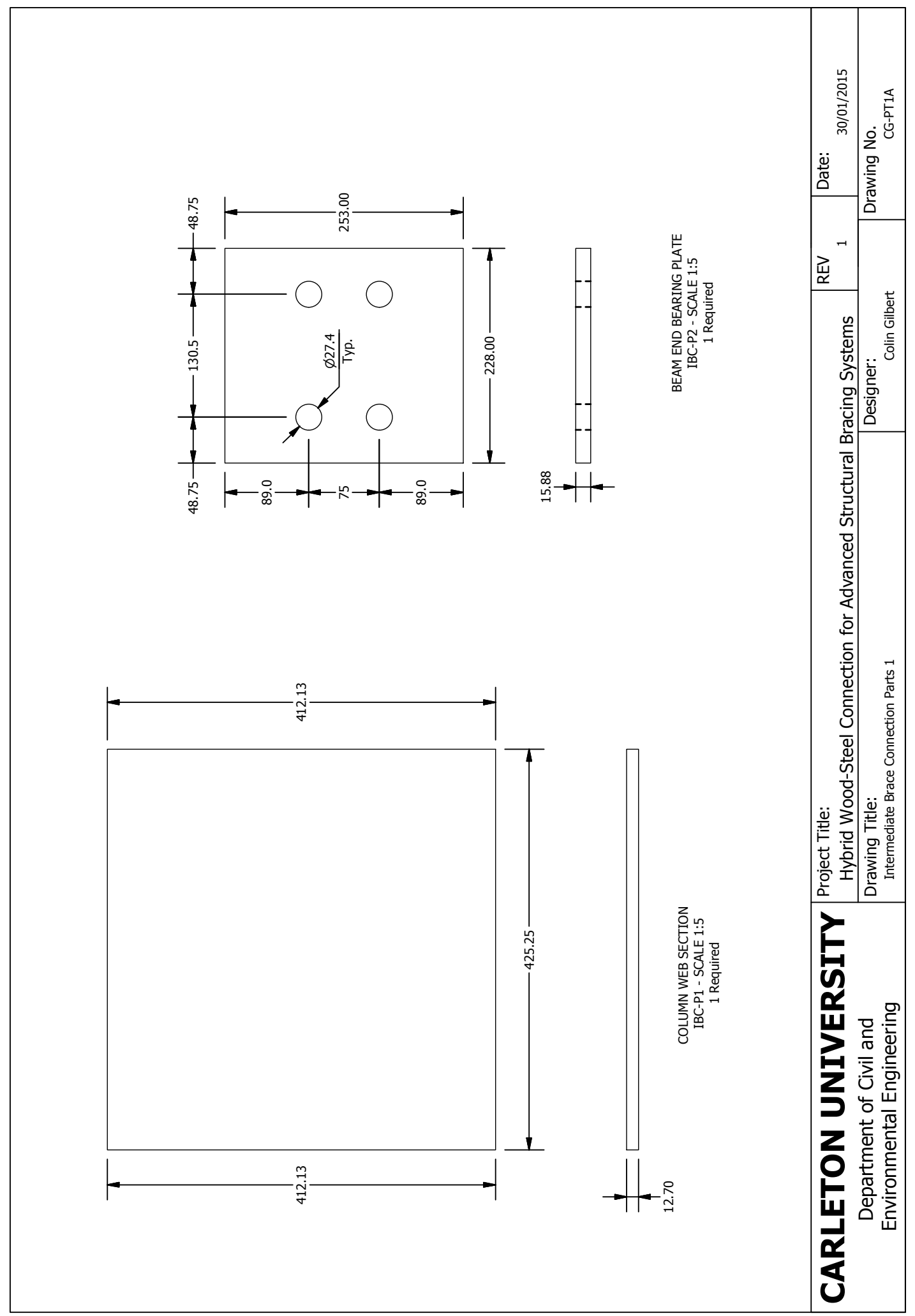

Sean Miller, Department of Civil and Environmental Engineering, Carleton University 


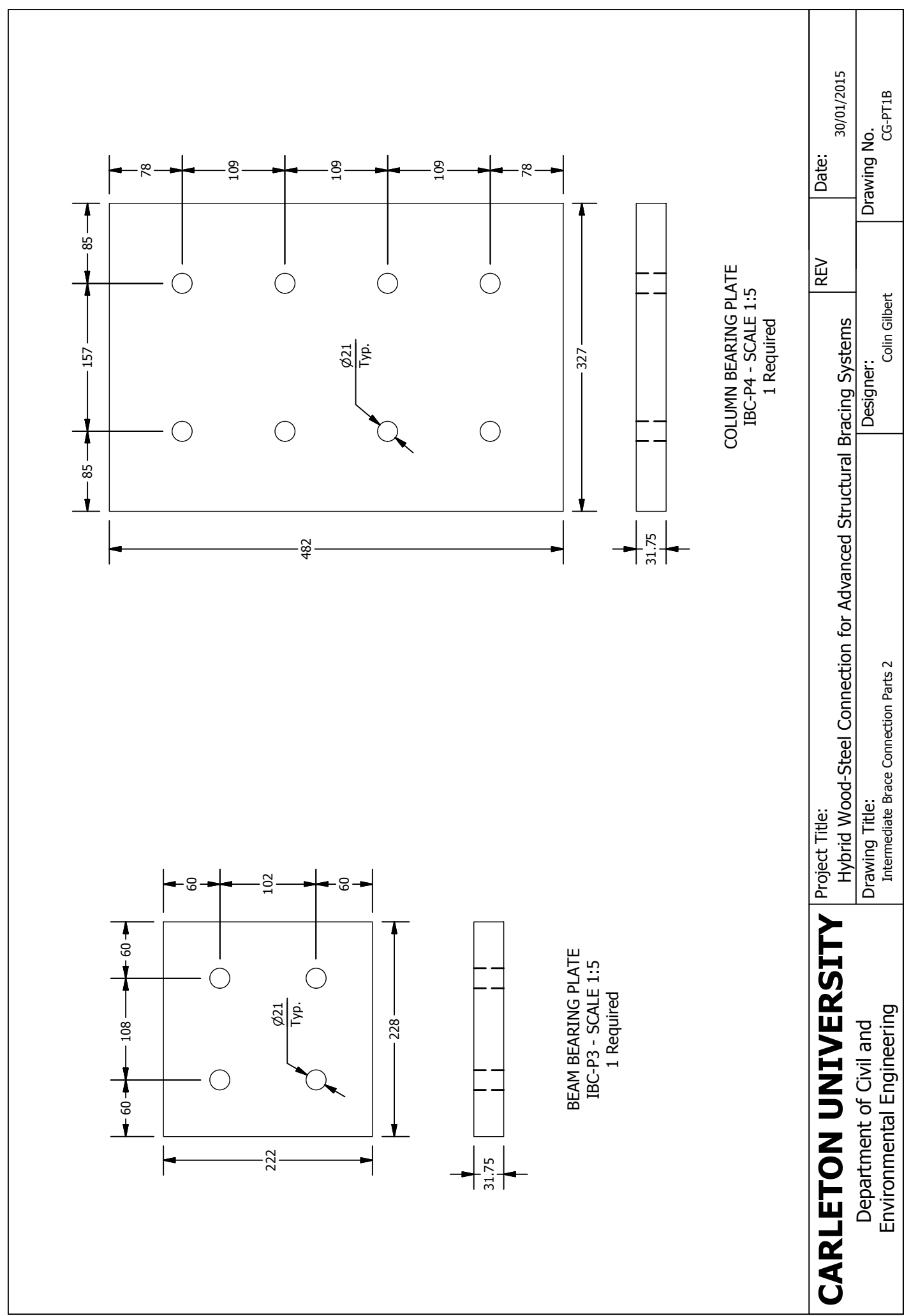

Sean Miller, Department of Civil and Environmental Engineering, Carleton University 


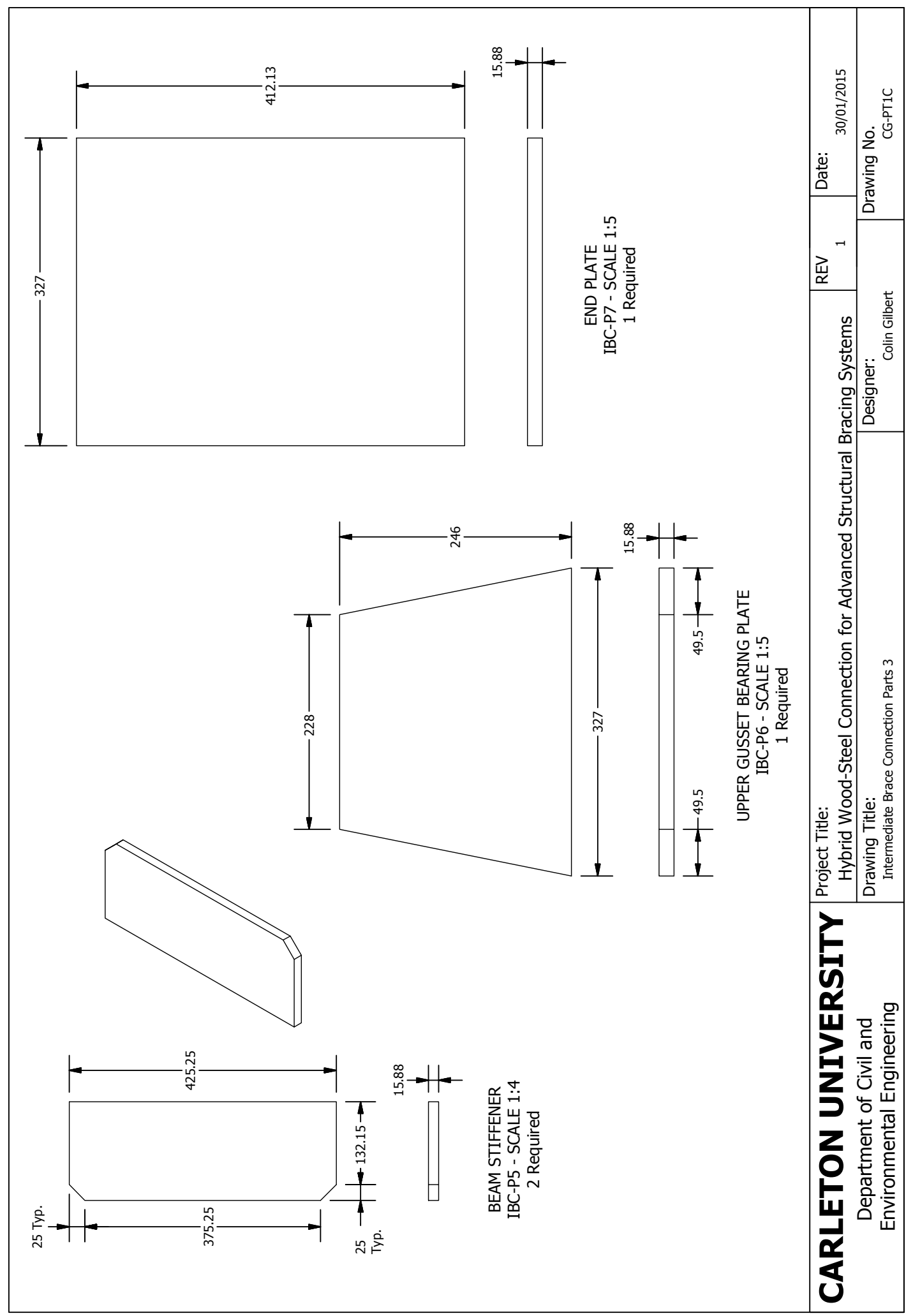

Sean Miller, Department of Civil and Environmental Engineering, Carleton University 


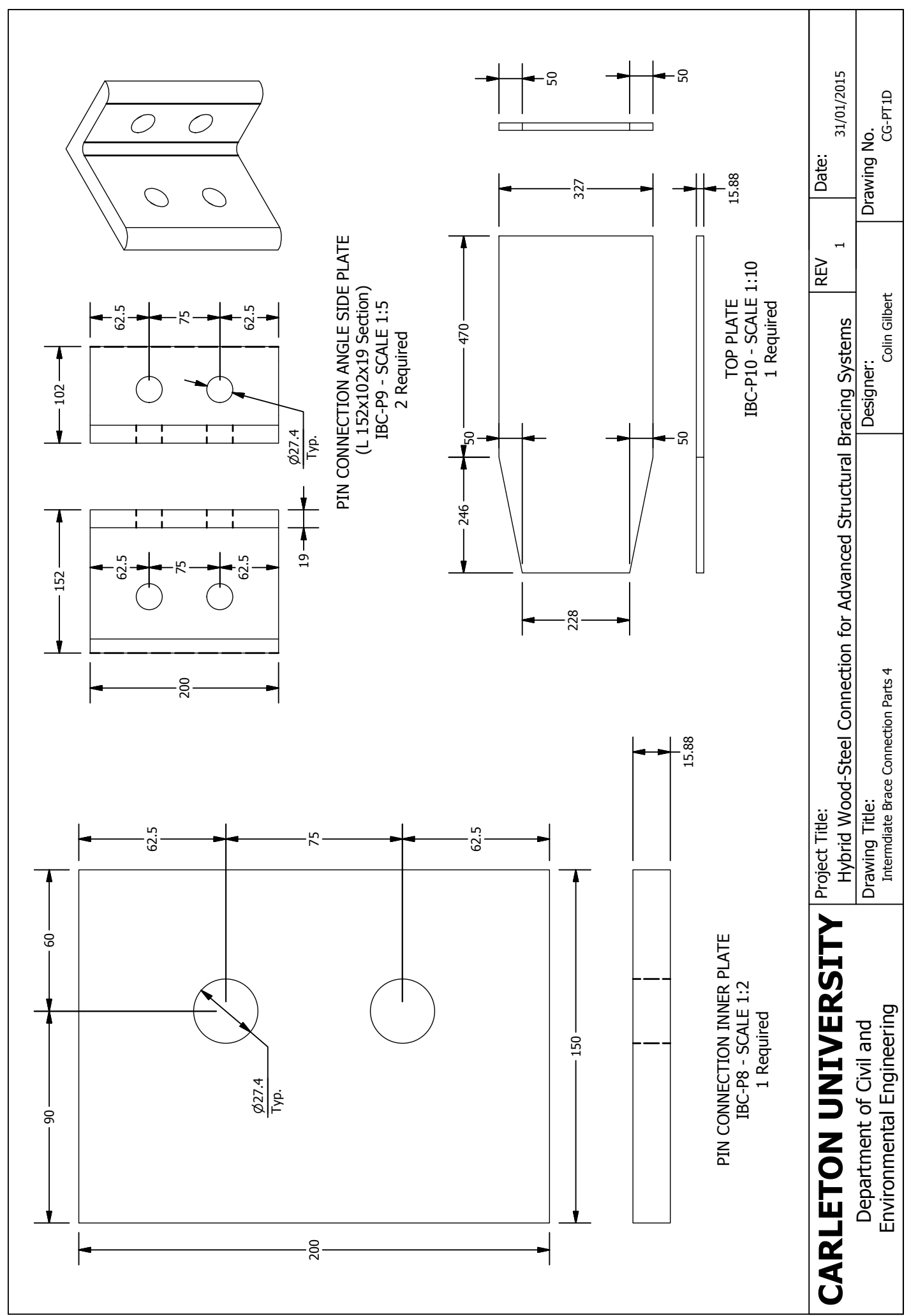




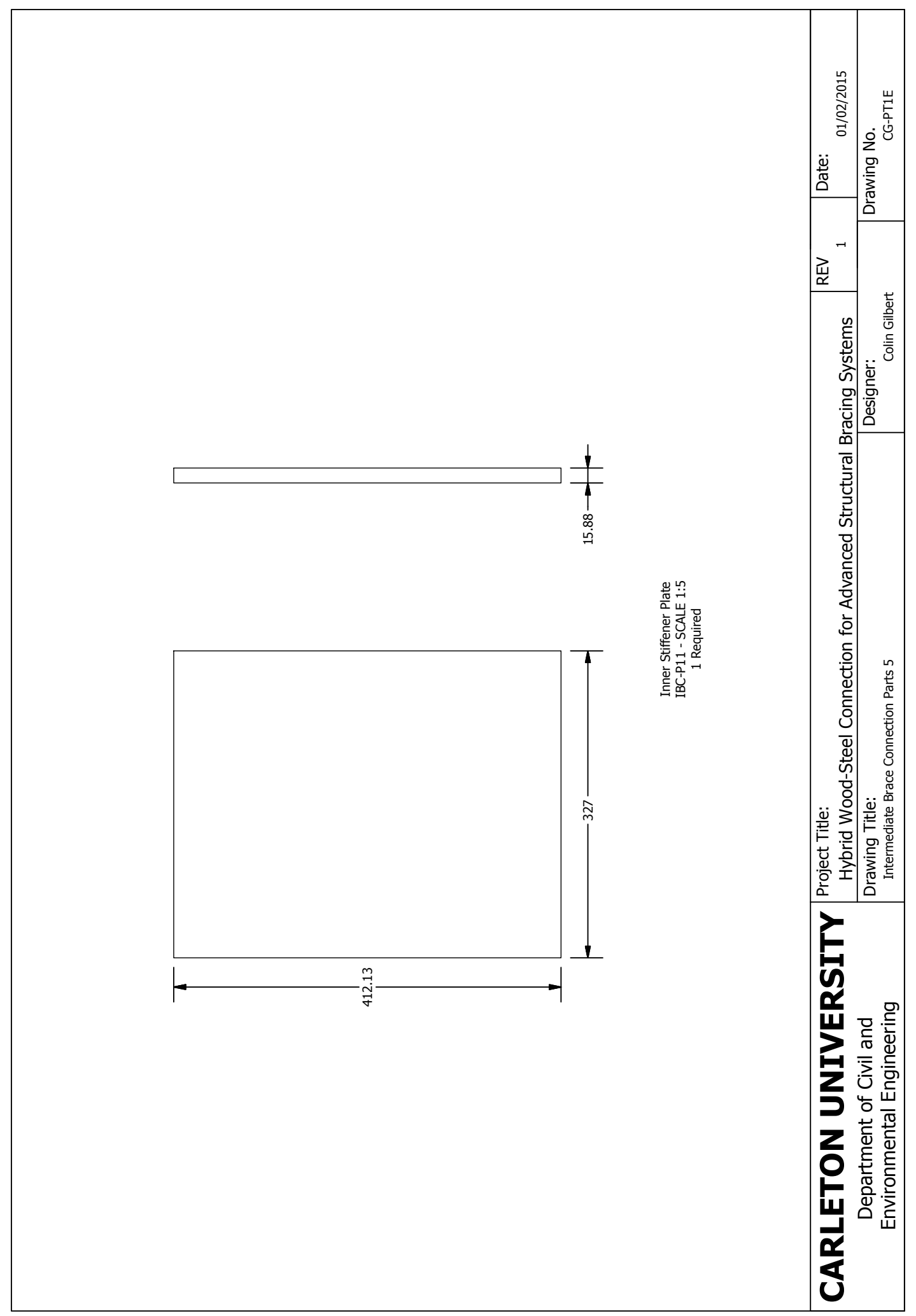




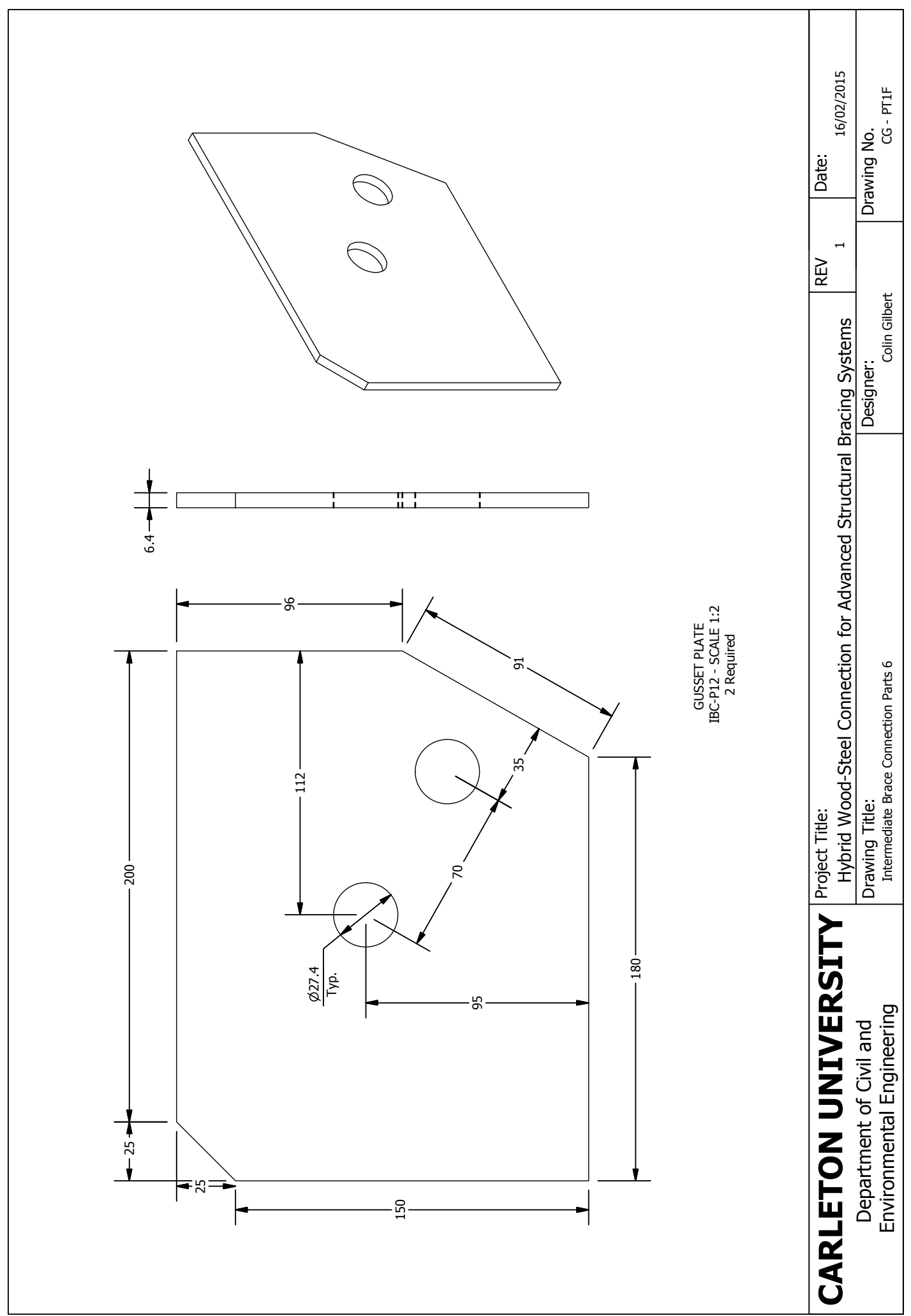

Sean Miller, Department of Civil and Environmental Engineering, Carleton University 


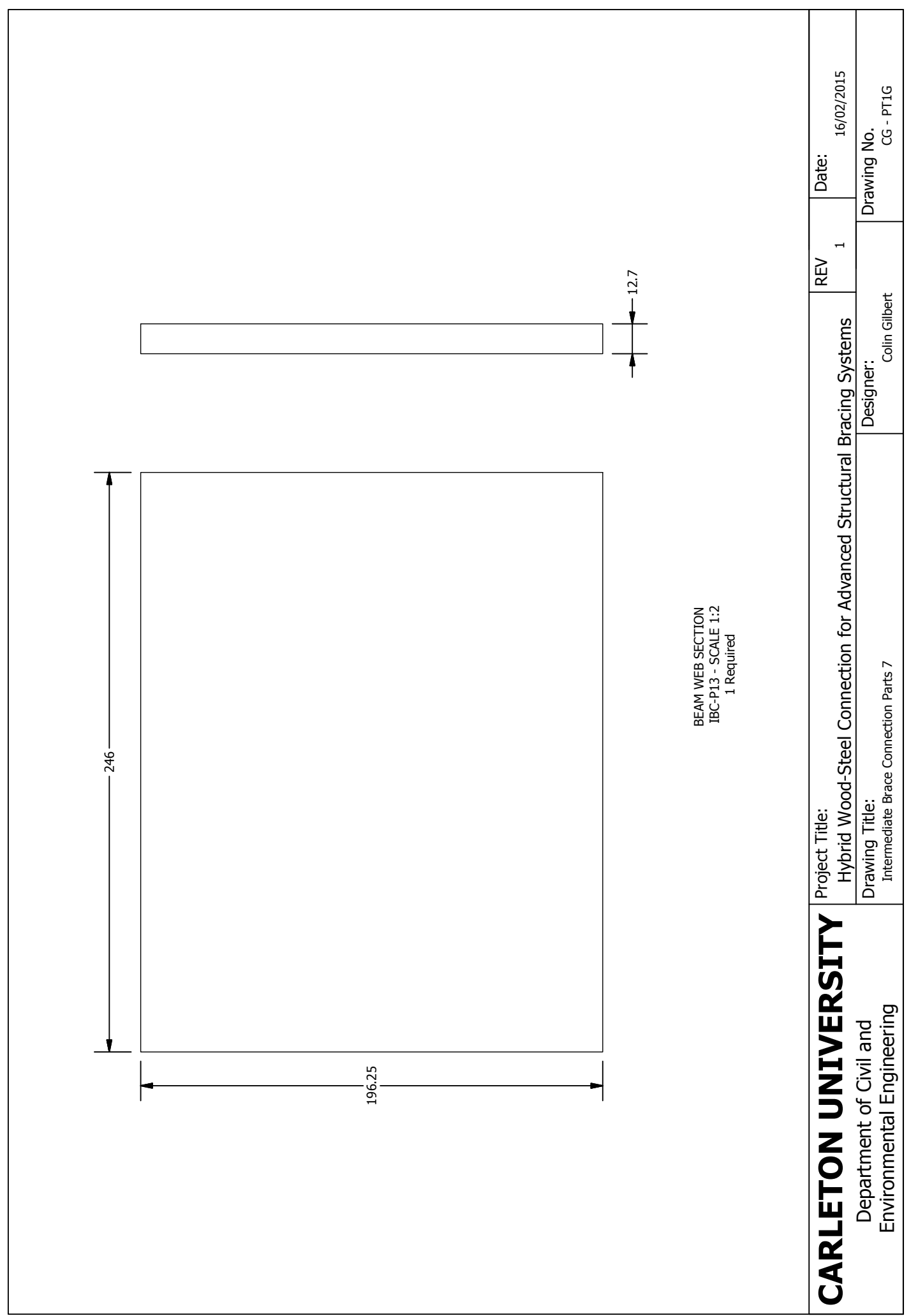




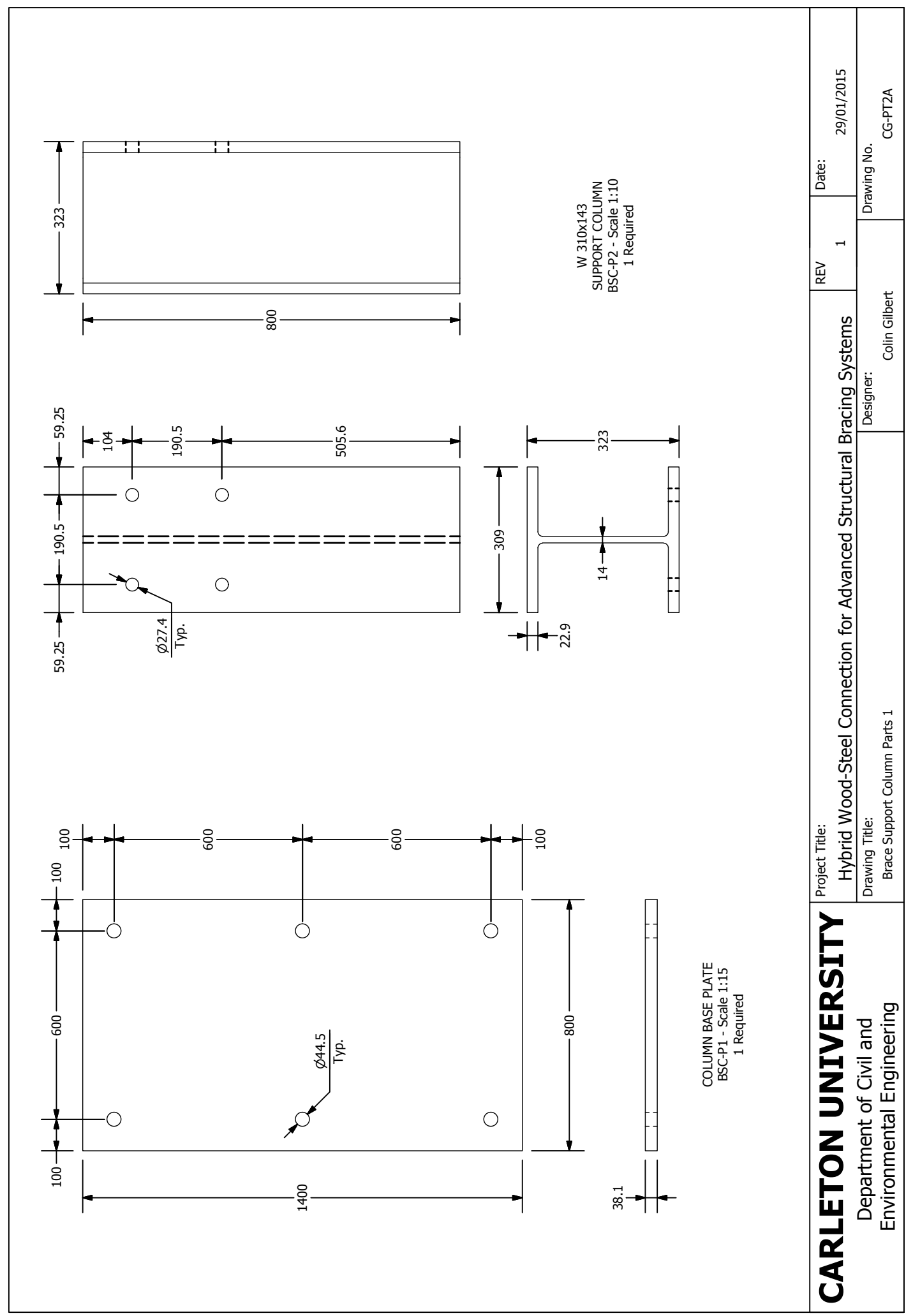




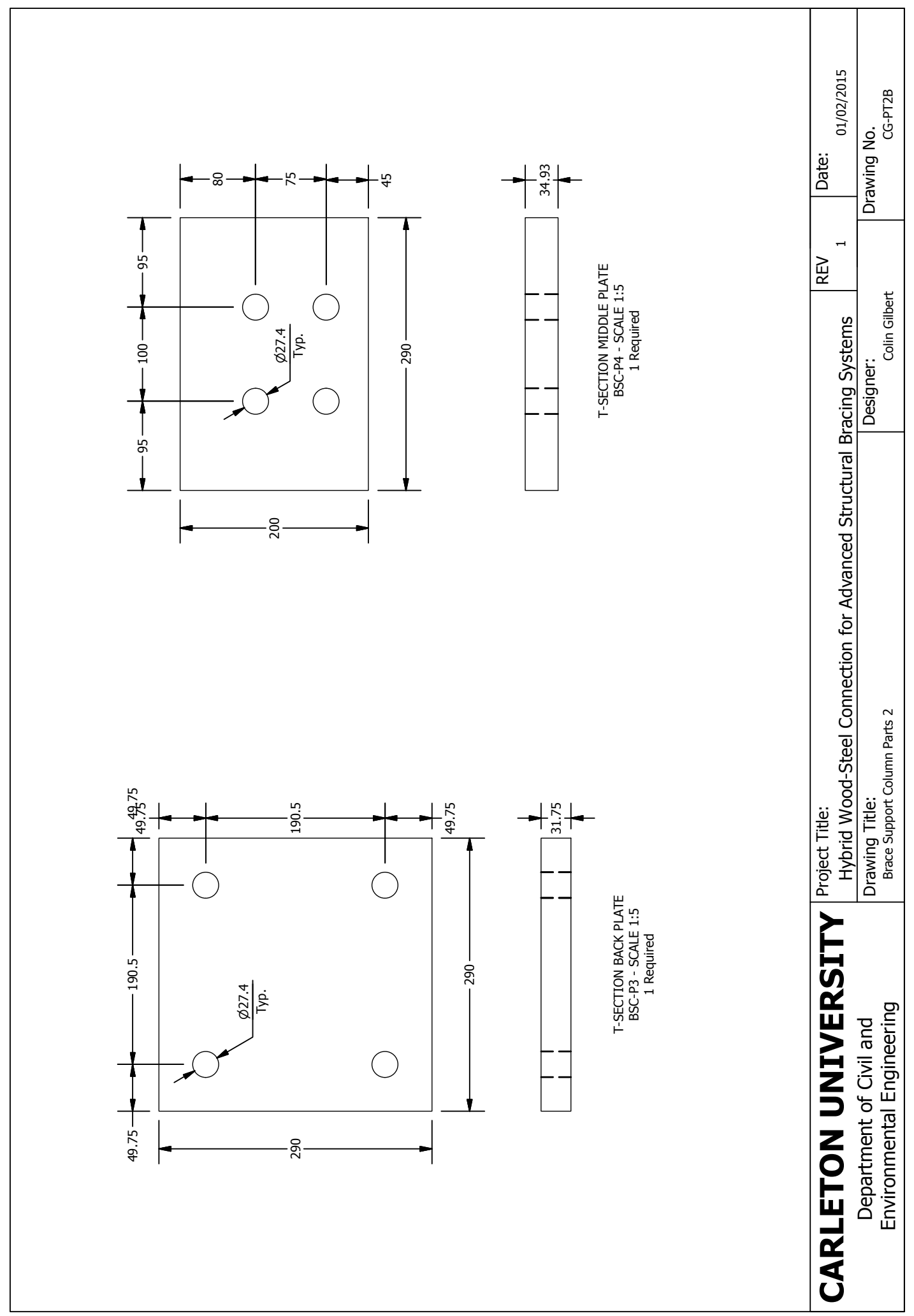

Sean Miller, Department of Civil and Environmental Engineering, Carleton University 


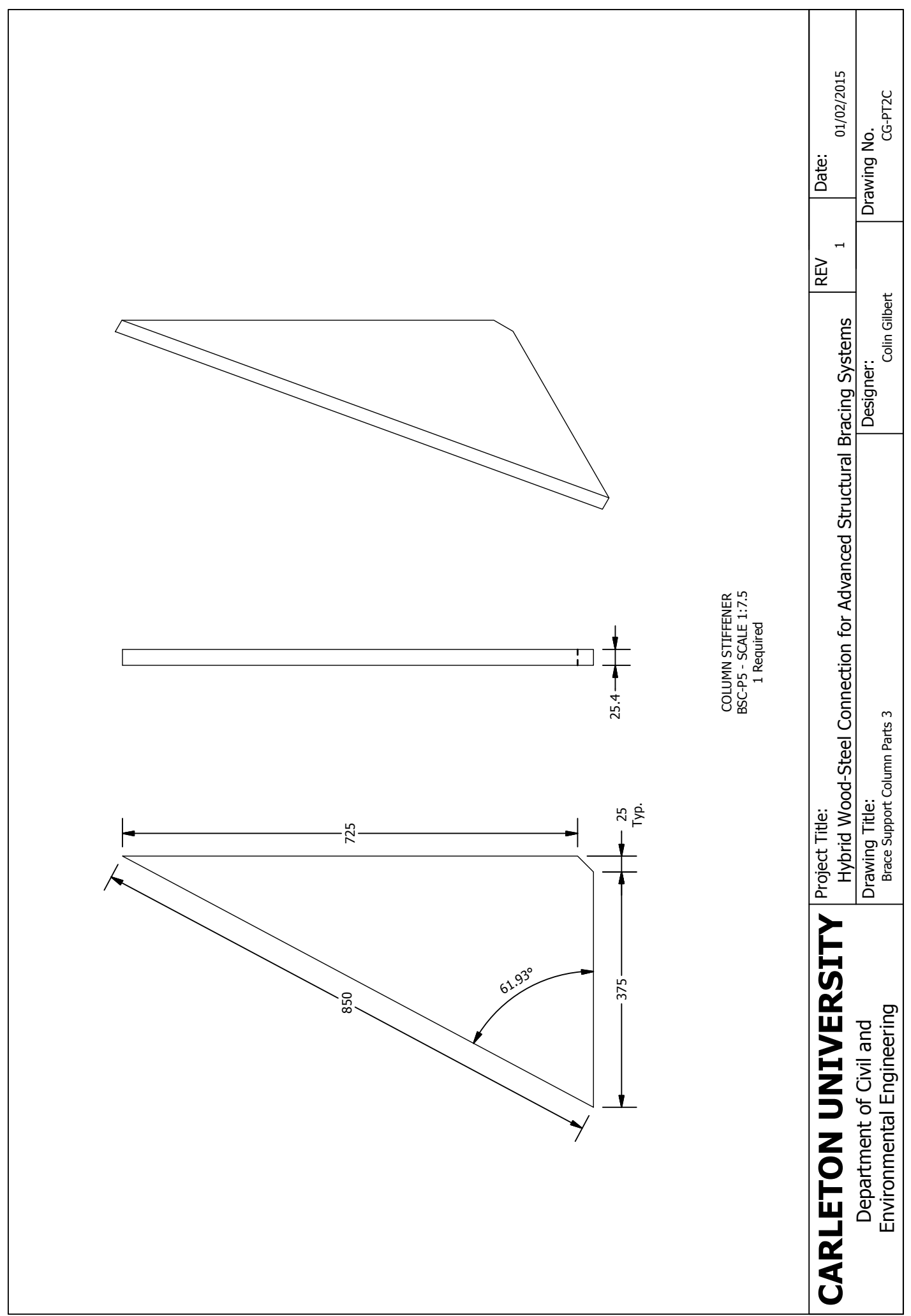

Sean Miller, Department of Civil and Environmental Engineering, Carleton University 


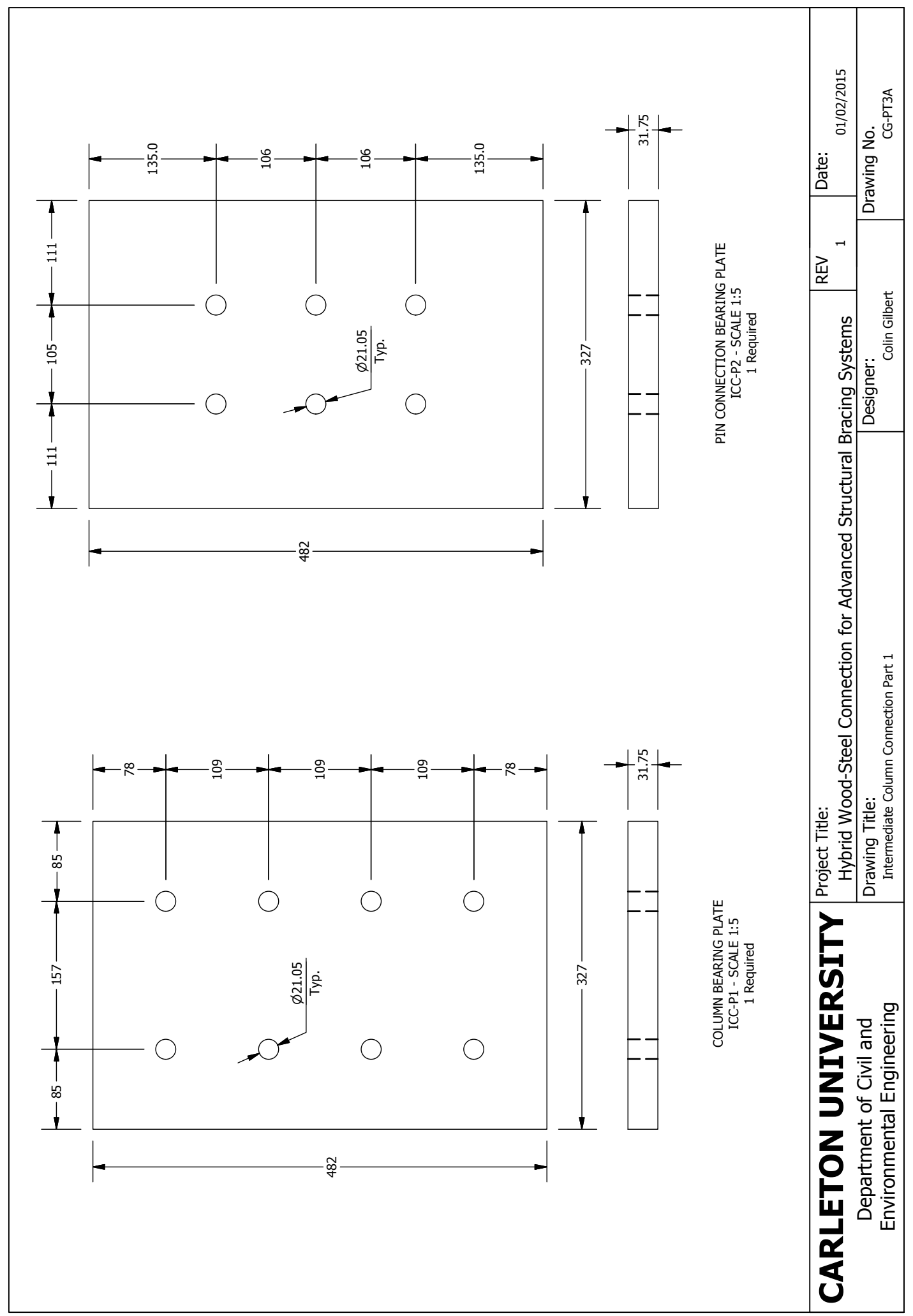

Sean Miller, Department of Civil and Environmental Engineering, Carleton University 


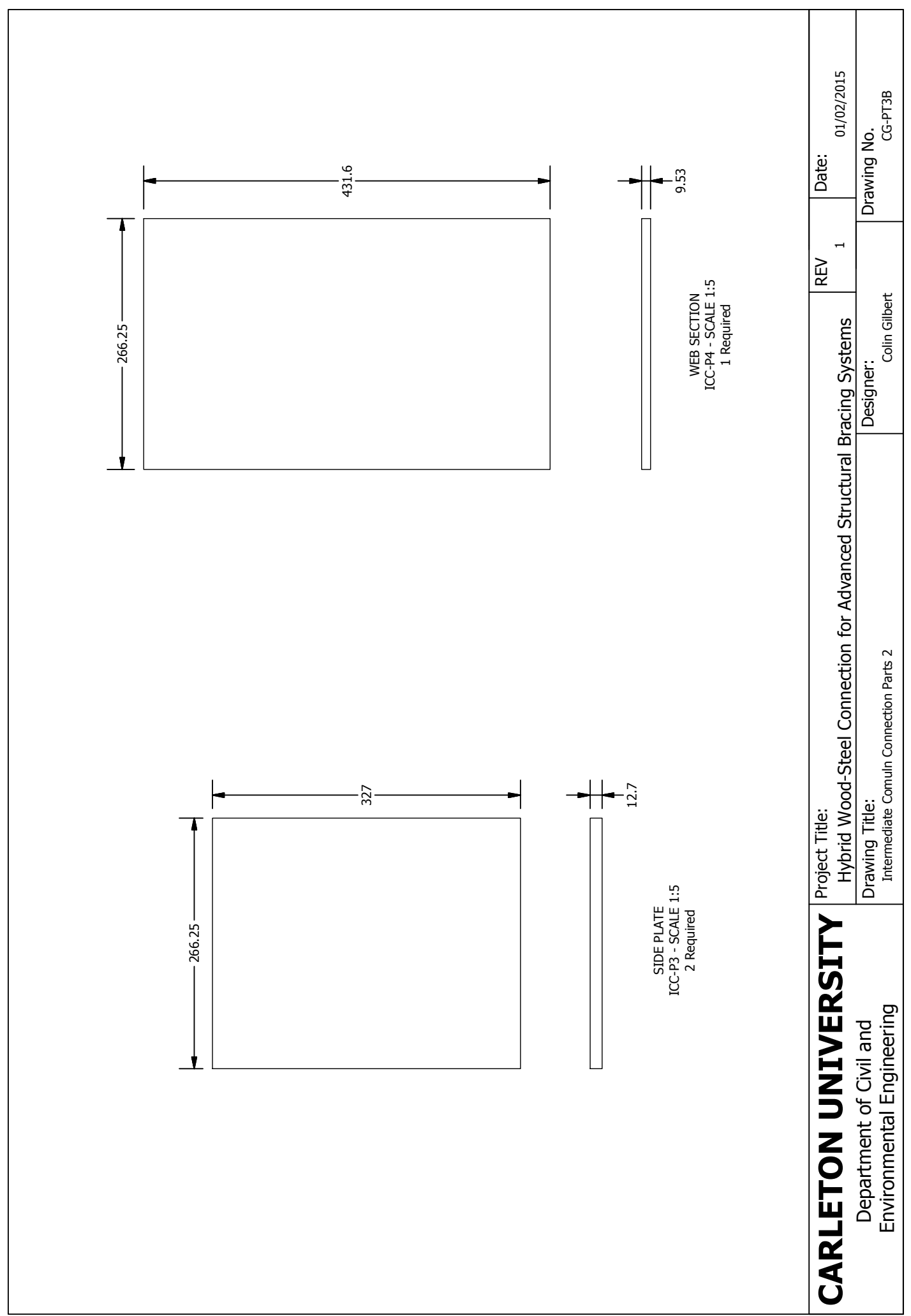

Sean Miller, Department of Civil and Environmental Engineering, Carleton University 


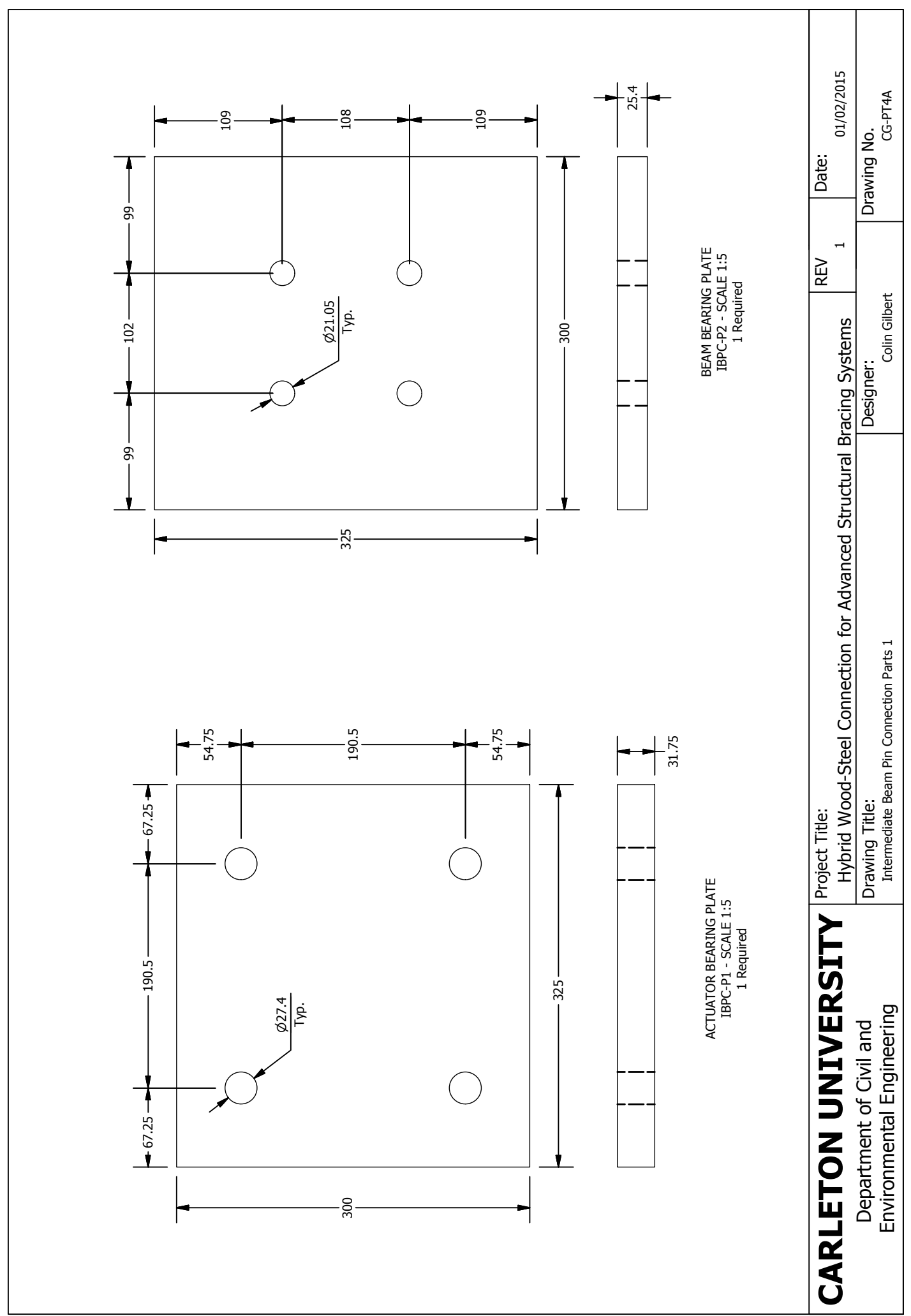




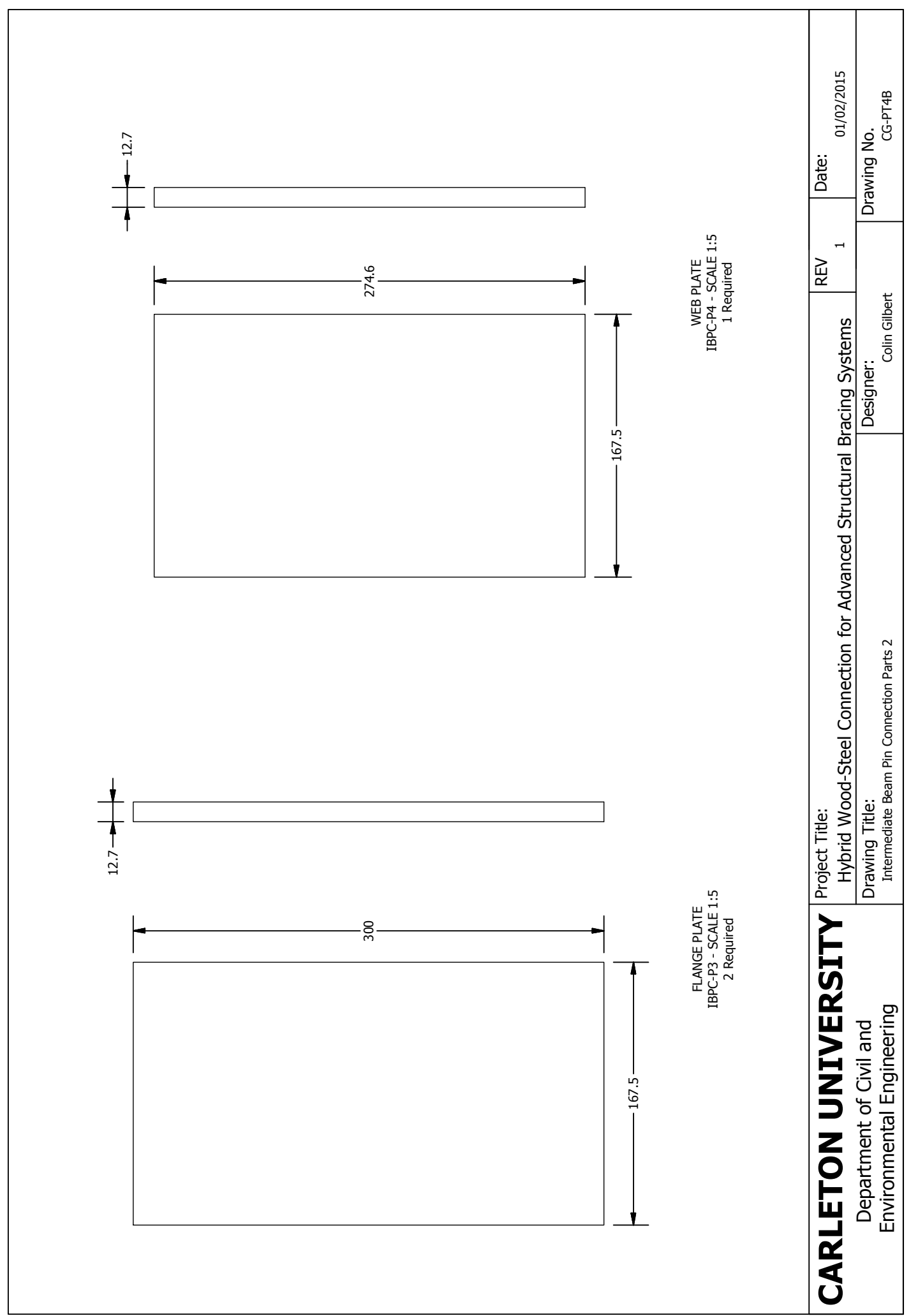

Sean Miller, Department of Civil and Environmental Engineering, Carleton University 


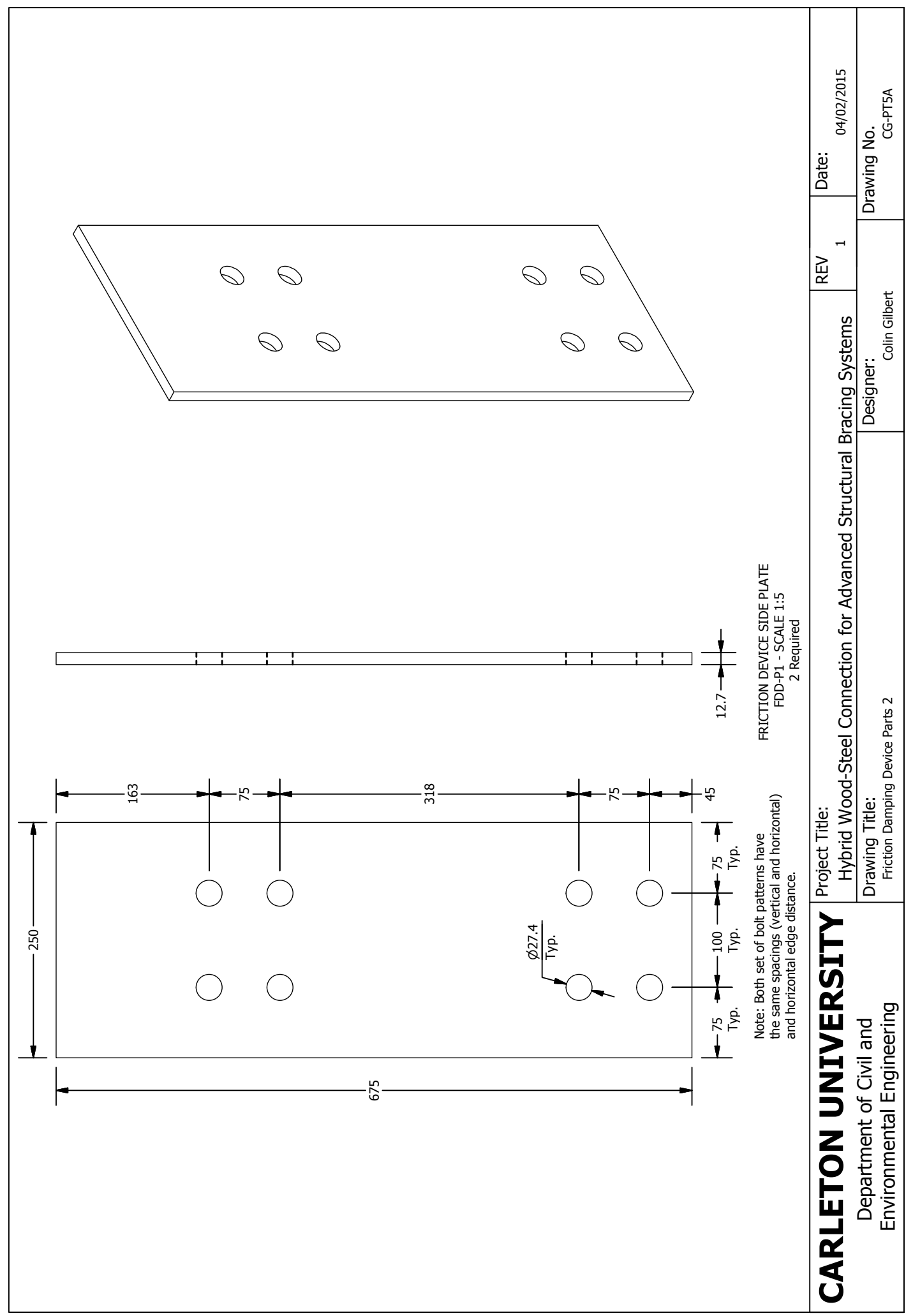

Sean Miller, Department of Civil and Environmental Engineering, Carleton University 


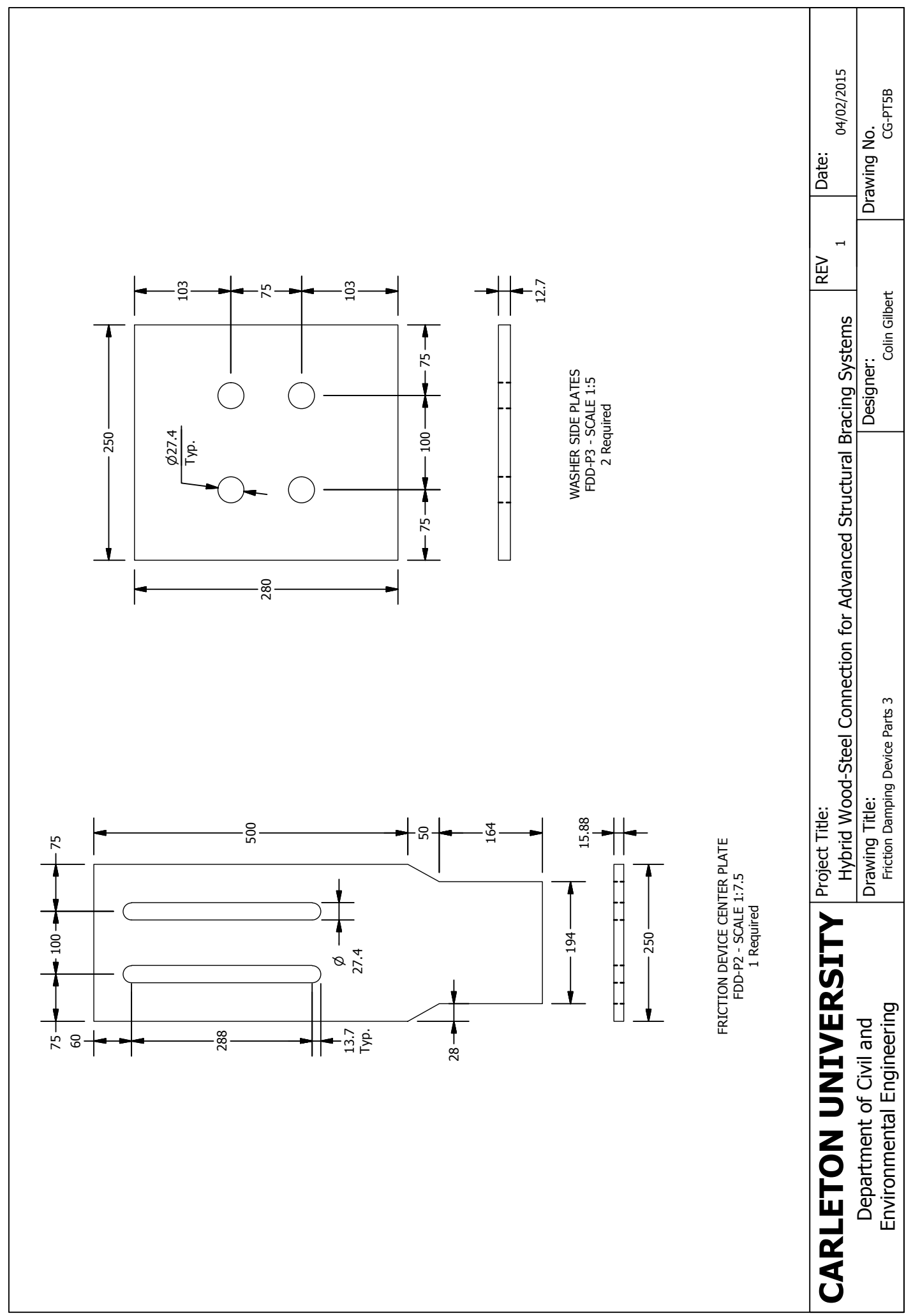




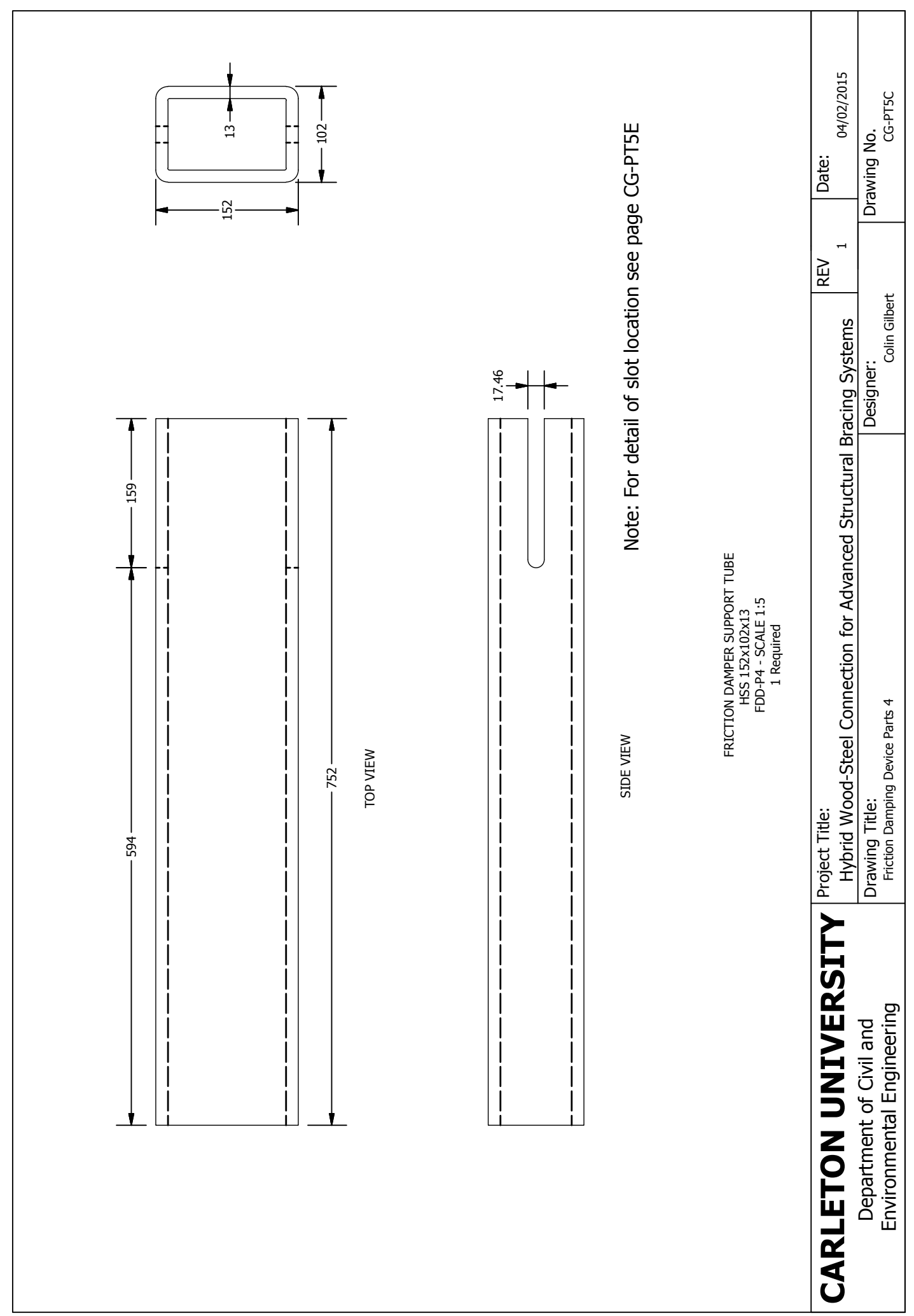

Sean Miller, Department of Civil and Environmental Engineering, Carleton University 


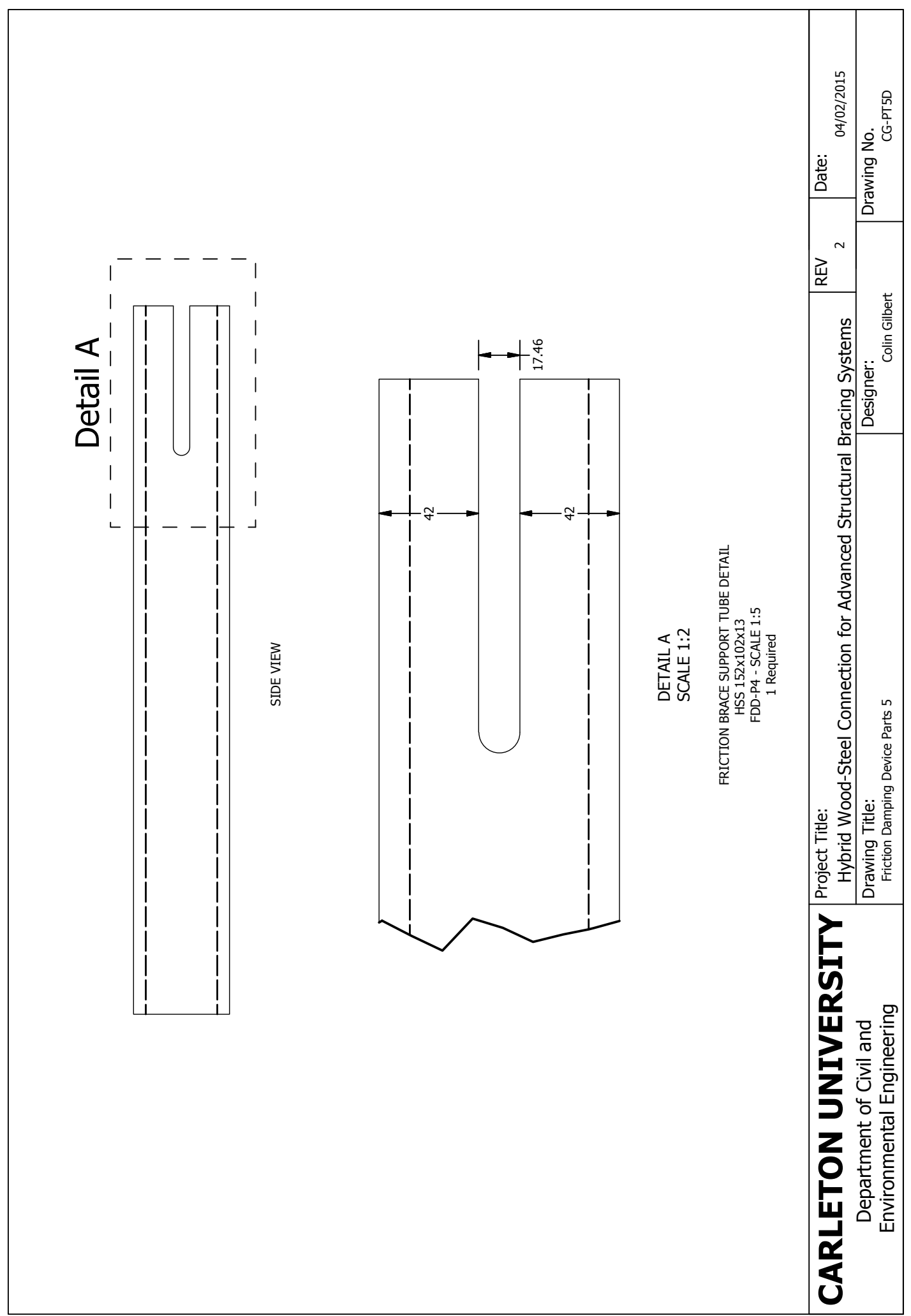

Sean Miller, Department of Civil and Environmental Engineering, Carleton University 


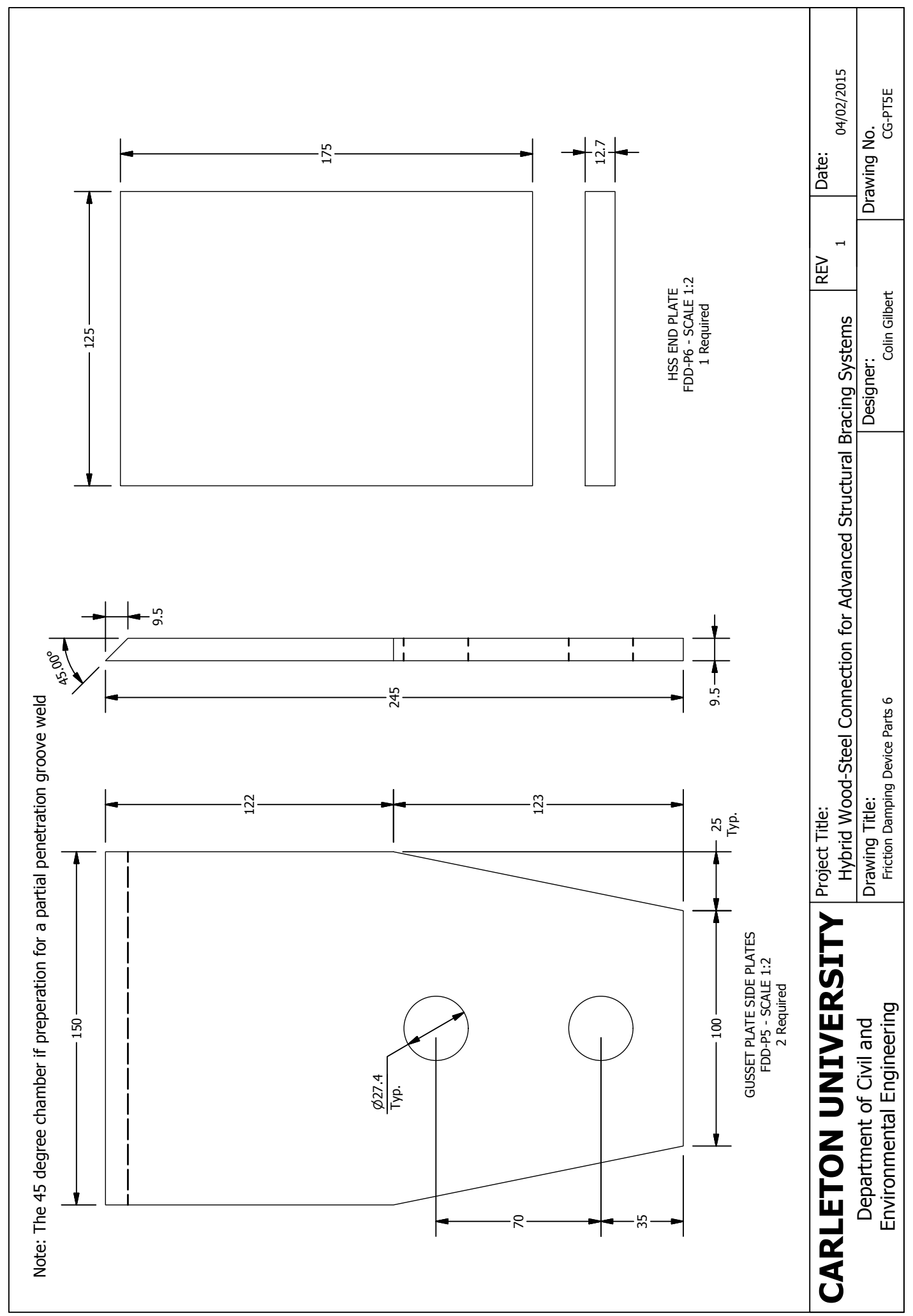

Sean Miller, Department of Civil and Environmental Engineering, Carleton University 


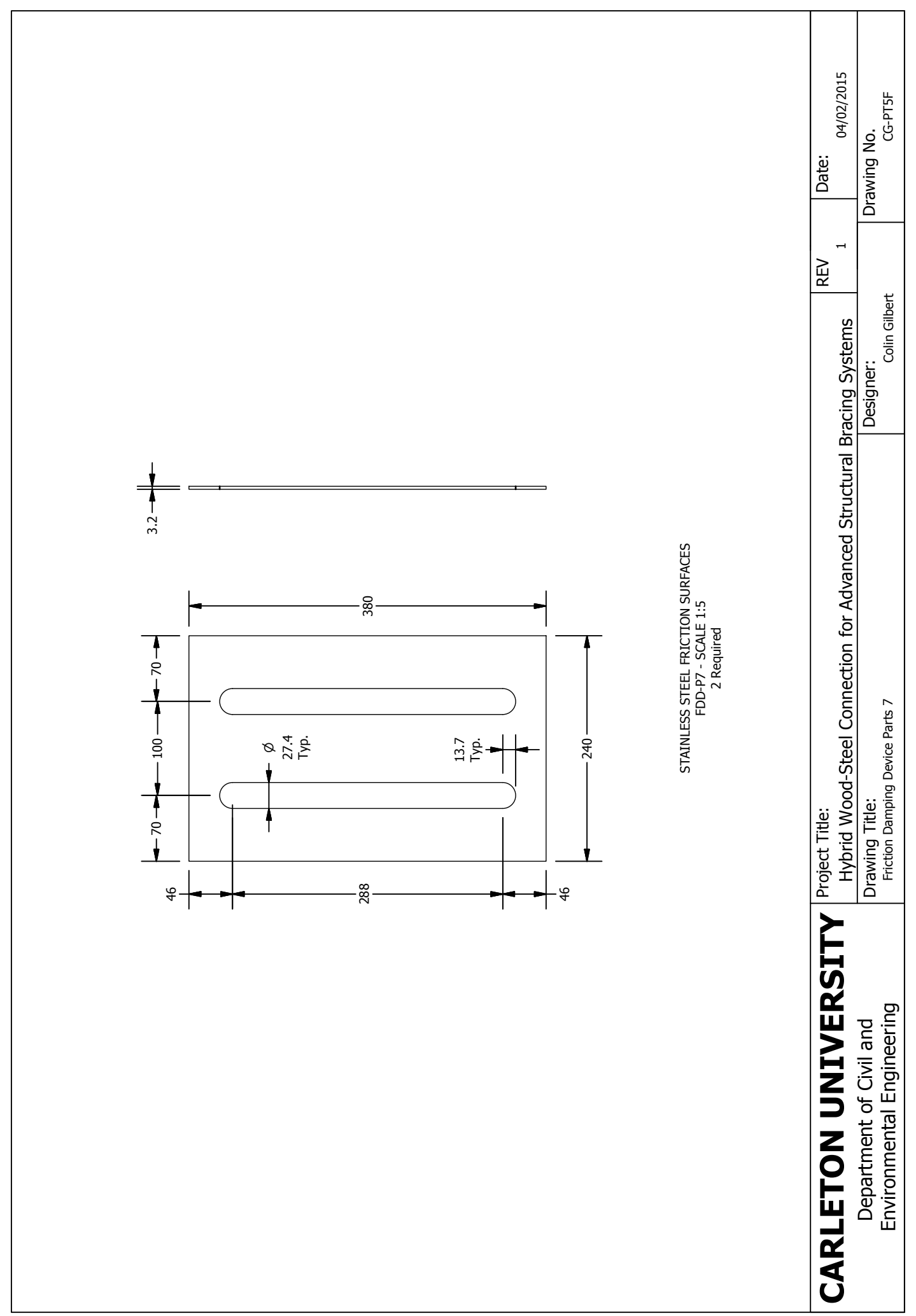




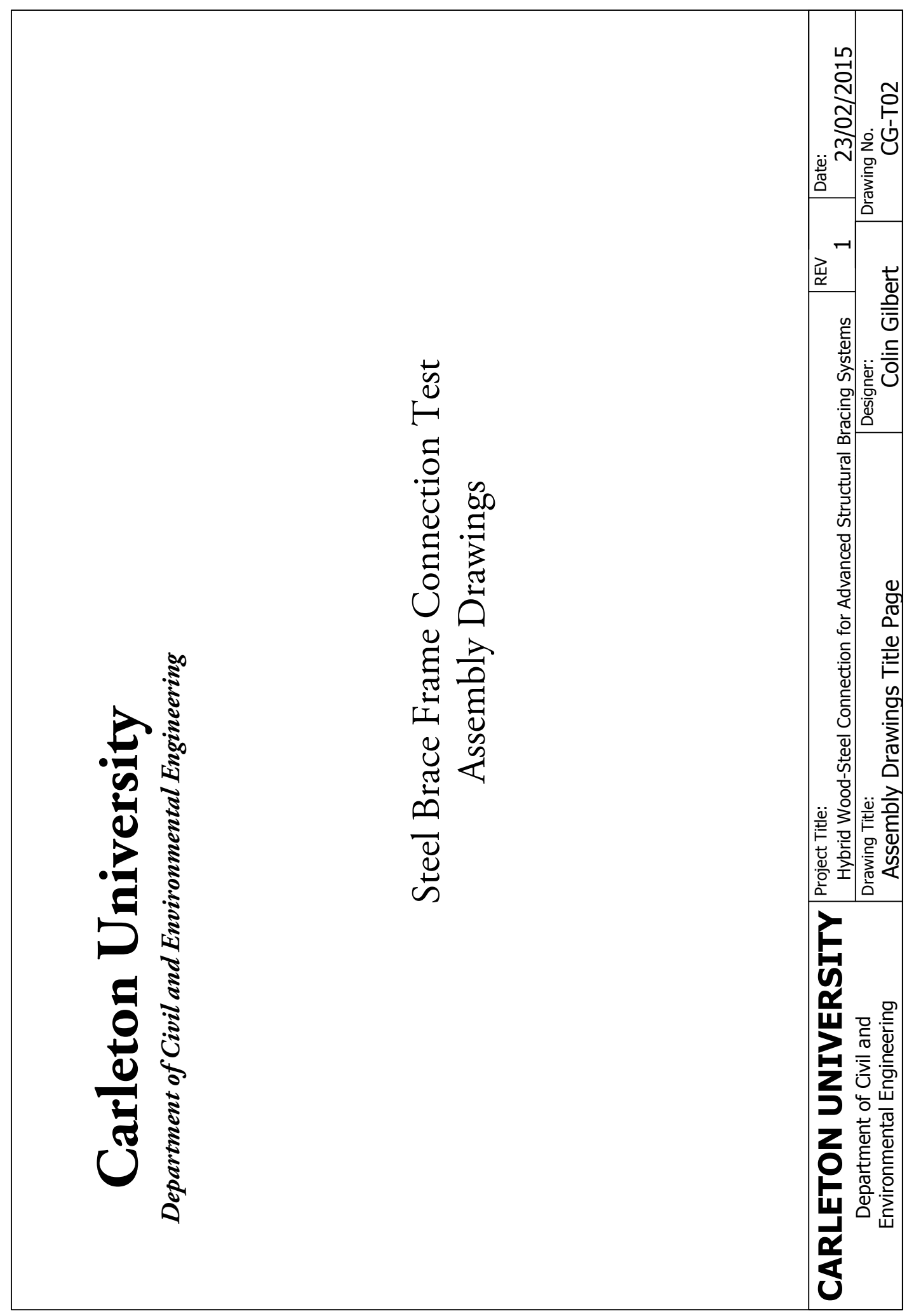




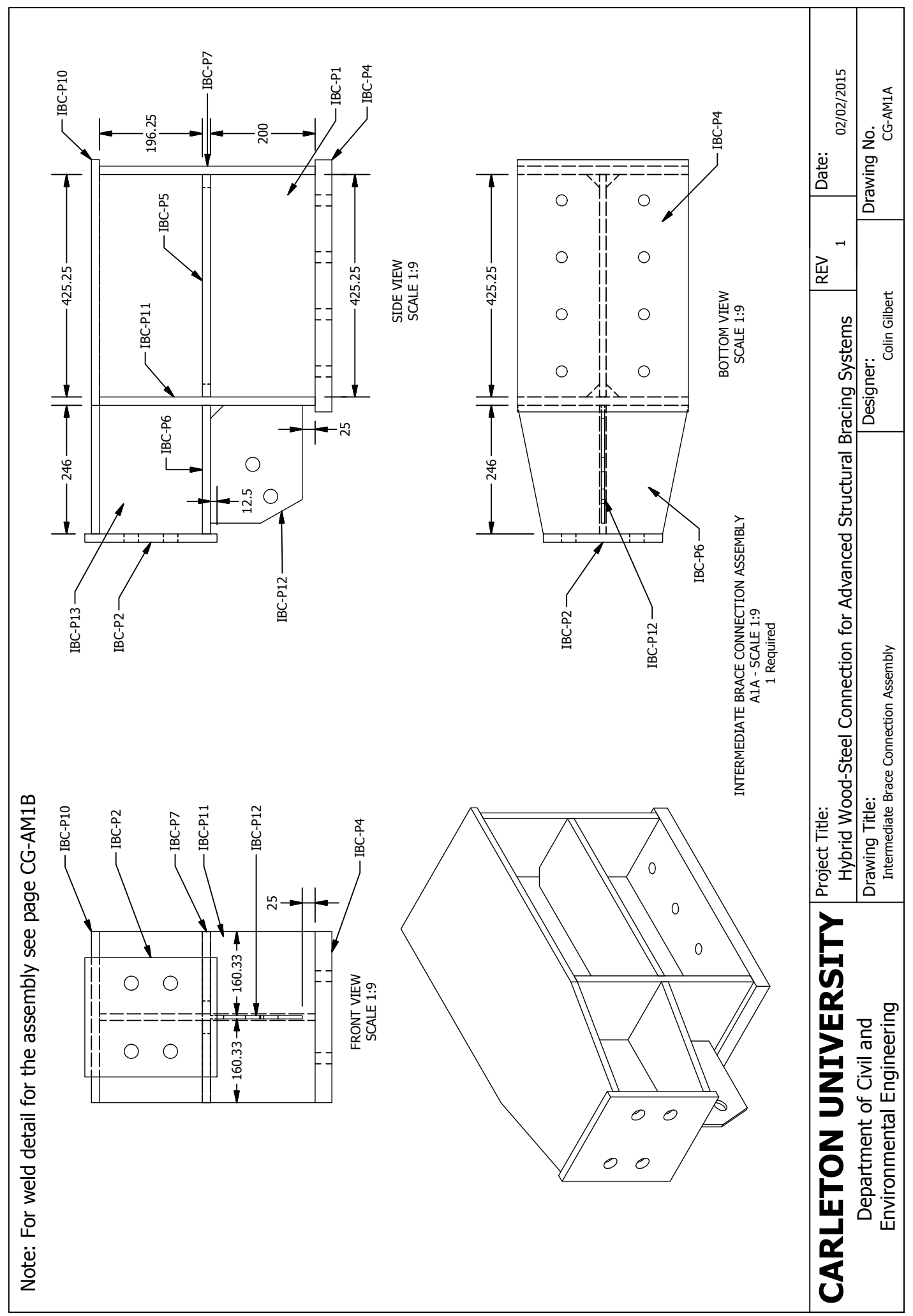

Sean Miller, Department of Civil and Environmental Engineering, Carleton University 


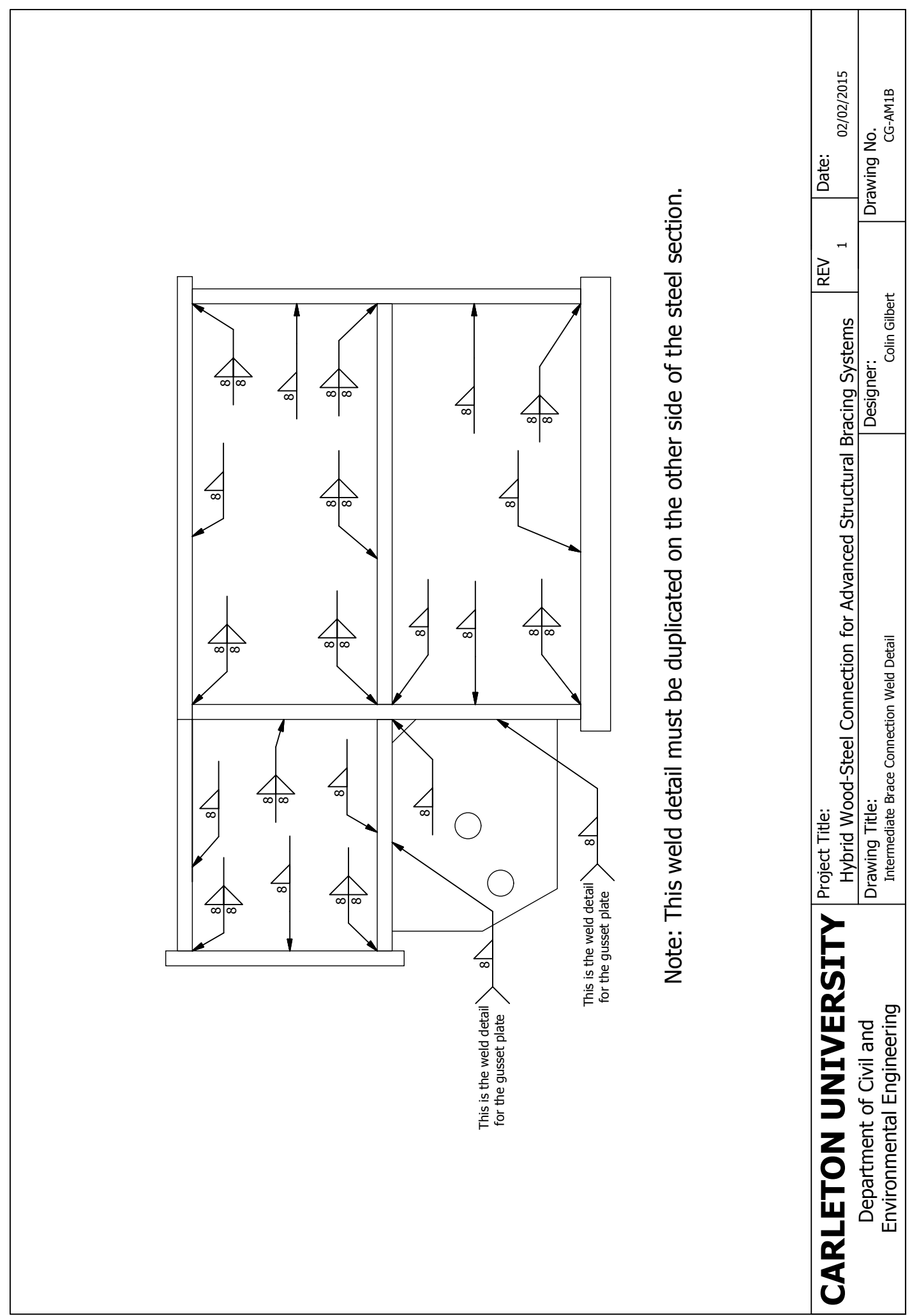

Sean Miller, Department of Civil and Environmental Engineering, Carleton University 


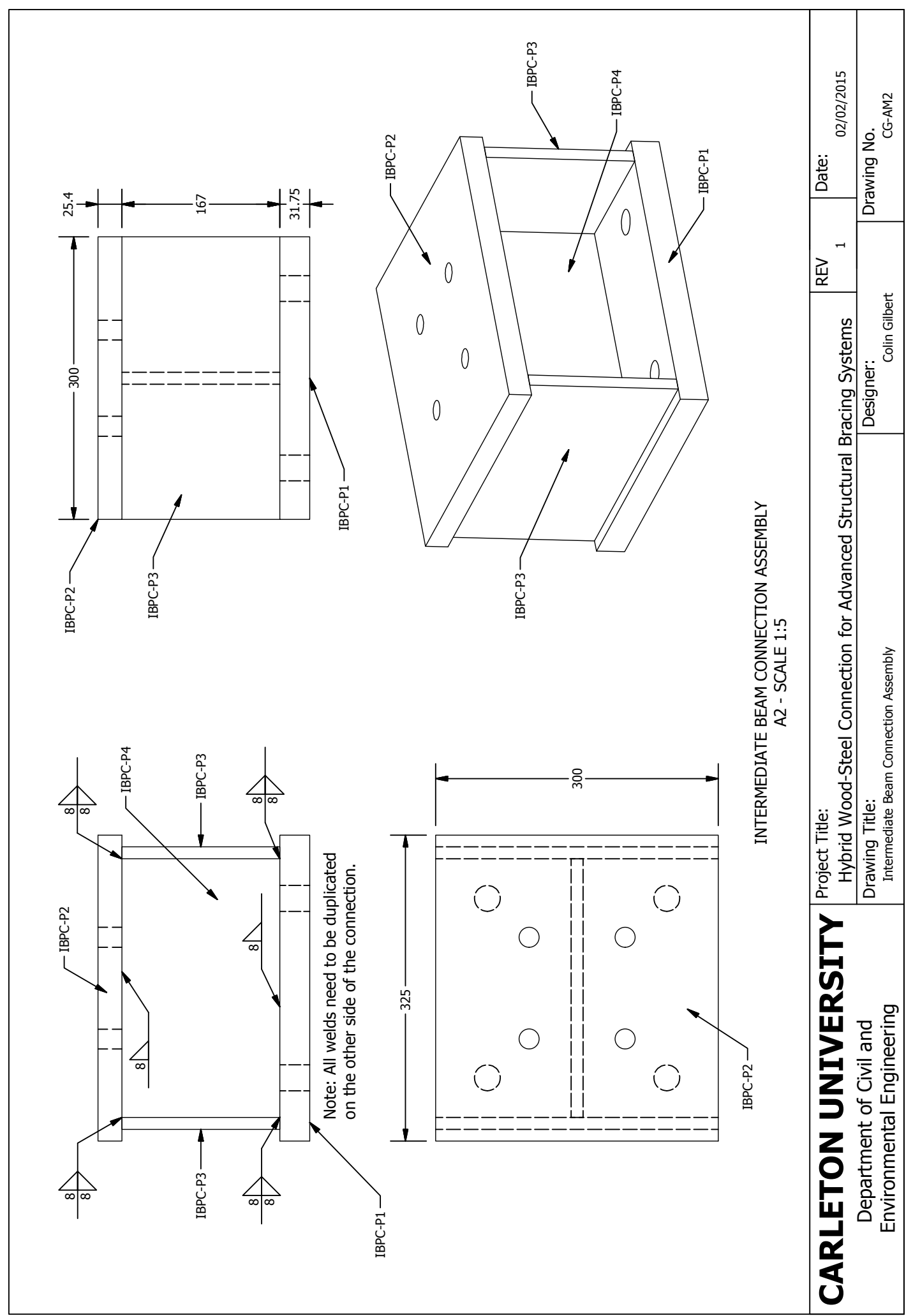

Sean Miller, Department of Civil and Environmental Engineering, Carleton University 


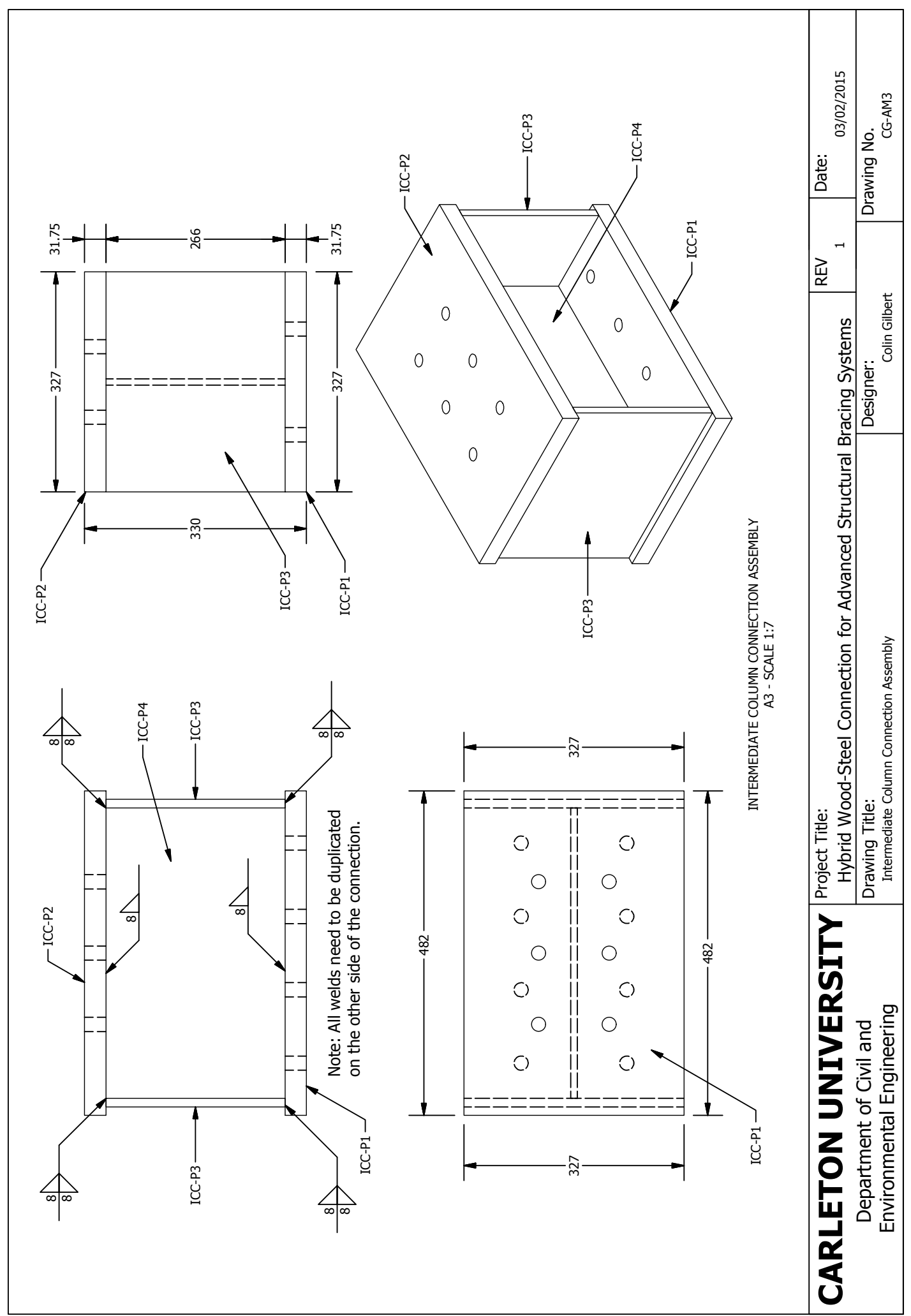

Sean Miller, Department of Civil and Environmental Engineering, Carleton University 


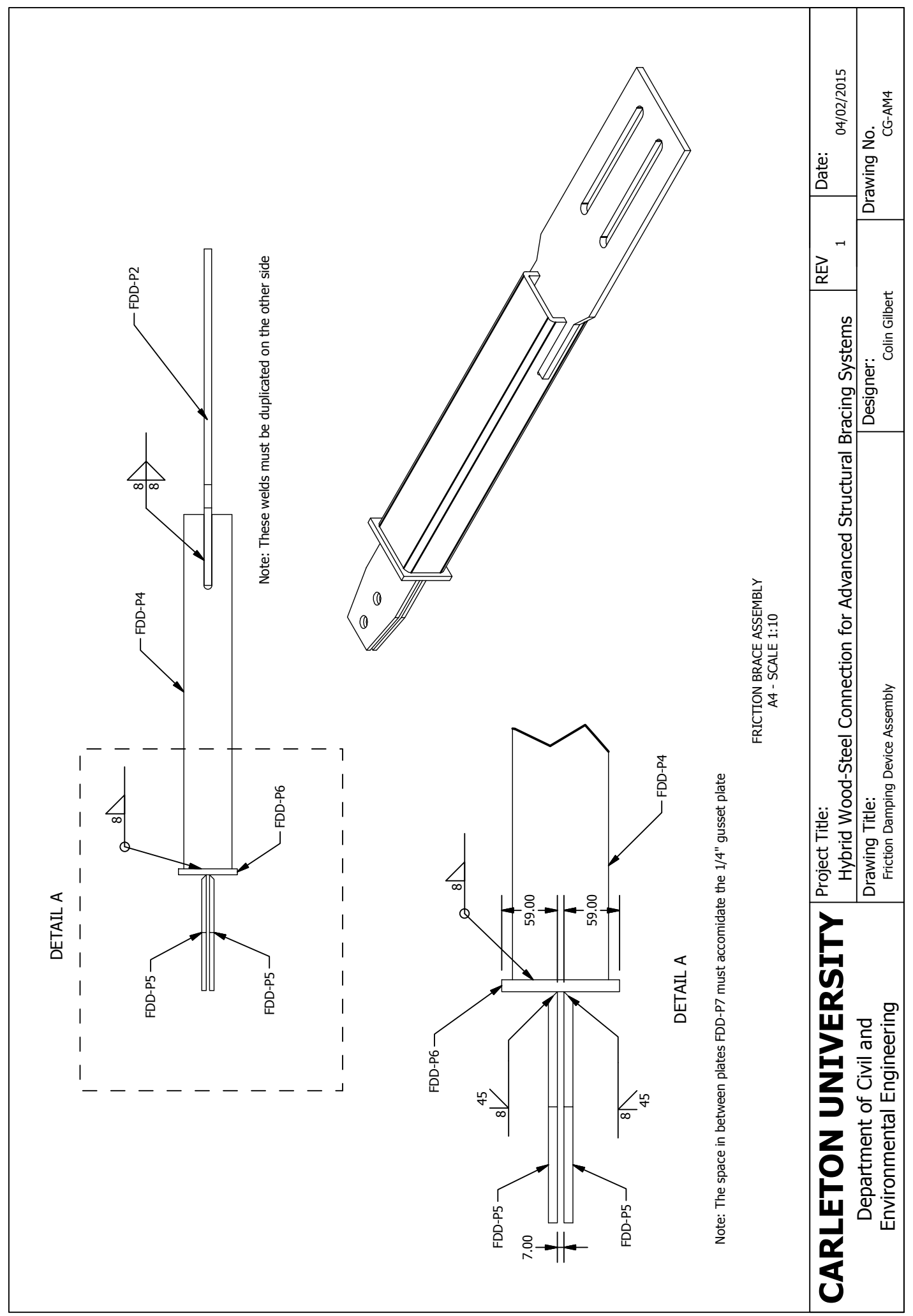

Sean Miller, Department of Civil and Environmental Engineering, Carleton University 


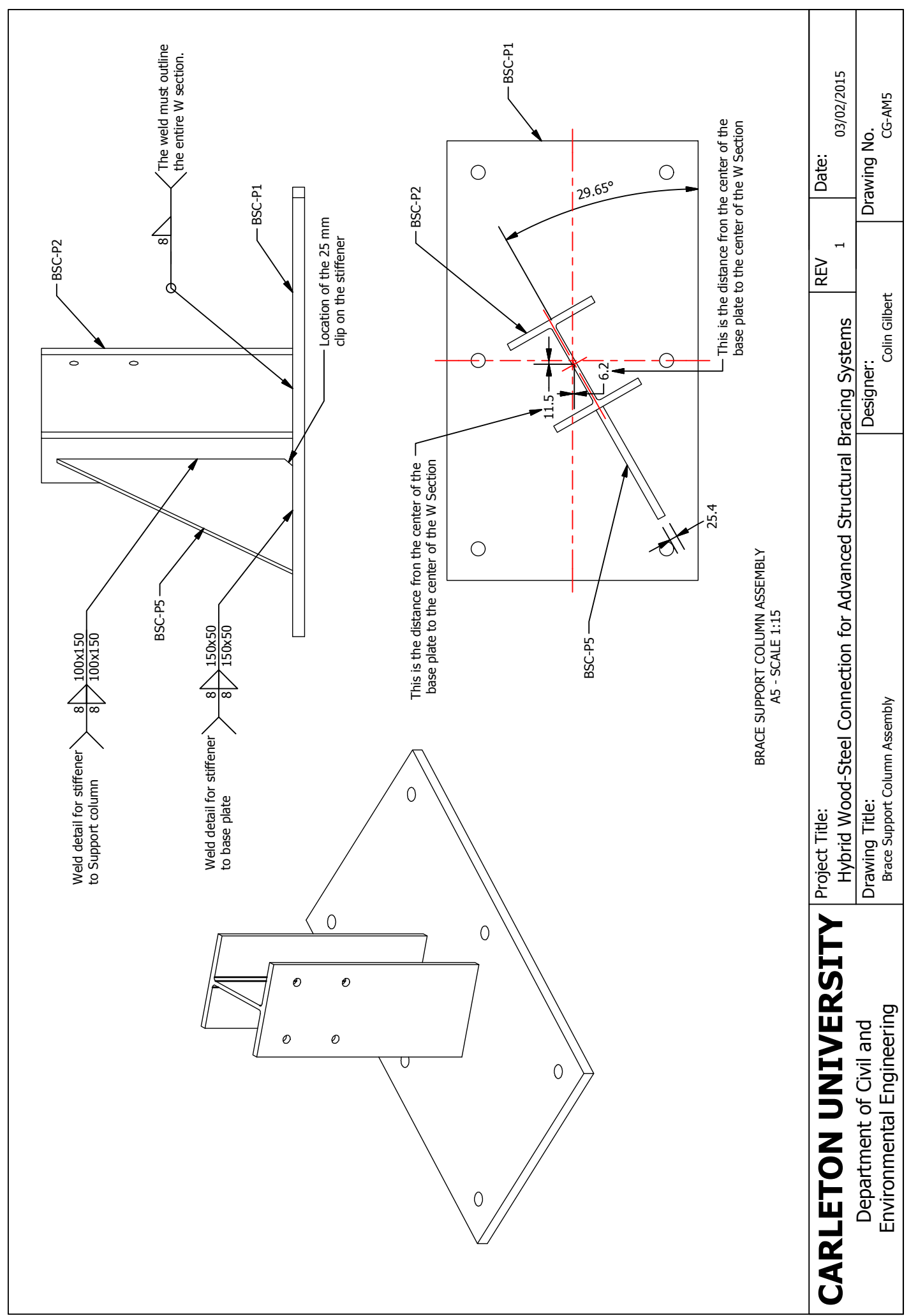

Sean Miller, Department of Civil and Environmental Engineering, Carleton University 


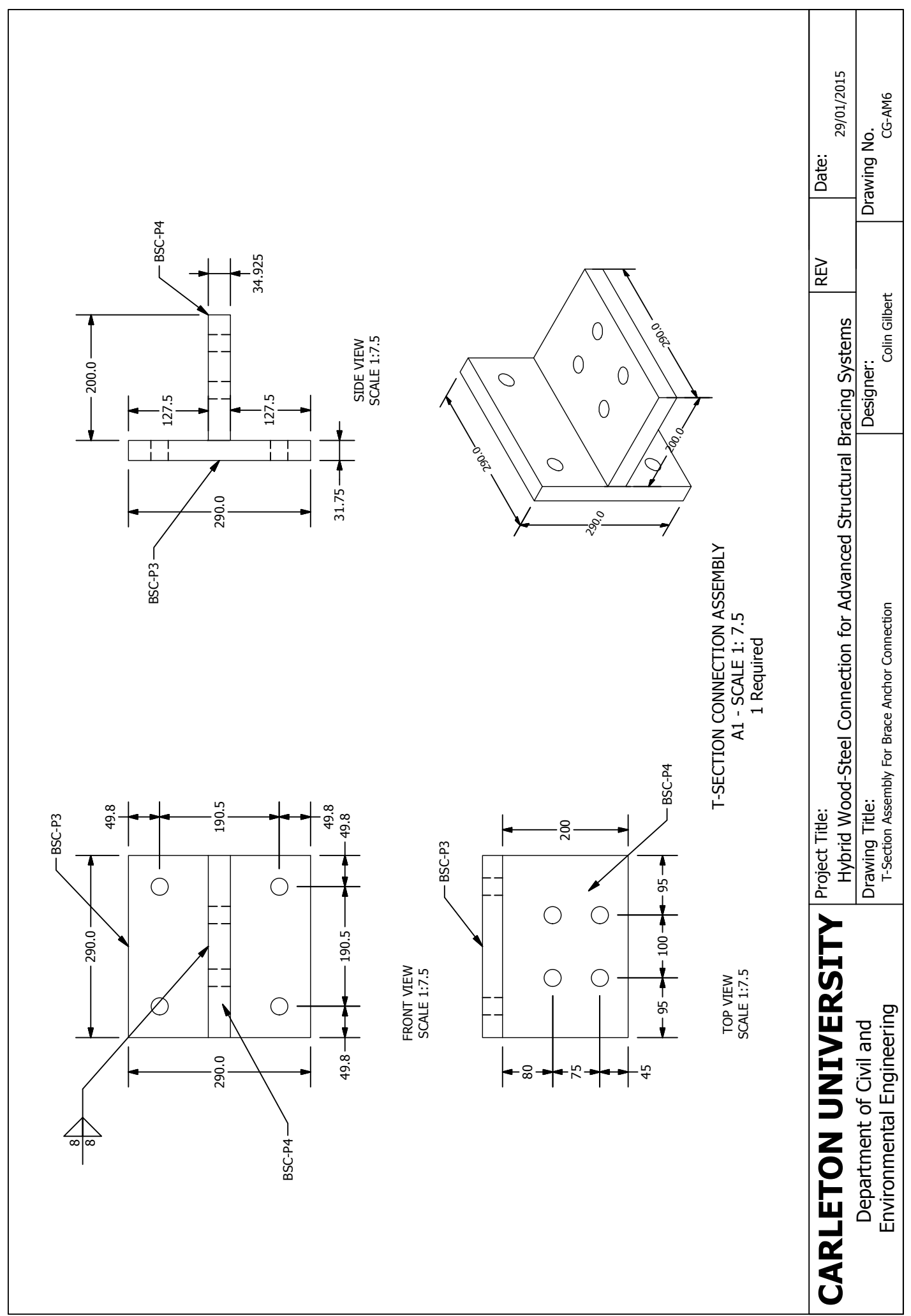

Sean Miller, Department of Civil and Environmental Engineering, Carleton University 


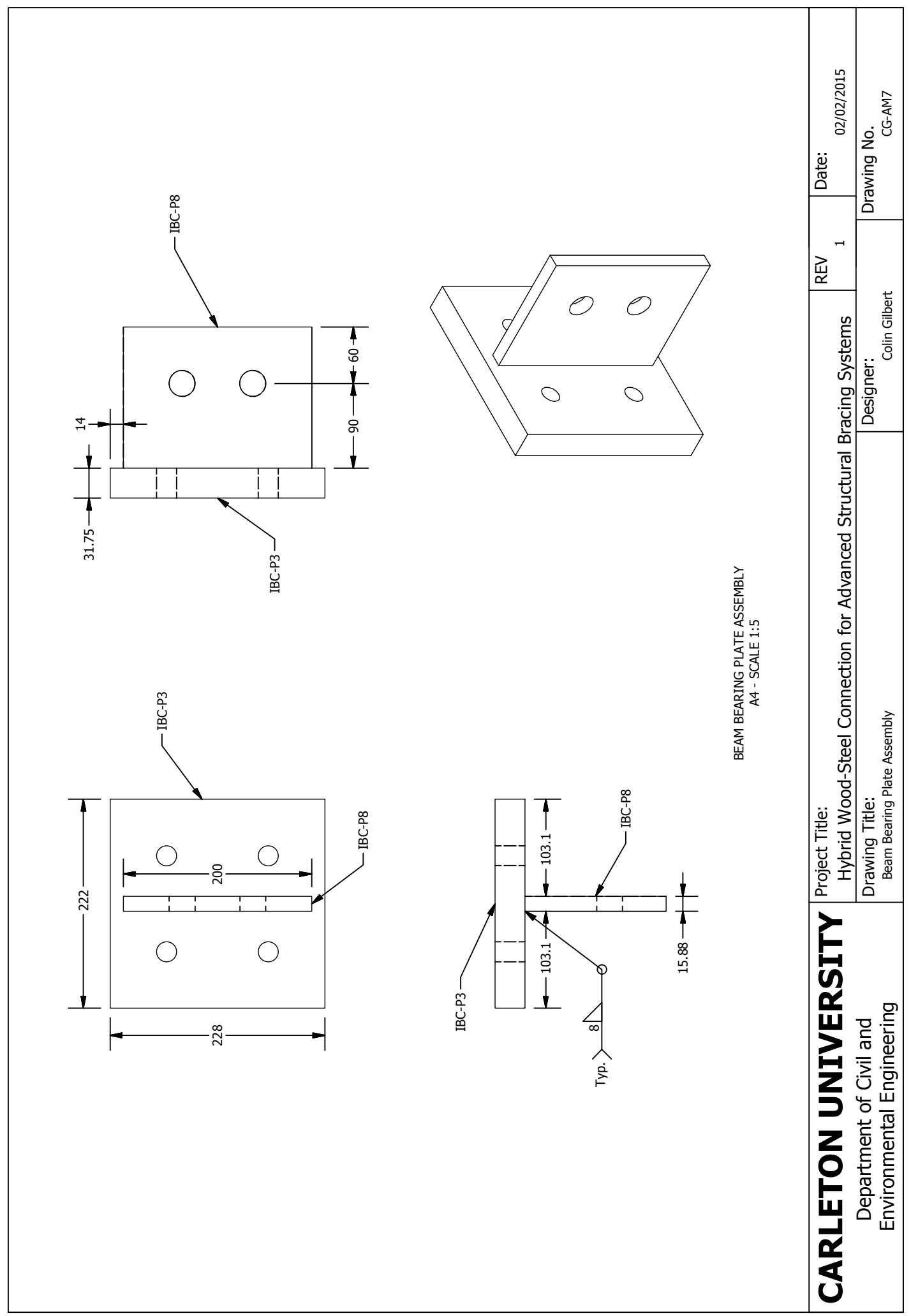

Sean Miller, Department of Civil and Environmental Engineering, Carleton University 